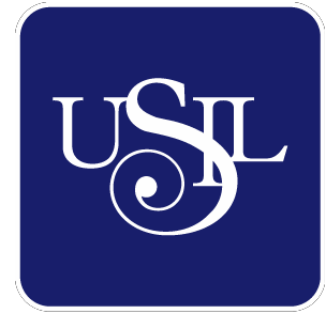

UNIVERSIDAD

SAN IGNACIO

DE LOYOLA

ESCUELA DE POSTGRADO

Maestría en Administración de Negocios - Executive MBA

\title{
PLAN DE NEGOCIOS PARA PRODUCCIÓN Y VENTA DE ARÁNDANOS, PIÑA Y MANZANA DESHIDRATADOS PARA USO INDUSTRIAL
}

Trabajo de Investigación para optar el Grado de Maestro en Administración de Negocios - Executive MBA

\section{CARLOS RODOLFO CARBAJAL ENCISO \\ JOHNNY ALFREDO BERROSPI HERRERA \\ JORGE SAÚL NIEVES LAZO \\ OMAR AGUILAR HUACAN}

\author{
Asesor: \\ José Antonio Chou Flores \\ Lima - Perú \\ 2019
}


Plan de Negocios Para Producción y Venta de Arándanos, Piña y Manzana Deshidratados Para Uso Industrial 


\section{INDICE}

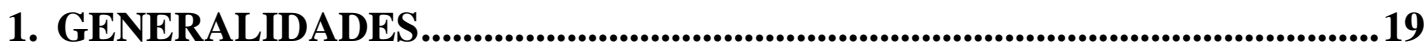

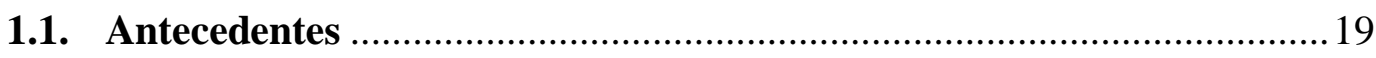

1.2. Determinación del problema u oportunidad......................................21

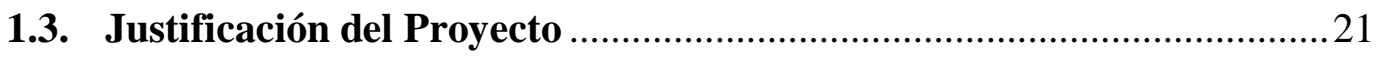

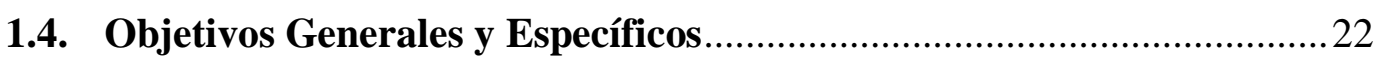

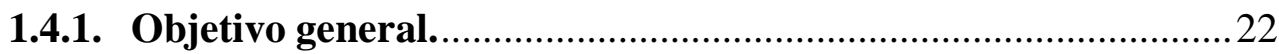

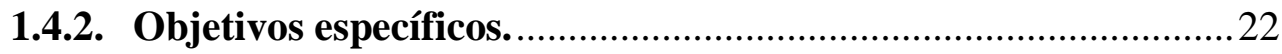

1.5. Alcances y limitaciones de la investigación ............................................22

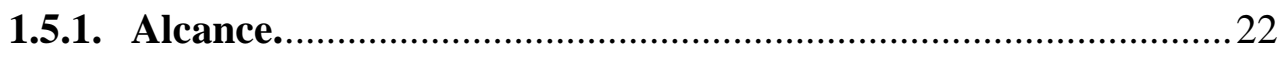

1.5.2. Limitaciones ......................................................................... 23

2. ESTRUCTURA ECONÓMICA DEL SECTOR ..............................................24

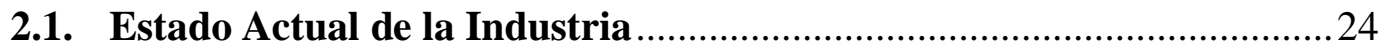

2.1.1. Segmentación de la industria ..................................................25

2.1.2. Empresas que la conforman ...................................................26

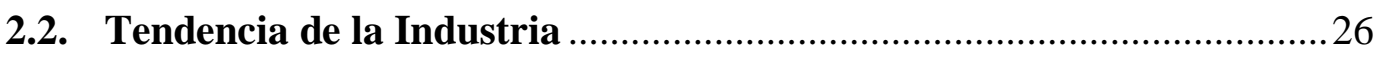

2.3. Análisis Estructural del Sector Industrial............................................28

2.3.1. Poder de negociación de los clientes.........................................28

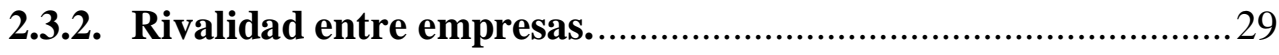

2.3.3. Amenaza de los nuevos entrantes...........................................29

2.3.4. Poder de negociación de los proveedores. ....................................30

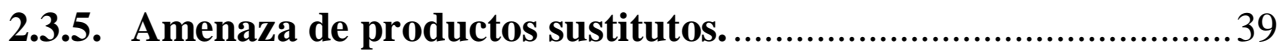

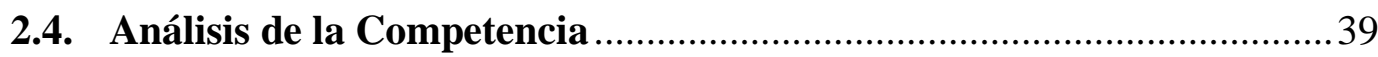

2.4.1. Empresas que ofrecen el mismo producto.................................40

2.4.2. Participación de mercado de cada uno de ellos. ........................41

2.4.3. Matriz de perfil competitivo. .................................................. 41

2.5. Análisis del Contexto Actual y Esperado ............................................43

2.5.1. Análisis político gubernamental. ............................................43

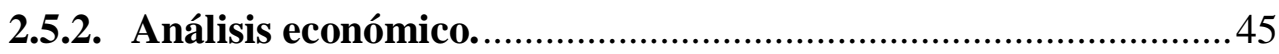

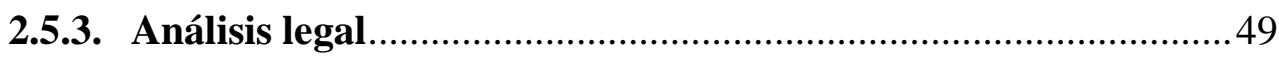

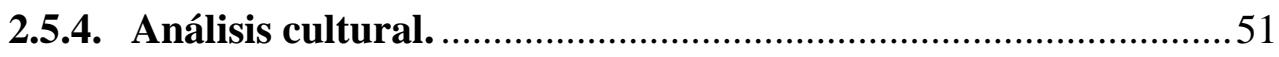

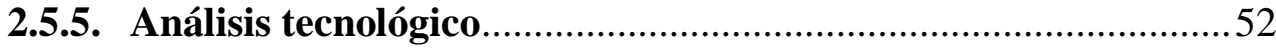

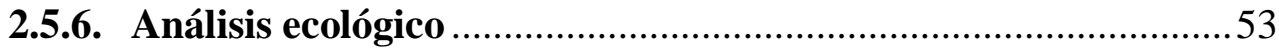




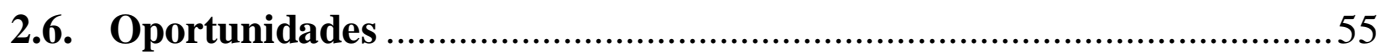

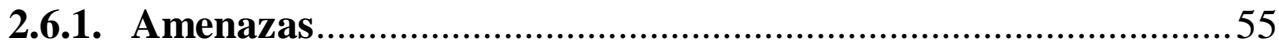

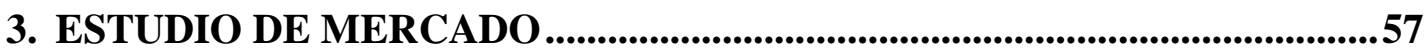

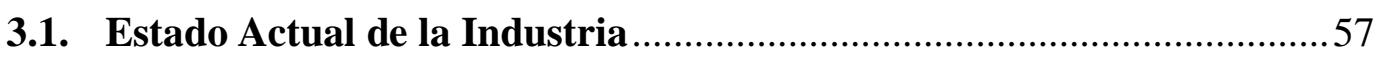

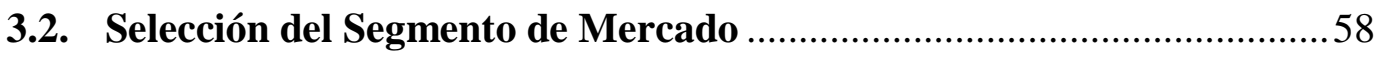

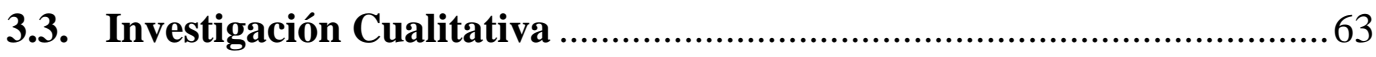

3.3.1. Técnica cualitativa: Entrevista a profundidad ........................63

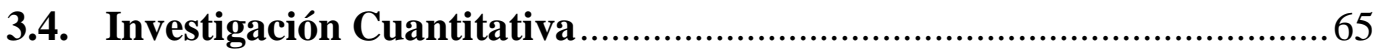

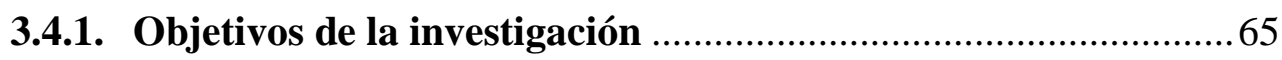

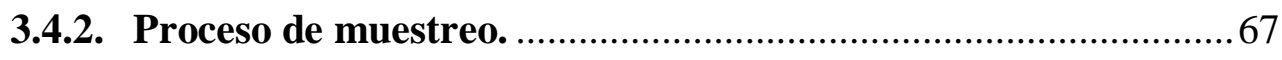

3.4.3. Diseño de instrumento......................................................... 72

3.4.4. Análisis y procesamiento de datos............................................... 73

3.5. Conclusiones del Estudio Cualitativo ….............................................. 95

3.6. Conclusiones del Estudio Cuantitativo ..................................................99

4. PROYECCIÓN DEL MERCADO OBJETIVO ..................................................100

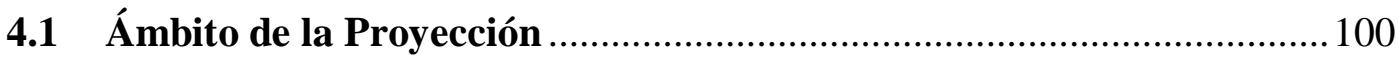

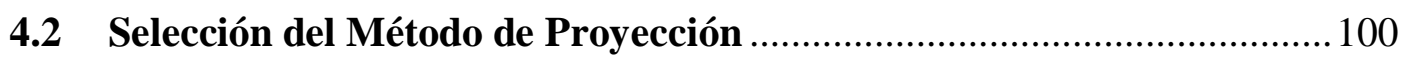

4.2.1 Mercado potencial .................................................................. 100

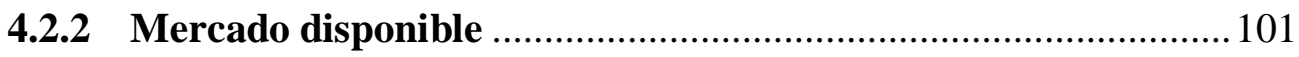

4.2.3 Mercado efectivo ...................................................................... 102

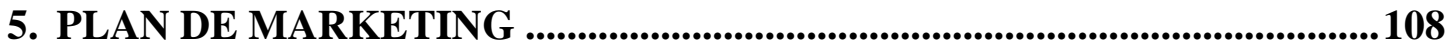

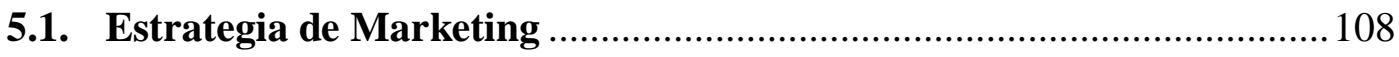

5.1.1 Estrategia de Producto............................................................. 110

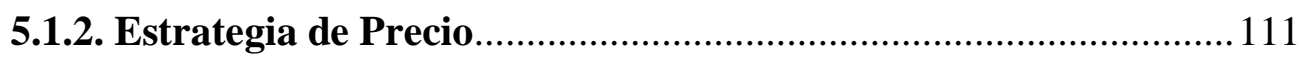

5.1.3. Estrategia plaza y distribución. .............................................. 112

5.1.4. Estrategia de Promoción y Publicidad........................................ 113

5.1.5. Estrategia de Personas ............................................................ 114

5.1.6. Estrategia de Procesos ............................................................ 114

5.1.7. Estrategia de Presencia física ...................................................... 114

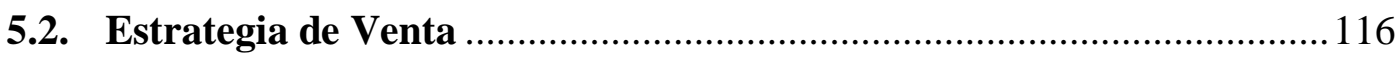

5.2.1. Estrategia de Presencia física ................................................. 117

5.2.2. Políticas de servicios y garantías .............................................. 117

6. PRONÓSTICO DE VENTAS .................................................................119 
6.1. Fundamentos y Supuestos

6.2. Justificación

6.3. Análisis de los Riesgos y Aspectos Críticos que Impactan el Pronóstico120

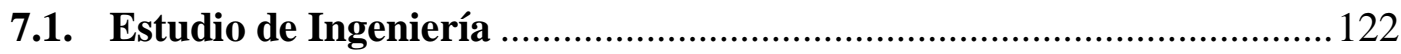

7.1.1. Modelamiento y selección de procesos productivos.................... 122

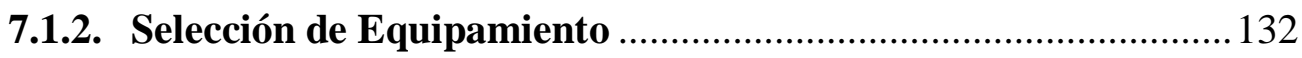

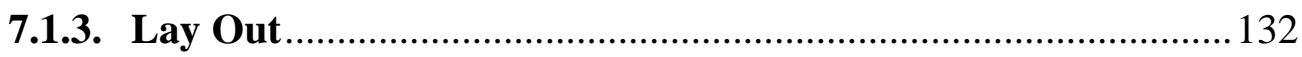

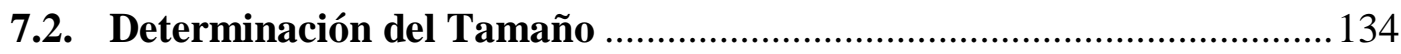

7.2.1. Proyección de crecimiento. ....................................................... 134

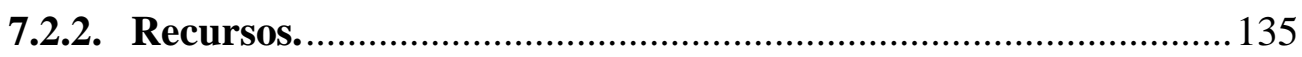

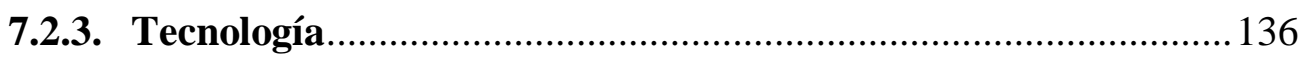

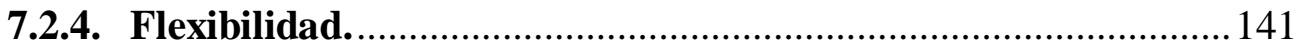

7.2.5. Selección del tamaño ideal. ....................................................... 141

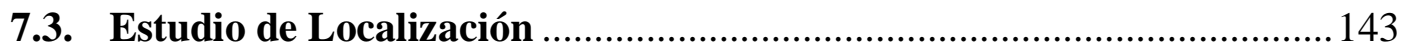

7.3.1. Definición de factores locacionales............................................... 143

7.3.2. Consideraciones legales........................................................ 144

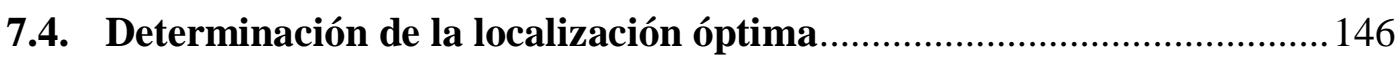

8. ASPECTOS ORGANIZACIONALES ........................................................147

8.1. Caracterización de la Cultura Organizacional Deseada...................... 147

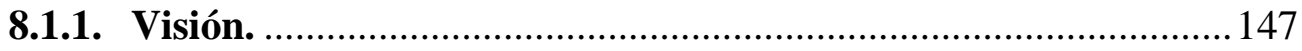

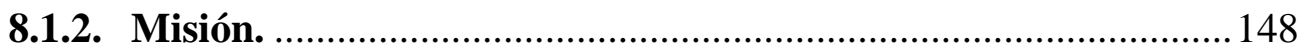

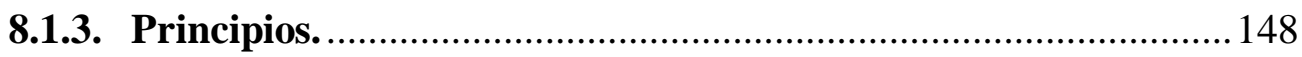

8.2. Formulación de Estrategias del Negocio ............................................... 148

8.3. Determinación de las Ventajas Competitivas Críticas........................... 149

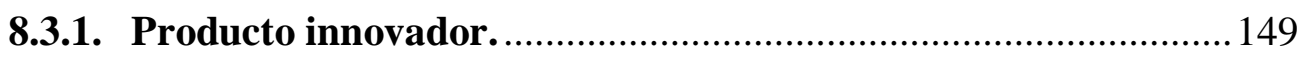

8.3.2. Gestión de la calidad................................................................... 149

8.3.3. Capacidad de respuesta a los clientes ....................................... 150

8.4. Diseño de la Estructura Organizacional Deseada ................................ 151

8.5. Diseño de los Perfiles de Puestos Clave .................................................. 152

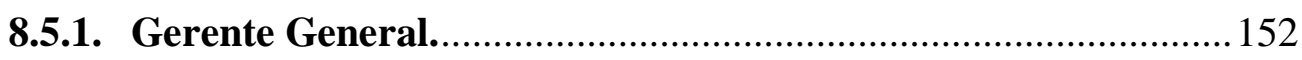

8.5.2. Jefe de Administración y Finanzas. .......................................... 153

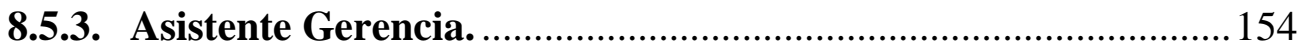




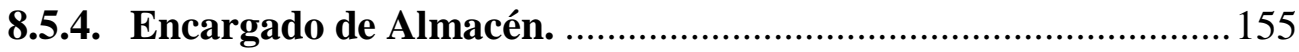

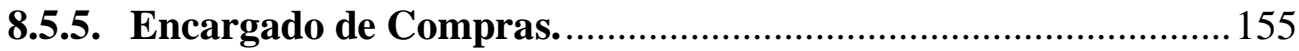

8.5.6. Jefatura de Operaciones. ............................................................... 156

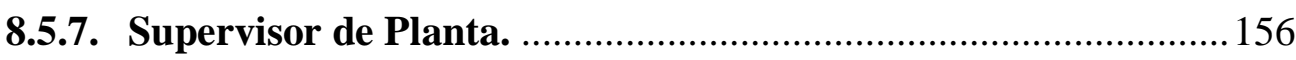

8.5.8. Técnico Calidad ......................................................................... 157

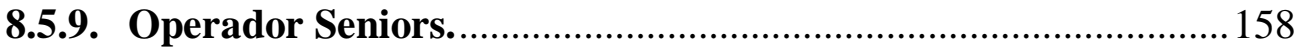

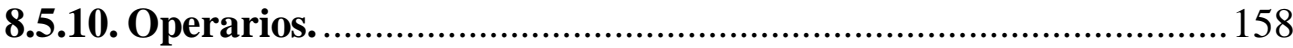

8.5.11. Jefe Marketing y Ventas. ........................................................... 159

8.6. Remuneraciones, Compensaciones e Incentivos ................................... 160

8.6.1. Compensación e incentivos. ......................................................... 161

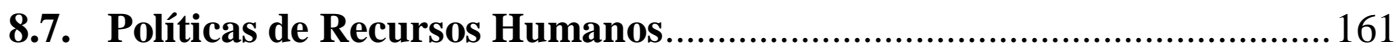

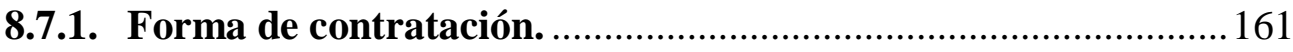

8.7.2. Régimen laboral...................................................................... 161

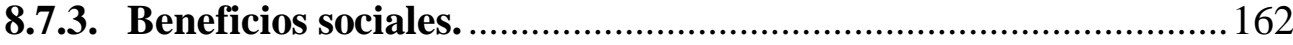

9. PLANIFICACIÓN FINANCIERA ...................................................................163

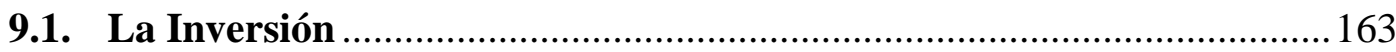

9.1.1. Inversión pre operativa................................................................ 163

9.1.2. Inversión en capital de trabajo................................................... 163

9.1.3. Costo del proyecto. .................................................................... 164

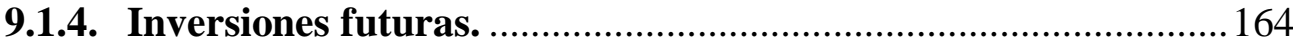

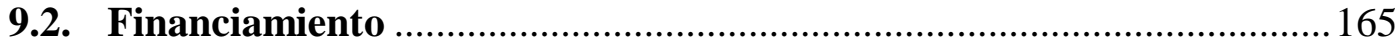

9.2.1. Capital y costo de oportunidad.................................................. 165

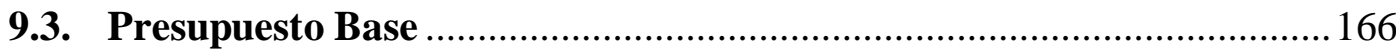

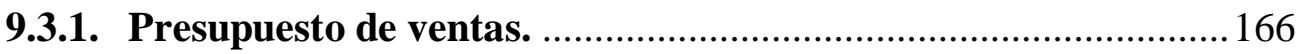

9.3.2. Presupuesto de costos de producción.......................................... 167

9.3.3. Presupuesto de compras............................................................ 168

9.3.4. Presupuesto de costo de ventas................................................... 170

9.3.5. Presupuesto de gastos administrativos. ...................................... 170

9.3.6. Presupuesto de gastos marketing y de ventas. ........................... 170

9.3.7. Estado de ganancias y pérdidas proyectado............................... 172

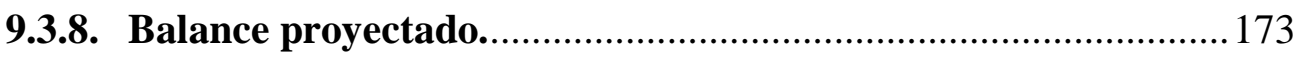

9.3.9. Flujo de caja proyectado........................................................ 174

10. EVALUACIÓN ECONÓMICO FINANCIERA ...................................175 


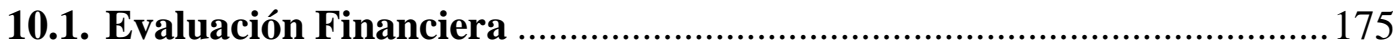

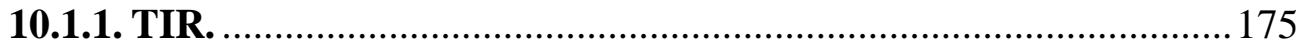

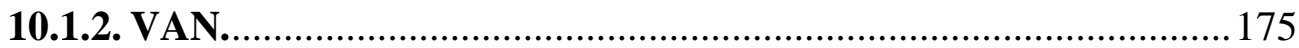

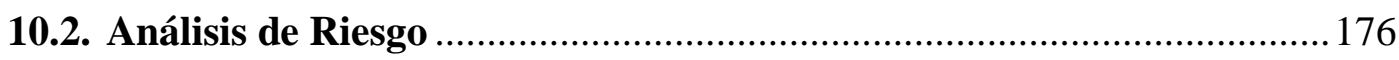

10.2.1. Análisis de punto de equilibrio.............................................. 176

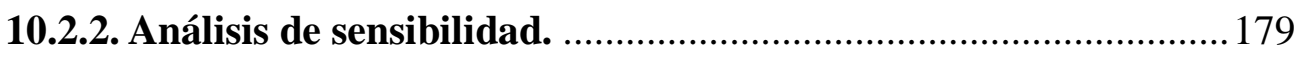

10.2.3. Análisis de escenarios. ............................................................. 182

CONCLUSIONES Y RECOMENDACIONES .......................................................183

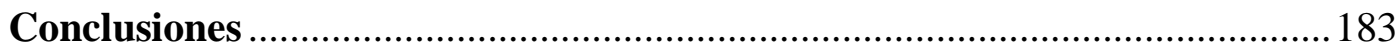

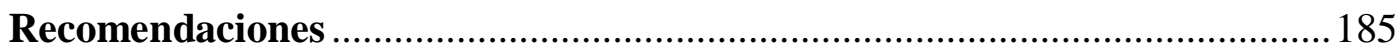




\section{ÍNDICE DE CUADROS}

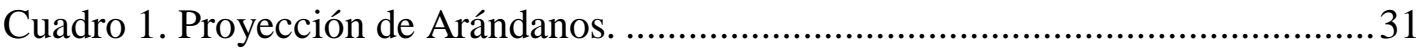

Cuadro 2. Producción Nacional de Frutas 2013 - 2017 ............................................ 32

Cuadro 3. Precios de Frutas 2013 - 2017 .................................................................. 33

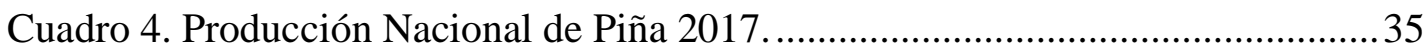

Cuadro 5. Producción Nacional de Manzana 2017. ....................................................36

Cuadro 6. Producción Nacional de Arándanos 2017...................................................37

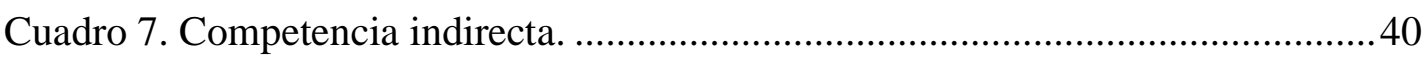

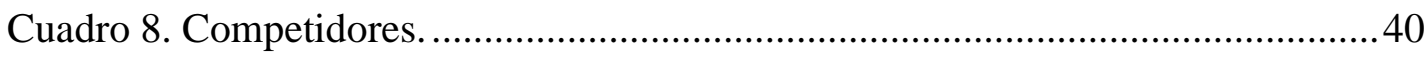

Cuadro 9. Participantes del Mercado............................................................... 41

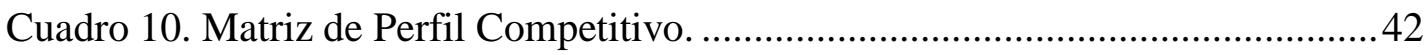

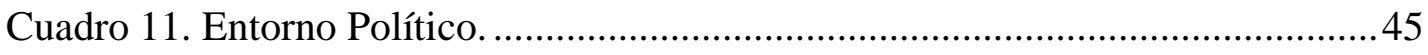

Cuadro 12. Entorno Económico. …....................................................................49

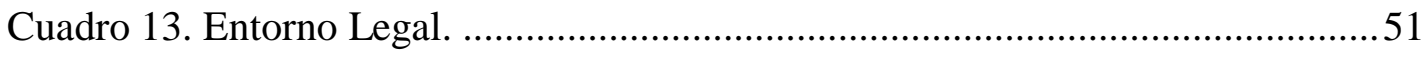

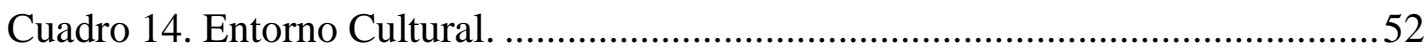

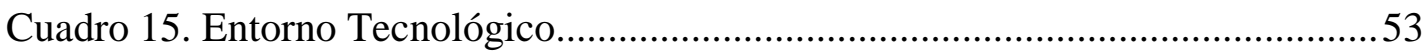

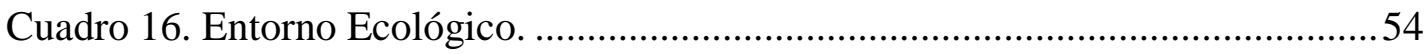

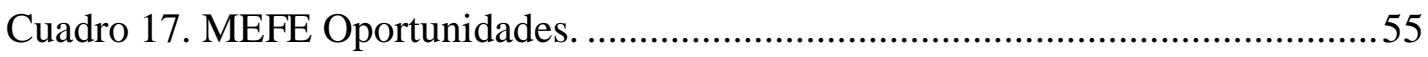

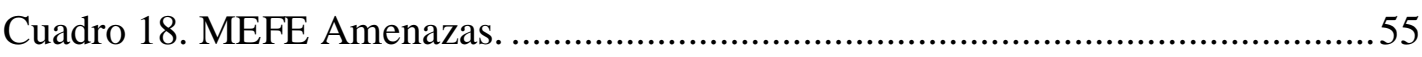

Cuadro 19. Selección del segmento de mercado por criterios de elección de juicio.59

Cuadro 20. Distribución de empresas grandes y medianas pertenecientes a la actividad económica de Molinería, Chocolatería, Panadería y Otros ubicada en sector de Lima: Año 2016. 60 
Cuadro 21. Lista de empresas grandes y medianas pertenecientes a la actividad económica de Molinería, Chocolatería, Panadería y Otros ubicada en sector de Lima: Año 2016. 63

Cuadro 22. Distribución de muestra de empresas grandes y medianas pertenecientes a la actividad económica de Molinería, Chocolatería, Panadería y Otros ubicada en sector de Lima: Año 2016 .68

Cuadro 23. Criterios de elección por juicio .68

Cuadro 24. Muestra de empresas grandes y medianas pertenecientes a la actividad económica de Molinería, Chocolatería, Panadería y Otros ubicada en sector de Lima: Año 2016. .71

Cuadro 25. Nivel de empresas que producen y comercializan alimentos (Conformado en porcentajes) 73

Cuadro 26. Interés en compra de frutos deshidratados (Conformado en porcentajes).74 Cuadro 27. Nivel de conocimiento de las empresas productoras y comercializadora de alimentos sobre tipo de fruta deshidratada. (Conformado en porcentajes). .75

Cuadro 28. Medios de información de preferencia sobre fruta deshidratada. (Conformado en porcentajes) .766

Cuadro 29. Nivel de empresas que utiliza la fruta deshidratada para elaboración de productos. (Conformado en porcentajes) 77

Cuadro 30. Interés de compra de fruta deshidratada de arándanos, piña manzana por parte de las empresas productoras de alimentos. (Conformado en porcentajes). 78

Cuadro 31. Tipo o variedad de fruta deshidratada que compran las empresas productoras de alimentos. (Conformado en porcentajes). 79

Cuadro 32. Importancia asignada a la compra de frutas deshidratadas (Conformado en porcentajes) .80 
Cuadro 33. Volumen en kilos de compra de fruta deshidratada de arándanos, piña y manzana por parte de las empresas productoras de alimentos. (Conformado en kilos) 81 Cuadro 34. Volumen en kilos de compra de fruta deshidratada de arándanos, piña y manzana por parte de las empresas productoras de alimentos. (Conformado en kilos) 82 Cuadro 35. Frecuencia de compra de fruta deshidratada de arándanos, piña y manzana por parte de las empresas productoras de alimentos. (Conformado en frecuencia). .83 Cuadro 36. Expectativas de crecimiento de la demanda de frutas deshidratadas de arándanos, piña y manzana por parte de las empresas productoras de alimentos. (Conformado en porcentajes).

Cuadro 37. Expectativas de crecimiento de la demanda de frutas deshidratadas de arándanos, piña y manzana por parte de las empresas productoras de alimentos. (Conformado en porcentaje) .85

Cuadro 38. Proveedores de frutas deshidratadas de arándanos, piña y manzana de las empresas productoras de alimentos. (Conformado en frecuencia). 86

Cuadro 39. Criterios de selección de proveedores de fruta deshidratada de arándanos, piña y manzana de las empresas productoras de alimentos. (Conformado en frecuencia) 87 Cuadro 40. Debilidades de los proveedores de fruta deshidratada de arándanos, piña y manzana (Conformado en frecuencia). 88

Cuadro 41. Precio por kilo de la fruta deshidratada de arándanos, piña y manzana al que compran las empresas productoras de alimentos (Conformado en frecuencia). .889

Cuadro 42. Criterios más importantes para la selección de fruta deshidratada (Conformado en frecuencia). .90

Cuadro 43. Disposición de compra de las frutas deshidratadas de arándanos, piña y manzana por parte de las empresas productoras de alimentos. (Conformado en porcentaje) 
Cuadro 44. Tipo de empaque de frutos deshidratados de arándanos, piña y manzana deseado por las empresas productoras de alimentos. (Conformado en porcentaje)..92 Cuadro 45. kilos que contendrá el empaque de frutos deshidratados de arándanos, piña y manzana deseados por las empresas elaboradoras de alimentos. (Conformado en porcentajes)

Cuadro 46. Condiciones de pago por la compra de frutos deshidratados de arándanos, piña y manzana por parte de las empresas elaboradoras de alimentos (Conformado en porcentajes) 94

Cuadro 47. Criterios de segmentación y mercado potencial 101

Cuadro 48. Mercado disponible (Conformado en porcentajes). 101

Cuadro 49. Mercado efectivo (Conformado en porcentajes). 103

Cuadro 50. Porción de captación de mercado objetivo (Conformado en porcentajes).104 Cuadro 51. Definición de mercado objetivo -McDaniels (Conformado en kilogramos).

Cuadro 52. Porción a captar del mercado objetivo 105

Cuadro 53. Porción a captar del mercado objetivo: McDaniels 106

Cuadro 54. Porción de captación de mercado objetivo a través de los años Conformado en porcentajes) 106

Cuadro 55. Porción de captación de mercado objetivo a través de los años (Conformado en kilos). 107

Cuadro 56. Matriz de crecimiento producto mercado. 109

Cuadro 57. Costo unitario de un kilo de fruta deshidratada

Cuadro 58. Cuadro comparativo de competidores de fruta deshidratada.

Cuadro 59. Presupuesto de promoción y publicidad. 115

Cuadro 60. Cronograma de actividades de promoción y publicidad. 115 
Cuadro 61. Proyección trimestral de ventas 2023 (Conformado en kilos).

Cuadro 62. Pronóstico de demanda objetiva (unidades)

Cuadro 63. Proveedores de arándanos.

Cuadro 64. Resumen flujo deshidratado.

Cuadro 65. Activo fijo depreciable.

Cuadro 66. Cuadro de optimización de recursos.

Cuadro 67. Capacidad y uso de la planta.

Cuadro 68. Cuadro de personal 136

Cuadro 69. Áreas de la planta deshidratadora. 142

Cuadro 70. Macro localización. 143

Cuadro 71. Micro localización 144

Cuadro 72. Planilla de Operaciones en Soles. 160

Cuadro 73. Resumen de activo fijo (en nuevos soles). 163

Cuadro 74. Resumen de activo intangible y gastos pre operativos (en nuevos soles). 163

Cuadro 75. Resumen de capital de trabajo (en nuevos soles). 164

Cuadro 76. Costo del proyecto (en nuevos soles). 164

Cuadro 77. Calculo del COK del proyecto. 166

Cuadro 78. Proyección de venta por producto $(\mathrm{Kg})$. 166

Cuadro 79. Valor de venta por producto (S/.). 167

Cuadro 80. Presupuesto de venta anual por producto y total (S/.). 167

Cuadro 81. Costos unitarios de producción por producto (S/.). 168

Cuadro 82. Presupuesto de producción por producto y total (S/.). 168

Cuadro 83. Presupuesto de materia prima por producto y total (S/.). 169

Cuadro 84. Presupuesto de compras por producto y total (S/.). 170

Cuadro 85. Presupuesto de costo de ventas por producto y total (S/.). 170 
Cuadro 86. Presupuesto de gastos administrativos (S/.) ........................................... 170

Cuadro 87. Presupuesto de gastos de marketing y ventas (S/.). ............................... 170

Cuadro 88. Estado de ganancias y pérdidas proyectado (S/.)................................. 172

Cuadro 89. Balance proyectado (S/.).............................................................. 173

Cuadro 90. Flujo de caja proyectado (S/.) …..................................................... 174

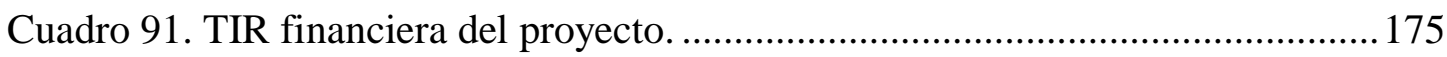

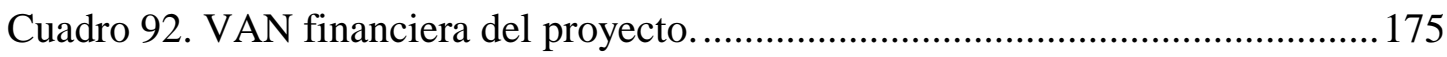

Cuadro 93. Evolución del ROA del proyecto........................................................ 176

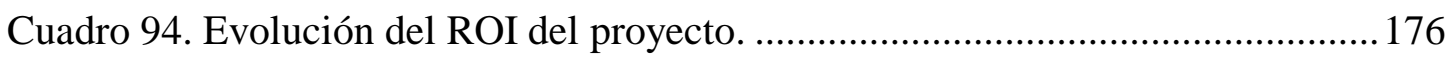

Cuadro 95. Evolución del ROE del proyecto........................................................ 176

Cuadro 96. Evaluación margen contribución ponderado por año. ............................177

Cuadro 97. Análisis de punto de equilibro por año.............................................. 178

Cuadro 98. Análisis de sensibilidad del efecto del precio de la materia prima en la

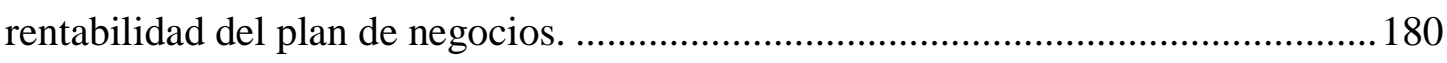

Cuadro 99. Análisis de sensibilidad del valor de venta y la demanda objetica en la

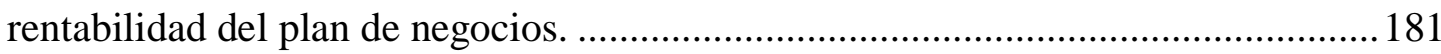

Cuadro 100. Análisis de sensibilidad por disminución en la productividad del proceso

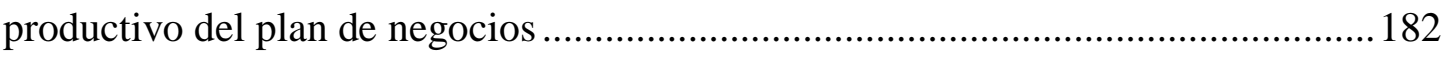

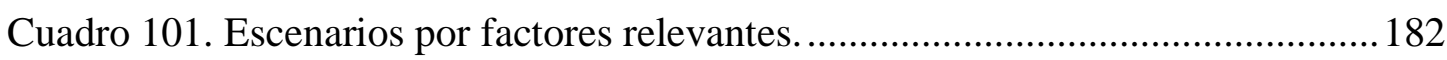




\section{ÍNDICE DE GRÁFICOS}

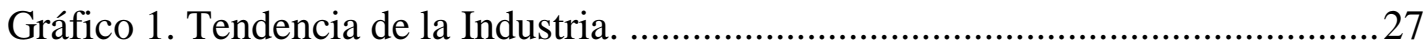

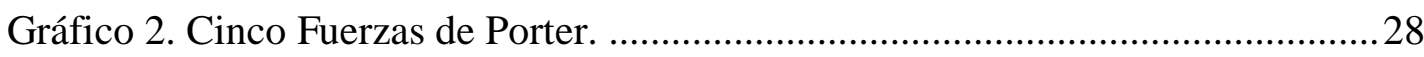

Gráfico 3. Producción Nacional de Frutas 2013 - 2017............................................. 32

Gráfico 4. Precio de Frutas recibido por agricultor 2013 - 2017............................. 34

Gráfico 5. Producción nacional de Piña por regiones 2017. ..................................... 35

Gráfico 6. Producción nacional de Manzana por regiones 2017................................36

Gráfico 7. Producción nacional de Arándanos por regiones 2017. ........................... 37

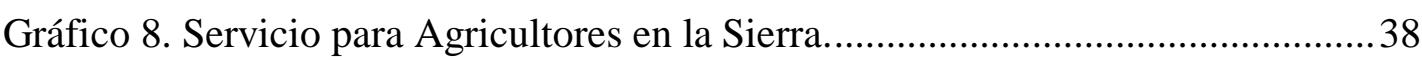

Gráfico 9. Índice de volumen físico de la producción manufacturera........................46

Gráfico 10. Incremento de producción que trajo el fenómeno "El Niño Costero". ..47

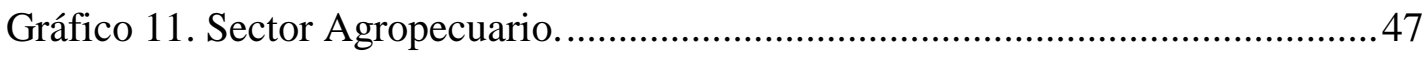

Gráfico 12. Sub Sector Manufacturero No Primario................................................ 48

Gráfico 13. Nivel de empresas que producen y comercializan alimentos................73

Gráfico 14. Interés en compra de frutos deshidratados. ........................................ 74

Gráfico 15. Nivel de conocimiento de las empresas productoras y comercializadora de

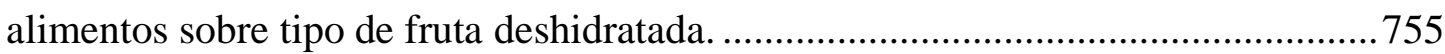

Gráfico 16. Medios de información de preferencia sobre fruta deshidratada. ..........76

Gráfico 17. Nivel de empresas que utiliza la fruta deshidratada para elaboración de

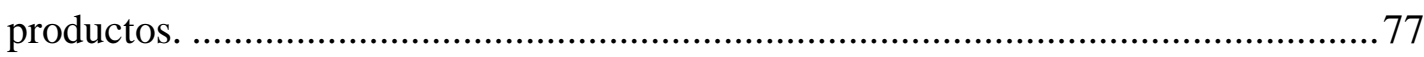

Gráfico 18. Interés de compra de fruta deshidratada de arándanos, piña manzana por parte de las empresas productoras de alimentos .78

Gráfico 19. Tipo o variedad de fruta deshidratada que compran las empresas productoras de alimentos 
Gráfico 20. Nivel de importancia del uso de los frutos deshidratados en la elaboración de productos. .80

Gráfico 21. Volumen en kilos de compra de fruta deshidratada de arándanos, piña y manzana por parte de las empresas productoras de alimentos.

Gráfico 22. Volumen en kilos de compra de fruta deshidratada de arándanos, piña y manzana por parte de las empresas productoras de alimentos. .82

Gráfico 23. Frecuencia de compra de fruta deshidratada de arándanos, piña y manzana por parte de las empresas productoras de alimentos.

Gráfico 24. Tipos de productos en los que se utiliza como ingrediente la fruta deshidratada de arándanos, piña y manzana. .84

Gráfico 25. Expectativas de crecimiento de la demanda de frutas deshidratadas de arándanos, piña y manzana por parte de las empresas productoras de alimentos. ....85 Gráfico 26. Expectativas de crecimiento de la demanda de frutas deshidratadas de arándanos, piña y manzana por parte de las empresas productoras de alimentos. ....86 Gráfico 27. Proveedores de frutas deshidratadas de arándanos, piña y manzana de las empresas productoras de alimentos. .87

Gráfico 28. Criterios de selección de proveedores de fruta deshidratada de arándanos, piña y manzana de las empresas productoras de alimentos. .88 Gráfico 29. Debilidades de los proveedores de fruta deshidratada de arándanos, piña y manzana. 89

Gráfico 30. Precio por kilo de la fruta deshidratada de arándanos, piña y manzana al que compran las empresas productoras de alimentos .90

Gráfico 31. Criterios más importantes para la selección de fruta deshidratada. 91 Gráfico 32. Disposición de compra de las frutas deshidratadas de arándanos, piña y manzana por parte de las empresas productoras de alimentos. 
Gráfico 33. Tipo de empaque de frutos deshidratados de arándanos, piña y manzana deseado por las empresas productoras de alimentos. .93

Gráfico 34. Kilos que contendrá el empaque de frutos deshidratados de arándanos, piña y manzana deseados por las empresas elaboradoras de alimentos.

Gráfico 35. Condiciones de pago por la compra de frutos deshidratados de arándanos, piña y manzana por parte de las empresas elaboradoras de alimentos. 95

Gráfico 36. Mercado disponible. 102

Gráfico 37. Mercado efectivo. 103

Gráfico 38. Porción de captación de mercado objetivo 104

Gráfico 39. Estrategia plaza y distribución. 109

Gráfico 40. Estrategia plaza y distribución. 112

Gráfico 41. Crecimiento anual de arándano (t). 120

Gráfico 42. Saldos de producción nacional de arándanos. 123

Gráfico 43. Producción nacional de arándanos.

Gráfico 44. Zonas potenciales de producción de arándanos. 124

Gráfico 45. Diagrama de proceso 126

Gráfico 46. Diagrama de flujo. 131

Gráfico 47. Layout de planta deshidratadora. 134

Gráfico 48. Organigrama de Frutos deshidratados SAC. 152

Gráfico 49. Tendencias del punto de equilibrio y ventas anuales. 178 


\section{ÍNDICE DE FIGURAS}

Figura 1. Tanque de lavado. ...............................................................................136

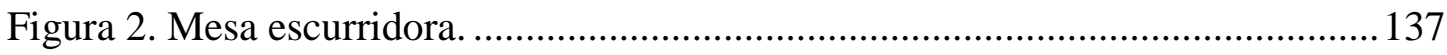

Figura 3. Cámara de frío...................................................................................... 137

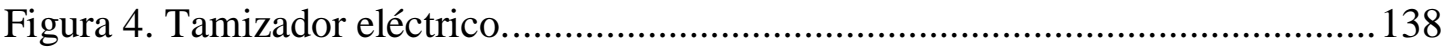

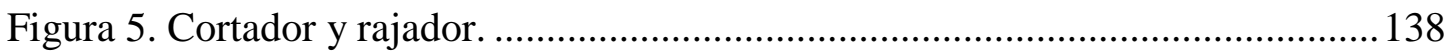

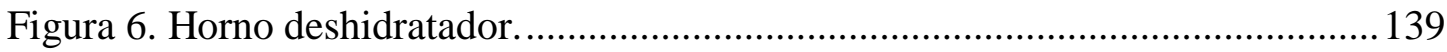

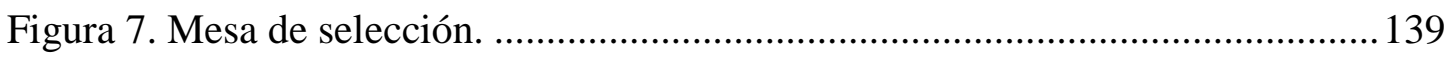

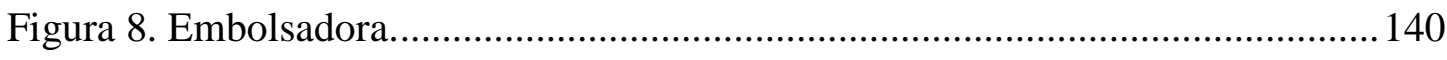

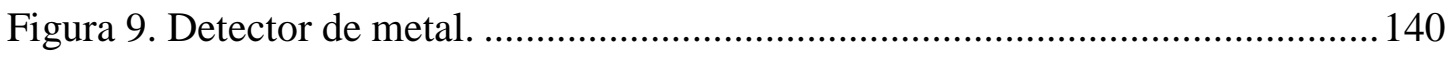

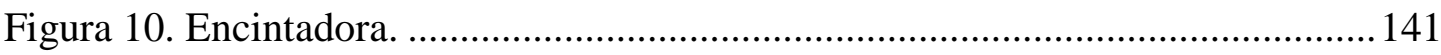

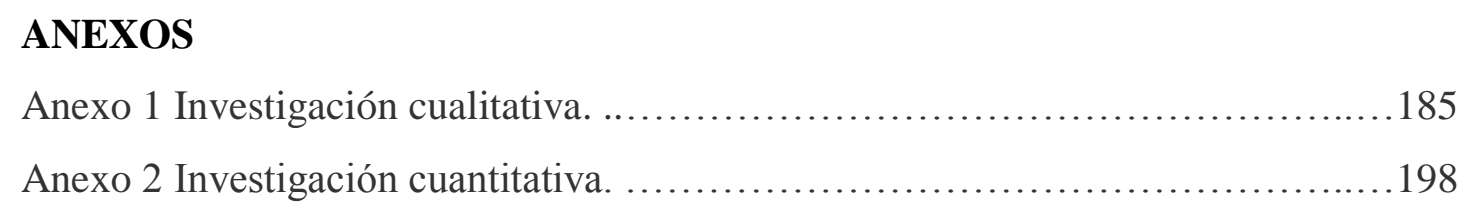




\section{Resumen Ejecutivo}

Frutos Deshidratados SAC estará ubicada en el distrito de Santa Anita de la provincia de Lima.

La empresa se dedicará a la producción y venta de arándano, piña y manzana deshidratada para el sector industrial.

El objetivo del plan de negocios de Frutos Deshidratados SAC será determinar la factibilidad técnico-económica de la implementación de una empresa dedicada a la deshidratación y venta de arándanos, piña y manzana para uso industrial en el distrito de Santa Anita. Del mismo modo identificar los riesgos del análisis de variables endógenas y exógenas.

Frutos Deshidratados SAC establecerá como estrategia la diferenciación, la cual estará basada en la calidad del producto y servicio ofrecido, características identificadas como elementos de selección por parte de los clientes.

La inversión para el presente proyecto a cinco años será de S/. 666,773, el COK para esta industria es de $23.87 \%$, de igual forma se obtendrá un VANE y el VANF de S/. 126,146, finalmente el TIRE y el TIRF arrojará un 26.72\%. 


\section{Generalidades}

\subsection{Antecedentes}

Un primer trabajo corresponde a la empresa de consultoría estratégica Proexpansión (2014) que indica que el mercado de snack llego a alcanzar 374 mil millones de dólares, lo que representó un crecimiento del 2\% con respecto al año anterior. Sin embargo aunque no haya sido importante dicho crecimiento es bueno revisar los sectores que han tenido una variación importante. En dicha investigación se menciona que, de acuerdo a la compañía Nielsen, Europa representa un 45\%; pero que la región de América Latina se ha conseguido el mayor crecimiento de la región con un 9\%, superior al promedio.

Asimismo dicho informe menciona que el incremento en la región se ha presentado en los piqueos y snack salados, los cuales han alcanzado un $21 \%$; por ejemplo en Perú ha comenzado la producción de cancha chullpi o el maíz gigante del Cusco.

El tema de salud pesa más a la hora de elegir un snack; de acuerdo al estudio cada vez más consumidores prefieren que los ingredientes sean naturales. El $45 \%$ de encuestados mencionaron que desean snacks que no tengan dentro de sus ingredientes colores ni saborizantes artificiales, así como también organismos genéticamente modificados.

Finalmente el estudio menciona que los snack presentes en el mercado contienen un alto porcentaje de elementos calóricos y no benefician en nada al consumidor. Sin embargo, muchos encuestados mencionan que consumen snack en el desayuno, almuerzo o cena. De igual forma el estudio concluye que más personas reemplazarán sus comidas por snack. 
Un segundo trabajo está referido a la nota descriptiva de la Organización Mundial de la Salud OMS (2017) desde el año 1975 la obesidad se ha triplicado en el mundo. El estudio explica que en el 2016, cerca del 39\% de las personas adultas de 18 o más años contaban con sobrepeso, y el $13 \%$ eran obesas.

La nota afirma que en el 2016, existen 41 millones de niños con menos de cinco años que sufren de sobrepeso o eran obesos. De igual forma más de 340 millones de niños y adolescentes (entre los 5 a 19 años) tienen sobrepeso u obesidad.

La nota recomienda que dentro de los hábitos individuales de las personas, estas deben consumir frutas, legumbres y frutos secos.

Para finalizar se menciona también que la industrias alimentarias son actores importantes en la difusión de dietas sanas.

Un tercer trabajo es el comentario de la dietética Grecia Bellmun recogido por el Portal de Radio Programas RPP (2017) en donde recomienda consumir de 25 a 30 gramos al día de frutos secos, los cuales, están considerados como súper alimentos por su alto porcentaje de hierro, magnesio, fibra, grasa y vitaminas del complejo B; de igual forma lo propone como una opción de snack a través del día.

Finalmente el reporte especial de la Escuela de Medicina de Harvard (2012) Reducing Sugar and Salt: Strategies for minimizing risks to your health menciona que es recomendable mezclar los frutos secos, así como consumir barra de cereales y granolas con bajo nivel de azúcar.

Por otro lado existen proveedores de arándanos, pina y manzana deshidratados que abastecen a diversas empresas procesadoras de alimentos; sin embargo estas no ofrecen un producto que cumpla con los requisitos de inocuidad adecuados ni las especificaciones técnicas de corte y calibre. Esto finalmente genera que las empresas industriales de alimentos tengan dificultades en encontrar un insumo de acuerdo a sus 
necesidades de calidad; de igual forma los insumos recibidos deberán ser adecuados a sus propias especificaciones, generando un costo adicional.

Del mismo modo el gobierno ha reglamentado la Ley de Alimentación Saludable N 30021, el cual fomenta acciones preventivas para el aumento en el mercado de alimentos saludables a fin de contrarrestar los problemas de sobrepeso y obesidad en la población.

\subsection{Determinación del problema u oportunidad}

Se observa que existe una demanda creciente por productos alimenticios saludables a base de frutas deshidratadas por los consumidores finales.

Las empresas de la industria alimenticia están demandando frutas deshidratadas con especificaciones técnicas específicas de calidad.

Actualmente dentro de la industria del sector alimenticio se identifica que las empresas que deshidratan frutas ofrecen un producto que no cumple las especificaciones técnicas solicitadas por las empresas procesadoras de alimentos.

En tal sentido se identifica la oportunidad de establecer un negocio de producción y venta de arándanos, piña y manzana deshidratados que cumplan las especificaciones técnicas exigidas por las empresas procesadoras de alimentos.

\subsection{Justificación del Proyecto}

Dada la oportunidad identificada se hace necesario desarrollar un plan de negocios que permita determinar la viabilidad de implementar una empresa productora de arándanos, piña y manzanas deshidratadas que tenga como factores críticos de éxito el abastecimiento continuo de la materia prima, la productividad del proceso y la reacción de la competencia. 


\subsection{Objetivos Generales y Específicos}

\subsubsection{Objetivo general.}

Elaborar un plan de negocios para determinar la factibilidad técnico-económica de implementación de una empresa dedicada a la producción y venta de arándanos, piña y manzana deshidratada para uso industrial en el distrito de Santa Anita. Del mismo modo identificar los riesgos del análisis de variables endógenas y exógenas.

\subsubsection{Objetivos específicos.}

a) Determinar el nivel de demanda de arándanos, piña y manzana deshidratados por parte de las medianas y grandes empresas procesadoras de alimentos a nivel nacional y establecer estrategias que permita posicionar los productos.

b) Analizar a las empresas procesadoras y comercializadores nacionales y extranjeras de arándanos, piña y manzana.

c) Determinar la ventaja competitiva entre la oferta actual y la propuesta del proyecto.

d) Realizar un estudio técnico que permita determinar la tecnología óptima a utilizar en el procesamiento de arándanos, piña y manzana deshidratados, así como establecer el tamaño óptimo de la planta.

e) Elaborar un estudio económico financiero para establecer la viabilidad del proyecto.

\subsection{Alcances y limitaciones de la investigación}

\subsubsection{Alcance.}

El ámbito del proyecto tomará en cuenta lo siguiente:

a) El plan de negocio tendrá un alcance a nivel Lima.

b) El segmento al que está dirigido serán todas las medianas y grandes empresas de molinería, chocolatería, panadería y otros que elaboran Barras Energéticas, 
Granolas, Galletas y Snacks ubicadas en el departamento de Lima, que utilizan como insumo arándanos, piña y manzana deshidratadas para la elaboración de sus productos.

c) El periodo de análisis será a un periodo de 5 años.

\subsubsection{Limitaciones}

a) Dificultad para obtener información relacionada a la industria puesto que está en etapa de crecimiento, lo que puede causar aplazamiento en la realización del plan negocios respectivo.

b) Accesibilidad de tiempo por parte de los potenciales clientes, responsables de compras. 


\section{Estructura Económica del Sector}

\subsection{Estado Actual de la Industria}

En el mercado nacional peruano existen empresas productoras de frutas deshidratadas establecidas, sin embargo el mercado de los berries deshidratados aún está en desarrollo y con crecimiento expectante.

Existen empresas bien establecidas que ofrecen productos a los consumidores finales e industriales tales como Terra Fértil SAC, Frutos y Especias SAC, Frutas e Industrias SAC y las marcas propias de las cadenas de supermercados.

En la industria de los berries deshidratados no se tienen empresas que brinden arándano deshidratado con la calidad necesitada por las empresas industriales procesadoras de alimentos que lo utilizan como insumo para la producción de otros productos como las galletas, barras energéticas, etc.

Las frutas deshidratadas ofrecidas en venta a granel dentro de los mercados de abarrotes del país en su mayoría son producidas por micro productores; estos productos no cumplen con las especificaciones técnicas necesitadas por las empresas industriales procesadores de alimentos.

Las frutas deshidratadas ofrecidas por las empresas importadoras y comercializadoras, cumplen con algunas especificaciones técnicas y certificados sanitarios, además de que el producto al ser importado tiene un costo mayor para las empresas industriales que tienen como insumo para fabricar otros productos alimenticios.

Dentro del mercado industrial existe necesidad de frutas deshidratadas que cumplan con las especificaciones técnicas exigentes y que satisfaga el volumen necesitado por las empresas procesadoras de alimentos. 
La producción de productos alimenticios que utilizan como insumo los arándanos está en pleno crecimiento. Las empresas están ofreciendo sus productos al mercado nacional e internacional; la demanda internacional de este producto está en pleno crecimiento lo que hace que se necesite éste fruto en su opción deshidratada por que conserva sus propiedades organolépticas.

En referencia a las frutas como la manzana y piña son netamente de producción y consumo a nivel nacional, de acuerdo a las estadísticas de exportaciones de Adex no se evidencia mayores movimientos de estas frutas.

A nivel nacional tenemos una producción promedio anual de piña de 460 mil toneladas y el $80 \%$ de la producción es de origen de la región Junín y selva central.

También a nivel nacional tenemos una producción promedio anual de manzana de 156 mil toneladas y el 90\% de la producción es de origen de la región Lima.

Esta información estadística es de producción agrícola y ganadera desde el año 2013 al 2017 del ministerio de agricultura.

\subsubsection{Segmentación de la industria}

Según clasificación CIIU revisión 3, la industria de producción de frutas deshidratadas se encuentra dentro de la sección D división 15 como Elaboración de Productos Alimenticios y Bebidas, y clase 1513 como Elaboración y Conservación de Frutas, Legumbres y Hortalizas.

Se estudiarán las micro, pequeñas y medianas empresas nacionales (MIPYME). El segmento de la industria al cual se estudiará en el Plan de Negocio es la producción de frutas deshidratadas. 


\subsubsection{Empresas que la conforman}

La industria está conformada por las empresas nacionales, que producen frutos deshidratados en general. Se tiene la siguiente lista de empresas más importantes de la industria de acuerdo a la investigación cuantitativa del presente estudio.

- Frutos y Especias SAC

- Frutas e Industrias SAC

- Terrafertil Perú SAC

- Oxiquim

- Narvid EIRL

- Peruvian Nature S\&S SAC

- Vitallanos SAC

\subsection{Tendencia de la Industria}

El consumo de frutas deshidratadas está atravesando un período de crecimiento sostenido debido a la toma de conciencia de los consumidores sobre el consumo de alimentos saludables, la fruta deshidratada conserva un alto porcentaje de las propiedades organolépticas de la fruta fresca.

La industria de producción de verduras, especias y frutas deshidratadas está dentro de la industria de alimentos y bebidas, la cual ha tenido un incremento casi sostenido desde el año 2007 al año 2014, desde el año 2015 se mantiene la misma producción mostrada en el siguiente gráfico 1. 


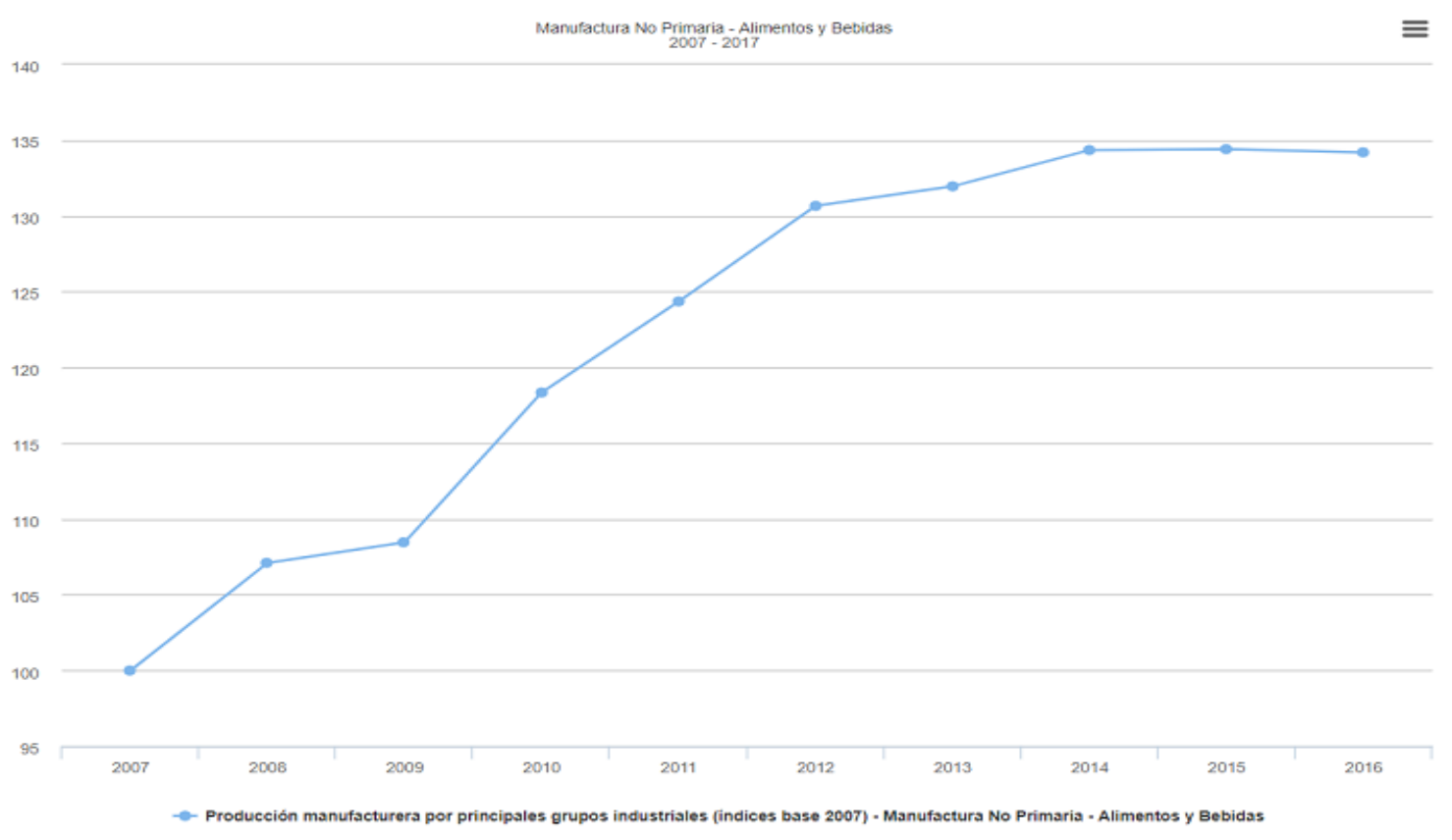

Gráfico 1. Tendencia de la Industria.

Adaptado de PBI por sectores 2007 al 2016 Manufactura no primaria - Alimentos y bebidas BCRP.

La producción de productos que utilizan frutos deshidratados como el arándano ha aumentado debido al incremento de la demanda de estos productos. Las empresas procesadoras de alimentos nacionales han incrementado el volumen de producción para satisfacer la demanda nacional y la demanda internacional mayor de estos productos. Según un estudio de marketing de Canadean, en Perú se proyecta un crecimiento sostenido del $3.08 \%$ interanual del 2015 al 2020 para las barras de cereal y de $3.22 \%$ interanual en el mismo período para las barras energéticas.

Debido a la gran demanda de arándano, considerado una fruta con grandes cualidades alimenticias, en los mercados internacionales, la producción nacional de arándano ha crecido enormemente durante los últimos años, lo que ha hecho que haya una mayor oferta de arándano en el mercado nacional y también ha conseguido que el precio de arándano fresco en chacra disminuya. 


\subsection{Análisis Estructural del Sector Industrial}

El análisis estructural del sector incluye aquellos factores con los cuales la organización interactúa directamente, es decir aquellas fuerzas que operan en el entorno inmediato de una organización y pueden afectar la capacidad de ésta para lograr una rentabilidad aceptable o superior.

Para efectuar el análisis sobre las diferentes variables del micro entorno del sector Manufactura y en especial del subsector de alimentos y bebidas, utilizamos el Modelo de las 5 fuerzas de Porter.

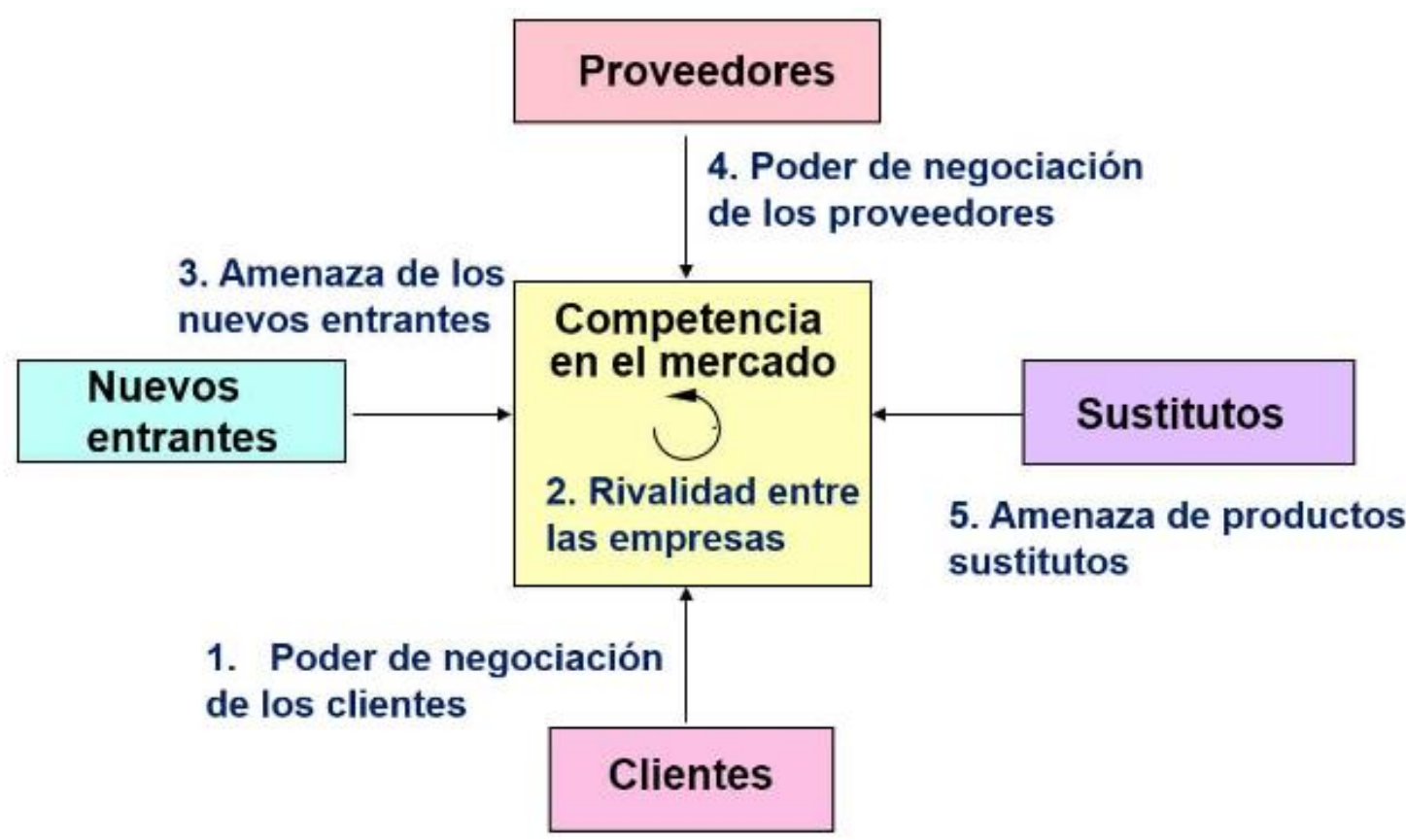

Gráfico 2. Cinco Fuerzas de Porter.

Tomado de Centro de Innovación y Creatividad Empresarial - Universidad Ricardo Palma.

\subsubsection{Poder de negociación de los clientes.}

Esta primera fuerza nos refiere el poder que cuentan los clientes de la industria al cual se dirige el proyecto, para obtener buenos precios y condiciones favorables a la compañía.

En la propuesta de negocio tenemos pocos clientes o compradores por estar en el sector industrial lo cual hace que tengan en primera instancia mayor poder o capacidad de 
negociación; pero al ser empresas industriales su necesidad de frutas deshidratadas es mayor en cantidad y con cumplimiento de estándares de calidad.

Entonces podemos afirmar que existe un equilibrio de poderes con los clientes de acuerdo a la oferta y demanda del mercado.

Aspectos a tomar en cuenta son: el factor diferenciador y la información que tienen en referencia a los precios y productos.

\subsubsection{Rivalidad entre empresas.}

La segunda fuerza es catalogada como la más poderosa de todas, esta fuerza se refiere a la competitividad y rivalidad entre las empresas del sector que compiten directamente y comercializan un mismo tipo de producto.

Para el plan de negocio, de acuerdo a investigación cuantitativa, se ha identificado las principales empresas competidoras que a continuación se detalla: Terrafertil Perú SAC como distribuidor autorizado de Ocean Spray, Frutos y Especies SAC, Frutas e Industrias SAC, Narvid EIRL, Oxiquim, Vitallanos SAC y Peruvian Nature S\&S SAC.

La rivalidad y competitividad con estas empresas se incrementará por la demanda creciente de frutas deshidratadas. Actualmente la tendencia en crecimiento por el consumo de alimentos saludables impulsará la necesidad de mayor demanda.

El factor de diferenciación en los productos es bajo por ser frutas deshidratadas y perecederas, pero son pocas empresas que ofrecen productos de alta calidad.

\subsubsection{Amenaza de los nuevos entrantes.}

Son empresas que potencialmente pueden ingresar a la industria de frutas deshidratadas.

Sin embargo se puede citar algunas barreras de entrada que permite proteger y hacer difícil el ingreso de nuevos competidores. 
Know how del proceso de deshidratado; por tratarse del procesamiento de alimentos para consumo masivo, el nivel de calidad debe ser superior; con uso de tecnología de punta que permita asegurar el proceso de acuerdo a las especificaciones técnicas.

\subsubsection{Poder de negociación de los proveedores.}

El poder de negociación de los proveedores se incrementa cuando son pocos los que participan dentro del mercado y sector industrial definido y los materiales y suministros utilizados son escasos.

Para el plan de negocios tenemos a los pequeños y medianos agricultores de las regiones del sur centro y norte del Perú.

Debido al crecimiento sostenido de las exportaciones de frutas como palta, arándanos, aguaymanto, piña, naranjas etc; tienen prioridad en atender la demanda externa y los saldos que están fuera de especificación o calibre son comercializados en el mercado interno. La calidad de los saldos de exportación son de primera, cumpliendo estándares de grados brix, sabor y color.

Se tiene como referencia en el cuadro 1 las proyecciones de áreas de cultivo y hectáreas en producción citados por sierra exportadora en el seminario de berries y cerezas del 2016.

Se evidencia que para el 2018 se proyecta contar con 5300 hectáreas de arándanos de las cuales el 78\% estarán en producción. 


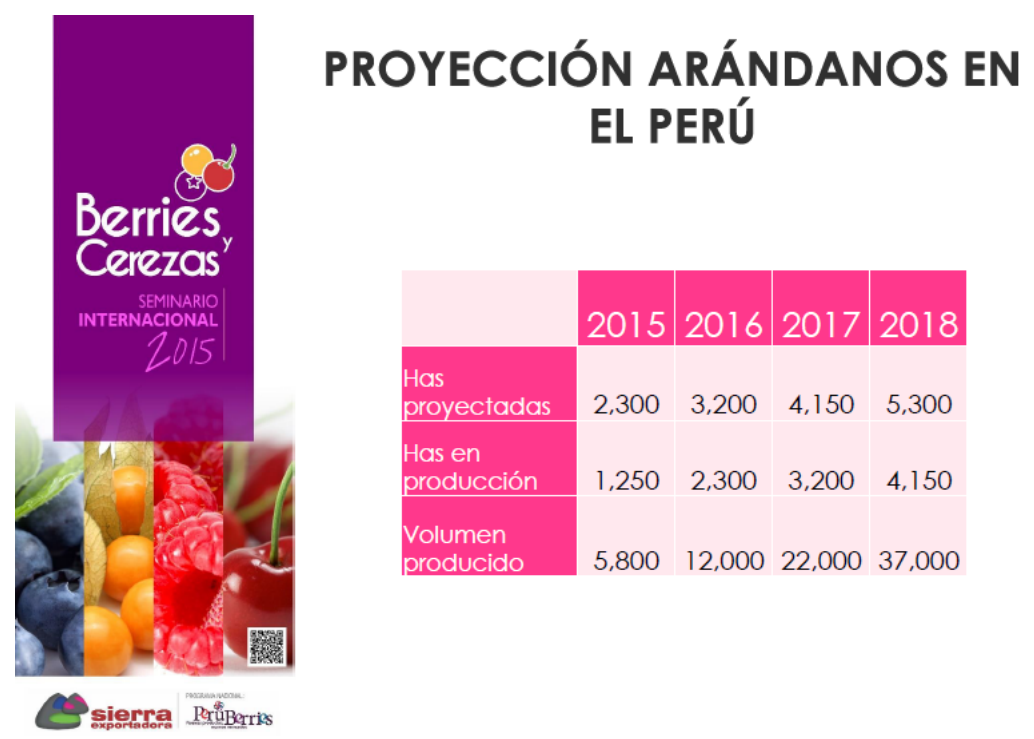

Cuadro 1. Proyección de Arándanos.

Tomado de Seminario de Berries y Cerezas de Sierra Exportadora.

Así mismo se tiene datos estadísticos del Ministerio de Agricultura y Riego, Boletín Estadístico de Producción Agrícola y Ganadera; en referencia a la producción nacional de arándanos, manzana y piña desde el año 2013 hasta el año 2017. Producción nacional por regiones del año 2017 y Precios recibidos por agricultores en forma anual del 2013 al 2017.

En el cuadro 2 se muestra la producción de los principales cultivos de frutas del país. La producción nacional de piña muestra una tendencia creciente, haciendo un cálculo lineal con la ecuación Y= 8.5215X-16710 para el año 2023 se tendría 529 mil toneladas. Con respecto a la producción de manzana el cálculo lineal tiene la siguiente ecuación

$Y=-1.4104 X+2998.9$ siendo la tendencia decreciente para el año 2023 de 145.6 mil toneladas. Para el caso de la producción de arándanos el cálculo lineal tiene la siguiente ecuación Y = 15.809X-31833 siendo la tendencia creciente para el año 2023 de 148.7 mil toneladas. 


\section{C.9 PERÚ: PRODUCCIÓN DE LOS PRINCIPALES CULTIVOS POR PRODUCTO SEGÚN AÑO, 2013-2017}

\begin{tabular}{|c|c|c|c|c|c|}
\hline \multirow[b]{2}{*}{ Producto } & \multicolumn{5}{|c|}{ Miles de toneladas } \\
\hline & 2013 & 2014 & 2015 & 2016 & 2017 \\
\hline \multicolumn{6}{|l|}{ Frutas y nueces } \\
\hline Palta & 288.85 & 349.32 & 376.60 & 455.39 & 461.47 \\
\hline Banano y plátano & $2,113.81$ & $2,125.84$ & $2,056.34$ & $2,073.99$ & $2,025.65$ \\
\hline Mango & 458.77 & 376.00 & 345.98 & 373.52 & 380.41 \\
\hline Piña & 448.88 & 455.30 & 450.63 & 461.29 & 488.50 \\
\hline Granadilla & 45.22 & 47.49 & 49.32 & 50.77 & 56.01 \\
\hline Limón & 228.47 & 263.80 & 267.95 & 270.31 & 167.40 \\
\hline Naranja & 441.12 & 450.42 & 456.15 & 490.87 & 488.10 \\
\hline Mandarina & 313.80 & 339.60 & 357.91 & 403.86 & 387.12 \\
\hline Uva & 439.24 & 507.10 & 597.94 & 689.96 & 645.98 \\
\hline Manzana & 156.43 & 159.88 & 159.55 & 158.10 & 150.27 \\
\hline Melocotón & 50.20 & 52.61 & 51.25 & 50.95 & 45.56 \\
\hline Arándanos & 1.75 & 2.57 & 10.73 & 27.86 & 68.15 \\
\hline
\end{tabular}

Cuadro 2. Producción Nacional de Frutas 2013 - 2017.

Fuente: SIEA - Boletín estadístico de la producción agrícola y ganadera.

En el gráfico 3 se muestra la producción real de frutas a nivel nacional seguido con la tendencia lineal hasta el año 2023 como horizonte del proyecto.

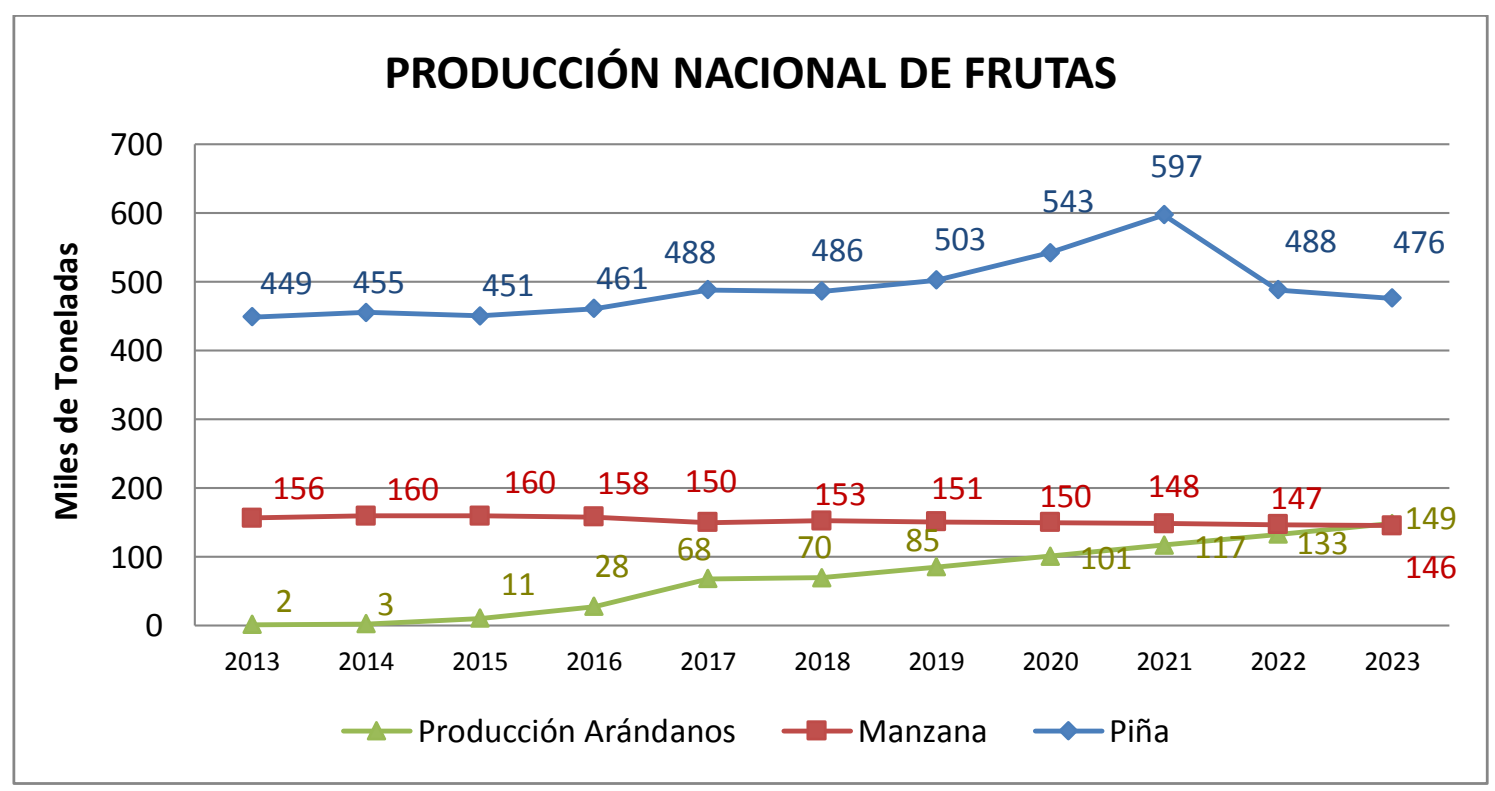

Gráfico 3. Producción Nacional de Frutas 2013 - 2017.

Elaboración propia. 
Para el plan de negocio se ha establecido los precios de la materia prima del año 2017 según se muestra en el cuadro 3 teniendo como fuente al SIEA. Para el caso de arándano tiene un precio de S/. 2.50 por kilo, para la piña tiene un precio de S/. 0.70 por kilo y para la manzana un precio de S/. 0.50 por kilo.

\begin{tabular}{|c|c|c|c|c|c|c|}
\hline \multirow{2}{*}{\multicolumn{2}{|c|}{ Producto }} & \multicolumn{5}{|c|}{ Soles / Kg } \\
\hline & & 2013 & 2014 & 2015 & 2016 & 2017 \\
\hline \multicolumn{7}{|l|}{ Frutas y nueces } \\
\hline & Palta & 1.75 & 1.90 & 1.94 & 2.48 & 2.98 \\
\hline & Banano y plátano & 0.49 & 0.49 & 0.52 & 0.58 & 0.62 \\
\hline & Mango & 0.54 & 1.09 & 1.04 & 0.74 & 0.67 \\
\hline & Piña & 0.57 & 0.62 & 0.67 & 0.70 & 0.70 \\
\hline & Granadilla & 2.01 & 1.86 & 1.67 & 1.66 & 1.74 \\
\hline & Limón & 1.03 & 0.95 & 0.97 & 0.79 & 1.58 \\
\hline & Naranja & 0.53 & 0.54 & 0.58 & 0.61 & 0.58 \\
\hline & Mandarina & 1.11 & 1.34 & 1.19 & 1.10 & 1.13 \\
\hline & Uva & 2.05 & 2.09 & 2.21 & 2.18 & 2.39 \\
\hline & Manzana & 0.71 & 0.74 & 0.76 & 0.85 & 0.50 \\
\hline & Melocotón & 1.93 & 1.94 & 1.98 & 2.17 & 2.18 \\
\hline & Arándanos & 18.12 & 15.09 & 10.22 & 6.00 & 2.50 \\
\hline
\end{tabular}

Cuadro 3. Precios de Frutas 2013 - 2017.

Tomado de SIEA - Boletín estadístico de la producción agrícola y ganadera.

Según el cuadro 3 que refiere los precios de las frutas frescas desde el año 2013 hasta el 2017, nos muestra que el arándano tiende a la baja debido principalmente al incremento de la oferta por mayor producción y áreas de cultivos; en el caso de la piña se mantiene el precio estable con mínimas variaciones por factores del mercado. Para el caso de la manzana el último año tuvo una reducción debido a la mayor oferta del mercado por temporadas y en general los precios se presentan muy estables.

En el gráfico 4 se visualiza los precios reales desde el año 2013 hasta el año 2017 mostrando las tendencias indicadas en el párrafo anterior. Como complemento específico a la caída de precio de arándano también se da por la disponibilidad de los saldos de exportación, debido a que los agricultores prefieren negociar inmediatamente antes que arriesgar y perder todo el saldo por ser estás frutas muy perecibles. 
Esta información fue manifestada en el estudio cualitativo de mercado con entrevista a gerente de la empresa deshidratadora Vitallanos SAC el señor Luis Llanos. Las preguntas tipo para las entrevistas a profundidad las podrá ver detallada en el Anexo $\mathrm{N}^{\mathrm{o}} 01$.

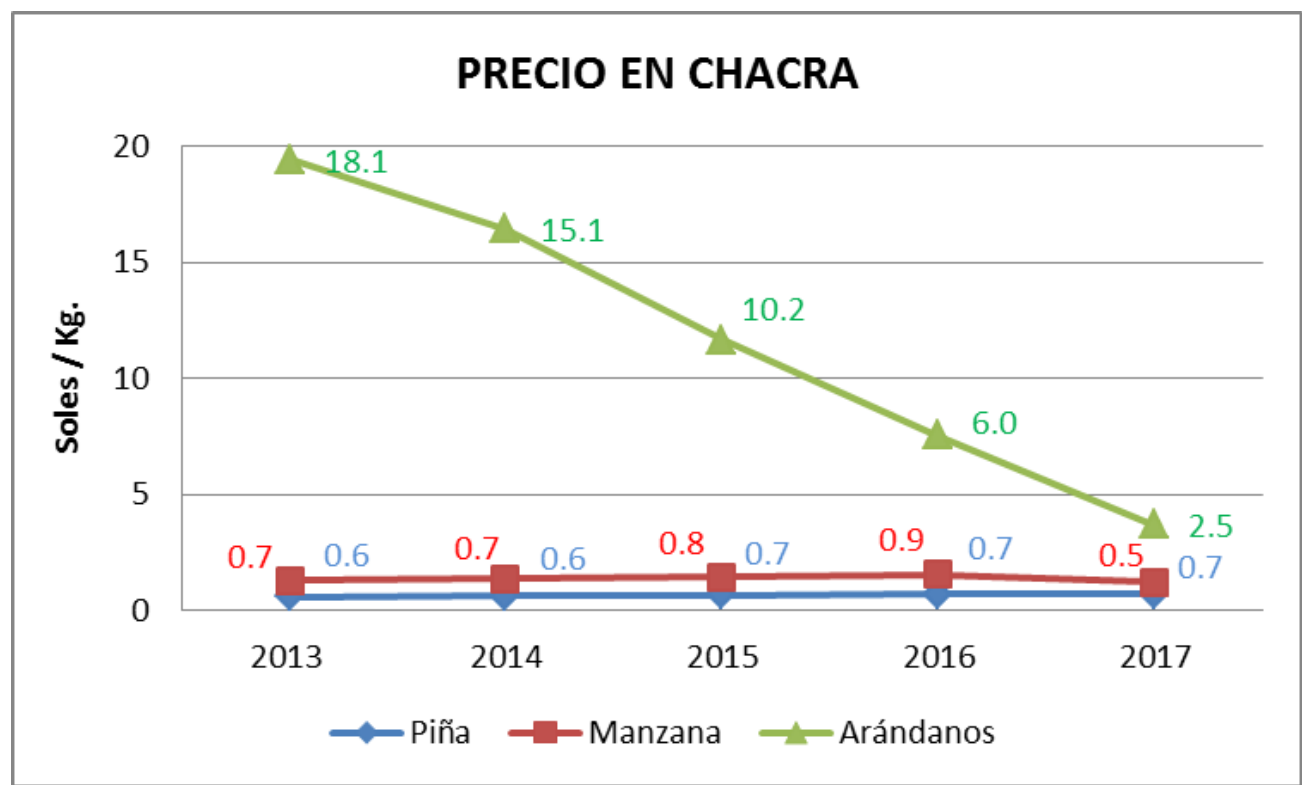

Gráfico 4. Precio de Frutas recibido por agricultor 2013 - 2017. Elaboración propia.

En la información estadística del SIEA también se muestra la producción por regiones para cada fruta a nivel nacional.

En el cuadro 4 se muestra la producción nacional de piña durante el año 2017 llegando a 488.5 mil toneladas.

La región con mayor volumen productivo es Junín representando el 74\% del volumen total tal como se muestra en el gráfico 5, la selva central produce el $6.4 \%$ del volumen total.

Para el plan de negocio se abastecería del $80 \%$ que mayormente se comercializa en la ciudad de lima, específicamente en el mercado mayorista de fruta número 2. 


\begin{tabular}{|c|c|}
\hline Región & Producción (t) \\
\hline NACIONAL & $488,497.39$ \\
\hline Amazonas & 9,864 \\
\hline Ayacucho & 2,164 \\
\hline Cajamarca & 4,794 \\
\hline Cusco & 10,181 \\
\hline Huánuco & 8,462 \\
\hline Junín & 362,851 \\
\hline La Libertad & 23,058 \\
\hline Loreto & 17,270 \\
\hline Madre de Dios & 4,644 \\
\hline Pasco & 449 \\
\hline Puno & 21,999 \\
\hline San Martin & 11,783 \\
\hline Ucayali & 10,978 \\
\hline
\end{tabular}

Cuadro 4. Producción Nacional de Piña 2017.

Tomado de SIEA - Boletín estadístico de la producción agrícola y ganadera.

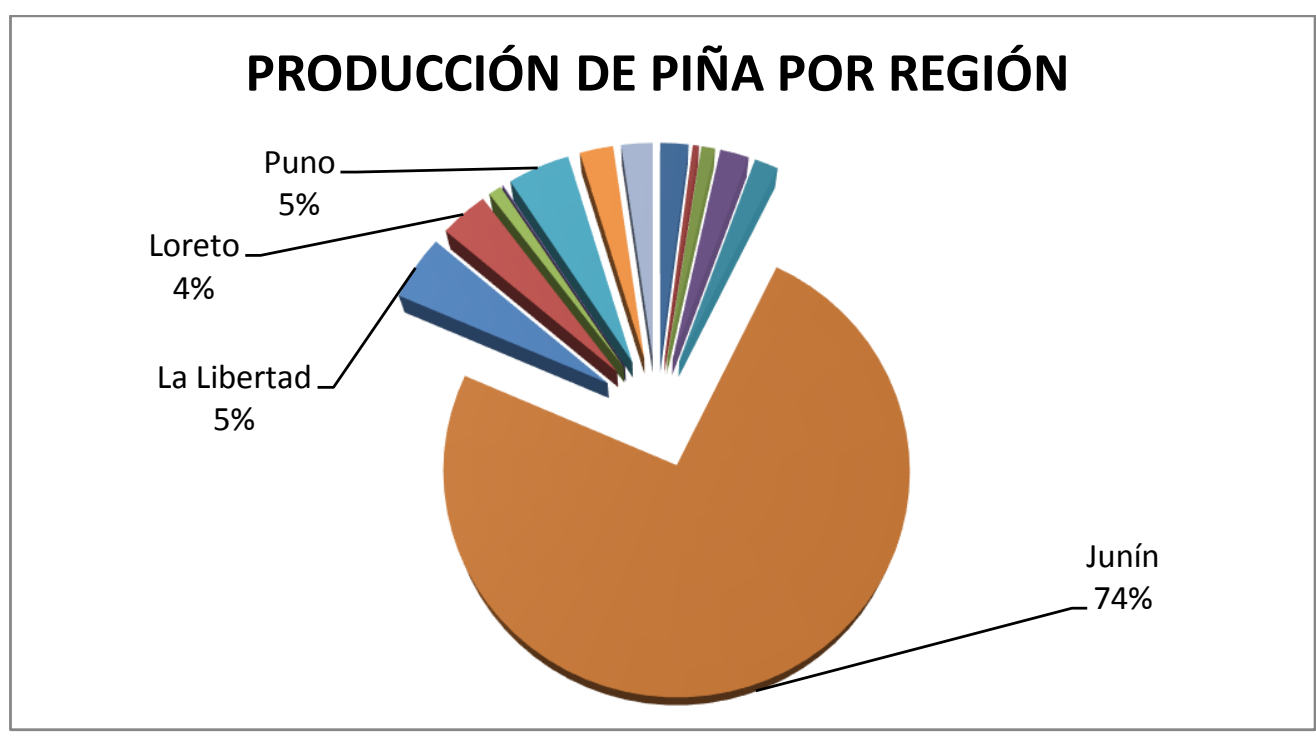

Gráfico 5. Producción nacional de Piña por regiones 2017. Elaboración propia.

En el cuadro 5 se muestra la producción nacional por regiones de manzana. Se puede evidenciar que la región de mayor producción es Lima provincias con 138 mil toneladas; en el gráfico 6 nos muestra que llega al 92\% de la producción nacional. El principal mercado de comercialización es el Mayorista de fruta número 2 en donde nos abasteceremos para cumplir con el plan de negocio. 


\section{C.40 PERÚ: MANZANA POR REGIÓN SEGÚN VARIABLES PRODUCTIVAS, 2017}

\begin{tabular}{lr}
\multicolumn{1}{c}{ Región } & Producción $(\mathbf{t})$ \\
\hline \multicolumn{1}{c}{ NACIONAL } & \\
\hline Amazonas & $150,269.3$ \\
Ancash & 4.0 \\
Apurímac & $3,593.4$ \\
Arequipa & 659.3 \\
Ayacucho & 992.6 \\
Cajamarca & 675.0 \\
Cusco & 422.8 \\
Huancavelica & 764.0 \\
Huánuco & 220.3 \\
lca & 66.0 \\
Junín & $1,192.2$ \\
La Libertad & 110.2 \\
Lima (excluye Lima Metro & 988.2 \\
Lima Metropolitana & $138,008.0$ \\
Moquegua & $1,078.4$ \\
Tacna & 463.0 \\
\hline
\end{tabular}

Cuadro 5. Producción Nacional de Manzana 2017.

Tomado de SIEA - Boletín estadístico de la producción agrícola y ganadera.

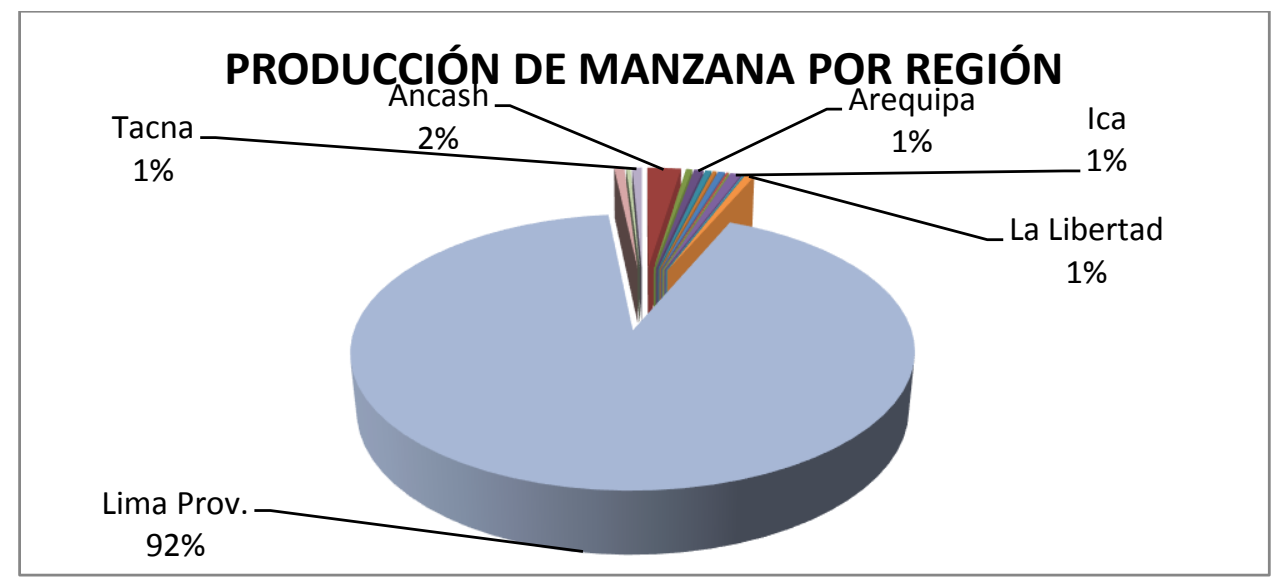

Gráfico 6. Producción nacional de Manzana por regiones 2017. Elaboración propia.

En el cuadro 6 se muestra la producción nacional de arándanos del año 2017. La región de mayor producción es La Libertad con 56.6 mil toneladas.

En el gráfico 7 visualizamos la participación por cada región, las más representativas son La Libertad con el 83\% y Lambayeque con el 14\%; Lima y los otras regiones con el $1 \%$. 
Podemos afirmar que los agricultores de arándanos no tienen el poder de fijación de precios de los saldos de exportación.

\section{C.42 PERÚ: ARÁNDANOS POR REGIÓN SEGÚN VARIABLES PRODUCTIVAS, 2017}

\begin{tabular}{l|r}
\multicolumn{1}{c|}{ Región } & \multicolumn{1}{c}{ Producción (t) } \\
& \\
\hline \multicolumn{1}{c}{ NACIONAL } & $68,117.6$ \\
\hline Ancash & 755.0 \\
Arequipa & 3.0 \\
Ica & 633.5 \\
La Libertad & $56,602.1$ \\
Lambayeque & $9,390.0$ \\
Lima (excluye Lima Metror & 734.0 \\
\hline
\end{tabular}

Cuadro 6. Producción Nacional de Arándanos 2017.

Tomado de SIEA - Boletín estadístico de la producción agrícola y ganadera.

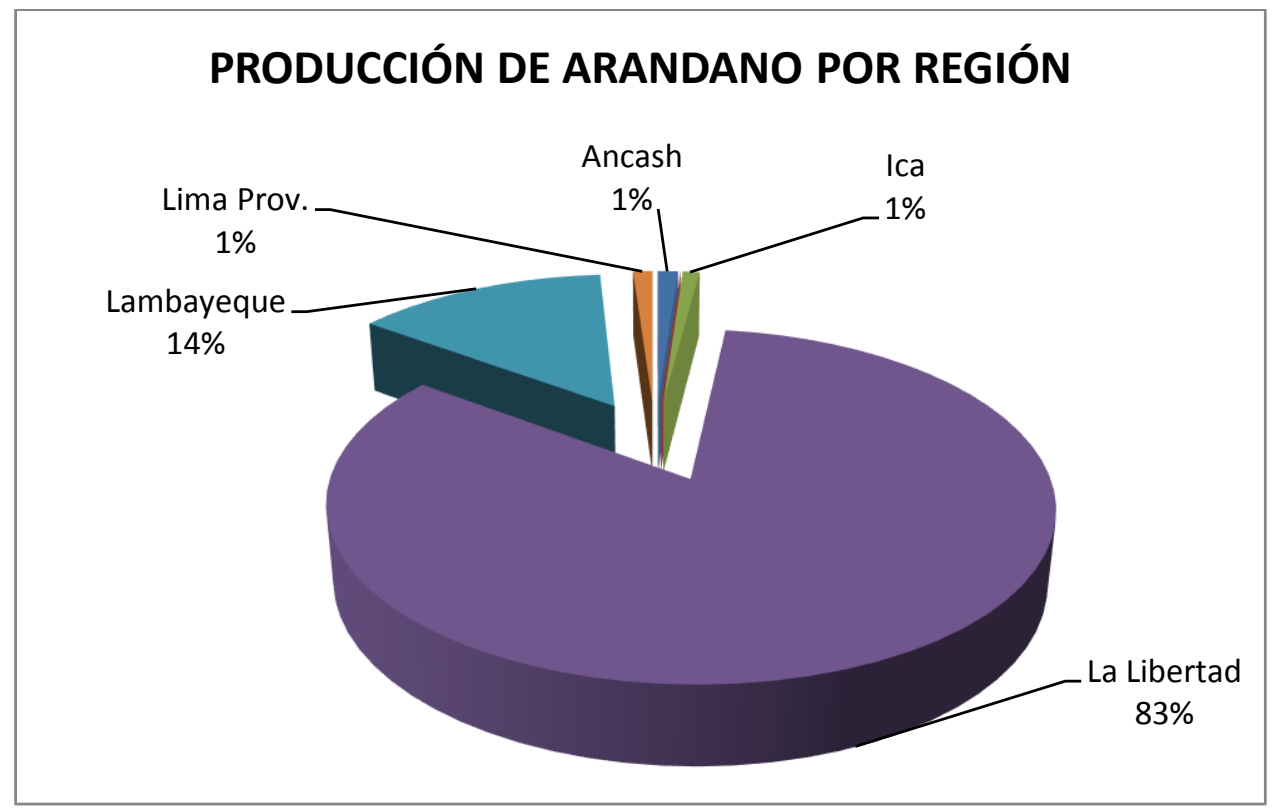

Gráfico 7. Producción nacional de Arándanos por regiones 2017.

Elaboración propia. 
Sierra y Selva Exportadora es un organismo público, que tiene como unos de sus objetivos principales incrementar la productividad y diversificación de los bienes y servicios producidos en la región andina y promover su exportación. Sierra exportadora ha creado una serie de programas de apoyo para sectores específicos. Por ejemplo está el Programa Nacional de Berries; ha desarrollado un servicio de intervención para los productores de la sierra organizando en 18 sedes regionales y llamándoles corredores.

La finalidad es mejorar la calidad de los productos agrícolas y buscar productos innovadores y rentables. En el gráfico 8 mostramos el detalle de los corredores regionales norte, centro, sur y centro sur.

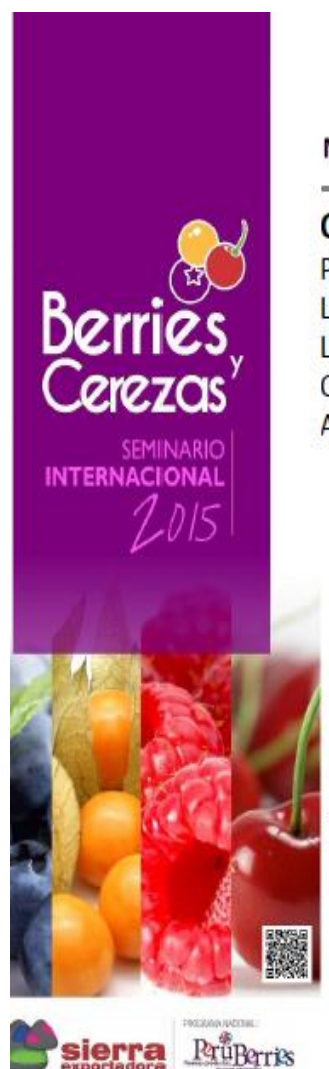

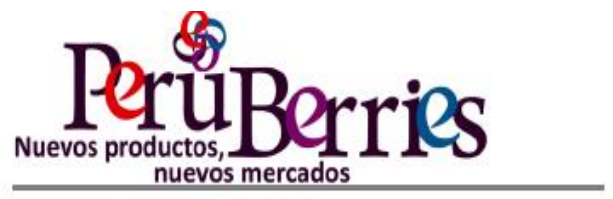

CORREDORES NORTE

Piura

Lambayeque

La Libertad

Cajamarca

Amazonas

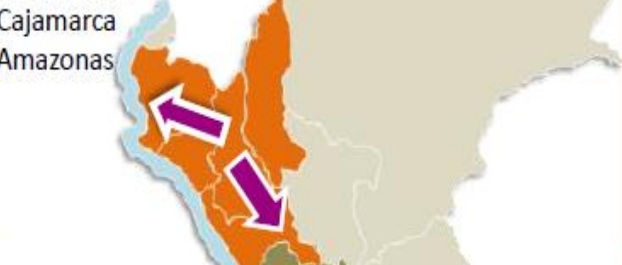

CORREDORES

CENTRO

Ancash

Junín

Huánuco

Lima

Pasco

SUR

Arequipa

Puno

Moquegua

Tacna

\section{Servicio Intervención con los productores de la Sierra}

\section{8 sedes regionales \\ trabajando en corredores económicos productivos ejecutados con un modelo de negocios inclusivos que promueve proyectos de inversión productiva.}

\section{CORREDORES}

CENTRO SUR

Huancavelica

Ayacucho

Apurímac

Cusco

Gráfico 8. Servicio para Agricultores en la Sierra.

Tomado de Seminario de Berries y Cerezas de Sierra Exportadora. 


\subsubsection{Amenaza de productos sustitutos.}

Son las empresas que producen y venden productos alternativos a los de la industria.

En el plan de negocio se ha identificado los siguientes productos: verduras deshidratadas, frutos secos y cereales deshidratados.

El producto de mayor presencia son las verduras deshidratas, el mayor consumo se da en comidas. Por un factor de hábito y costumbre del consumidor peruano es poco probable su reemplazo por las frutas.

La teoría correspondiente al Modelo de las cinco fuerzas de Porter propone en cada fuerza competitiva, una serie de condiciones que generan un impacto sobre la empresa; según esta información y considerando la opinión de expertos del sector e información recabada en campo y opinión de nuestro equipo de trabajo, nos muestra un resultado final que refiere un entorno neutral en atractividad para el plan de negocio propuesto.

\subsection{Análisis de la Competencia}

Se define a la competencia como aquellas empresas que procesan y comercializan frutas deshidratadas, empresas distribuidoras e importadoras de frutas deshidratadas que operan en el área de influencia del proyecto.

El análisis de la competencia permitirá evaluar el producto, servicio, precio y participación del mercado para realizar un comparativo con la propuesta de negocio.

También se ha realizado una evaluación a la competencia indirecta como son las empresas que ofrecen productos deshidratados y secos al consumidor final. 


\begin{tabular}{lllr} 
& VENTA EN AUTOSERVICIOS & \multicolumn{2}{l}{} \\
\cline { 2 - 4 } EMPRESA & PRODUCTO DESHIDRATADO & \multicolumn{2}{l}{ PRECIO } \\
Frutivida & Aguaymanto de $100 \mathrm{~g}$ & $\mathrm{~S} /$. & 10.00 \\
Vallealto & Pasas con Nueces $180 \mathrm{~g}$ & $\mathrm{~S} /$. & 8.50 \\
Metro y Wong & Aguaymanto y Durazno $200 \mathrm{~g}$ a gr: S/. & 5.00 \\
Delipéruano & Mango y Manzanas $45 \mathrm{~g}$ & $\mathrm{~S} /$. & 7.50 \\
Plaza Vea & Pasas Bells de $250 \mathrm{~g}$ & $\mathrm{~S} /$. & 5.90 \\
Villanatura & Guindones de $250 \mathrm{~g}$ & $\mathrm{~S} /$. & 8.90
\end{tabular}

Cuadro 7. Competencia indirecta.

Elaboración propia.

En el cuadro 7 se detalla los productos con sus precios

En autoservicios, bodegas, grifos, etc. se evidencia que existe poca oferta de fruta deshidratada y a precios elevados. Específicamente no se encontró arándano deshidratado como producto final para el consumidor.

\subsubsection{Empresas que ofrecen el mismo producto.}

En el cuadro 8 se muestra la información de competidores directos.

\begin{tabular}{|l|l|l|l|l|}
\cline { 2 - 5 } \multicolumn{1}{c|}{} & \multicolumn{1}{c|}{ Terrafertil Perú SAC } & \multicolumn{1}{c|}{ Frutos y Especies SAC } & Frutos e Industrias SAC & \multicolumn{1}{c|}{ Narvid EIRL } \\
\hline Certificación & SQF 2000, KOSHER, HACCP & BPM, POES & BPM, POES & BPM, POES \\
\hline Productos & $\begin{array}{l}\text { Craisins Arandanos, jugos de } \\
\text { arandanos, Granel de } 10 \mathrm{~kg}\end{array}$ & $\begin{array}{l}\text { Arandanos, Almendras, } \\
\text { Guindones, Pasas }\end{array}$ & $\begin{array}{l}\text { Arandanos, Aguaymanto, Piña, } \\
\text { Manzana, Pasas, higo, coco, } \\
\text { pecana, nueces }\end{array}$ & $\begin{array}{l}\text { Aguaymanto, Piña, Manzana, } \\
\text { Durazno, albaricoque, pasas } \\
\text { guindones }\end{array}$ \\
\hline Canales & Mayorista, Autoservicios & $\begin{array}{l}\text { Mayorista, Autoservicios, } \\
\text { tradicional. }\end{array}$ & Mayorista & Autosenicios, tradicional. \\
\hline Comptidores & Directo & Directo & Directo & Directo
\end{tabular}

Cuadro 8. Competidores.

Fuente: Elaboración propia.

En el mercado peruano se ha identificado a empresas competidoras directas como

Terrafertil Perú SAC, Frutos y Especies SAC, Frutos e Industrias SAC, Narvid EIRL,

Oxiquim, Vitallanos SAC y Peruvian Nature S\&S SAC.

La empresa de competencia indirecta identificadas en el sondeo y que dentro de su portafolio no ofertan arándanos deshidratados son: Valle alto SAC e Industrias y

Gourmet SAC; ofertan frutas deshidratadas a nivel industrial para panaderías y restaurantes y para consumo masivo en todos los canales de comercialización. 


\subsubsection{Participación de mercado de cada uno de ellos.}

En el mercado industrial de Lima Metropolitana tenemos a las cuatro principales empresas competidoras como Terrafertil Perú SAC, Frutos y Especies SAC, Frutos e Industrias SAC y Narvid EIRL. Con los resultados de la encuesta, el cuadro 9 muestra la participación de cada empresa.

\begin{tabular}{|l|c|}
\hline Terrafertil Perú SAC & $22 \%$ \\
\hline Frutosy Especies SAC & $19 \%$ \\
\hline Frrutas e Industrias SAC & $19 \%$ \\
\hline Narvid EIRL & $11 \%$ \\
\hline Otros & $29 \%$ \\
\hline
\end{tabular}

Cuadro 9. Participantes del Mercado. Tomado de Encuesta de Investigación Cuantitativo. Elaboración propia.

\subsubsection{Matriz de perfil competitivo.}

Se ha realizado la matriz de perfil competitivo (MPC), con la finalidad de comparar la posición frente a los dos principales competidores como son Terrafertil Perú SAC (Ocean Spray), Frutos y Especies SAC y Frutos e Industrias SAC.

Como parte del análisis se ha construido la Matriz de perfil competitivo (MPC), cuyo objetivo es comparar la posición competitiva de "Frutos Deshidratados SAC" frente a los más importantes competidores.

El procedimiento para la construcción de la matriz se desarrolla en las siguientes etapas:

a. Identificación de los principales competidores tomando en cuenta a aquellas empresas que se dirigen al mismo público objetivo que "Frutos Deshidratados SAC" y que tienen una mayor participación en el mercado. Asimismo y de acuerdo al reporte estadístico de Adex Data Trade en referencia a empresas importadoras y comercializadoras con datos del año 2010 hasta el año 2017; 
muestra a Terrafertil Perú SAC, Frutos y Especies SAC y Frutas e Industrias

SAC. comercializando arándanos deshidratados y frutos secos. Ver anexo 3.

b. Definición y asignación de una ponderación a cada "factor clave de éxito" tomándose en cuenta la opinión de expertos del sector. Los factores de “especificación técnica” y "características organolépticas" "certificados de calidad" y "abastecimiento continuo" fueron mencionados por el Jefe de Cadena de Abastecimiento de la empresa Industrias Alimenticias Cusco SA. Mientras que "el precio" y las "formas de pago" por el Gerente de Logística de Compañía Nacional de Chocolates.

Los factores con ponderaciones más altas (de 0.25) fueron definidos luego de considerar dentro de la investigación cuantitativa aquellos atributos que obtuvieron las mejores calificaciones por parte de las empresas elaboradoras de productos alimenticios "especificaciones técnicas" "abastecimiento continua" y "certificado HACCP". Los criterios con puntaje más bajos fueron "forma de pago" y "precio" Las preguntas tipo para las entrevistas a profundidad las podrá ver detallada en el Anexo $\mathrm{N}^{\mathrm{o}} 01$.

Cuadro № 4 Matríz de Perfíl competitivo

\begin{tabular}{|c|c|c|c|c|c|c|c|}
\hline \multirow[b]{2}{*}{ FACTORES CLAVES DE ÉXITO } & \multirow[b]{2}{*}{ PESO } & \multicolumn{2}{|c|}{ TERRA FERTIL SAC } & \multicolumn{2}{|c|}{ FRUTOS Y ESPECIES SAC } & \multicolumn{2}{|c|}{ FRUTOS E INDUSTRIAS SAC } \\
\hline & & VALOR & PUNTUACIÓN & JALOR & PUNTUACIÓN & VALOR & PUNTUACIÓN \\
\hline Especificación técnica & 0.25 & 4 & $\begin{array}{r}1 \\
\end{array}$ & 2 & 0.5 & 2 & 0.5 \\
\hline Características organolépticas & 0.2 & 3 & 0.6 & 3 & 0.6 & 2 & 0.4 \\
\hline Precio & 0.05 & 3 & 0.15 & 4 & 0.2 & 4 & 0.2 \\
\hline Abastecimiento continuo & 0.2 & 3 & 0.6 & 2 & 0.4 & 2 & 0.4 \\
\hline Forma de pago & 0.1 & 4 & 0.4 & 3 & 0.3 & 3 & 0.3 \\
\hline Certificación HACCP & 0.2 & 5 & 1 & 1 & 0.2 & 1 & 0.2 \\
\hline TOTAL & & & 3.75 & & 2.2 & & 2 \\
\hline
\end{tabular}

Puntuación: 1 Debilidad mayo, 2 Debilidad menor, 3 Fortaleza menor, 4 Fortaleza mayor, 5 Fortaleza principal

Cuadro 10. Matriz de Perfil Competitivo.

Fuente: Elaboración propia. 
En la matriz se observa que los factores claves de mayor relevancia son la especificación técnica, precio y características organolépticas; siendo la empresa Terrafertil SAC quien tiene el mayor puntaje ponderado de 3.75 superando a Frutos y Especies SAC y Frutos e Industrias SAC.

Ocean Spray mediante su distribuidor oficial en Perú Terrafertil es una empresa especializada y de experiencia en la siembra, procesamiento y comercialización de arándanos.

\subsection{Análisis del Contexto Actual y Esperado}

\subsubsection{Análisis político gubernamental.}

La actual política del gobierno peruano es absolutamente en favor de fomentar el capital privado y también la eficiencia del Estado, reflejándose sólidamente en el crecimiento económico siendo el principal objetivo de la actual gestión gubernamental, promoviendo la publicación de la ${ }^{1}$ Ley de promoción y formalización de la micro y pequeña empresa (MYPE) - N 28015 abordando, la función que le compete al Estado para fomentar la entrada de la MYPE a los recursos financieros; así como la exoneración de impuestos en la amazonia peruana, así como promoviendo proyectos de inversión privada reforzando la ejecución de la reforma del Estado en un contexto de austeridad en el gasto público, enfocándose decididamente a la suscripción de alianzas comerciales con las primordiales economías del mundo, el fomento de la inversión privada nacional e internacional, el impulso de la formalidad en la economía, el empleo y la reducción de la pobreza.

\footnotetext{
${ }^{1}$ Sunat (2003). Ley $N^{\circ} 28015$ Ley de promoción y formalización de la micro y pequeña empresa. Recuperado de http://www.sunat.gob.pe/orientacion/mypes/normas/ley-28015.pdf
} 
Con respecto a los beneficios tributarios en la amazonia peruana, el sector agropecuario lidera este exclusivo grupo de beneficiados por la exención del IGV para hortalizas, frutos y diversos insumos.

${ }^{2}$ La Ley de Promoción Agraria del 2000 (esta norma en realidad perjudicó los beneficios laborales de los agricultores y dispuso el recorte de sus vacaciones, gratificaciones y cts.), le permitió a las empresas del sector beneficiarse con cuatro excepciones fiscales: la depreciación acelerada del costo de su infraestructura, la disminución del Impuesto a la Renta (IR) al 15\%, el descuento de 20\% de sus impuestos por inversión en zonas eriazas y la devolución de IGV, lo cual se considera una oportunidad para nuestros proveedores de materia prima de las frutas frescas como el arándano, manzana y piñas.

Adicionalmente el Estado Peruano a través de sus entidades ministeriales como el Ministerio de Salud (Minsa) publicó el reglamento de la ${ }^{3}$ Ley de Promoción de la Alimentación Saludable para niños, niñas y adolescentes, que considera los parámetros técnicos sobre los niveles permitidos de azúcar, sodio y grasas saturadas que deben contener los alimentos y bebidas no alcohólicas procesados, así como la reducción gradual de grasas trans hasta su eliminación.

"El encargo del Ministerio de Salud para la elaboración del reglamento de la ley es establecer los parámetros técnicos que son reconocidos como saludables", la elaboración de esta ley representa una oportunidad para la elaboración de frutos deshidratados, ya que nuestros potenciales clientes están obligados a reducir los altos

2 Congreso, 2000. Ley de Promoción del Sector Agrario. Recuperado de http://www2.congreso.gob.pe/sicr/cendocbib/con4_uibd.nsf/BB496712581D782805257B7A004AE57C/\$F ILE/885.pdf

3 Congreso, 2003. Ley de Promoción de la Alimentación Saludable para niños, niñas y adolescentes. Recuperado de http://www4.congreso.gob.pe/pvp/leyes/ley30021.pdf 
índices de grasas en la elaboración de sus productos, orientándolos a incrementar el consumo de productos naturales.

Este reglamento, corresponderá a diversos ministerios como Educación que contribuye a la promoción y la enseñanza de la alimentación saludable en los centros educativos.

\begin{tabular}{|c|c|c|}
\hline Suceso-Tendencia & Clientes-Proveedor & $\begin{array}{c}\text { Impacto en Plan de } \\
\text { Negocios }\end{array}$ \\
\hline $\begin{array}{l}\text { El gobierno Peruano } \\
\text { fomenta la creación de } \\
\text { micro y pequeñas } \\
\text { empresas. }\end{array}$ & Formalización del sector. & $\begin{array}{l}\text { Crecimiento de } \\
\text { proveedores y clientes. }\end{array}$ \\
\hline $\begin{array}{l}\text { Políticas del gobierno que } \\
\text { contribuya al fomento y } \\
\text { enseñanza de alimentación } \\
\text { saludable. }\end{array}$ & $\begin{array}{l}\text { Incremento en la oferta y } \\
\text { demanda de productos } \\
\text { naturales. }\end{array}$ & $\begin{array}{l}\text { Penetración y desarrollo de } \\
\text { mercado. }\end{array}$ \\
\hline
\end{tabular}

Cuadro 11. Entorno Político.

Tomado de Reporte producción manufacturera- Ministerio de la Producción.

\subsubsection{Análisis económico.}

En octubre del 2017, el índice de la producción manufacturera creció en 1.6\% en relación a octubre de 2016. En este mes, ambos subsectores, primario y no primario, contribuyeron al crecimiento positivo del mes. Con este resultado, la manufactura acumula un avance de $1.0 \%$ entre enero y octubre del 2017. En tanto, en los últimos doce meses, la producción manufacturera acumula un avance de $1.8 \%$. 


\section{(C) Índice de Volumen Físico de la Producción Manufacturera Total y según subsectores}

(Variaciones porcentuales)

\begin{tabular}{lrcc} 
& $\begin{array}{l}\text { Oct 17/ } \\
\text { Oct 16 }\end{array}$ & $\begin{array}{l}\text { Ene - Oct 17/ } \\
\text { Ene - Oct 16 }\end{array}$ & $\begin{array}{c}\text { Nov 16- Oct 17/ } \\
\text { Nov 15- Oct 16 }\end{array}$ \\
\hline IVF Total & 1,6 & 1,0 & 1,8 \\
Subsector No primario & 1,4 & $-1,7$ & $-1,2$ \\
Subsector Primario & 2,4 & 9,3 & 11,0 \\
& & & \\
\hline
\end{tabular}

Gráfico 9. Índice de volumen físico de la producción manufacturera. Fuente: OEE (PRODUCE).

Conservas de frutas y legumbres Luego de siete meses de bajo crecimiento, la industria que elabora conservas de frutas y legumbres presentó un crecimiento positivo de $8.5 \%$ en octubre, resultado que deriva principalmente de la mayor demanda externa, de productos como almíbar, piña, arándanos, jalapeño, pimiento, conservas de espárragos y espárragos congelados. Asimismo, esta industria reúne entre enero y octubre una descendencia de $12.7 \%$, en los últimos doce meses una reducción de $10.7 \%$; en ambos casos afectada por los problemas que trajo el fenómeno "El Niño Costero" en marzo del 2017, de arroz por menores siembras en Piura y de páprika por menores áreas cosechadas en Lima. Por el contrario, aumentó la producción de papa, alcachofa y maíz amarillo duro por mejores condiciones climáticas que la campaña anterior, arándanos y cacao por mayores áreas cosechadas. 


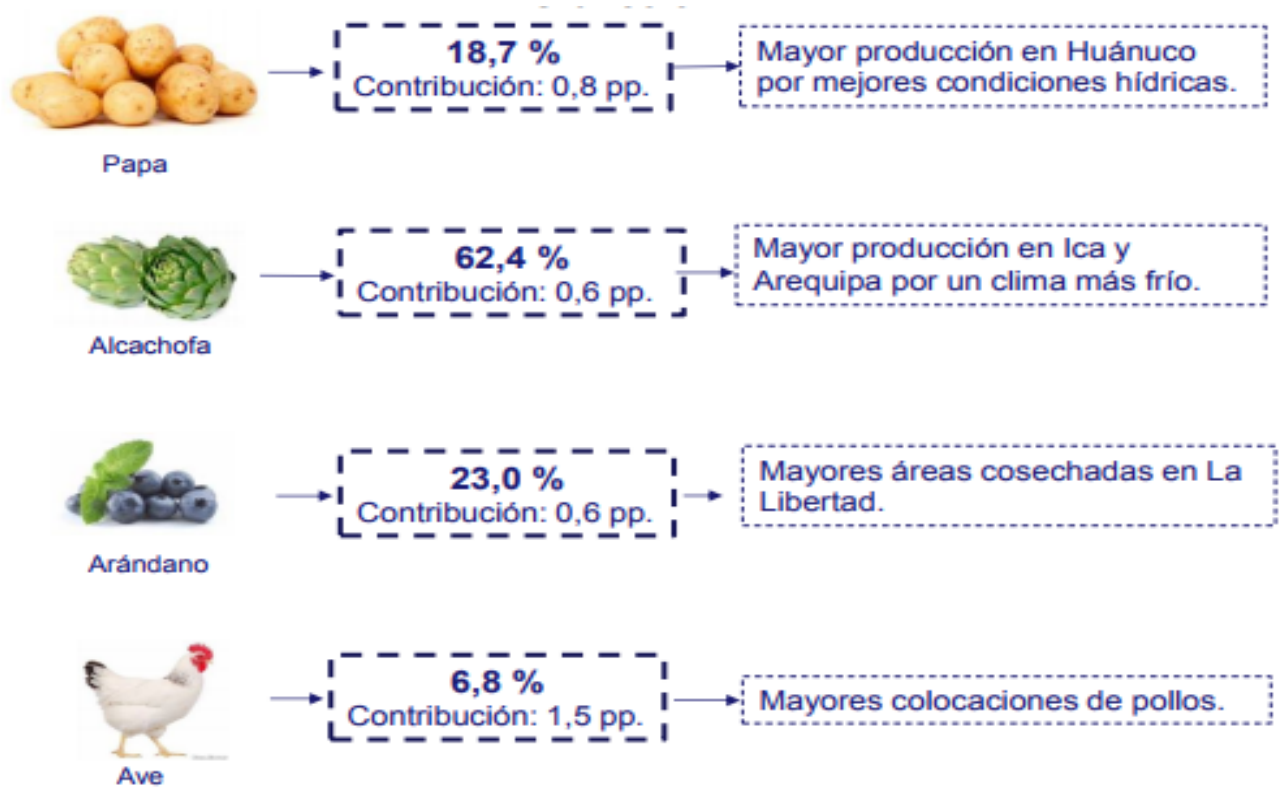

Gráfico 10. Incremento de producción que trajo el fenómeno "El Niño Costero". Elaboración propia.

SECTOR AGROPECUARIO

(Mies de Toneladas)

\begin{tabular}{|c|c|c|c|c|c|c|}
\hline & \multirow{2}{*}{$\begin{array}{c}\text { Estructura } \\
\text { Porcentual } \\
2016^{1 s}\end{array}$} & \multicolumn{3}{|c|}{ Noviembre } & \multicolumn{2}{|c|}{ Enero - noviembre } \\
\hline & & Volumen & Var. \% & Contribución & Var. \% & Contribución \\
\hline AGRICOLA & $\underline{60.2}$ & & $\underline{-1,3}$ & $\underline{-0,8}$ & $\underline{0,0}$ & $\underline{0,0}$ \\
\hline Mercado Interno & 37,1 & & 3,1 & 0,9 & $-1,2$ & $-0,4$ \\
\hline Arroz Cáscara & 7,9 & 146 & $-17,8$ & $-1,0$ & $-5,3$ & $-0,4$ \\
\hline Papa & 6,3 & 280 & 18,7 & 0,8 & 5,8 & 0,4 \\
\hline Plátano & 2,2 & 169 & $-6,4$ & $-0,2$ & $-6,6$ & $-0,1$ \\
\hline Cebolla & 1,2 & 64 & 15,0 & 0,2 & $-1,3$ & 0,0 \\
\hline Naranja & 0,6 & 32 & 14,5 & 0,1 & 0,0 & 0,0 \\
\hline Tomate & 0,5 & 34 & 31,1 & 0,2 & 0,7 & 0,0 \\
\hline Yuca & 1,2 & 116 & 8,5 & 0,1 & $-1,1$ & 0,0 \\
\hline Limon & 0,4 & 17 & $-23,1$ & $-0,1$ & $-38,4$ & $-0,1$ \\
\hline Alo & 0,3 & 26 & 18,1 & 0,2 & 13,8 & 0,0 \\
\hline Maiz Choclo & 0,7 & 27 & 18,0 & 0,1 & $-3,0$ & 0,0 \\
\hline Arveja Grano Verde & 0,3 & 8 & 69,1 & 0,1 & 4,6 & 0,0 \\
\hline Agroindustrial & $\underline{5,3}$ & & 14,5 & 0,8 & $-4,0$ & $-0,2$ \\
\hline Maiz amarillo duro & $\frac{1,5}{2,5}$ & 105 & 12,4 & 0,3 & $-2,2$ & $-0,1$ \\
\hline Palma Aceitera & 0,7 & 86 & 25,1 & 0,2 & 14,8 & 0,1 \\
\hline Caña de azúcar & 1,8 & 1017 & 7,2 & 0,2 & $-3,9$ & $-0,1$ \\
\hline Agroexportación & 17,7 & & $-10,9$ & $-2,5$ & $\mathbf{3 , 7}$ & 0,7 \\
\hline Cafe & 4,1 & 1 & 207,2 & 0,1 & 11,8 & 0,5 \\
\hline Espárrago & 3,5 & 38 & 3,0 & 0,1 & 0,2 & 0,0 \\
\hline Uva & 3,0 & 126 & $-33,3$ & $-3,6$ & $-17,3$ & $-0,5$ \\
\hline Mango & 0,6 & 19 & $-29,5$ & $-0,2$ & 6,8 & 0,0 \\
\hline Cacao & 1,7 & 9 & 21,0 & 0,3 & 13,4 & 0,2 \\
\hline Arándano & 0.7 & 9 & 23,0 & 0,6 & 24,7 & 0,2 \\
\hline Paprika & 0,6 & 1 & $-60,7$ & $-0,4$ & $-23,3$ & $-0,1$ \\
\hline Alcachofa & 0,5 & 27 & 62,4 & 0,6 & 28,1 & 0,1 \\
\hline PECUARIO & 40,1 & & $\underline{3,9}$ & 1,7 & $\underline{2,9}$ & $\underline{1,2}$ \\
\hline Ave & 21,4 & 157 & 6,8 & 1,5 & 4,0 & 0,8 \\
\hline Huevo & 3,8 & 35 & 2,5 & 0,1 & 3,6 & 0,1 \\
\hline SECTOR AGROPECUARIO & 100,0 & & $\underline{0,9}$ & $\underline{0,9}$ & 1,2 & $\underline{1,2}$ \\
\hline
\end{tabular}

Gráfico 11. Sector Agropecuario.

Tomado de Ministerio de Agricultura y Riego, INEI. 


\section{Subsector Manufacturero No Primario}

Según principales clases orientadas al mercado exterior

(Incidencia sobre IVF manufacturero en puntos porcentuales. Octubre 2017 )

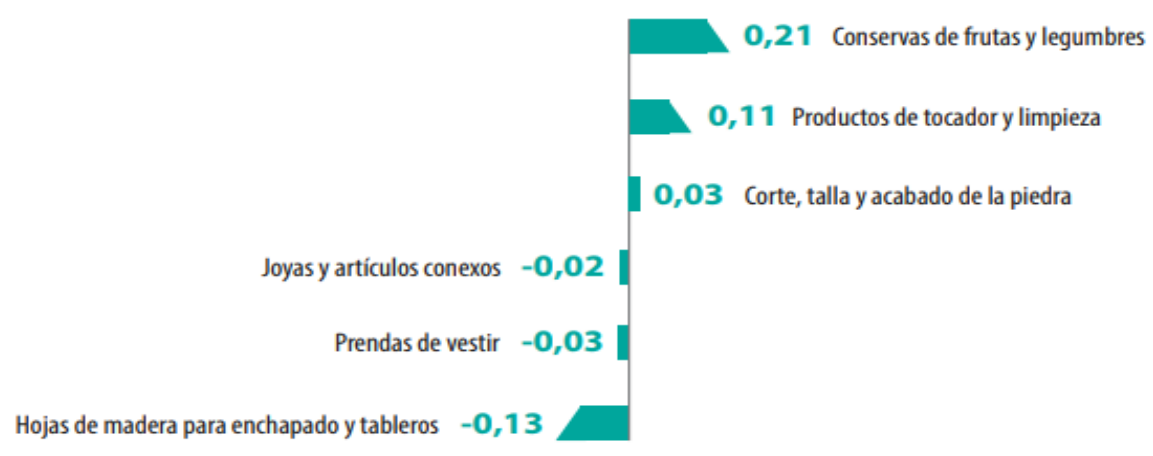

Gráfico 12. Sub Sector Manufacturero No Primario.

Fuente: OEE (Produce).

El mayor dinamismo en un sector específico podría ser atribuido a un aumento de la productividad del sector en mención, lo que implicaría una mayor difusión de nuevas tecnologías y una consecuente mayor asimilación de las mismas. En tanto, el mayor dinamismo de ocupación en industria de alimentos y bebidas, que coincide con un avance de la demanda interna de $4.0 \%$ su media anual en los últimos 5 años, ha venido siendo estimulado principalmente por la creciente demanda de mano laboral no calificada.

Por lo tanto, pese al dinamismo del sector alimentos y bebidas, a nivel interno, existe una alta heterogeneidad que genera que el avance del sector no tuviera un correlato con las mejoras tecnológicas e innovaciones.

\begin{tabular}{|l|l|l|}
\hline \multicolumn{1}{|c|}{ Suceso-Tendencia } & Clientes-Proveedor & \multicolumn{1}{|c|}{ Impacto en Plan de } \\
Negocios \\
\hline Índice de la producción & Sector manufacturero con & Crecimiento \\
manufacturera creció en & tendencia al crecimiento & proveedores y clientes. \\
\hline
\end{tabular}




\begin{tabular}{|c|c|c|}
\hline $\begin{array}{l}\text { la industria que elabora } \\
\text { conservas de frutas y } \\
\text { legumbres presentó un } \\
\text { crecimiento positivo de } \\
8.5 \% \text { en octubre } 2017\end{array}$ & $\begin{array}{l}\text { Resultado que deriva } \\
\text { principalmente de la mayor } \\
\text { demanda externa, como los } \\
\text { mercados de EE.UU, Asia, } \\
\text { UE. }\end{array}$ & $\begin{array}{l}\text { Reconocimiento a la } \\
\text { calidad de las frutas } \\
\text { peruanas, genera confianza } \\
\text { y buena imagen de nuestros } \\
\text { productos. }\end{array}$ \\
\hline $\begin{array}{l}\text { La agro exportación de } \\
\text { arándanos de } 9 \text { mil } \\
\text { toneladas refleja un } \\
\text { incremento porcentual de } \\
\text { casi } 2 \% \text { con respecto al año } \\
\text { anterior }\end{array}$ & $\begin{array}{l}\text { Penetración de mercado de } \\
\text { los arándanos peruanos en } \\
\text { mercados internacionales. }\end{array}$ & $\begin{array}{l}\text { Mayor demanda de } \\
\text { nuestros productos hacia el } \\
\text { mercado exterior. }\end{array}$ \\
\hline
\end{tabular}

Cuadro 12. Entorno Económico.

Tomado de Reporte producción manufacturera- Ministerio de la Producción.

\subsubsection{Análisis legal}

\subsubsection{Garantías generales a la inversión privada.}

Estado Peruano brinda las confianzas generales al capital privado "El marco legal vigente, iniciando por la Constitución Política del Perú y los Tratados Internacionales suscritos por el Perú, está orientado para salvaguardar el capital privado y para fomentar la inversión privada sin discriminación".

De tal manera, la ${ }^{4}$ Ley Marco de Crecimiento de la Inversión Privada - Decreto Legislativo $\mathrm{N}^{\circ} 757$ aprobado presente Ley tiene por objeto garantizar la libre iniciativa y las inversiones privadas, efectuadas o por efectuarse, en todos los sectores de la actividad

4 Proinversion (1991), Decreto Legislativo $\mathrm{N}^{\mathrm{o}} 757$ - Ley marco para el crecimiento de la $\begin{array}{ll}\text { inversión } & \text { privada. } \\ \text { https://www.proinversion.gob.pe/RepositorioAPS/0/0/arc/ML_GRAL_INVERSION_DL_757/11- }\end{array}$ de D_L_757.pdf 
económica y en cualesquiera de las formas empresariales o contractuales permitida por la Constitución y las Leyes".

Adicionalmente existen leyes como la ${ }^{5}$ Ley 30021, Ley de Promoción de la Alimentación Saludable para Niños, Niñas y Adolescentes, dispone en el artículo 1. La presente Ley tiene por objeto la promoción y protección efectiva del derecho a la salud pública, al crecimiento y desarrollo adecuado de las personas, a través de las acciones de educación, fortalecimiento y fomento de la actividad física, así como la implementación de kioscos y comedores saludables en las instituciones de educación básica regular y la supervisión de la publicidad y otras prácticas relacionadas con los alimentos y bebidas no alcohólicas dirigidos a los niños, niñas y adolescentes.

Además, el reglamento tiene afinidad con el ${ }^{6}$ Decreto Legislativo $\mathrm{N}^{\circ} 1062$, el Reglamento sobre Vigilancia y Control Sanitario de Alimentos y Bebidas, aprobado por el Decreto Supremo N 007-98-SA y sus normas modificatorias; el Reglamento de Alimentación Infantil, aprobado por Decreto Supremo N 009-2006-SA, y demás normas relacionadas.

Estas leyes representan una oportunidad para los proveedores ya que las empresas industriales incrementara el consumo de productos naturales en distintas presentaciones, ya que de acuerdo a Ley es eliminar las grasas trans y la creciente tendencia al consumo de productos naturales deshidratados en la elaboración de sus productos como granolas, barras de cereales, etc., ya que conservan sus productos nutricionales aún después del proceso de deshidratación.

\footnotetext{
${ }^{5}$ Congreso, 2003. Ley de Promoción de la Alimentación Saludable para niños, niñas y adolescentes. Recuperado de http://www4.congreso.gob.pe/pvp/leyes/ley30021.pdf

6 Congreso, 2008. Ley de Inocuidad de los Alimentos. Recuperado de http://www.leyes.congreso.gob.pe/Documentos/DecretosLegislativos/01062.pdf
} 


\subsubsection{Régimen tributario}

El impuesto a la renta para las sociedades domiciliadas en Perú será 27\% durante los ejercicios 2017 y 2018, y 26\% a partir del ejercicio 2019.

El gobierno central dentro de sus estrategias y reformas está implementando la promoción del empleo y la reducción del impuesto a la renta, orientando a obtener un dinamismo mayor en la inversión 'privada y el consumo, impulsando el crecimiento económico del país.

\begin{tabular}{|c|c|c|}
\hline Suceso-Tendencia & Clientes-Proveedor & $\begin{array}{c}\text { Impacto en Plan de } \\
\text { Negocios }\end{array}$ \\
\hline $\begin{array}{l}\text { Mayor regulación y } \\
\text { reglamentación de } \\
\text { consumo alimentos } \\
\text { saludables. }\end{array}$ & $\begin{array}{l}\text { Oferta y demanda con } \\
\text { tendencia al crecimiento }\end{array}$ & $\begin{array}{l}\text { Oportunidad de } \\
\text { negociación con nuestros } \\
\text { proveedores y clientes. }\end{array}$ \\
\hline $\begin{array}{l}\text { Reducción de Impuestos a } \\
\text { la renta. }\end{array}$ & $\begin{array}{l}\text { Formalización de empresas } \\
\text { informales. }\end{array}$ & $\begin{array}{l}\text { Crecimiento de nuestro } \\
\text { potencial clientes, ya que } \\
\text { solo atendemos empresas } \\
\text { formales. }\end{array}$ \\
\hline
\end{tabular}

Cuadro 13. Entorno Legal.

Elaboración propia

\subsubsection{Análisis cultural.}

La industria de alimentos y la gastronomía juegan un rol importante al buscar insumos que cuiden la salud; alimentos con bajos niveles de grasa y sodio, alternativas reducidas en azúcares y calorías, ricos con fibras y minerales serán los preferidos. A través del tiempo en el Perú se está incrementando el consumo de alimentos saludables, ya que la población está tomando conciencia de las enfermedades que generan el consumo de alimentos altos en grasas y carbohidratos. Por lo cual se publicó el reglamento de la Ley de Alimentación Saludable ( $\left.{ }^{\circ} 30021\right)$, expertos y autoridades han 
explicado que dicha norma es importante para combatir dos problemas urgentes: la obesidad y el sobrepeso, lo cual el estado lo considera acciones preventivas para combatir dichas enfermedades.

Dentro de esta preferencia de vivir sano, los millenials lideran la lista de lo más exigente pues no sólo buscan insumos no industrializados, conocer el origen de los alimentos y que sean ricos al paladar, sino que además sea simple de preparar. Los alimentos sanos para niños, las opciones reducidas en sal, grasas y las bebidas sugar free son y serán las elegidas por este nuevo mercado que crece día a día.

Los consumidores se han vuelto más rigurosos a la hora de comer, pues no sólo buscan lo saludable sino que el sabor sea igual de seductor que una comida tradicional.

\begin{tabular}{|l|l|lr|}
\hline \multicolumn{1}{|c|}{ Suceso-Tendencia } & \multicolumn{2}{|c|}{ Clientes-Proveedor } & \multicolumn{2}{|c|}{$\begin{array}{l}\text { Impacto en Plan de } \\
\text { Negocios }\end{array}$} \\
\hline $\begin{array}{l}\text { Conciencia de la población } \\
\text { en consumo de alimentos } \\
\text { saludables. }\end{array}$ & $\begin{array}{l}\text { Oferta y demanda con } \\
\text { tendencia al crecimiento }\end{array}$ & $\begin{array}{l}\text { Demanda creciente de } \\
\text { nuestros }\end{array}$ & $\begin{array}{c}\text { productos } \\
\text { naturales deshidratados. }\end{array}$ \\
\hline
\end{tabular}

Cuadro 14. Entorno Cultural.

Elaboración propia

\subsubsection{Análisis tecnológico}

En el mercado local se tienen proveedores que suministran los hornos o cámaras industriales de deshidratación y brindan el soporte técnico en cuanto a la deshidratación de frutas y verduras. También en América del Sur existen varios proveedores que ofertan hornos industriales de deshidratación. Por tanto la tecnología de deshidratación de frutas y verduras está al alcance de quien las necesita para una capacidad determinada, todos los parámetros productivos de los hornos de deshidratación han sido determinados, lo que facilita la información suficiente para realizar las proyecciones de los costos del proceso de deshidratación. 
El proceso de deshidratación de frutas y verduras es conocido, se tiene suficiente información para entender, adaptar y optimizar el proceso de deshidratación en toda la cadena de valor.

En la actualidad, se viene intensificando la presencia de proveedores de tecnología agrícola, sobre todo de capital extranjeros, dado lo atractivo del sector; con lo que se espera que la productividad de los cultivos siga creciendo, donde también se espera una mayor profesionalización del agro que ayudaría a incrementar dicha productividad.

\begin{tabular}{|l|l|l|}
\hline \multicolumn{1}{|c|}{ Suceso-Tendencia } & \multicolumn{1}{|c|}{ Clientes-Proveedor } & \multicolumn{1}{|c|}{$\begin{array}{c}\text { Impacto en Plan de } \\
\text { Negocios }\end{array}$} \\
\hline TLC & $\begin{array}{l}\text { Desarrollo de investigación } \\
\text { y desarrollo con tecnología } \\
\text { de punta. }\end{array}$ & $\begin{array}{l}\text { Reducción de costos en la } \\
\text { automatización } \\
\text { producción }\end{array}$ \\
& $\begin{array}{llr}\text { deshidratación de los frutos } \\
\text { frescos. }\end{array}$ \\
\hline
\end{tabular}

Cuadro 15. Entorno Tecnológico.

Elaboración propia

\subsubsection{Análisis ecológico}

Actualmente se conserva una gran preocupación por el medio ambiente, varios de los factores que dañan la salud se relacionan directamente con la deforestación de áreas naturales, el calentamiento global, los fenómenos climáticos como es el caso de la niña, (La Niña es considerada la contraparte del fenómeno de El Niño, ya que consiste en un constante enfriamiento de la temperatura superficial del mar).

El Ministerio del Ambiente (2016) se puede considerar “orgánicos”, a todos los alimentos, en general vegétales y frutas que en ninguna etapa de su producción intervienen pesticidas químicos, herbicidas o fertilizantes, así como menos aún en los suelos donde son cultivados y procuran establecer una relación de armonía con el 
ambiente. Esta institución indica que su consumo aumentado en $70 \%$ en los últimos 10 años y el desarrollo apunta a que siga creciendo.

Según un revelador artículo publicado en la revista Academia Nacional de Ciencias de EEUU (PNAS), comer de manera saludable no solo es bueno para el organismo, también puede contribuir positivamente al cuidado del medioambiente.

Los investigadores, analizaron el impacto de la alimentación del ser humano en el planeta a partir de dietas recomendadas de 37 países que representan casi dos tercios (64\%) de la población mundial.

Según la investigación, esto podría disminuir si las personas siguieran las recomendaciones que entrega su respectiva nación. De ser así, los gases que se obtiene del efecto invernadero correlacionados con la producción de alimentos caerían entre un 13 y un $25 \%$ Además, la cantidad necesaria de tierra que se necesita para producir alimentos se reduciría hasta en un $17 \%$. El estudio señala que las dietas recomendadas a nivel nacional son un método relevante para informar al público sobre las elecciones dietéticas.

\begin{tabular}{|l|l|l|}
\hline \multicolumn{1}{|c|}{ Suceso-Tendencia } & \multicolumn{1}{|c|}{ Clientes-Proveedor } & \multicolumn{1}{|c|}{$\begin{array}{c}\text { Impacto en Plan de } \\
\text { Negocios }\end{array}$} \\
\hline $\begin{array}{l}\text { Impacto de la buena } \\
\text { alimentación en el cuidado } \\
\text { del medio ambiente. }\end{array}$ & $\begin{array}{l}\text { Mayor conciencia de las } \\
\text { personas por el cuidado de } \\
\text { su salud y el ambiente que } \\
\text { lo rodea. }\end{array}$ & $\begin{array}{l}\text { Posicionamiento } \\
\text { acuerdo a las tendencias de } \\
\text { alimentación y cuidado del } \\
\text { medio ambiente de los } \\
\text { frutos frescos. }\end{array}$ \\
\hline
\end{tabular}

Cuadro 16. Entorno Ecológico.

Fuente: Elaboración propia. 


\subsection{Oportunidades}

A continuación detallamos las oportunidades a través de la Matriz de Evaluación de los Factores Externos.

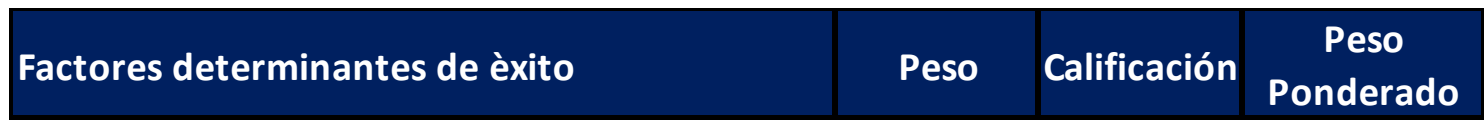

\begin{tabular}{|l|l|c|c|c|}
\hline Oportunidades & \multicolumn{2}{l|}{} \\
\hline 1 & Beneficio fiscales a proveedores & 0.1 & 3 & 0.3 \\
\hline 2 & $\begin{array}{l}\text { Politicas gubernametales con mayor } \\
\text { regulacion y reglamentacion de consumo de } \\
\text { alimentación saludable }\end{array}$ & 0.3 & 4 & 1.2 \\
\hline 3 & $\begin{array}{l}\text { Concientización de la población en consumo } \\
\text { de alimentos saludables }\end{array}$ & 0.2 & 4 & 0.8 \\
\hline 4 & $\begin{array}{l}\text { Intensificación presencial proveedores de } \\
\text { tecnologia agricola }\end{array}$ & 0.1 & 3 & 0.3 \\
\hline & & & 2.6 \\
\hline
\end{tabular}

Cuadro 17. MEFE Oportunidades.

Fuente: Elaboración propia.

\subsubsection{Amenazas}

A continuación detallamos las amenazas a través de la Matriz de Evaluación de los Factores Externos.

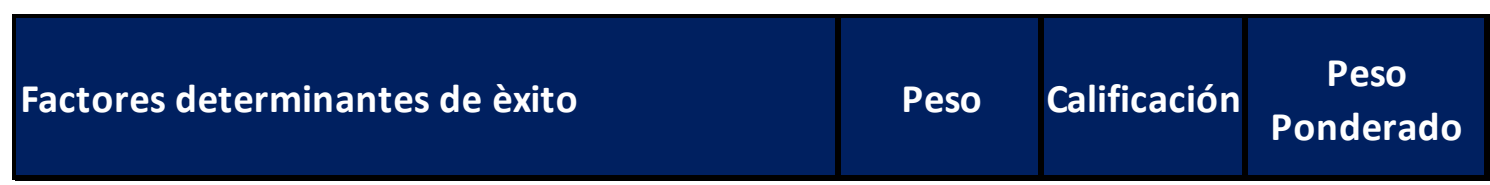

\begin{tabular}{|c|c|c|c|c|}
\hline \multicolumn{2}{|c|}{ Amenazas } & \multirow[b]{2}{*}{0.1} & \multirow[b]{2}{*}{3} & \multirow[b]{2}{*}{0.3} \\
\hline 1 & Ingreso de competidores potenciales & & & \\
\hline 2 & Crecimiento de exportaciones frutas frescas & 0.05 & 2 & 0.1 \\
\hline 3 & Cambios en las regulaciones gubernamentales & 0.05 & 2 & 0.1 \\
\hline 4 & Fenomenos climaticos & 0.1 & 3 & 0.3 \\
\hline \multirow{2}{*}{\multicolumn{2}{|c|}{ Subtotal Amenazas }} & & & 0.8 \\
\hline & & 1 & & 3.4 \\
\hline
\end{tabular}

Cuadro 18. MEFE Amenazas.

Fuente: Elaboración propia. 
La clave de la Matriz de Evaluación de los Factores Externos, consiste en que el valor del peso ponderado total de las oportunidades sea mayor al peso ponderado total de las amenazas. En este caso el peso ponderado total de las oportunidades es de 2.6 y el de las amenazas es 0.8, lo cual establece que el ambiente externo es favorable a la organización. 


\section{Estudio de Mercado}

El estudio de mercado ayudará a obtener información con el fin de determinar el mercado objetivo, perfil del consumidor, preferencias sobre los productos a ofrecer, y como punto más importante el grado de aceptación en la compra por parte de las empresas de alimentos que utilizan como insumo: arándanos, manzana y piña deshidratados.

\subsection{Estado Actual de la Industria}

El negocio consiste en la producción y venta de arándanos, piña y manzana deshidratada que cumplan las especificaciones técnica, exigidas por las empresas procesadoras de alimentos.

Los berries, son conocidos como bayas o frutas del bosque, son una clase de frutas de reducido tamaño y comestibles que tradicionalmente no se sembraban sino que se desarrollaban en arbustos agrestes.

En términos coloquiales, se denominan frutas del bosque a las frutitas pequeñas, dulces (o ácidas), jugosas e intensamente coloreadas sacadas de arbustos agrestes. En la mayoría de los casos son comestibles, aunque existen algunas que son nocivas para el consumo humano. Sus intensos colores son pigmentos sintetizados por la planta. Algunos investigadores han descubierto propiedades medicinales de los polifenoles pigmentados, como flavonoide, antocianina, tanino y otros fitoquímicos identificados en la piel y semillas. Muchas frutas del bosque tienen pigmentos antioxidantes y una alta capacidad de absorción de radicales de oxígeno ("ORAC") entre alimentos vegetales. ${ }^{7}$

\footnotetext{
7 MINISTERIO DE AGRICULTURA Y RIEGO. El arándano en el Perú y el mundo: Producción comercio y perspectivas. [en línea]. Lima: 2016. [citado 5 enero 2018]. Acrobat PDF. Disponible: http://www:minagri.gob.pe/portal/analisis-economico/analisis-2016?download...del...peru...
} 
En el caso de los arándanos deshidratados, estos logran también, conservar gran cantidad de nutriente, siendo los más importantes: Hierro, Potasio, Magnesio, Vitamina C, D, E, Complejo B y Fósforo.

Este fruto contiene baja cantidad de potasio, lo cual representa beneficioso para personas con inconvenientes renales, de hipertensión o colesterol alto.

La piña deshidratada es considerada como una fruta rica en carbohidratos y minerales como el potasio, de igual forma es una excelente fuente de fibra y tiene propiedades antiinflamatorias, anticoagulantes y diuréticas.

La manzana deshidratada contiene quercetina, muy apropiado para el buen funcionamiento del corazón y la circulación. Asimismo contiene ácido málico y tartárico, los cuales ayudan en la digestión de alimentos grasos. Del mismo modo contiene vitamina $\mathrm{C}$ que ayuda al sistema inmunológico.

Es útil para las personas que sufren de diabetes, la pectina ayuda a mantener niveles adecuados de azúcar. Del mismo modo ayuda a nuestro cuerpo a eliminar metales pesados como el plomo y mercurio. El consumo habitual de manzana deshidratada puede ayudar a personas que tienen el colesterol alto.

La forma de presentación de estos tres tipos de frutos será en bolsas de polietileno de 10 kilogramos dentro de caja de cartón corrugado.

\subsection{Selección del Segmento de Mercado}

Para la definición del segmento de mercado se utilizó el Directorio Nacional de Empresas Manufactureras a fin de obtener el número de empresas del sector de Lima, el cual asciende a 932 empresas, a continuación se identificaron las empresas que pertenece 
a la actividad económica Molinería, Chocolatería, Panadería y Otros, el cual asciende a 346 empresas, finalmente se identificaron las empresas que usan los arándanos, manzanas piña deshidratada o potencialmente podrían usarlos como insumos para sus diferentes productos, ascendiendo finalmente a un total de 96 empresas.

Para la selección de las 96 empresas que usan arándanos, manzanas y piña deshidratada o potencialmente podrían usarlos como insumos para sus diferentes productos se aplicaron, de acuerdo a lo señalado por Jhonny Berrospi Herrera Jefe de Planta de Industrias Alimenticias Cusco SA los siguientes criterios de juicio:

- Empresas que trabajan con certificaciones HACCP.

- Empresas que actualmente consumen arándanos, manzana y piña deshidratada.

- Empresas que elaboran productos de Molinería, Chocolatería, Panadería y Otros.

- Empresas que usan como insumo, fruta y verdura fresca, en polvo, en néctares y esencia para la elaboración de sus productos.

\begin{tabular}{|c|l|l|}
\multicolumn{1}{|c|}{$\begin{array}{c}\mathbf{N}^{\circ} \text { DE } \\
\text { EMPRESAS }\end{array}$} & COMPOSICIÓN & CRITERIOS DE ELECCIÓN DE JUICIO \\
\hline \multirow{3}{*}{96} & $\begin{array}{l}17 \text { empresas que } \\
\text { consumen. }\end{array}$ & $\begin{array}{l}\text { Empresas que trabajan con certificación } \\
\text { HACCP }\end{array}$ \\
\cline { 2 - 4 } & $\begin{array}{l}79 \text { empresas que } \\
\text { consumirían } \\
\text { potencialmente. }\end{array}$ & $\begin{array}{l}\text { Empresas que trabajan con certificación } \\
\text { HACCP. }\end{array}$ \\
& $-\begin{array}{l}\text { Empresas que elaboran productos de } \\
\text { Molinería, Chocolatería, Panadería y Otros. } \\
\end{array}$ & $\begin{array}{l}\text { Empresas que usan como insumo, fruta y } \\
\text { verdura fresca, en polvo, en néctares y } \\
\text { esencia para la elaboración de sus productos. }\end{array}$ \\
\hline
\end{tabular}

Cuadro $\mathrm{N}^{\circ} 19$ Selección del segmento de mercado por criterios de elección de juicio Fuente: Elaboración propia 


\begin{tabular}{|c|c|c|c|}
\multicolumn{1}{c}{} & \multicolumn{1}{c|}{$\mathbf{N}^{\mathbf{0}}$} & $\mathbf{\%}$ \\
\hline $\begin{array}{c}\text { TAMAÑO DE } \\
\text { EMPRESA }\end{array}$ & EMPRESA GRANDE & $\mathbf{8 0}$ & $\mathbf{8 3 , 3 3 \%}$ \\
\hline & ELAB DE OTROS PROD. ALIMENTICIOS. & 42 & $43,75 \%$ \\
\hline ACTIVIDAD & ELAB. CACAO CHOCOLATE Y CONFIT. & 8 & $8,33 \%$ \\
\hline ECONÓMICA & ELAB. DE PRODUCTOS DE MOLINERIA. & 14 & $14,58 \%$ \\
\hline & ELAB. PROD. DE PANADERIA. & 16 & $16,67 \%$ \\
\hline TAMAÑO DE & EMPRESA MEDIANA & $\mathbf{1 6}$ & $\mathbf{1 6 , 6 7 \%}$ \\
\hline EMPRESA & ELAB DE OTROS PROD. ALIMENTICIOS. & 5 & $5,21 \%$ \\
\hline ACTIVIDAD & ELAB. CACAO CHOCOLATE Y CONFIT. & 1 & $1,04 \%$ \\
\hline ECONÓMICA & ELAB. DE PRODUCTOS DE MOLINERIA. & 2 & $2,08 \%$ \\
\hline & ELAB. PROD. DE PANADERIA. & 8 & $8,33 \%$ \\
\hline & TOTAL & $\mathbf{9 6}$ & $\mathbf{1 0 0 , 0 0 \%}$ \\
\hline
\end{tabular}

Cuadro 20. Distribución de empresas grandes y medianas pertenecientes a la actividad económica de Molinería, Chocolatería, Panadería y Otros ubicada en sector de Lima: Año 2016.

Tomado de Ministerio de la Producción Directorio Nacional de Empresas

\begin{tabular}{|c|c|c|c|c|}
\hline $\mathbf{N}^{0}$ & EMPRESA & TAMAÑO & CRITERIO & ACTIVIDAD \\
\hline 1 & AGRICOLAS Y FORESTALES SAC & EG & POTEN & $\begin{array}{l}\text { ELAB DE OTROS PROD. } \\
\text { ALIMENTICIOS. }\end{array}$ \\
\hline 2 & AJINOMOTO DEL PERU S A & EG & POTEN & $\begin{array}{l}\text { ELAB DE OTROS PROD. } \\
\text { ALIMENTICIOS. }\end{array}$ \\
\hline 3 & ALIMENTOS SAN CHARBEL S.A.C. & EG & POTEN & $\begin{array}{l}\text { ELAB DE OTROS PROD. } \\
\text { ALIMENTICIOS. }\end{array}$ \\
\hline 4 & ANANIAS GONZALES JOSE ALFREDO & EG & POTEN & $\begin{array}{l}\text { ELAB DE OTROS PROD. } \\
\text { ALIMENTICIOS. }\end{array}$ \\
\hline 5 & AROMAS DEL PERU SA & EG & POTEN & $\begin{array}{l}\text { ELAB DE OTROS PROD. } \\
\text { ALIMENTICIOS. }\end{array}$ \\
\hline 6 & BAKELS PERU S.A.C. & EG & POTEN & $\begin{array}{l}\text { ELAB DE OTROS PROD. } \\
\text { ALIMENTICIOS. }\end{array}$ \\
\hline 7 & BARTORI S.A.C. & EG & POTEN & $\begin{array}{l}\text { ELAB DE OTROS PROD. } \\
\text { ALIMENTICIOS. }\end{array}$ \\
\hline 8 & CIANO TRADING \& SERVICES SAC & EG & POTEN & $\begin{array}{l}\text { ELAB DE OTROS PROD. } \\
\text { ALIMENTICIOS. }\end{array}$ \\
\hline 9 & COMERCIAL ASVEL E.I.R.L & EG & POTEN & $\begin{array}{l}\text { ELAB DE OTROS PROD. } \\
\text { ALIMENTICIOS. }\end{array}$ \\
\hline 10 & CORPORACION ORO VERDE S.A.C. & EG & POTEN & $\begin{array}{l}\text { ELAB DE OTROS PROD. } \\
\text { ALIMENTICIOS. }\end{array}$ \\
\hline 11 & CORPORACION TDN S.A.C. & EG & POTEN & $\begin{array}{l}\text { ELAB DE OTROS PROD. } \\
\text { ALIMENTICIOS. }\end{array}$ \\
\hline 12 & EMBOTELLADORA DON JORGE S.A.C. & EG & POTEN & $\begin{array}{l}\text { ELAB DE OTROS PROD. } \\
\text { ALIMENTICIOS. }\end{array}$ \\
\hline 13 & ETANFOR S.A. & EG & POTEN & $\begin{array}{l}\text { ELAB DE OTROS PROD. } \\
\text { ALIMENTICIOS. }\end{array}$ \\
\hline 14 & FERYMAR S.A.C & EG & POTEN & $\begin{array}{l}\text { ELAB DE OTROS PROD. } \\
\text { ALIMENTICIOS. }\end{array}$ \\
\hline 15 & GELAFRUT S.R.L. & EG & POTEN & $\begin{array}{l}\text { ELAB DE OTROS PROD. } \\
\text { ALIMENTICIOS. }\end{array}$ \\
\hline 16 & GELATERIA LARITZA D SA & EG & POTEN & $\begin{array}{l}\text { ELAB DE OTROS PROD. } \\
\text { ALIMENTICIOS. }\end{array}$ \\
\hline 17 & INCA OIL S.A. & EG & POTEN & $\begin{array}{l}\text { ELAB DE OTROS PROD. } \\
\text { ALIMENTICIOS. }\end{array}$ \\
\hline 18 & $\begin{array}{l}\text { INDUSTRIAL COMERCIAL HOLGUIN E } \\
\text { HIJOS S.A. }\end{array}$ & EG & POTEN & $\begin{array}{l}\text { ELAB DE OTROS PROD. } \\
\text { ALIMENTICIOS. }\end{array}$ \\
\hline 19 & INDUSTRIAS UNIDAS DEL PERU S.A. & EG & CONSU & $\begin{array}{l}\text { ELAB DE OTROS PROD. } \\
\text { ALIMENTICIOS. }\end{array}$ \\
\hline 20 & INKA CROPS S.A. & EG & POTEN & $\begin{array}{l}\text { ELAB DE OTROS PROD. } \\
\text { ALIMENTICIOS. }\end{array}$ \\
\hline
\end{tabular}




\begin{tabular}{|c|c|c|c|c|}
\hline 21 & $\begin{array}{c}\text { INVERSIONES ARTIKA SOCIEDAD } \\
\text { ANONIMA CERRADA }\end{array}$ & EG & CONSU & $\begin{array}{l}\text { ELAB DE OTROS PROD. } \\
\text { ALIMENTICIOS. }\end{array}$ \\
\hline 22 & $\begin{array}{l}\text { JM LUDAFA SOCIEDAD ANONIMA } \\
\text { CERRADA }\end{array}$ & EG & POTEN & $\begin{array}{l}\text { ELAB DE OTROS PROD. } \\
\text { ALIMENTICIOS. }\end{array}$ \\
\hline 23 & KIKKO CORPORATION S.A. & EG & POTEN & $\begin{array}{l}\text { ELAB DE OTROS PROD. } \\
\text { ALIMENTICIOS. }\end{array}$ \\
\hline 24 & $\begin{array}{l}\text { MANUFACTURA DE ALIMENTOS S.A. } \\
\text { (MALSA) }\end{array}$ & EG & POTEN & $\begin{array}{l}\text { ELAB DE OTROS PROD. } \\
\text { ALIMENTICIOS. }\end{array}$ \\
\hline 25 & $\begin{array}{l}\text { MEAD JOHNSON NUTRITION (PERU) } \\
\text { S.R.L. }\end{array}$ & EG & POTEN & $\begin{array}{l}\text { ELAB DE OTROS PROD. } \\
\text { ALIMENTICIOS. }\end{array}$ \\
\hline 26 & $\begin{array}{l}\text { MIRANDA - LANGA AGRO EXPORT } \\
\text { S.A.C - MIRANDA - LANG }\end{array}$ & EG & POTEN & $\begin{array}{l}\text { ELAB DE OTROS PROD. } \\
\text { ALIMENTICIOS. }\end{array}$ \\
\hline 27 & MULTIFOODS S.A.C. & EG & POTEN & $\begin{array}{l}\text { ELAB DE OTROS PROD. } \\
\text { ALIMENTICIOS. }\end{array}$ \\
\hline 28 & NEGRISA S.A.C. & EG & POTEN & $\begin{array}{l}\text { ELAB DE OTROS PROD. } \\
\text { ALIMENTICIOS. }\end{array}$ \\
\hline 29 & NIISA CORPORATION S.A. & EG & POTEN & $\begin{array}{l}\text { ELAB DE OTROS PROD. } \\
\text { ALIMENTICIOS. }\end{array}$ \\
\hline 30 & NOVUS PERU S.R.L. & EG & POTEN & $\begin{array}{l}\text { ELAB DE OTROS PROD. } \\
\text { ALIMENTICIOS. }\end{array}$ \\
\hline 31 & NUTRITIONAL TECHNOLOGIES S.A.C. & EG & POTEN & $\begin{array}{l}\text { ELAB DE OTROS PROD. } \\
\text { ALIMENTICIOS. }\end{array}$ \\
\hline 32 & OVOSUR S.A & EG & POTEN & $\begin{array}{l}\text { ELAB DE OTROS PROD. } \\
\text { ALIMENTICIOS. }\end{array}$ \\
\hline 33 & PERUVIAN NATURE S \& S S.A.C. & EG & POTEN & $\begin{array}{l}\text { ELAB DE OTROS PROD. } \\
\text { ALIMENTICIOS. }\end{array}$ \\
\hline 34 & $\begin{array}{l}\text { PREMEZCLAS LATINOAMERICANAS } \\
\text { S.A. }\end{array}$ & EG & POTEN & $\begin{array}{l}\text { ELAB DE OTROS PROD. } \\
\text { ALIMENTICIOS. }\end{array}$ \\
\hline 35 & PRIMA FARMS S.A.C. & EG & POTEN & $\begin{array}{l}\text { ELAB DE OTROS PROD. } \\
\text { ALIMENTICIOS. }\end{array}$ \\
\hline 36 & PRO NUTRITION PERU S.A.C. & EG & POTEN & $\begin{array}{l}\text { ELAB DE OTROS PROD. } \\
\text { ALIMENTICIOS. } \\
\end{array}$ \\
\hline 37 & $\begin{array}{c}\text { PROCESADORA CATALINA } \\
\text { SOCIEDAD ANONIMA CERRADA }\end{array}$ & EG & POTEN & $\begin{array}{l}\text { ELAB DE OTROS PROD. } \\
\text { ALIMENTICIOS. }\end{array}$ \\
\hline 38 & PRODUCTOS ENCURTIDOS S A & EG & POTEN & $\begin{array}{l}\text { ELAB DE OTROS PROD. } \\
\text { ALIMENTICIOS. }\end{array}$ \\
\hline 39 & $\begin{array}{l}\text { PRODUCTOS EXTRAGEL Y } \\
\text { UNIVERSAL S.A.C. }\end{array}$ & EG & POTEN & $\begin{array}{l}\text { ELAB DE OTROS PROD. } \\
\text { ALIMENTICIOS. }\end{array}$ \\
\hline 40 & $\begin{array}{c}\text { PRODUCTOS Y SERVICIOS VLADY } \\
\text { S.A.C. }\end{array}$ & EG & CONSU & $\begin{array}{l}\text { ELAB DE OTROS PROD. } \\
\text { ALIMENTICIOS. }\end{array}$ \\
\hline 41 & $\begin{array}{l}\text { SERVICIOS DE CONCESIONARIO SAN } \\
\text { FRANCISCO DE ASIS S }\end{array}$ & EG & POTEN & $\begin{array}{l}\text { ELAB DE OTROS PROD. } \\
\text { ALIMENTICIOS. }\end{array}$ \\
\hline 42 & SOLRAC S.A.C. & EG & POTEN & $\begin{array}{l}\text { ELAB DE OTROS PROD. } \\
\text { ALIMENTICIOS. }\end{array}$ \\
\hline 43 & AGRO INDUSTRIA EL VADO EIRL & EM & CONSU & $\begin{array}{l}\text { ELAB DE OTROS PROD. } \\
\text { ALIMENTICIOS. }\end{array}$ \\
\hline 44 & D'VIERI PERU SAC & EM & POTEN & $\begin{array}{l}\text { ELAB DE OTROS PROD. } \\
\text { ALIMENTICIOS. }\end{array}$ \\
\hline 45 & $\begin{array}{l}\text { EXPORTACIONES MIRSA EMPRESA } \\
\text { INDIVIDUAL DE RESPOSAB }\end{array}$ & EM & POTEN & $\begin{array}{l}\text { ELAB DE OTROS PROD. } \\
\text { ALIMENTICIOS. }\end{array}$ \\
\hline 46 & PRINCE'S S.A.C & EM & POTEN & $\begin{array}{l}\text { ELAB DE OTROS PROD. } \\
\text { ALIMENTICIOS. }\end{array}$ \\
\hline 47 & QUISPE OLMEDO PAULINO & EM & POTEN & $\begin{array}{l}\text { ELAB DE OTROS PROD. } \\
\text { ALIMENTICIOS. }\end{array}$ \\
\hline 48 & BOMBONERIA DI PERUGIA S.A.C. & EG & POTEN & $\begin{array}{l}\text { ELAB. CACAO CHOCOLATE Y } \\
\text { CONFIT. }\end{array}$ \\
\hline 49 & COMERCIAL ALIMENTICIA S.A.C. & EG & POTEN & $\begin{array}{l}\text { ELAB. CACAO CHOCOLATE Y } \\
\text { CONFIT. }\end{array}$ \\
\hline
\end{tabular}




\begin{tabular}{|c|c|c|c|c|}
\hline 50 & $\begin{array}{l}\text { COMPAÃ'IA NACIONAL DE } \\
\text { CHOCOLATES DE PERU S.A. }\end{array}$ & EG & CONSU & $\begin{array}{l}\text { ELAB. CACAO CHOCOLATE Y } \\
\text { CONFIT. }\end{array}$ \\
\hline 51 & CONFIPERU S.A. & EG & POTEN & $\begin{array}{l}\text { ELAB. CACAO CHOCOLATE Y } \\
\text { CONFIT. }\end{array}$ \\
\hline 52 & F Y D INVERSIONES S.A.C. & EG & CONSU & $\begin{array}{l}\text { ELAB. CACAO CHOCOLATE Y } \\
\text { CONFIT. }\end{array}$ \\
\hline 53 & MACHU PICCHU FOODS S.A.C. & EG & POTEN & $\begin{array}{l}\text { ELAB. CACAO CHOCOLATE Y } \\
\text { CONFIT. }\end{array}$ \\
\hline 54 & MONDELEZ PERU S.A. & EG & POTEN & $\begin{array}{c}\text { ELAB. CACAO CHOCOLATE Y } \\
\text { CONFIT. }\end{array}$ \\
\hline 55 & $\begin{array}{l}\text { SUMAQAO SOCIEDAD ANONIMA } \\
\text { CERRADA }\end{array}$ & EG & POTEN & $\begin{array}{l}\text { ELAB. CACAO CHOCOLATE Y } \\
\text { CONFIT. }\end{array}$ \\
\hline 56 & ADRIMPEX SA & EM & POTEN & $\begin{array}{l}\text { ELAB. CACAO CHOCOLATE Y } \\
\text { CONFIT. }\end{array}$ \\
\hline 57 & $\begin{array}{c}\text { AGROINDUSTRIA SANTA MARIA } \\
\text { S.A.C. }\end{array}$ & EG & POTEN & $\begin{array}{l}\text { ELAB. DE PRODUCTOS DE } \\
\text { MOLINERIA. }\end{array}$ \\
\hline 58 & $\begin{array}{l}\text { COMERCIAL MOLINERA SAN LUIS } \\
\text { SAC }\end{array}$ & EG & POTEN & $\begin{array}{l}\text { ELAB. DE PRODUCTOS DE } \\
\text { MOLINERIA. }\end{array}$ \\
\hline 59 & $\begin{array}{l}\text { COMPAÃ'IA MOLINERA DEL CENTRO } \\
\text { S.A./CIA. MOLINERA DE }\end{array}$ & EG & POTEN & $\begin{array}{l}\text { ELAB. DE PRODUCTOS DE } \\
\text { MOLINERIA. }\end{array}$ \\
\hline 60 & EXPORTADORA EL SOL S.A.C. & EG & CONSU & $\begin{array}{l}\text { ELAB. DE PRODUCTOS DE } \\
\text { MOLINERIA. }\end{array}$ \\
\hline 61 & GLOBAL ALIMENTOS S.A.C. & EG & CONSU & $\begin{array}{l}\text { ELAB. DE PRODUCTOS DE } \\
\text { MOLINERIA. }\end{array}$ \\
\hline 62 & GOMAS Y TANINOS S.A.C. & EG & POTEN & $\begin{array}{l}\text { ELAB. DE PRODUCTOS DE } \\
\text { MOLINERIA. }\end{array}$ \\
\hline 63 & $\begin{array}{c}\text { INDUSTRIA ARROCERA DE AMERICA } \\
\text { SOCIEDAD ANONIMA CER }\end{array}$ & EG & CONSU & $\begin{array}{l}\text { ELAB. DE PRODUCTOS DE } \\
\text { MOLINERIA. }\end{array}$ \\
\hline 64 & $\begin{array}{l}\text { INDUSTRIAS ALIMENTICIAS CUSCO } \\
\text { S.A. }\end{array}$ & EG & CONSU & $\begin{array}{l}\text { ELAB. DE PRODUCTOS DE } \\
\text { MOLINERIA. }\end{array}$ \\
\hline 65 & MOLINERA EL TRIGAL S.A.C. & EG & CONSU & $\begin{array}{l}\text { ELAB. DE PRODUCTOS DE } \\
\text { MOLINERIA. }\end{array}$ \\
\hline 66 & $\begin{array}{c}\text { MOLINO SARACOLCA SOCIEDAD } \\
\text { ANONIMA CERRADA }\end{array}$ & EG & POTEN & $\begin{array}{l}\text { ELAB. DE PRODUCTOS DE } \\
\text { MOLINERIA. }\end{array}$ \\
\hline 67 & MOLITALIA S.A & EG & CONSU & $\begin{array}{l}\text { ELAB. DE PRODUCTOS DE } \\
\text { MOLINERIA. }\end{array}$ \\
\hline 68 & ALICORP SAA & EG & CONSU & $\begin{array}{l}\text { ELAB. DE PRODUCTOS DE } \\
\text { MOLINERIA. }\end{array}$ \\
\hline 69 & $\begin{array}{l}\text { PODER PANADERO SOCIEDAD } \\
\text { COMERCIAL DE RESPONSABILID }\end{array}$ & EG & POTEN & $\begin{array}{l}\text { ELAB. DE PRODUCTOS DE } \\
\text { MOLINERIA. }\end{array}$ \\
\hline 70 & PURATOS PERU S.A. & EG & POTEN & $\begin{array}{l}\text { ELAB. DE PRODUCTOS DE } \\
\text { MOLINERIA. }\end{array}$ \\
\hline 71 & $\begin{array}{c}\text { PRODUCTOS ALIMENTICIOS CARTER } \\
\text { SOCIEDAD ANONIMA }\end{array}$ & EM & CONSU & $\begin{array}{l}\text { ELAB. DE PRODUCTOS DE } \\
\text { MOLINERIA. }\end{array}$ \\
\hline 72 & MOLINO EL TRIUNFO S A & EM & POTEN & $\begin{array}{l}\text { ELAB. DE PRODUCTOS DE } \\
\text { MOLINERIA. } \\
\end{array}$ \\
\hline 73 & BARLETTA S.A. & EG & CONSU & ELAB. PROD. DE PANADERIA. \\
\hline 74 & CORPORACION SYZARD S.A.C. & EG & POTEN & ELAB. PROD. DE PANADERIA. \\
\hline 75 & GRUPO ONCE S.A.C. & EG & POTEN & ELAB. PROD. DE PANADERIA. \\
\hline 76 & INTERNATIONAL BAKERY S.A.C. & EG & POTEN & ELAB. PROD. DE PANADERIA. \\
\hline 77 & LESAFFRE PERU S.A.C. & EG & POTEN & ELAB. PROD. DE PANADERIA. \\
\hline 78 & NUTRA S.A. & EG & POTEN & ELAB. PROD. DE PANADERIA. \\
\hline 79 & PANADERIA SAN JORGE S A & EG & CONSU & ELAB. PROD. DE PANADERIA. \\
\hline 80 & PANIFICADORA TORRES S.A.C. & EG & POTEN & ELAB. PROD. DE PANADERIA. \\
\hline 81 & PASTELERIA SAN ANTONIO S.A. & EG & POTEN & ELAB. PROD. DE PANADERIA. \\
\hline
\end{tabular}




\begin{tabular}{|c|c|c|c|c|}
\hline 82 & $\begin{array}{l}\text { PASTIPAN SOCIEDAD ANONIMA } \\
\text { CERRADA }\end{array}$ & EG & POTEN & ELAB. PROD. DE PANADERIA. \\
\hline 83 & $\begin{array}{l}\text { PRODUCTOS ALIMENTICIOS } \\
\text { PEGUTSA S.A. }\end{array}$ & EG & CONSU & ELAB. PROD. DE PANADERIA. \\
\hline 84 & PRODUCTOS EL CEDRO S A & EG & POTEN & ELAB. PROD. DE PANADERIA. \\
\hline 85 & PRODUCTOS VANSS S.A.C. & EG & POTEN & ELAB. PROD. DE PANADERIA. \\
\hline 86 & RED STAR DEL PERU S A & EG & POTEN & ELAB. PROD. DE PANADERIA. \\
\hline 87 & SOLUCIONES ALIMENTICIAS S.A.C & EG & POTEN & ELAB. PROD. DE PANADERIA. \\
\hline 88 & T \& C REPRESENTACIONES S R LTDA & EG & POTEN & ELAB. PROD. DE PANADERIA. \\
\hline 89 & LA CASA DEL ALFAJOR S.A.C. & EM & POTEN & ELAB. PROD. DE PANADERIA. \\
\hline 90 & TORTAS BON S.A.C. & EM & POTEN & ELAB. PROD. DE PANADERIA. \\
\hline 91 & CALSA PERU S.A.C. & EM & POTEN & ELAB. PROD. DE PANADERIA. \\
\hline 92 & $\begin{array}{l}\text { CORPORACION DE ALIMENTOS } \\
\text { SOCIEDAD ANOMINA CERRADA }\end{array}$ & EM & POTEN & ELAB. PROD. DE PANADERIA. \\
\hline 93 & $\begin{array}{l}\text { INDUSTRIA PANIFICADORA DEL SUR } \\
\text { S.A.C. }\end{array}$ & EM & POTEN & ELAB. PROD. DE PANADERIA. \\
\hline 94 & $\begin{array}{l}\text { INDUSTRIA PANIFICADORA EL GRAN } \\
\text { MOLINO S.A.C. }\end{array}$ & EM & POTEN & ELAB. PROD. DE PANADERIA. \\
\hline 95 & $\begin{array}{l}\text { INDUSTRIAS DE ALIMENTOS HILDAS } \\
\text { S.A.C. }\end{array}$ & EM & POTEN & ELAB. PROD. DE PANADERIA. \\
\hline 96 & PANADERÍA MAIA SAC & EM & POTEN & ELAB. PROD. DE PANADERIA. \\
\hline
\end{tabular}

Cuadro 21. Lista de empresas grandes y medianas pertenecientes a la actividad económica de Molinería, Chocolatería, Panadería y Otros ubicada en sector de Lima: Año 2016.

Tomado de Ministerio de la Producción Directorio Nacional de Empresas

\subsection{Investigación Cualitativa}

Para la investigación se hará uso de la técnica de Entrevista en profundidad.

\subsubsection{Técnica cualitativa: Entrevista a profundidad}

Esta técnica de investigación permite obtener información relevante de expertos del sector, respecto a las especificaciones técnicas que las empresas elaboradoras de alimentos requieren respecto al producto ofrecido; así como también la aceptación de nuestro producto. Finalmente conocer los procedimientos de elaboración y venta de la fruta deshidratada, desde la compra del insumo y la forma de acopio hasta la venta al cliente. 
Los entrevistados han sido elegidos teniendo en cuenta los siguientes criterios: nivel de autoridad jerárquica en la empresa, capacidad de decisión en las negociaciones entre cliente y proveedor, experiencia y conocimiento en el sector.

Por lo tanto se definió los siguientes participantes:

- Jefe de cadena de abastecimiento.

- Gerente de Logística

- Comercializador de Frutas deshidratadas.

- Coordinador de Sierra y Selva Exportadora.

\subsubsection{Objetivos de la investigación.}

- Identificar los productos deshidratados de mayor demanda

- Identificar los productos sustitutos de las frutas deshidratadas.

- Determinar las principales especificaciones técnicas de las frutas deshidratadas.

- Determinar las expectativas y razones de crecimiento de la demanda de berries y frutas deshidratadas por parte de las empresas elaboradoras de alimentos.

- Determinar los criterios de selección de proveedores.

- Evaluar la tendencia a futuro de la producción de frutos frescos.

- Determinar las zonas de mayor producción de frutos frescos.

- Determinar la estacionalidad de los frutos frescos.

- Evaluar el volumen de frutos frescos que no se exportan.

- Determinar el rango de precios de fruta fresca que no se exporta.

- Describir la cadena de abastecimiento de fruta fresca que no exporta.

- Determinar usos alternativos de la fruta fresca que no se exporta. 


\subsection{Investigación Cuantitativa}

Para dicha investigación se hará uso de la encuesta como técnica de recolección de información.

\subsubsection{Objetivos de la investigación}

- Determinar el nivel de empresas que producen y comercializan alimentos.

- Determinar el interés por parte de las empresas productoras y comercializadoras de alimentos en conocer sobre fruta deshidratada.

- Determinar el nivel de conocimiento de las empresas productoras y comercializadora alimentos sobre tipo de fruta deshidratada.

- Identificar los medios, de comunicación sobre frutas deshidratadas, de preferencia por parte de las empresas productoras y comercializadoras de alimentos.

- Señalar el nivel de empresas que utiliza la fruta deshidratada para elaboración de productos.

- Identificar el nivel de intención de compra de fruta deshidratada de arándanos, piña manzana por parte de las empresas productoras de alimentos.

- Determinar el tipo o variedad de fruta deshidratada que se compran las empresas productoras de alimentos.

- Determinar el nivel de importancia del uso de los frutos deshidratados en la elaboración de productos.

- Determinar el volumen en kilos de compra de fruta deshidratada de arándanos, piña y manzana por parte de las empresas productoras de alimentos.

- Identificar la frecuencia de compra de fruta deshidratada de arándanos, piña y manzana por parte de las empresas productoras de alimentos.

- Identificar los tipos de productos en los que se utiliza como ingrediente la fruta deshidratada de arándanos, piña y manzana. 
- Determinar las expectativas de crecimiento de la demanda de frutas deshidratadas de arándanos, piña y manzana por parte de las empresas productoras de alimentos.

- Determinar las expectativas de crecimiento de la demanda de frutas deshidratadas de arándanos, piña y manzana por parte de las empresas productoras de alimentos.

- Identificar los proveedores de frutas deshidratadas de arándanos, piña y manzana de las empresas productoras de alimentos.

- Señalar los criterios de selección de proveedores de fruta deshidratada de arándanos, piña y manzana de las empresas productoras de alimentos.

- Identificar las desventajas de los proveedores de fruta deshidratada de arándanos, piña y manzana de las empresas productoras de alimentos.

- Determinar el precio por kilo de la fruta deshidratada de arándanos, piña y manzana al que compran las empresas productoras de alimentos.

- Describir las principales especificaciones técnicas de las frutas deshidratadas de arándanos, piña y manzana que requieren las empresas productoras de alimentos.

- Determinar la disposición de compra de las frutas deshidratadas de arándanos, piña y manzana por parte de las empresas productoras de alimentos.

- Determinar el tipo de empaque de frutos deshidratados de arándanos, piña y manzana deseado por las empresas productoras de alimentos.

- Señalar los kilos que contendrá el empaque de frutos deshidratados de arándanos, piña y manzana deseados por las empresas elaboradoras de alimentos.

- Determinar las condiciones de pago deseados por la compra de frutos deshidratados de arándanos, piña y manzana por parte de las empresas elaboradoras de alimentos. 


\subsubsection{Proceso de muestreo.}

\subsubsection{Definición de la población.}

Nuestro marco muestral serán las empresas medianas y grandes, elaboradoras de alimentos de Lima.

\subsubsection{Tamaño de muestra.}

El tamaño de la muestra se refiere al número de elementos que se incluyen en el estudio. Por cuestiones estadísticas, se asumirá un nivel de confianza de 90\% (Z), con un nivel de tolerancia o error de $10 \%(\mathrm{E})$ :

Como se trata de una población finita $\mathrm{N}$ menor a 100,000 se utiliza la fórmula de tamaño de muestra finita.

$$
\frac{N * Z^{2} * p * q}{e^{2}(N-1)+Z^{2} * p * q}=\frac{96 * 1.96^{2} * 0.5 * 0.5}{0.05^{2}(96-1)+1.96^{2} * 0.5 * 0.5}=76
$$

Datos:

$\mathrm{N}=96$

$\mathrm{Z}=1.96$

$e=5 \%$

$\mathrm{p}=0.5$

$q=0.5$

$\mathrm{n}=76$ encuestas 


\begin{tabular}{|c|c|c|c|}
\hline & & \\
\hline & & $\mathbf{N}^{0}$ & $\%$ \\
\hline $\begin{array}{l}\text { TAMAÑO DE } \\
\text { EMPRESA }\end{array}$ & EMPRESA GRANDE & 63 & $83,33 \%$ \\
\hline \multirow{4}{*}{$\begin{array}{l}\text { ACTIVIDAD } \\
\text { ECONÓMICA }\end{array}$} & ELAB DE OTROS PROD. ALIMENTICIOS. & 33 & $43,75 \%$ \\
\hline & ELAB. CACAO CHOCOLATE Y CONFIT. & 6 & $8,33 \%$ \\
\hline & ELAB. DE PRODUCTOS DE MOLINERIA. & 11 & $14,58 \%$ \\
\hline & ELAB. PROD. DE PANADERIA. & 13 & $16,67 \%$ \\
\hline $\begin{array}{l}\text { TAMAÑO DE } \\
\text { EMPRESA }\end{array}$ & EMPRESA MEDIANA & 13 & $16,67 \%$ \\
\hline \multirow{5}{*}{$\begin{array}{l}\text { ACTIVIDAD } \\
\text { ECONÓMICA }\end{array}$} & ELAB DE OTROS PROD. ALIMENTICIOS. & 4 & $5,21 \%$ \\
\hline & ELAB. CACAO CHOCOLATE Y CONFIT. & 1 & $1,04 \%$ \\
\hline & ELAB. DE PRODUCTOS DE MOLINERIA. & 2 & $2,08 \%$ \\
\hline & ELAB. PROD. DE PANADERIA. & 6 & $8,33 \%$ \\
\hline & TOTAL & 76 & $100,00 \%$ \\
\hline
\end{tabular}

Cuadro 22. Distribución de muestra de empresas grandes y medianas pertenecientes a la actividad económica de Molinería, Chocolatería, Panadería y Otros ubicada en sector de Lima: Año 2016.

Tomado de Ministerio de la Producción Directorio Nacional de Empresas

\subsubsection{Selección de los elementos de la muestra}

Se utilizará la técnica de muestreo no probabilístico, en la categoría de muestreo por juicio. Dichos criterios de juicio, indicados por Jhonny Berrospi Herrera Jefe de Planta de Industrias Alimenticias Cusco SA, son los siguientes:

- Las empresas elegidas representan el $80 \%$ del consumo directo.

- Empresas que usan como insumo, fruta fresca, en polvo y en néctares para la elaboración de productos.

\begin{tabular}{|c|c|c|}
\hline $\begin{array}{l}\mathbf{N}^{\circ} \text { DE } \\
\text { EMPRESAS }\end{array}$ & COMPOSICIÓN & CRITERIOS DE ELECCIÓN POR JUICIO \\
\hline \multirow{2}{*}{76} & $\begin{array}{l}14 \text { empresas que } \\
\text { consumen. }\end{array}$ & $\begin{array}{l}\text { - Empresas que cubren un consumo de } \\
\text { alrededor de } 80 \%\end{array}$ \\
\hline & $\begin{array}{l}62 \text { empresas que } \\
\text { consumirían } \\
\text { potencialmente. }\end{array}$ & $\begin{array}{l}\text { Empresas que usan como insumo, fruta } \\
\text { fresca, en polvo, en néctares para la } \\
\text { elaboración de sus productos. }\end{array}$ \\
\hline
\end{tabular}

Cuadro 23. Criterios de elección por juicio Elaboración propia. 
De acuerdo a Naresh K. Malhotra (2008)8 los ejemplos comunes del muestreo por juicio son: Ingenieros de compras elegidos en una investigación de mercados industriales porque se les considera repetitivos de la compañía. Asimismo, puede ser útil si no es necesario hacer inferencias sobre poblaciones muy grandes.

\begin{tabular}{|c|c|c|c|c|}
\hline $\mathbf{N}^{\mathbf{0}}$ & EMPRESA & TAMAÑO & CRITERIO & ACTIVIDAD \\
\hline 1 & AJINOMOTO DEL PERU S A & EG & POTEN & $\begin{array}{l}\text { ELAB DE OTROS PROD. } \\
\text { ALIMENTICIOS. }\end{array}$ \\
\hline 2 & ALIMENTOS SAN CHARBEL S.A.C. & EG & POTEN & $\begin{array}{l}\text { ELAB DE OTROS PROD. } \\
\text { ALIMENTICIOS. }\end{array}$ \\
\hline 3 & AROMAS DEL PERU SA & EG & POTEN & $\begin{array}{l}\text { ELAB DE OTROS PROD. } \\
\text { ALIMENTICIOS. }\end{array}$ \\
\hline 4 & BAKELS PERU S.A.C. & EG & POTEN & $\begin{array}{l}\text { ELAB DE OTROS PROD. } \\
\text { ALIMENTICIOS. }\end{array}$ \\
\hline 5 & BARTORI S.A.C. & EG & POTEN & $\begin{array}{l}\text { ELAB DE OTROS PROD. } \\
\text { ALIMENTICIOS. } \\
\end{array}$ \\
\hline 6 & CORPORACION ORO VERDE S.A.C. & EG & POTEN & $\begin{array}{l}\text { ELAB DE OTROS PROD. } \\
\text { ALIMENTICIOS. }\end{array}$ \\
\hline 7 & CORPORACION TDN S.A.C. & EG & POTEN & $\begin{array}{l}\text { ELAB DE OTROS PROD. } \\
\text { ALIMENTICIOS. }\end{array}$ \\
\hline 8 & GELAFRUT S.R.L. & EG & POTEN & $\begin{array}{l}\text { ELAB DE OTROS PROD. } \\
\text { ALIMENTICIOS. } \\
\end{array}$ \\
\hline 9 & GELATERIA LARITZA D SA & EG & POTEN & $\begin{array}{l}\text { ELAB DE OTROS PROD. } \\
\text { ALIMENTICIOS. }\end{array}$ \\
\hline 10 & $\begin{array}{l}\text { INDUSTRIAL COMERCIAL HOLGUIN E } \\
\text { HIJOS S.A. }\end{array}$ & EG & POTEN & $\begin{array}{l}\text { ELAB DE OTROS PROD. } \\
\text { ALIMENTICIOS. }\end{array}$ \\
\hline 11 & INDUSTRIAS UNIDAS DEL PERU S.A. & EG & CONSU & $\begin{array}{l}\text { ELAB DE OTROS PROD. } \\
\text { ALIMENTICIOS. }\end{array}$ \\
\hline 12 & INKA CROPS S.A. & EG & POTEN & $\begin{array}{l}\text { ELAB DE OTROS PROD. } \\
\text { ALIMENTICIOS. }\end{array}$ \\
\hline 13 & $\begin{array}{c}\text { INVERSIONES ARTIKA SOCIEDAD } \\
\text { ANONIMA CERRADA }\end{array}$ & EG & CONSU & $\begin{array}{l}\text { ELAB DE OTROS PROD. } \\
\text { ALIMENTICIOS. }\end{array}$ \\
\hline 14 & KIKKO CORPORATION S.A. & EG & POTEN & $\begin{array}{l}\text { ELAB DE OTROS PROD. } \\
\text { ALIMENTICIOS. }\end{array}$ \\
\hline 15 & $\begin{array}{l}\text { MANUFACTURA DE ALIMENTOS S.A. } \\
\text { (MALSA) }\end{array}$ & EG & POTEN & $\begin{array}{l}\text { ELAB DE OTROS PROD. } \\
\text { ALIMENTICIOS. }\end{array}$ \\
\hline 16 & MEAD JOHNSON NUTRITION (PERU) S.R.L. & EG & POTEN & $\begin{array}{l}\text { ELAB DE OTROS PROD. } \\
\text { ALIMENTICIOS. }\end{array}$ \\
\hline 17 & MULTIFOODS S.A.C. & EG & POTEN & $\begin{array}{l}\text { ELAB DE OTROS PROD. } \\
\text { ALIMENTICIOS. }\end{array}$ \\
\hline 18 & NEGRISA S.A.C. & EG & POTEN & $\begin{array}{l}\text { ELAB DE OTROS PROD. } \\
\text { ALIMENTICIOS. }\end{array}$ \\
\hline 19 & NIISA CORPORATION S.A. & EG & POTEN & $\begin{array}{l}\text { ELAB DE OTROS PROD. } \\
\text { ALIMENTICIOS. }\end{array}$ \\
\hline 20 & NOVUS PERU S.R.L. & EG & POTEN & $\begin{array}{l}\text { ELAB DE OTROS PROD. } \\
\text { ALIMENTICIOS. }\end{array}$ \\
\hline 21 & NUTRITIONAL TECHNOLOGIES S.A.C. & EG & POTEN & $\begin{array}{l}\text { ELAB DE OTROS PROD. } \\
\text { ALIMENTICIOS. }\end{array}$ \\
\hline 22 & OVOSUR S.A & EG & POTEN & $\begin{array}{l}\text { ELAB DE OTROS PROD. } \\
\text { ALIMENTICIOS. }\end{array}$ \\
\hline
\end{tabular}

\footnotetext{
${ }^{8}$ MALHOTRA, Naresh. Investigación de mercados Ed. 5. Pearson Educación México. p. 343, 344.
} 


\begin{tabular}{|c|c|c|c|c|}
\hline 23 & PERUVIAN NATURE S \& S S.A.C. & EG & POTEN & $\begin{array}{l}\text { ELAB DE OTROS PROD. } \\
\text { ALIMENTICIOS. }\end{array}$ \\
\hline 24 & PREMEZCLAS LATINOAMERICANAS S.A. & EG & POTEN & $\begin{array}{l}\text { ELAB DE OTROS PROD. } \\
\text { ALIMENTICIOS. }\end{array}$ \\
\hline 25 & PRO NUTRITION PERU S.A.C. & EG & POTEN & $\begin{array}{l}\text { ELAB DE OTROS PROD. } \\
\text { ALIMENTICIOS. }\end{array}$ \\
\hline 26 & $\begin{array}{c}\text { PROCESADORA CATALINA SOCIEDAD } \\
\text { ANONIMA CERRADA }\end{array}$ & EG & POTEN & $\begin{array}{l}\text { ELAB DE OTROS PROD. } \\
\text { ALIMENTICIOS. } \\
\end{array}$ \\
\hline 27 & PRODUCTOS ENCURTIDOS S A & EG & POTEN & $\begin{array}{l}\text { ELAB DE OTROS PROD. } \\
\text { ALIMENTICIOS. }\end{array}$ \\
\hline 28 & $\begin{array}{l}\text { PRODUCTOS EXTRAGEL Y UNIVERSAL } \\
\text { S.A.C. }\end{array}$ & EG & POTEN & $\begin{array}{l}\text { ELAB DE OTROS PROD. } \\
\text { ALIMENTICIOS. }\end{array}$ \\
\hline 29 & PRODUCTOS Y SERVICIOS VLADY S.A.C. & EG & CONSU & $\begin{array}{l}\text { ELAB DE OTROS PROD. } \\
\text { ALIMENTICIOS. }\end{array}$ \\
\hline 30 & AGRO INDUSTRIA EL VADO EIRL & EM & CONSU & $\begin{array}{l}\text { ELAB DE OTROS PROD. } \\
\text { ALIMENTICIOS. } \\
\end{array}$ \\
\hline 31 & D'VIERI PERU SAC & EM & POTEN & $\begin{array}{l}\text { ELAB DE OTROS PROD. } \\
\text { ALIMENTICIOS. }\end{array}$ \\
\hline 32 & PRINCE'S S.A.C & EM & POTEN & $\begin{array}{l}\text { ELAB DE OTROS PROD. } \\
\text { ALIMENTICIOS. }\end{array}$ \\
\hline 33 & BOMBONERIA DI PERUGIA S.A.C. & EG & POTEN & $\begin{array}{l}\text { ELAB. CACAO CHOCOLATE Y } \\
\text { CONFIT. }\end{array}$ \\
\hline 34 & COMERCIAL ALIMENTICIA S.A.C. & EG & POTEN & $\begin{array}{l}\text { ELAB. CACAO CHOCOLATE Y } \\
\text { CONFIT. } \\
\end{array}$ \\
\hline 35 & $\begin{array}{l}\text { COMPAÃ'IA NACIONAL DE CHOCOLATES } \\
\text { DE PERU S.A. }\end{array}$ & EG & CONSU & $\begin{array}{l}\text { ELAB. CACAO CHOCOLATE Y } \\
\text { CONFIT. }\end{array}$ \\
\hline 36 & CONFIPERU S.A. & EG & POTEN & $\begin{array}{l}\text { ELAB. CACAO CHOCOLATE Y } \\
\text { CONFIT. }\end{array}$ \\
\hline 37 & F Y D INVERSIONES S.A.C. & EG & CONSU & $\begin{array}{l}\text { ELAB. CACAO CHOCOLATE Y } \\
\text { CONFIT. }\end{array}$ \\
\hline 38 & MACHU PICCHU FOODS S.A.C. & EG & POTEN & $\begin{array}{l}\text { ELAB. CACAO CHOCOLATE Y } \\
\text { CONFIT. } \\
\end{array}$ \\
\hline 39 & MONDELEZ PERU S.A. & EG & POTEN & $\begin{array}{l}\text { ELAB. CACAO CHOCOLATE Y } \\
\text { CONFIT. }\end{array}$ \\
\hline 40 & $\begin{array}{l}\text { SUMAQAO SOCIEDAD ANONIMA } \\
\text { CERRADA }\end{array}$ & EG & POTEN & $\begin{array}{l}\text { ELAB. CACAO CHOCOLATE Y } \\
\text { CONFIT. }\end{array}$ \\
\hline 41 & ADRIMPEX SA & EM & POTEN & $\begin{array}{l}\text { ELAB. CACAO CHOCOLATE Y } \\
\text { CONFIT. }\end{array}$ \\
\hline 42 & AGROINDUSTRIA SANTA MARIA S.A.C. & EG & POTEN & $\begin{array}{l}\text { ELAB. DE PRODUCTOS DE } \\
\text { MOLINERIA. }\end{array}$ \\
\hline 43 & COMERCIAL MOLINERA SAN LUIS SAC & EG & POTEN & $\begin{array}{l}\text { ELAB. DE PRODUCTOS DE } \\
\text { MOLINERIA. }\end{array}$ \\
\hline 44 & $\begin{array}{l}\text { COMPAÑIA MOLINERA DEL CENTRO } \\
\text { S.A./CIA. MOLINERA DE }\end{array}$ & EG & POTEN & $\begin{array}{l}\text { ELAB. DE PRODUCTOS DE } \\
\text { MOLINERIA. }\end{array}$ \\
\hline 45 & GLOBAL ALIMENTOS S.A.C. & EG & CONSU & $\begin{array}{l}\text { ELAB. DE PRODUCTOS DE } \\
\text { MOLINERIA. }\end{array}$ \\
\hline 46 & GOMAS Y TANINOS S.A.C. & EG & POTEN & $\begin{array}{l}\text { ELAB. DE PRODUCTOS DE } \\
\text { MOLINERIA. }\end{array}$ \\
\hline 47 & INDUSTRIAS ALIMENTICIAS CUSCO S.A. & EG & CONSU & $\begin{array}{l}\text { ELAB. DE PRODUCTOS DE } \\
\text { MOLINERIA. }\end{array}$ \\
\hline 48 & $\begin{array}{l}\text { MOLINO SARACOLCA SOCIEDAD } \\
\text { ANONIMA CERRADA }\end{array}$ & EG & POTEN & $\begin{array}{l}\text { ELAB. DE PRODUCTOS DE } \\
\text { MOLINERIA. }\end{array}$ \\
\hline 49 & MOLITALIA S.A & EG & CONSU & $\begin{array}{l}\text { ELAB. DE PRODUCTOS DE } \\
\text { MOLINERIA. }\end{array}$ \\
\hline 50 & ALICORP SAA & EG & CONSU & $\begin{array}{l}\text { ELAB. DE PRODUCTOS DE } \\
\text { MOLINERIA. }\end{array}$ \\
\hline 51 & $\begin{array}{l}\text { PODER PANADERO SOCIEDAD } \\
\text { COMERCIAL DE RESPONSABILID }\end{array}$ & EG & POTEN & $\begin{array}{l}\text { ELAB. DE PRODUCTOS DE } \\
\text { MOLINERIA. }\end{array}$ \\
\hline
\end{tabular}




\begin{tabular}{|c|c|c|c|c|}
\hline 52 & PURATOS PERU S.A. & EG & POTEN & $\begin{array}{l}\text { ELAB. DE PRODUCTOS DE } \\
\text { MOLINERIA. }\end{array}$ \\
\hline 53 & $\begin{array}{l}\text { PRODUCTOS ALIMENTICIOS CARTER } \\
\text { SOCIEDAD ANONIMA }\end{array}$ & EM & CONSU & $\begin{array}{l}\text { ELAB. DE PRODUCTOS DE } \\
\text { MOLINERIA. } \\
\end{array}$ \\
\hline 54 & MOLINO EL TRIUNFO S A & EM & POTEN & $\begin{array}{l}\text { ELAB. DE PRODUCTOS DE } \\
\text { MOLINERIA. }\end{array}$ \\
\hline 55 & BARLETTA S.A. & EG & CONSU & ELAB. PROD. DE PANADERIA. \\
\hline 56 & CORPORACION SYZARD S.A.C. & EG & POTEN & ELAB. PROD. DE PANADERIA. \\
\hline 57 & GRUPO ONCE S.A.C. & EG & POTEN & ELAB. PROD. DE PANADERIA. \\
\hline 58 & INTERNATIONAL BAKERY S.A.C. & EG & POTEN & ELAB. PROD. DE PANADERIA. \\
\hline 59 & LESAFFRE PERU S.A.C. & EG & POTEN & ELAB. PROD. DE PANADERIA. \\
\hline 60 & NUTRA S.A. & EG & POTEN & ELAB. PROD. DE PANADERIA. \\
\hline 61 & PANADERIA SAN JORGE S A & EG & CONSU & ELAB. PROD. DE PANADERIA. \\
\hline 62 & PANIFICADORA TORRES S.A.C. & EG & POTEN & ELAB. PROD. DE PANADERIA. \\
\hline 63 & PASTELERIA SAN ANTONIO S.A. & EG & POTEN & ELAB. PROD. DE PANADERIA. \\
\hline 64 & $\begin{array}{l}\text { PASTIPAN SOCIEDAD ANONIMA } \\
\text { CERRADA }\end{array}$ & EG & POTEN & ELAB. PROD. DE PANADERIA. \\
\hline 65 & $\begin{array}{l}\text { PRODUCTOS ALIMENTICIOS PEGUTSA } \\
\text { S.A. }\end{array}$ & EG & CONSU & ELAB. PROD. DE PANADERIA. \\
\hline 66 & PRODUCTOS EL CEDRO S A & EG & POTEN & ELAB. PROD. DE PANADERIA. \\
\hline 67 & PRODUCTOS VANSS S.A.C. & EG & POTEN & ELAB. PROD. DE PANADERIA. \\
\hline 68 & RED STAR DEL PERU S A & EG & POTEN & ELAB. PROD. DE PANADERIA. \\
\hline 69 & SOLUCIONES ALIMENTICIAS S.A.C & EG & POTEN & ELAB. PROD. DE PANADERIA. \\
\hline 70 & LA CASA DEL ALFAJOR S.A.C. & EM & POTEN & ELAB. PROD. DE PANADERIA. \\
\hline 71 & TORTAS BON S.A.C. & EM & POTEN & ELAB. PROD. DE PANADERIA. \\
\hline 72 & $\begin{array}{l}\text { CORPORACION DE ALIMENTOS } \\
\text { SOCIEDAD ANOMINA CERRADA }\end{array}$ & EM & POTEN & ELAB. PROD. DE PANADERIA. \\
\hline 73 & $\begin{array}{l}\text { INDUSTRIA PANIFICADORA DEL SUR } \\
\text { S.A.C. }\end{array}$ & EM & POTEN & ELAB. PROD. DE PANADERIA. \\
\hline 74 & $\begin{array}{l}\text { INDUSTRIA PANIFICADORA EL GRAN } \\
\text { MOLINO S.A.C. }\end{array}$ & EM & POTEN & ELAB. PROD. DE PANADERIA. \\
\hline 75 & $\begin{array}{l}\text { INDUSTRIAS DE ALIMENTOS HILDAS } \\
\text { S.A.C. }\end{array}$ & EM & POTEN & ELAB. PROD. DE PANADERIA. \\
\hline 76 & PANADERÍA MAIA SAC & EM & POTEN & ELAB. PROD. DE PANADERIA. \\
\hline
\end{tabular}

Cuadro 24. Muestra de empresas grandes y medianas pertenecientes a la actividad económica de Molinería, Chocolatería, Panadería y Otros ubicada en sector de Lima: Año 2016.

Tomado de Ministerio de la Producción Directorio Nacional de Empresas 


\subsubsection{Diseño de instrumento.}

\subsubsection{Diseño del instrumento: Cuestionario.}

Para la realización del cuestionario y en concordancia con los objetivos

formulados, se tomó en cuenta los pasos siguientes:

- Formulación del método de encuesta a realizar como: directa - estructurada, de tipo personal.

- Se definió el contenido de las preguntas a plantear.

- Se definió la estructura de las preguntas.

- Control de la redacción.

- Establecimiento de la secuencia de preguntas.

- Definición de la característica física del cuestionario, el cual comprende 22 preguntas distribuidas en 3 hojas.

- Realización de pruebas piloto para determinar el tiempo de demora para completar el test y además para evaluar la idoneidad del cuestionario.

El Cuestionario desarrollado se encuentra en el Anexo $\mathrm{N}^{\circ} 2$.

\subsubsection{Trabajo de campo.}

El método de la encuesta, en base a su aplicación, fue de tipo personal, con el soporte de un cuestionario impreso y el llenado a lapicero.

Los cuestionarios se aplicaron a los participantes del 13 de febrero al 23 de marzo del año 2018 en las oficinas administrativas de cada uno de los encargados.

Para la ejecución de los cuestionarios, se contrató los servicios de una consultora especializada en estudio de mercado, quienes se encargaron del proceso inicial de trabajo de campo, entendido como: selección y designación de los encuestadores, capacitación respecto al cuestionario elaborado, así como la supervisión del trabajo. No obstante, 
nuestro equipo se encargó de verificar en campo la presencia de los encuestadores y la ejecución de las actividades, acorde a lo planificado con la consultora.

\subsubsection{Análisis y procesamiento de datos.}

Con el total de los cuestionarios en físico se procedió a trasladar las respuestas a un archivo de Excel. Se utilizó una escala nominal para identificar a los encuestados registrándolos según programa de empresas grandes y medianas. También se elaboró un cuadro de consolidación de resultados que comprendía el total de los cuestionarios.

En su mayoría, el análisis estadístico se realizó por cada pregunta. La tabulación de los datos obtenidos para cada una de ellas, permitió construir una distribución de frecuencias, organizando los valores en cada clase. Esta información se presenta en forma tabular y además gráfica en forma de diagrama.

A continuación indicamos los resultados obtenidos en la Encuesta.

\begin{tabular}{|c|c|c|}
\hline & $\begin{array}{c}\mathbf{N}^{\circ} \text { de } \\
\text { empresas }\end{array}$ & Porcentaje \\
\hline Sí & 76.00 & $100 \%$ \\
\hline No & 0.00 & $0 \%$ \\
\hline Total & $\mathbf{7 6 . 0 0}$ & $\mathbf{1 0 0 \%}$ \\
\hline
\end{tabular}

Cuadro 24. Nivel de empresas que producen y comercializan alimentos (Conformado en porcentajes).

Elaboración propia.

1.- ¿Su empresa produce alimentos y/o los comercializa?

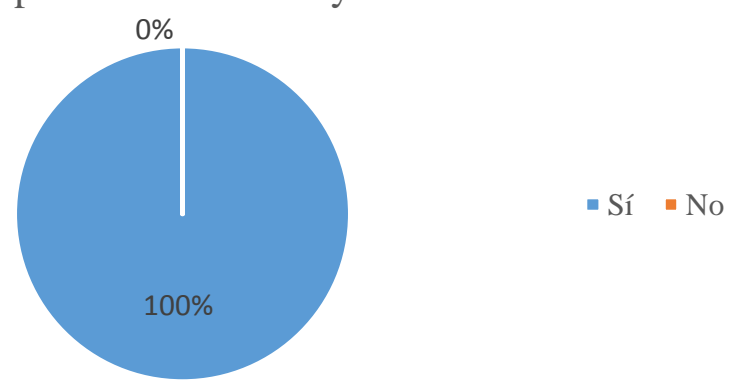

Gráfico 13. Nivel de empresas que producen y comercializan alimentos.

Elaboración propia. 
Como se puede observar en el gráfico el 100\% de empresas de alimento están compuestas por productoras y comercializadoras.

\begin{tabular}{|c|c|c|}
\hline & $\begin{array}{c}\mathbf{N}^{\circ} \text { de } \\
\text { empresas }\end{array}$ & Porcentaje \\
\hline Estaría muy interesado & 27 & $35 \%$ \\
\hline Estaría interesado & 23 & $30 \%$ \\
\hline Indiferente & 11 & $15 \%$ \\
\hline No estaría interesado & 8 & $10 \%$ \\
\hline Para nada estaría interesado & 8 & $10 \%$ \\
\hline Total & 76 & $100 \%$ \\
\hline
\end{tabular}

Cuadro 26. Interés en compra de frutos deshidratados (Conformado en porcentajes). Elaboración propia.

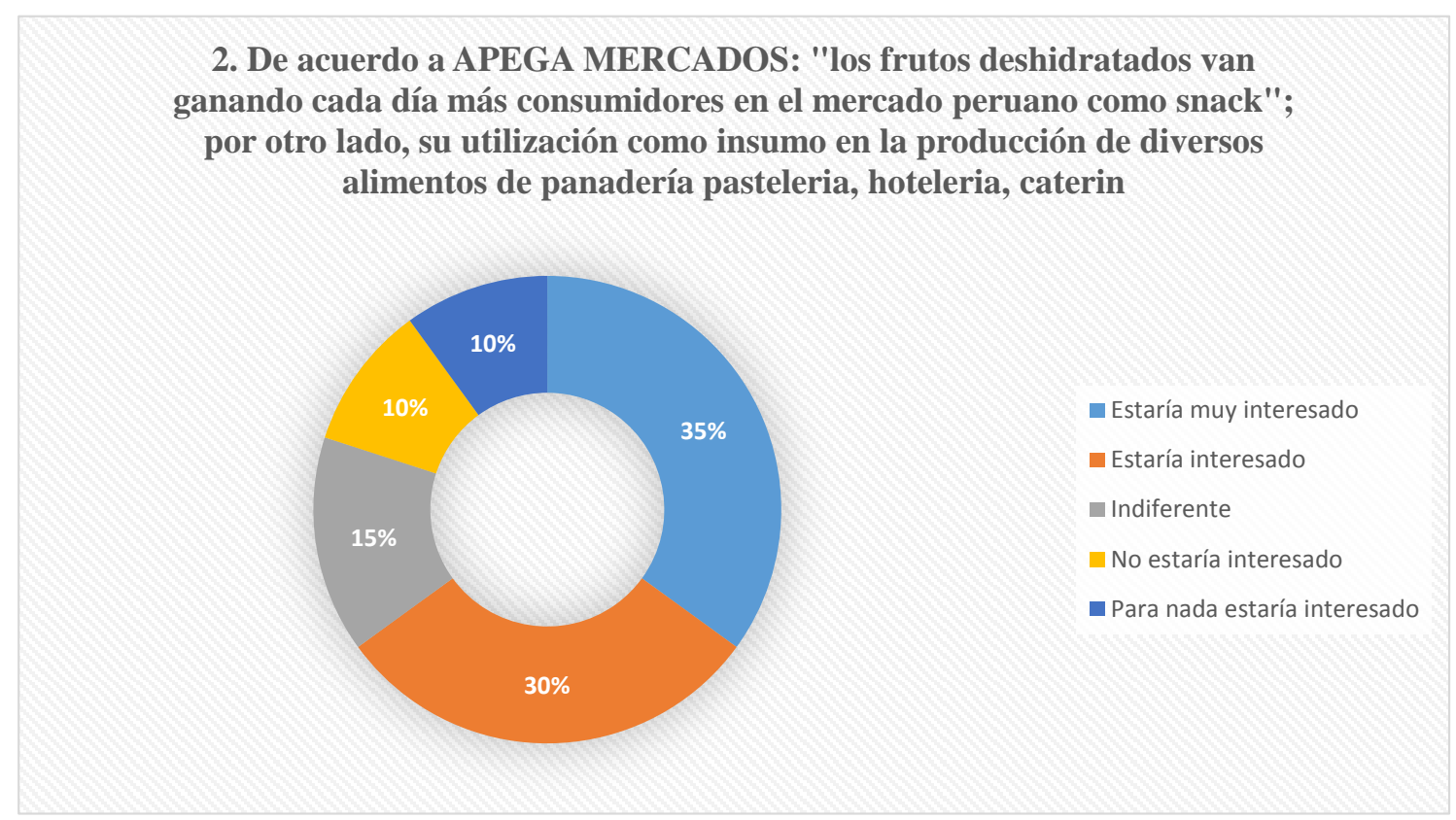

Gráfico 14. Interés en compra de frutos deshidratados.

Elaboración propia. 
Como se puede observar un $35 \%$ de las empresas indicaron que estarían muy interesados y un $30 \%$ estaría interesado. Mientras que un $10 \%$ no estaría interesado y para nada interesado.

\begin{tabular}{|c|c|c|}
\cline { 2 - 3 } \multicolumn{1}{c|}{} & Frecuencia & Porcentaje \\
\hline Arándanos & 39 & $14 \%$ \\
\hline Aguaymanto & 39 & $14 \%$ \\
\hline Manzana & 44 & $16 \%$ \\
\hline Piña & 33 & $12 \%$ \\
\hline Pasas & 56 & $18 \%$ \\
\hline Guindones & 17 & $6 \%$ \\
\hline Mango & 14 & $5 \%$ \\
\hline Durazno & 14 & $5 \%$ \\
\hline Plátano & 14 & $5 \%$ \\
\hline Fresas & 8 & $3 \%$ \\
\hline Total & $\mathbf{2 7 8}$ & $\mathbf{1 0 0 \%}$ \\
\hline
\end{tabular}

Cuadro 27. Nivel de conocimiento de las empresas productoras y comercializadora de alimentos sobre tipo de fruta deshidratada. (Conformado en porcentajes). Elaboración propia.

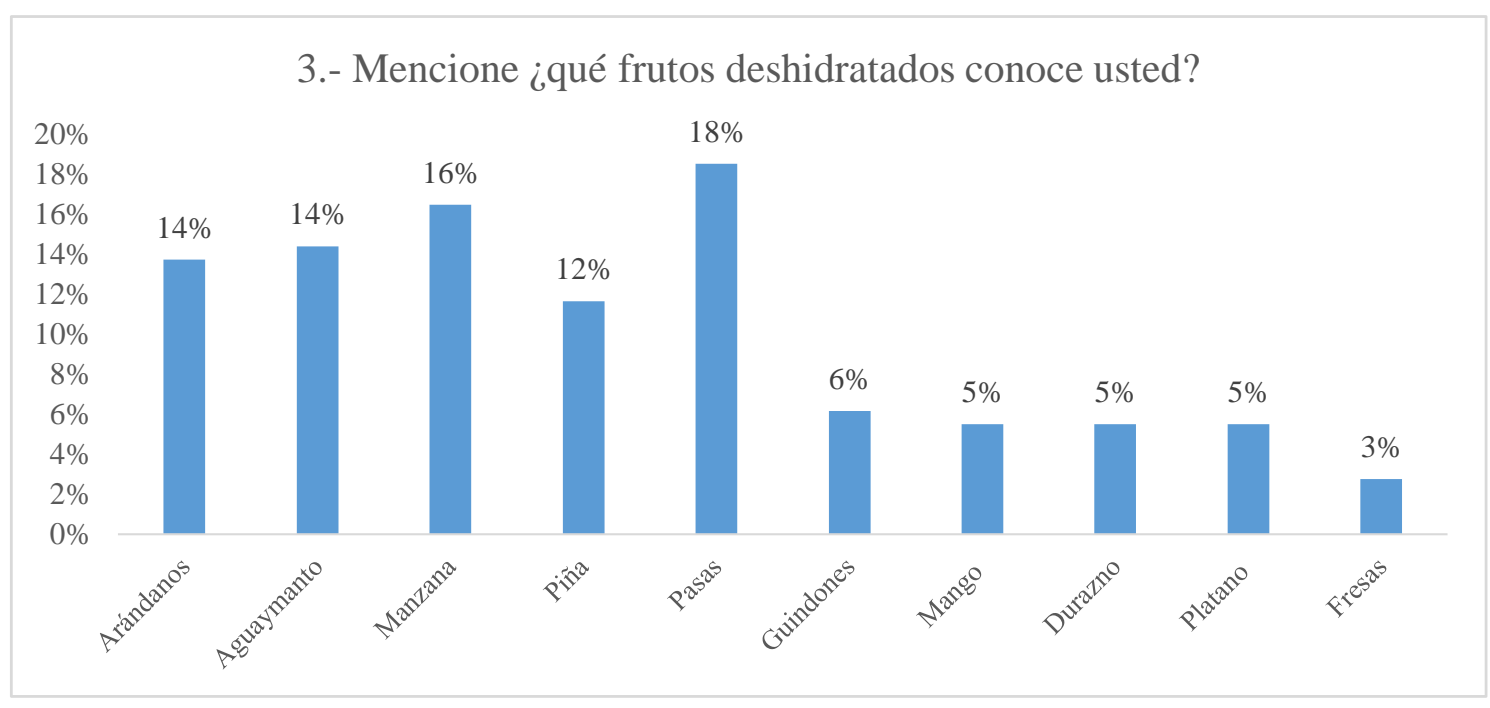

Gráfico 15. Nivel de conocimiento de las empresas productoras y comercializadora de alimentos sobre tipo de fruta deshidratada.

Elaboración propia. 
De acuerdo al gráfico mostrado los frutos de mayor conocimiento por parte de las empresas productoras y comercializadoras de alimentos son las pasas con un $18 \%$ y la manzana con un 16\%; seguida por los arándanos y aguaymanto con un 14\%; finalmente la piña con un $12 \%$.

\begin{tabular}{|c|c|c|}
\cline { 2 - 3 } \multicolumn{1}{c|}{} & $\mathbf{N}^{\circ}$ de empresas & Porcentaje \\
\hline Ferias sectoriales & 25 & $33 \%$ \\
\hline Publicidad en revistas especializadas & 11 & $14 \%$ \\
\hline Facebook & 4 & $5 \%$ \\
\hline Visitas comerciales & 8 & $10 \%$ \\
\hline E-mailing & 21 & $28 \%$ \\
\hline Folletos y dípticos & 8 & $10 \%$ \\
\hline Total & $\mathbf{7 6}$ & $\mathbf{1 0 0 \%}$ \\
\hline
\end{tabular}

Cuadro 28. Medios de información de preferencia sobre fruta deshidratada. (Conformado en porcentajes).

Fuente: Elaboración propia.

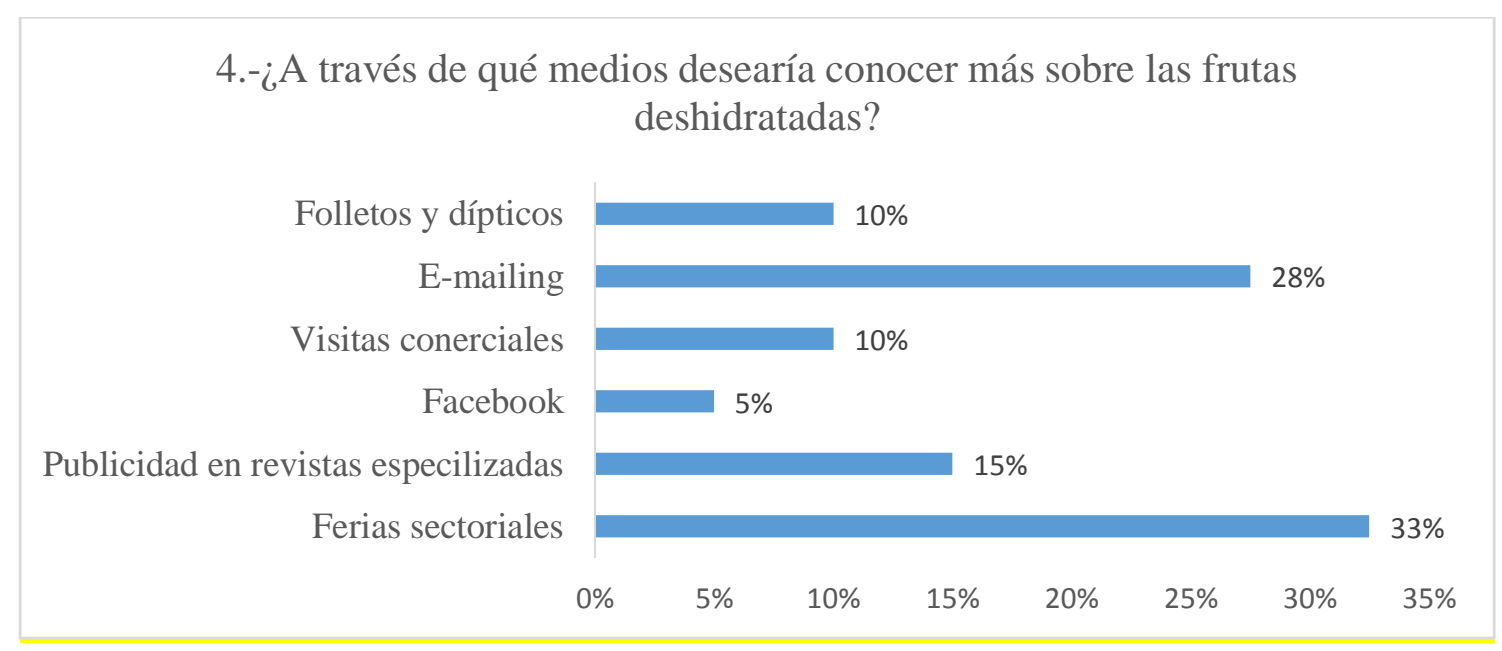

Gráfico 16. Medios de información de preferencia sobre fruta deshidratada. Elaboración propia. 
Como se puede observar en cuanto a preferencias de información, un 33\% de las empresas indicaron que estarían interesadas en usar el medio de las Ferias especializadas y con un $14 \%$ a través del E-Mailing. Mientras que un $10 \%$ preferiría Folletos y visitas comerciales.

\begin{tabular}{|c|c|c|}
\hline & $\begin{array}{l}\text { Número de } \\
\text { empresas }\end{array}$ & Porcentaje \\
\hline Sí & 14 & $18 \%$ \\
\hline No & 62 & $82 \%$ \\
\hline Total & 76 & $100 \%$ \\
\hline
\end{tabular}

Cuadro 29. Nivel de empresas que utiliza la fruta deshidratada para elaboración de productos. (Conformado en porcentajes).

Elaboración propia.

5.- ¿Su empresa compra alguna fruta deshidratada como insumo o ingrediente para la elaboración de sus productos?

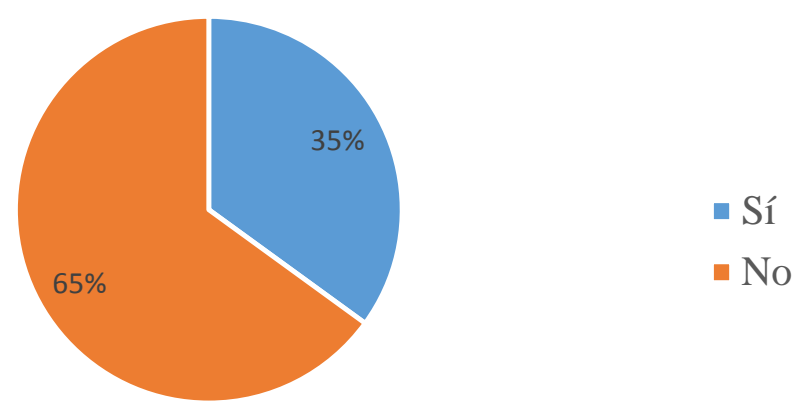

Gráfico 17. Nivel de empresas que utiliza la fruta deshidratada para elaboración de productos.

Elaboración propia.

De acuerdo a la información mostrada por el gráfico un 35\% de los encuestados compra fruta deshidratada como insumo o ingrediente para la elaboración de sus productos. 


\begin{tabular}{|l|c|c|}
\cline { 2 - 3 } \multicolumn{1}{c|}{} & $\begin{array}{c}\text { Número de } \\
\text { empresas }\end{array}$ & Porcentaje \\
\hline Muy interesado & 6 & $43 \%$ \\
\hline Interesado & 3 & $21 \%$ \\
\hline Indiferente & 3 & $21 \%$ \\
\hline No interesado & 2 & $14 \%$ \\
\hline Para nada interesado & 0 & $0 \%$ \\
\hline Total & $\mathbf{1 4}$ & $\mathbf{1 0 0 \%}$ \\
\hline
\end{tabular}

Cuadro 30. Interés de compra de fruta deshidratada de arándanos, piña manzana por parte de las empresas productoras de alimentos. (Conformado en porcentajes).

Fuente: Elaboración propia.

\section{6.- ¿Estaría usted interesado en comprar fruta deshidratada} como arandanos, manzana y piña para utilizarlo como insumo o ingrediente en la elaboración se sus productos?

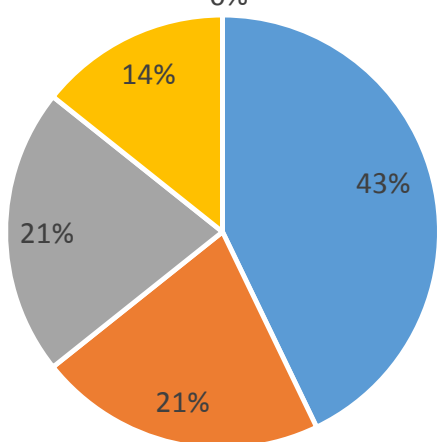

$\square$ Muy interesado $\square$ Interesado $\square$ Indiferente $\square$ No interesado $\square$ Para nada interesado

Gráfico 18. Interés de compra de fruta deshidratada de arándanos, piña manzana por parte de las empresas productoras de alimentos

Fuente: Elaboración propia.

De acuerdo al gráfico presentado únicamente el $43 \%$ del 18\% de empresas estaría muy interesado en comprar arándanos, manzana y piña deshidratada como insumo. 


\begin{tabular}{|c|c|c|}
\cline { 2 - 3 } \multicolumn{1}{c|}{} & Frecuencia & Porcentaje \\
\hline Arándanos & 5 & $25 \%$ \\
\hline Aguaymanto & 1 & $5 \%$ \\
\hline Manzana & 3 & $15 \%$ \\
\hline Piña & 3 & $15 \%$ \\
\hline Pasas & 5 & $25 \%$ \\
\hline Guindones & 1 & $5 \%$ \\
\hline Mango & 0 & $0 \%$ \\
\hline Durazno & 0 & $0 \%$ \\
\hline Plátano & 2 & $10 \%$ \\
\hline Fresas & 0 & $0 \%$ \\
\hline Total & $\mathbf{2 0}$ & $\mathbf{1 0 0 \%}$ \\
\hline
\end{tabular}

Cuadro 31. Tipo o variedad de fruta deshidratada que compran las empresas productoras de alimentos. (Conformado en porcentajes).

Fuente: Elaboración propia.

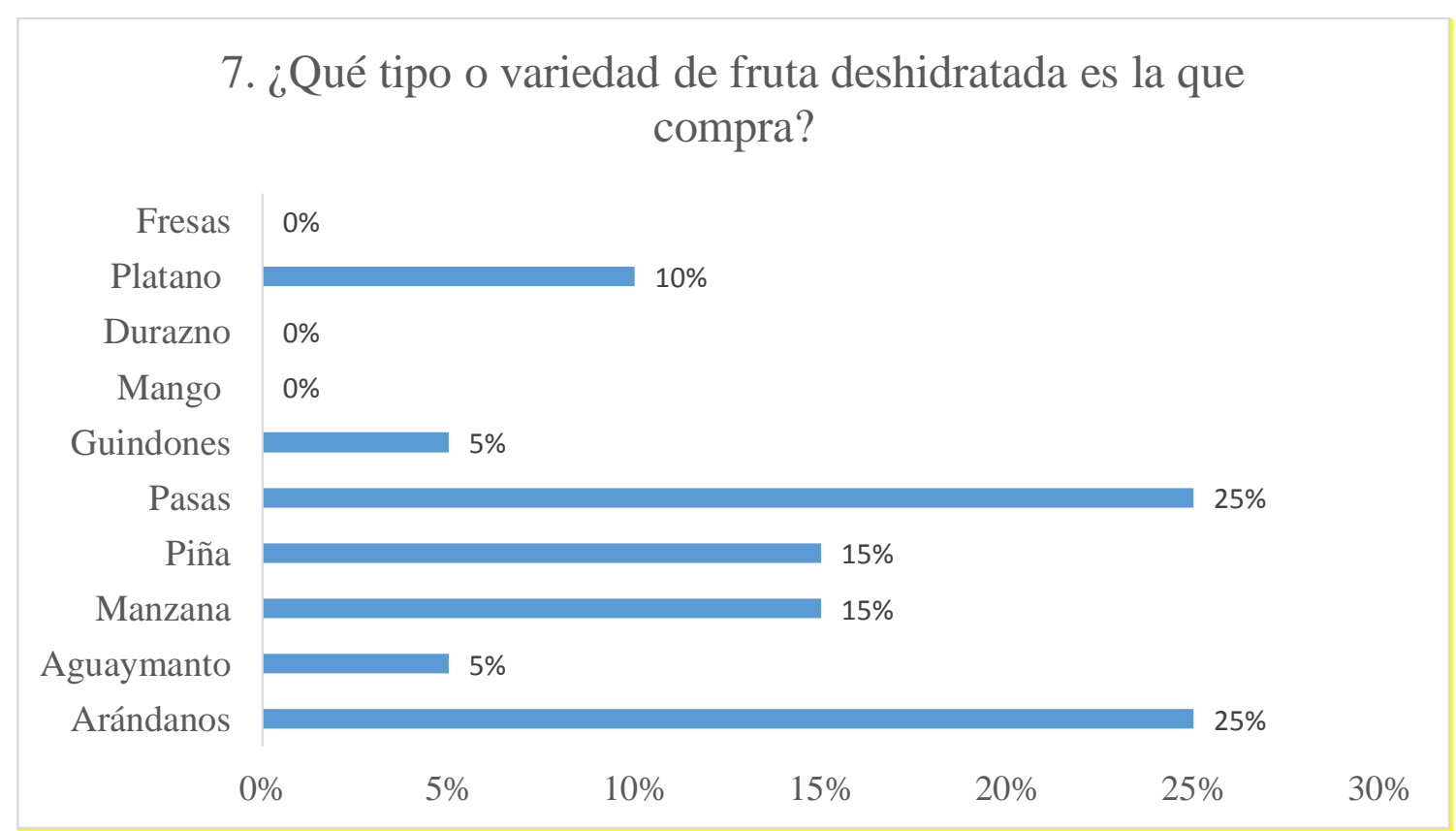

Gráfico 19. Tipo o variedad de fruta deshidratada que compran las empresas productoras de alimentos.

Fuente: Elaboración propia. 
Del total de las seis empresas un $25 \%$ indica que las frutas deshidratadas que más compran son las pasas y los arándanos; de igual manera un $15 \%$ indica que su consumo se da en manzanas y piñas,

\begin{tabular}{|c|c|c|}
\cline { 2 - 3 } \multicolumn{1}{c|}{} & $\begin{array}{c}\text { Número de } \\
\text { empresas }\end{array}$ & Porcentaje \\
\hline Muy importante & 6 & $100 \%$ \\
\hline Importante & 0 & $0 \%$ \\
\hline Ni importante ni poco \\
importante & 0 & $0 \%$ \\
\hline Poco importante & 0 & $0 \%$ \\
\hline Nada importante & 0 & $0 \%$ \\
\hline Total & $\mathbf{6}$ & $\mathbf{1 0 0 \%}$ \\
\hline
\end{tabular}

Cuadro 32. Importancia asignada a la compra de frutas deshidratadas (Conformado en porcentajes)

Elaboración propia.

8 Q Qué tan importante considera usted la compra de frutos deshidratados de arándanos, piña y manzana para la elaboración de sus productos?

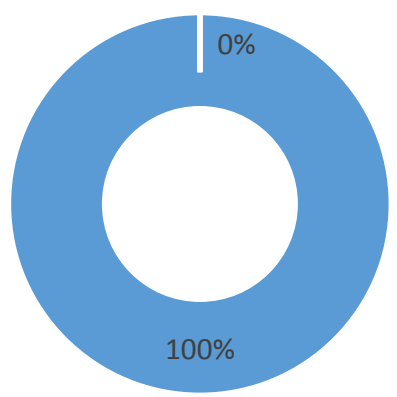

- Muy importante

- Importante

- Ni importante ni poco importante

- Poco importante

- Nada importante

Gráfico 20. Nivel de importancia del uso de los frutos deshidratados en la elaboración de productos.

Elaboración propia.

De las seis empresas interesadas el 100\% de empresas indicó que es muy importante la compra de fruta deshidrata para el uso industrial como insumo en sus productos. 
Arándanos Manzana Piña

\begin{tabular}{|l|c|c|c|}
\hline Incasur S.A. & 1000 & 488 & 100 \\
\hline Molitalia S.A. & 3000 & 1561 & 500 \\
\hline $\begin{array}{l}\text { Compañía nacional de chocolates del Perú } \\
\text { S.A. }\end{array}$ & 667 & 0 & 0 \\
\hline Global alimentos S.A.C. & 333 & 390 & 0 \\
\hline F\&D inversiones S.A.C. & 0 & 195 & 150 \\
\hline Alicorp S.A.A & 1667 & 1533 & 500 \\
\hline Total & $\mathbf{6 6 6 7}$ & $\mathbf{4 1 6 7}$ & $\mathbf{1 2 5 0}$ \\
\hline
\end{tabular}

Cuadro 33. Volumen en kilos de compra de fruta deshidratada de arándanos, piña y manzana por parte de las empresas productoras de alimentos. (Conformado en kilos) Elaboración propia.

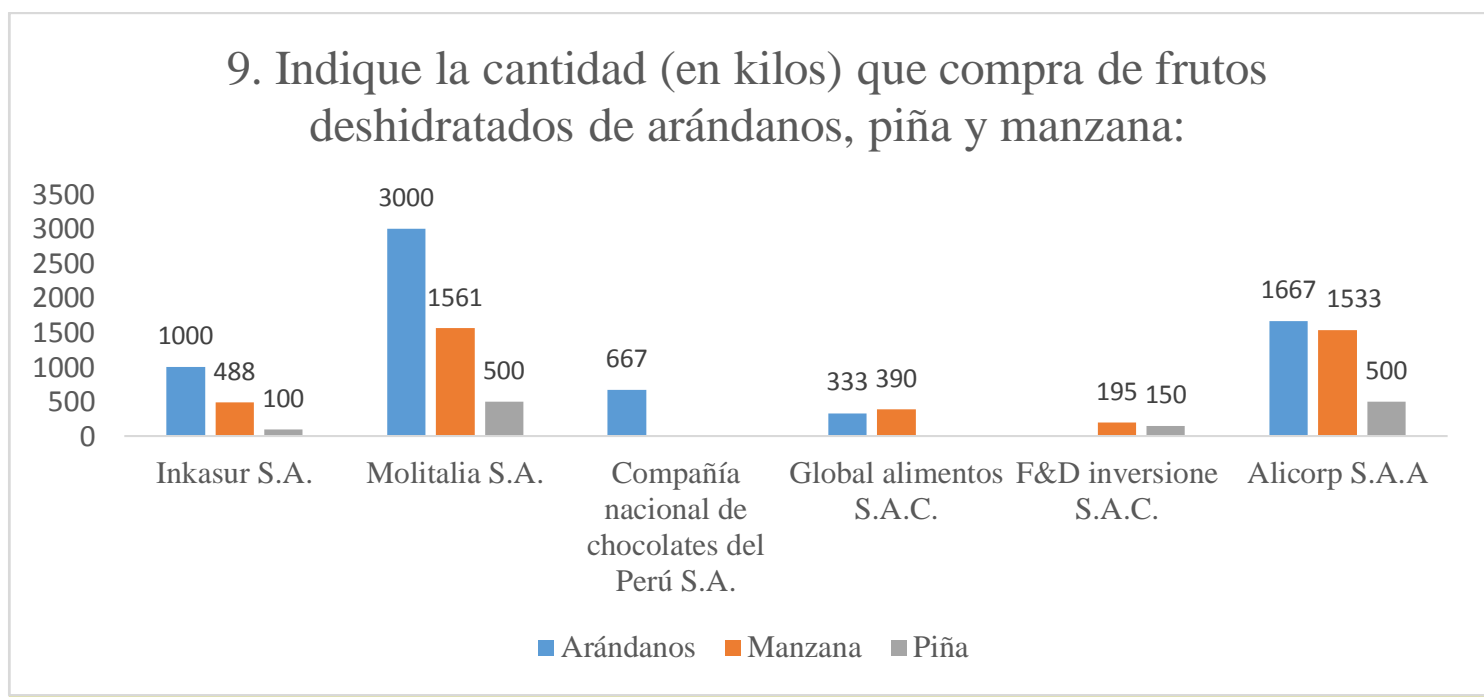

Gráfico 21. Volumen en kilos de compra de fruta deshidratada de arándanos, piña y manzana por parte de las empresas productoras de alimentos.

Elaboración propia.

De las seis empresas interesadas el 100\% de empresas indicó que es muy importante la compra de fruta deshidrata para el uso industrial como insumo en sus productos. 
Arándanos Manzana Piña

\begin{tabular}{|c|c|c|c|}
\hline Incasur S.A. & 3000 & 1000 & 300 \\
\hline Molitalia S.A. & 9000 & 5000 & 1400 \\
\hline Compañía nacional de chocolates del Perú & & & \\
\hline S.A. & 2000 & 0 & 0 \\
\hline Global alimentos S.A.C. & 1000 & 1000 & 0 \\
\hline F\&D inversiones S.A.C. & 0 & 1500 & 450 \\
\hline Alicorp S.A.A & 5000 & 4000 & 1600 \\
\hline Total & 20000 & 12500 & 3750 \\
\hline
\end{tabular}

Cuadro 33. Volumen en kilos de compra de fruta deshidratada de arándanos, piña y manzana por parte de las empresas productoras de alimentos. (Conformado en kilos) Elaboración propia.

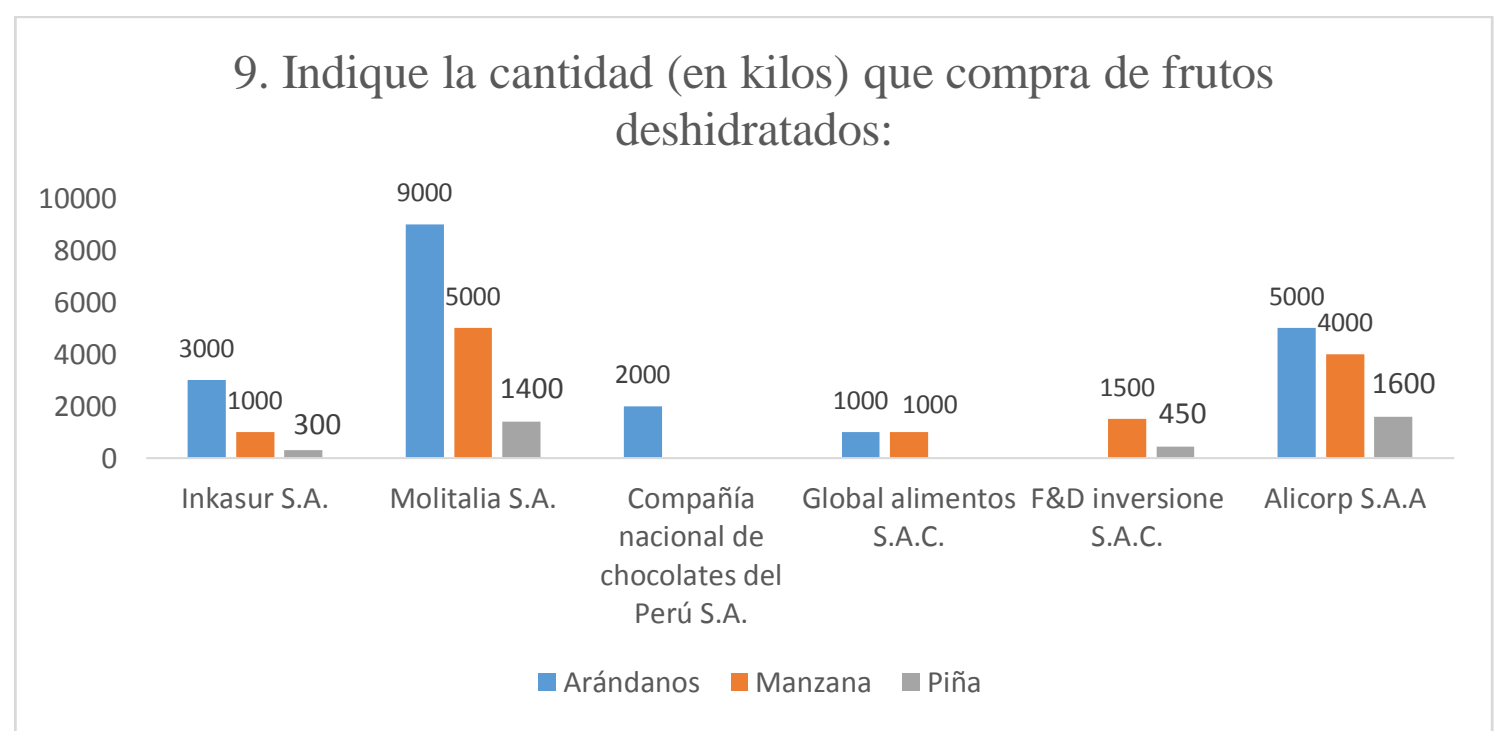

Gráfico 22. Volumen en kilos de compra de fruta deshidratada de arándanos, piña y manzana por parte de las empresas productoras de alimentos.

Elaboración propia.

A continuación se muestran a las empresas que estarían interesadas en comprar frutas deshidratadas y los kilos que compran por tipo de fruto. Como puede observarse el consumo de arándanos y manzanas son los más elevados. 


\begin{tabular}{|l|c|c|c|}
\cline { 2 - 4 } \multicolumn{1}{l|}{} & Arándanos & Manzanas & Piña \\
\hline Quincenal & 0 & 0 & 0 \\
\hline Mensual & 0 & 0 & 0 \\
\hline Bimestral & 0 & 0 & 0 \\
\hline Trimestral & 5 & 5 & 3 \\
\hline Semestral & 0 & 0 & 0 \\
\hline Total & $\mathbf{5}$ & $\mathbf{5}$ & $\mathbf{3}$ \\
\hline
\end{tabular}

Cuadro 34. Frecuencia de compra de fruta deshidratada de arándanos, piña y manzana por parte de las empresas productoras de alimentos. (Conformado en frecuencia). Elaboración propia.

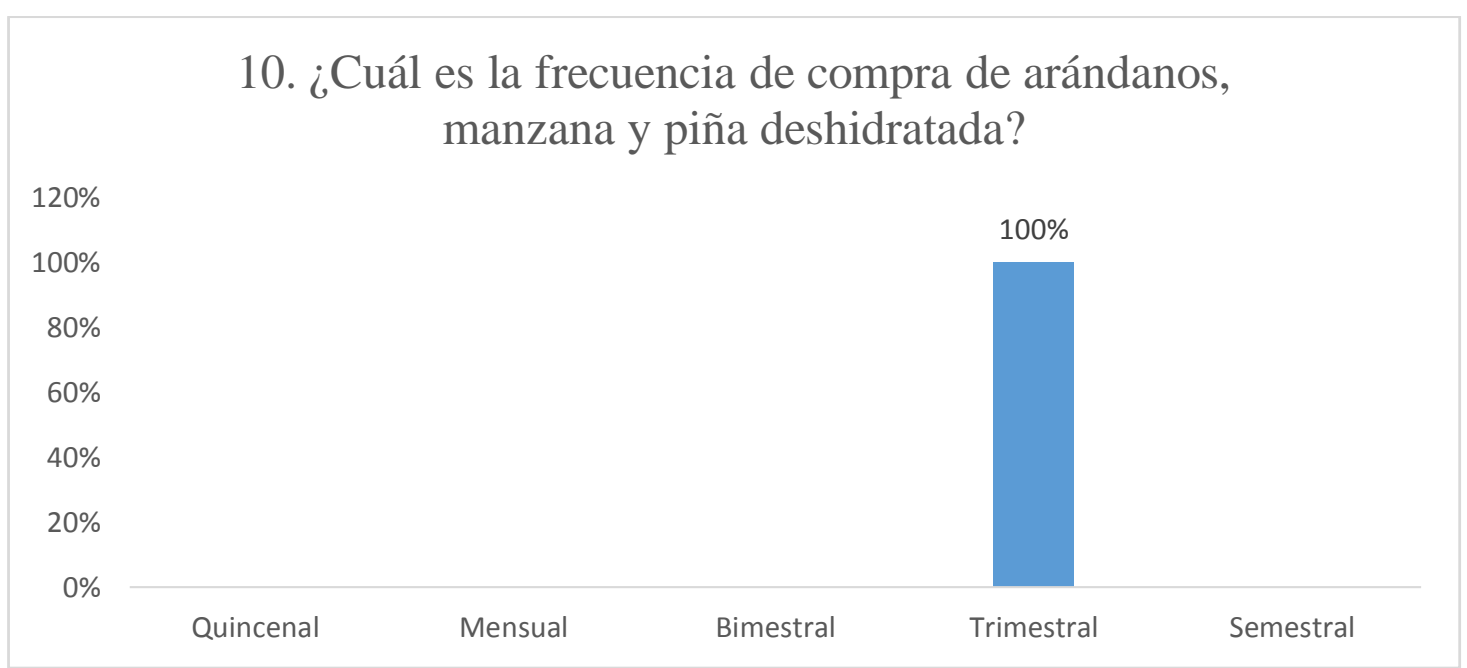

Gráfico 23. Frecuencia de compra de fruta deshidratada de arándanos, piña y manzana por parte de las empresas productoras de alimentos.

Elaboración propia.

El 100\% de empresas indicó que su frecuencia de compra es trimestral. 
11. ¿En qué tipos de productos utilza como insumo o ingrediente las frutas deshidratadas de arándanos, piña y manzana?

$$
\begin{array}{r}
35 \% \\
30 \% \\
25 \% \\
20 \% \\
15 \% \\
10 \% \\
5 \% \\
0 \%
\end{array}
$$$$
25 \%
$$$$
15 \%
$$$$
5 \%
$$
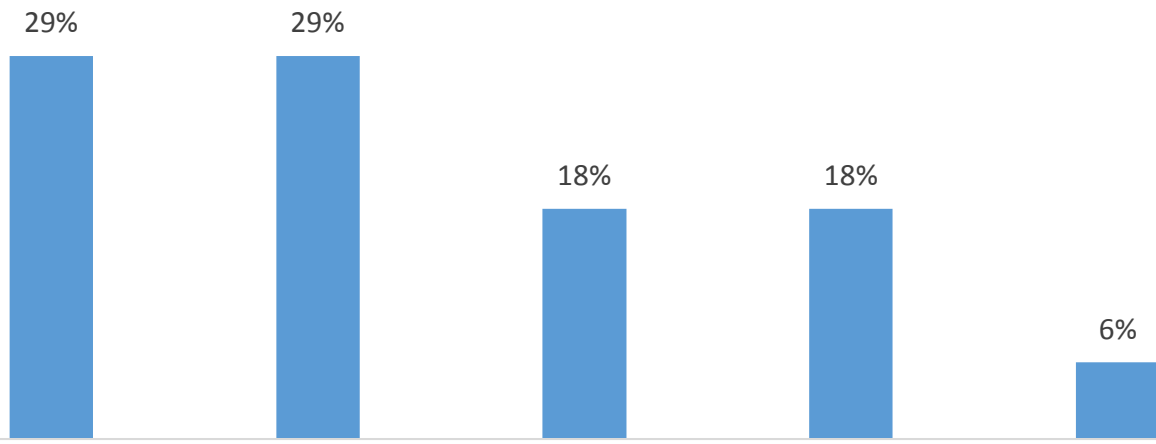

Galleta

Barra

Cereal

Granola

Exportación

Gráfico 24. Tipos de productos en los que se utiliza como ingrediente la fruta deshidratada de arándanos, piña y manzana.

Elaboración propia.

De las 6 empresas interesadas un $29 \%$ de veces mencionaros que la fruta deshidratada es usada en galletas y barras. Asimismo un $18 \%$ menciono a las granolas y cereales.

\section{Número de empresas Porcentaje}

\begin{tabular}{|c|c|c|}
\hline Definitivamente se incrementarán & 6 & $100 \%$ \\
\hline Probablemente se incrementarán & 0 & $0 \%$ \\
\hline Se mantendrán estables & 0 & $0 \%$ \\
\hline Probablemente se reducirán & 0 & $0 \%$ \\
\hline Definitivamente se reducirán & 0 & $0 \%$ \\
\hline Total & $\mathbf{6}$ & $\mathbf{1 0 0 \%}$ \\
\hline
\end{tabular}

Cuadro 36. Expectativas de crecimiento de la demanda de frutas deshidratadas de arándanos, piña y manzana por parte de las empresas productoras de alimentos. (Conformado en porcentajes).

Elaboración propia. 


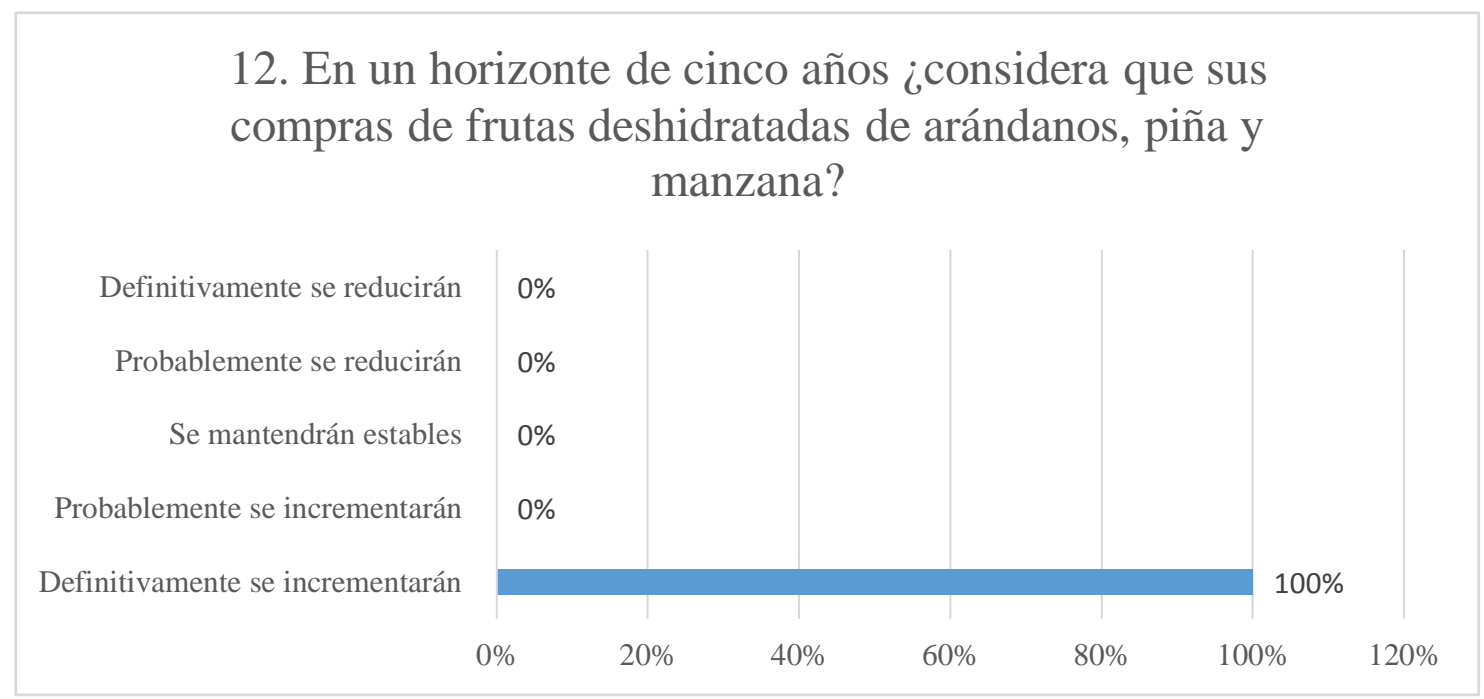

Gráfico 25. Expectativas de crecimiento de la demanda de frutas deshidratadas de arándanos, piña y manzana por parte de las empresas productoras de alimentos. Elaboración propia.

Como se puede observar en el siguiente gráfico las expectativas de crecimiento son unánimes con un $100 \%$.

\begin{tabular}{|c|c|}
\cline { 2 - 2 } \multicolumn{1}{c|}{} & Porcentaje \\
\hline INCASUR S.A. & $10 \%$ \\
\hline MOLITALIA S.A. & $12 \%$ \\
\hline PLER S.A. & $10 \%$ \\
\hline F\&D INVERSIONES S.A.C. & $12 \%$ \\
\hline ALICORP S.A.A & $8 \%$ \\
\hline
\end{tabular}

Cuadro 37. Expectativas de crecimiento de la demanda de frutas deshidratadas de arándanos, piña y manzana por parte de las empresas productoras de alimentos. (Conformado en porcentaje).

Elaboración propia. 


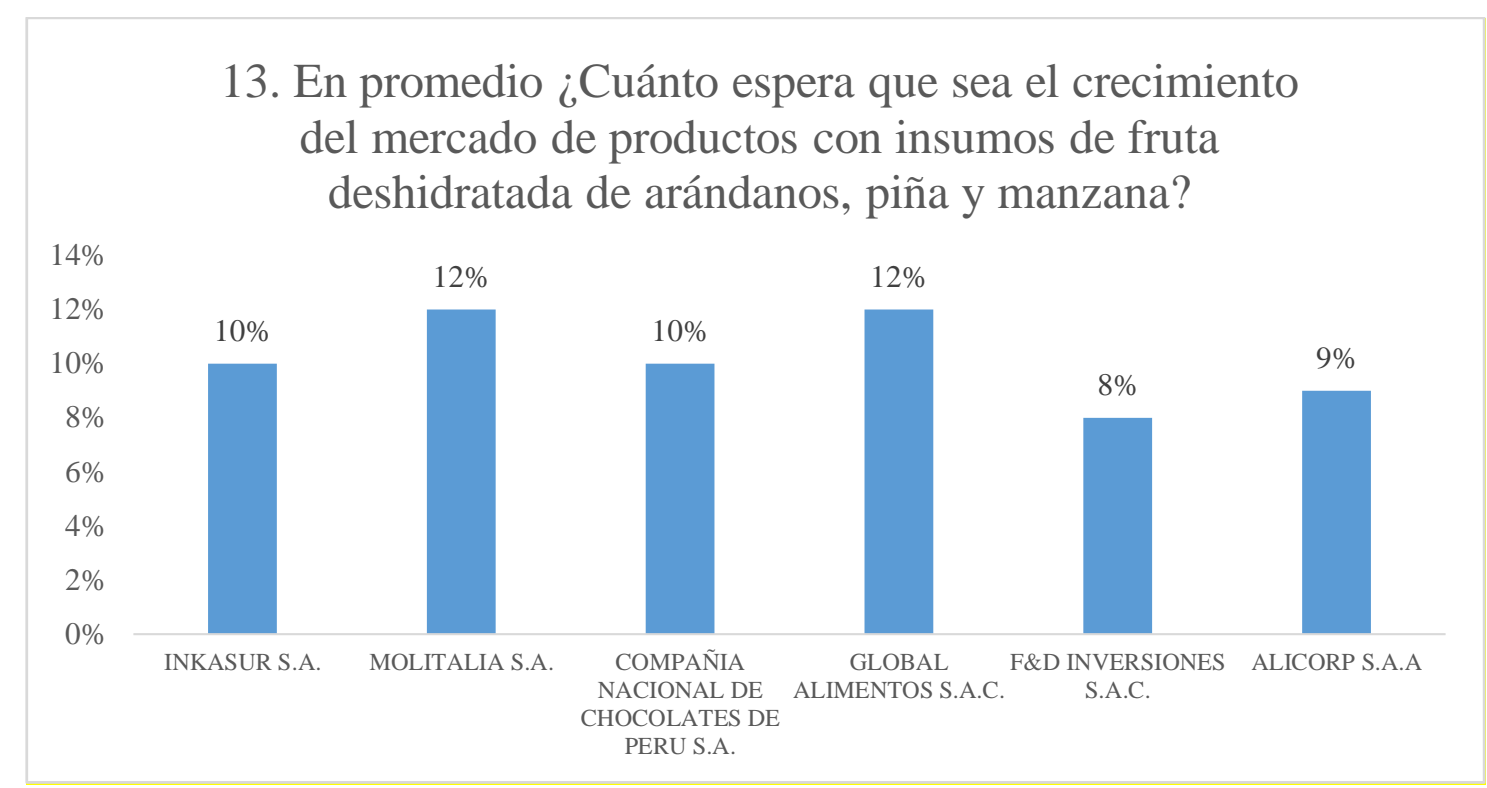

Gráfico 26. Expectativas de crecimiento de la demanda de frutas deshidratadas de arándanos, piña y manzana por parte de las empresas productoras de alimentos. Fuente: Elaboración propia.

De acuerdo a las empresas mencionadas estas indicaron que en promedio la expectativa de crecimiento del mercado de productos con insumos de fruta deshidratada tendrá en promedio un $10 \%$.

\begin{tabular}{|l|c|c|}
\cline { 2 - 3 } \multicolumn{1}{c|}{} & Frecuencia & Porcentaje \\
\hline TERRAFERTIL PERU S.A.C & 6 & $22 \%$ \\
\hline FRUTOS Y ESPECIAS S.A.C. & 5 & $19 \%$ \\
\hline PERUVIAN NATURE S\&S SAC & 3 & $11 \%$ \\
\hline VITALLANOS SAC & 2 & $7 \%$ \\
\hline FRUTAS E INDUSTRIAS SAC & 5 & $19 \%$ \\
\hline NARVID EIRL & 3 & $11 \%$ \\
\hline OXIQUIM Total & 3 & $11 \%$ \\
\hline \multicolumn{1}{|c|}{} & $\mathbf{2 7}$ & $\mathbf{1 0 0 \%}$ \\
\hline
\end{tabular}

Cuadro 38. Proveedores de frutas deshidratadas de arándanos, piña y manzana de las empresas productoras de alimentos. (Conformado en frecuencia). Elaboración propia. 


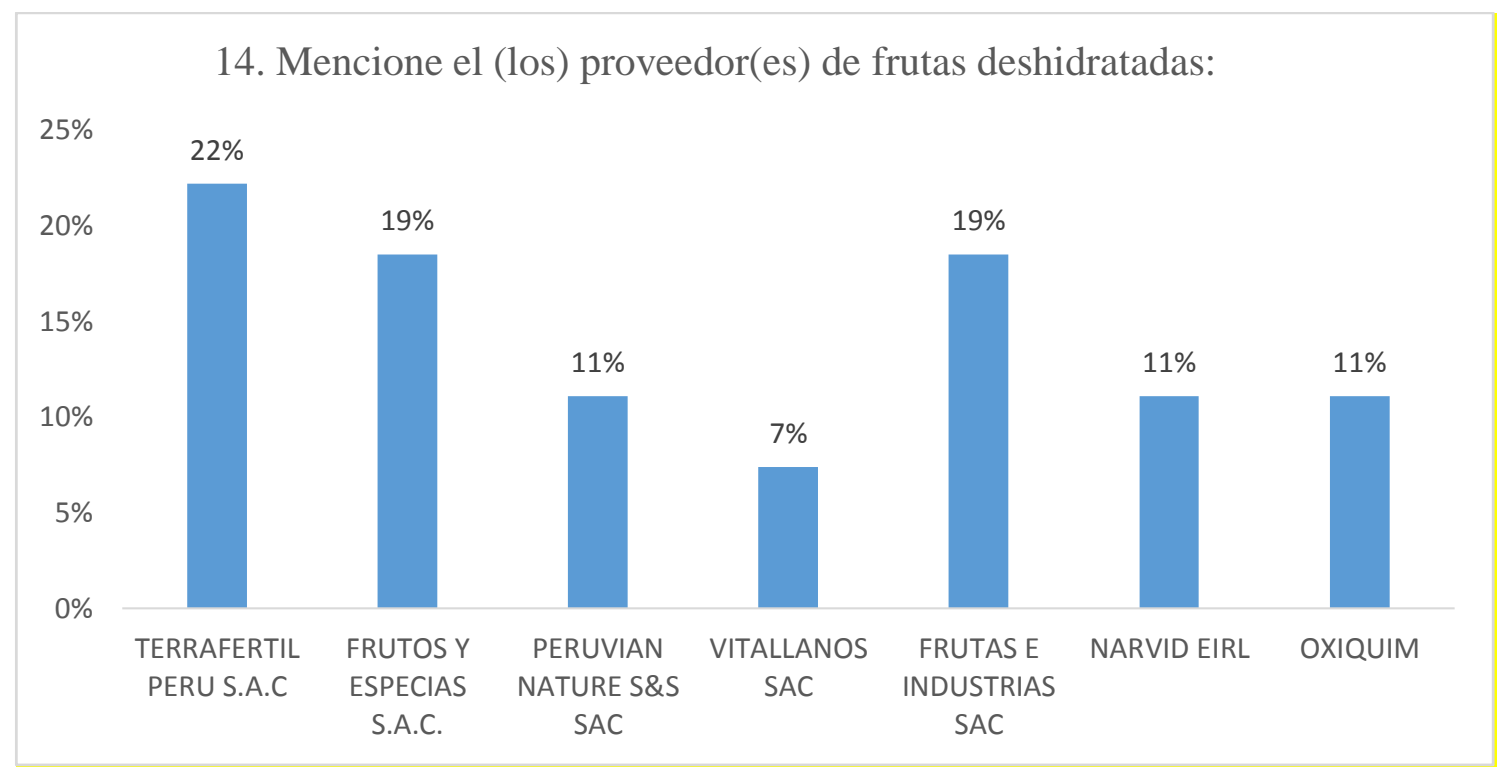

Gráfico 27. Proveedores de frutas deshidratadas de arándanos, piña y manzana de las empresas productoras de alimentos.

Elaboración propia.

Al consultárseles a las seis empresas para que puedan indicar los nombres de los competidores, estás mencionaron a Terrafertil Perú S.A.C, Frutos y especias S.A.C., Peruvian Nature S\&S S.A.C, Vitallanos S.A.C, Frutas e Industrias S.A.C, Narvid EIRL y Oxiquim

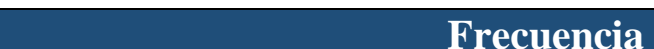

Certificado

Condiciones de calidad Tiempo Especificación Precio

de crédito e inocuidad de entrega del producto

\begin{tabular}{|c|c|c|c|c|c|}
\hline Muy importante & 0 & 1 & 0 & 6 & 0 \\
\hline Importante & 0 & 0 & 5 & 0 & 0 \\
\hline $\begin{array}{c}\text { Ni importante ni poco } \\
\text { importante }\end{array}$ & 2 & 5 & 0 & 0 & 5 \\
\hline Poco importante & 0 & 0 & 0 & 0 & 1 \\
\hline Nada importante & 1 & 0 & 1 & 0 & 0 \\
\hline Total & $\mathbf{3}$ & $\mathbf{6}$ & $\mathbf{6}$ & $\mathbf{6}$ & $\mathbf{6}$ \\
\hline
\end{tabular}

Cuadro 39. Criterios de selección de proveedores de fruta deshidratada de arándanos, piña y manzana de las empresas productoras de alimentos. (Conformado en frecuencia) Elaboración propia. 


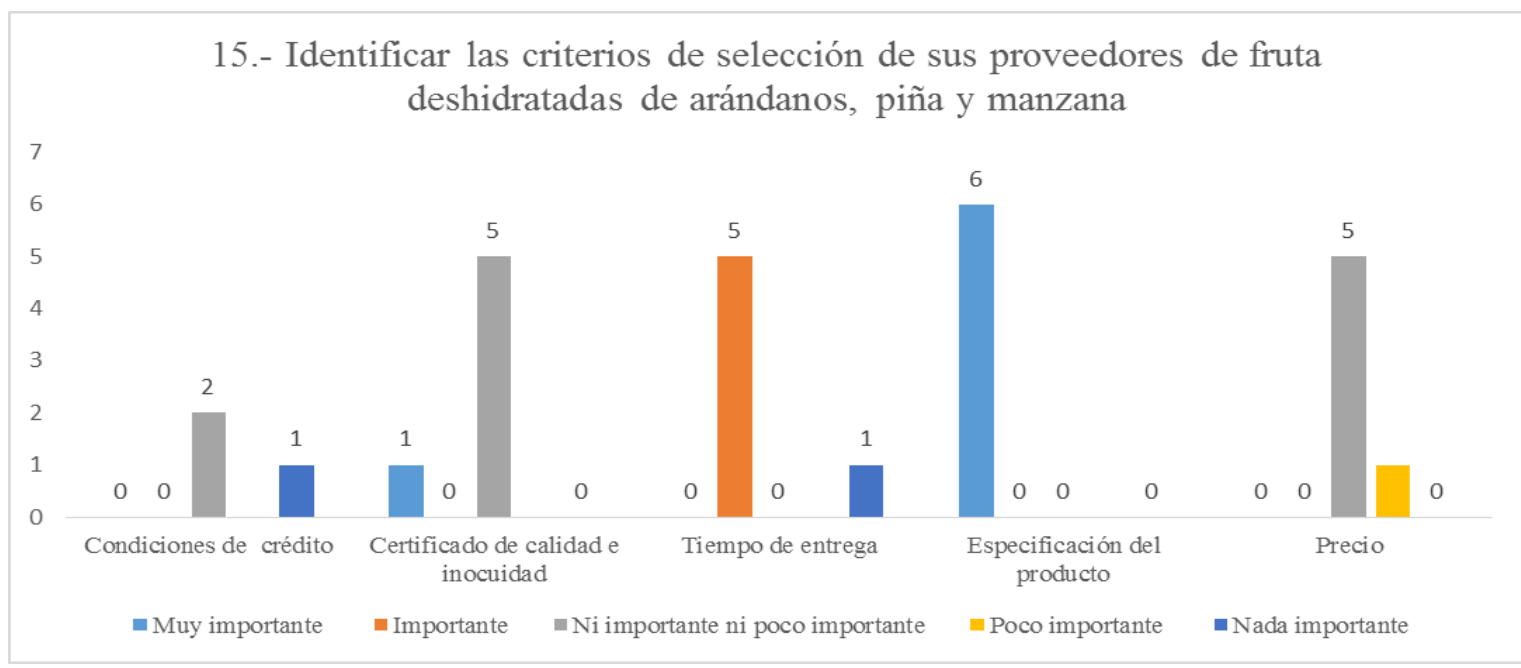

Gráfico 28. Criterios de selección de proveedores de fruta deshidratada de arándanos, piña y manzana de las empresas productoras de alimentos.

Elaboración propia.

Elaboración propia.

Las seis empresas consultadas mencionaron que el criterio más importante a la hora de elegir a un proveedor es el de especificación del producto y el de menor importancia el precio.

\begin{tabular}{|c|c|c|c|}
\cline { 2 - 4 } \multicolumn{1}{c|}{} & \multicolumn{3}{c|}{ Frecuencia } \\
\cline { 2 - 4 } \multicolumn{1}{c|}{} & $\mathbf{1}$ & $\mathbf{2}$ & $\mathbf{3}$ \\
\hline Calidad & 6 & & \\
\hline Abastecimiento & & 6 & 6 \\
\hline Precio & & & $\mathbf{6}$ \\
\hline Total & $\mathbf{6}$ & $\mathbf{6}$ & \\
\hline
\end{tabular}

Cuadro 40. Debilidades de los proveedores de fruta deshidratada de arándanos, piña y manzana (Conformado en frecuencia)

Elaboración propia. 


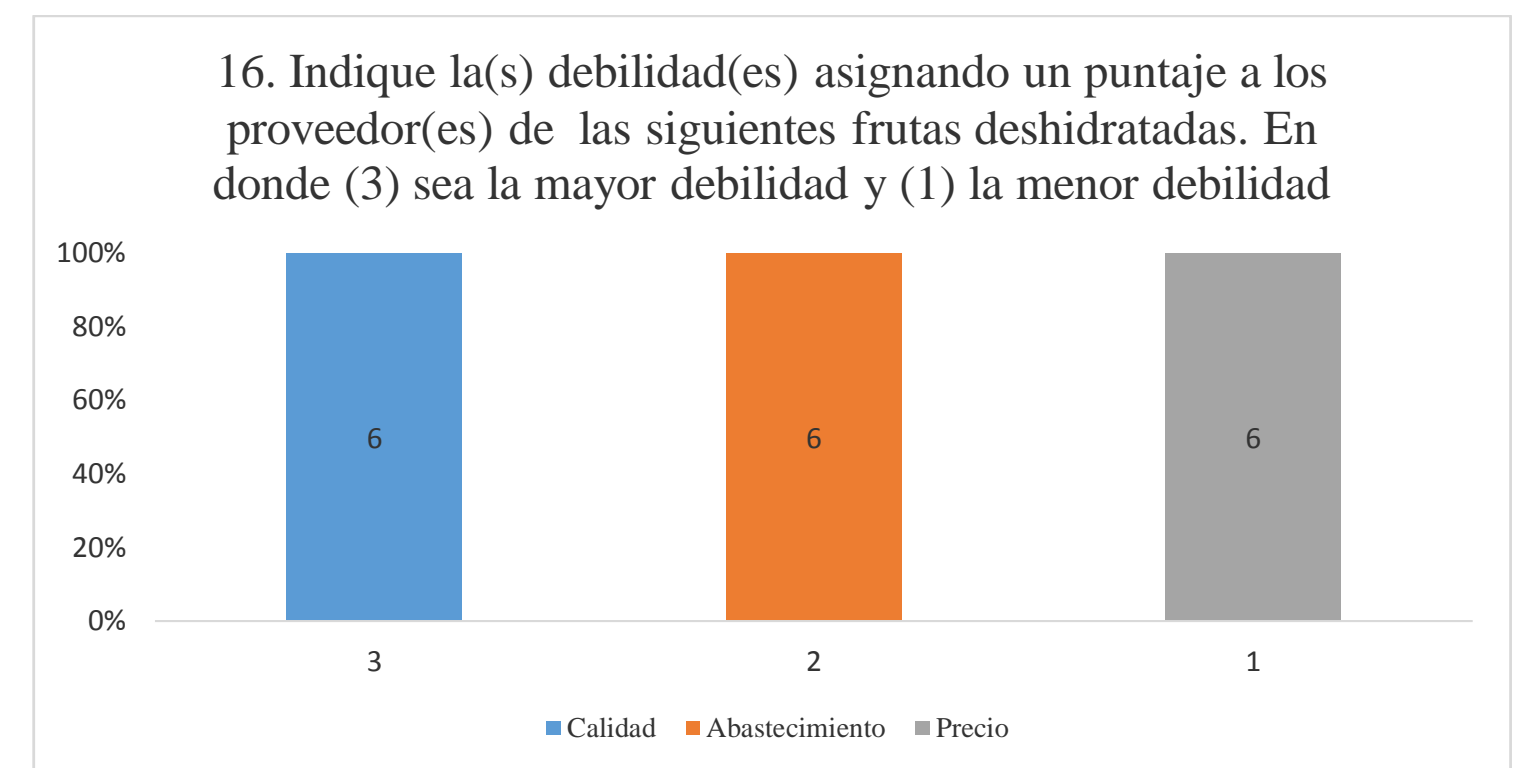

Gráfico 29. Debilidades de los proveedores de fruta deshidratada de arándanos, piña y manzana.

Fuente: Elaboración propia.

La mayor debilidad de los proveedores de acuerdo al estudio realizado a las empresas consumidoras de fruta deshidratada es en primer lugar la calidad y en último lugar el precio.

\begin{tabular}{|c|c|c|c|}
\hline Rango de precios & Arándanos & Manzana & Piña \\
\hline S/.35 - S/.40 & 2 & & \\
\hline S/.41 - S/.45 & 3 & 1 & 2 \\
\hline S/.46-S/.50 & & 3 & 1 \\
\hline S/.51-S/.55 & & 1 & \\
\hline S/.56-S/.60 & & & $\mathbf{3}$ \\
\hline Total & $\mathbf{5}$ & $\mathbf{5}$ & \\
\hline
\end{tabular}

Cuadro 41. Precio por kilo de la fruta deshidratada de arándanos, piña y manzana al que compran las empresas productoras de alimentos (Conformado en frecuencia). Elaboración propia. 
17. ¿Cuál es el precio promedio que usted paga por un kilo de la siguiente frutra deshidratada?

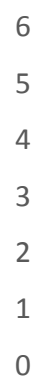

0

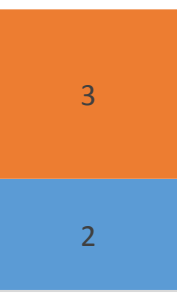

Arándanos

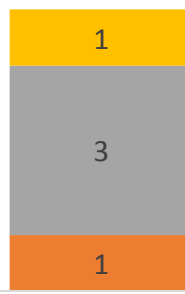

Manzana
Piña

$\square \mathrm{S} / .35-\mathrm{S} / .40 \square \mathrm{S} / .41-\mathrm{S} / .45 \square \mathrm{S} / .46-\mathrm{S} / .50 \square \mathrm{S} / .51-\mathrm{S} / .55 \square \mathrm{S} / .56-\mathrm{S} / .60$

Gráfico 30. Precio por kilo de la fruta deshidratada de arándanos, piña y manzana al que compran las empresas productoras de alimentos.

Elaboración propia.

Tres empresas mencionaron que el precio promedio de los arándanos es el de 35 a 40 nuevos soles, el de manzanas de 46 a 50 nuevos soles y finalmente dos empresas mencionaron que precio promedio de la piña era de 46 a 50 nuevos soles.

\begin{tabular}{|c|c|c|c|c|c|}
\cline { 2 - 6 } \multicolumn{2}{c|}{} & \multicolumn{6}{c|}{ Frecuencia } \\
\cline { 2 - 6 } & $\mathbf{1}$ & $\mathbf{2}$ & $\mathbf{3}$ & $\mathbf{4}$ & $\mathbf{5}$ \\
\hline Calibre & & & 5 & & 6 \\
\hline Libre de materia extraña visible & & & 2 & & \\
\hline Organoléptico & & & 8 & 2 & 9 \\
\hline Libre de materia extraña visible & & & 1 & & 4 \\
\hline Humedad & & 6 & & & \\
\hline Otros & 6 & & & & \\
\hline Total & $\mathbf{6}$ & $\mathbf{6}$ & $\mathbf{1 6}$ & $\mathbf{2}$ & $\mathbf{1 9}$ \\
\hline
\end{tabular}

Cuadro 42. Criterios más importantes para la selección de fruta deshidratada (Conformado en frecuencia).

Elaboración propia. 


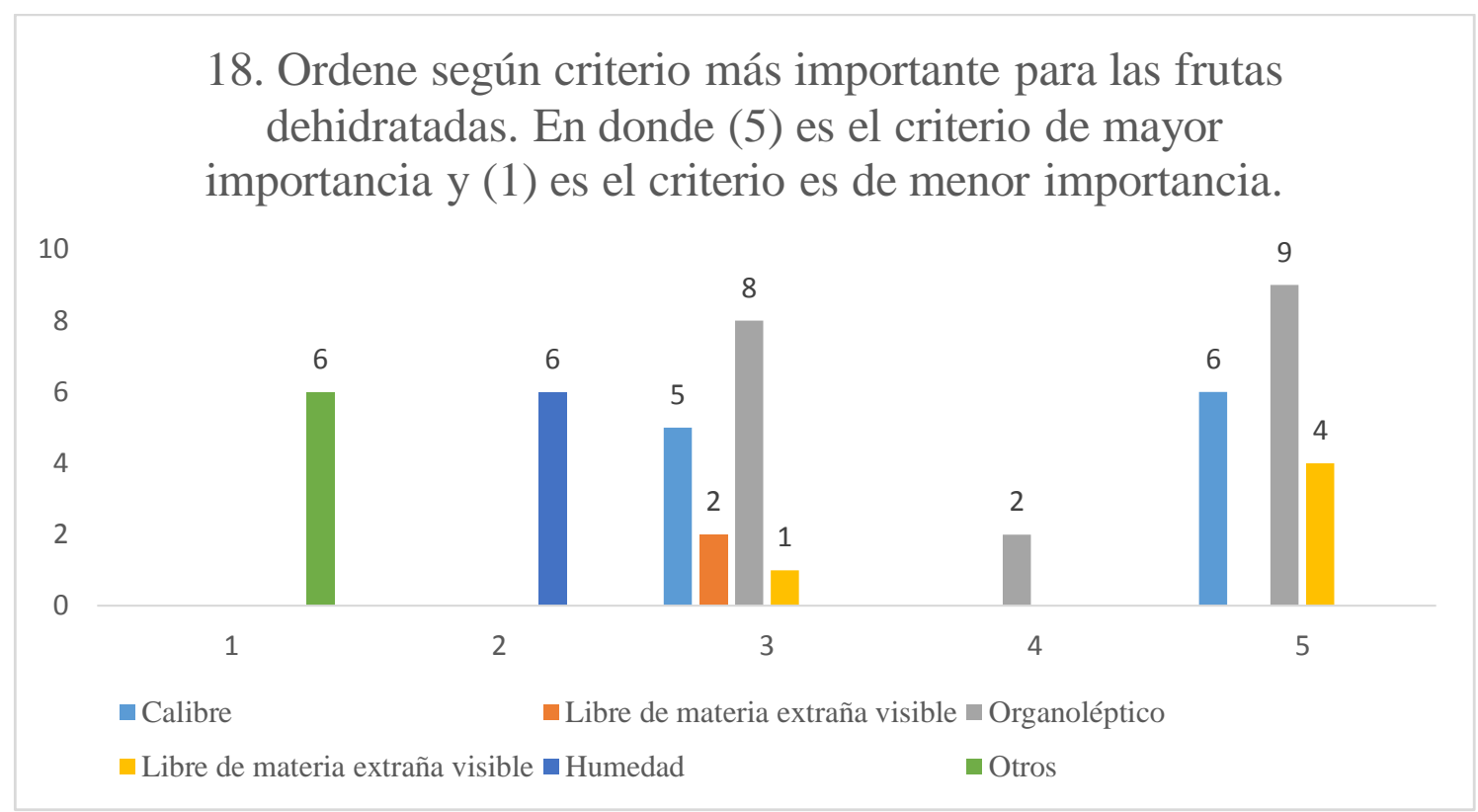

Gráfico 31. Criterios más importantes para la selección de fruta deshidratada. Elaboración propia.

Las empresas consultadas mencionaron que el criterio de mayor importancia, calificación 5, a la hora de comprar fruta deshidratada es la organoléptica, humedad y calibre con un 6, 9 y 4 de frecuencia de respuestas.

\begin{tabular}{|c|c|c|c|}
\cline { 2 - 4 } \multicolumn{1}{c|}{} & Número & Empresa & Porcentaje \\
\hline $\begin{array}{c}\text { Definitivamente si compraría } \\
\text { compraría }\end{array}$ & 1 & Incasur SA & $17 \%$ \\
\hline Indiferente & 0 & $\begin{array}{c}\text { Molitalia SA / Comp. } \\
\text { Nac de Choc SA }\end{array}$ & $33 \%$ \\
\hline $\begin{array}{c}\text { Probablemente no compraría } \\
\text { Definitivamente no }\end{array}$ & 2 & $\begin{array}{c}\text { Alicorp / Global } \\
\text { Alimentos SAC }\end{array}$ & $33 \%$ \\
\hline compraría & 1 & F\&D inversiones S.A.C & $17 \%$ \\
\hline Total & $\mathbf{6}$ & & $\mathbf{1 0 0 \%}$ \\
\hline
\end{tabular}

Cuadro 42. Disposición de compra de las frutas deshidratadas de arándanos, piña y manzana por parte de las empresas productoras de alimentos. (Conformado en porcentaje) Elaboración propia. 
19. Se está empezando a implementar una planta que elabore y venda fruta deshidratada: arándanos, manzana y piña para consumo industrial ¿Estaría usted dispuesto a comprar dichos productos?

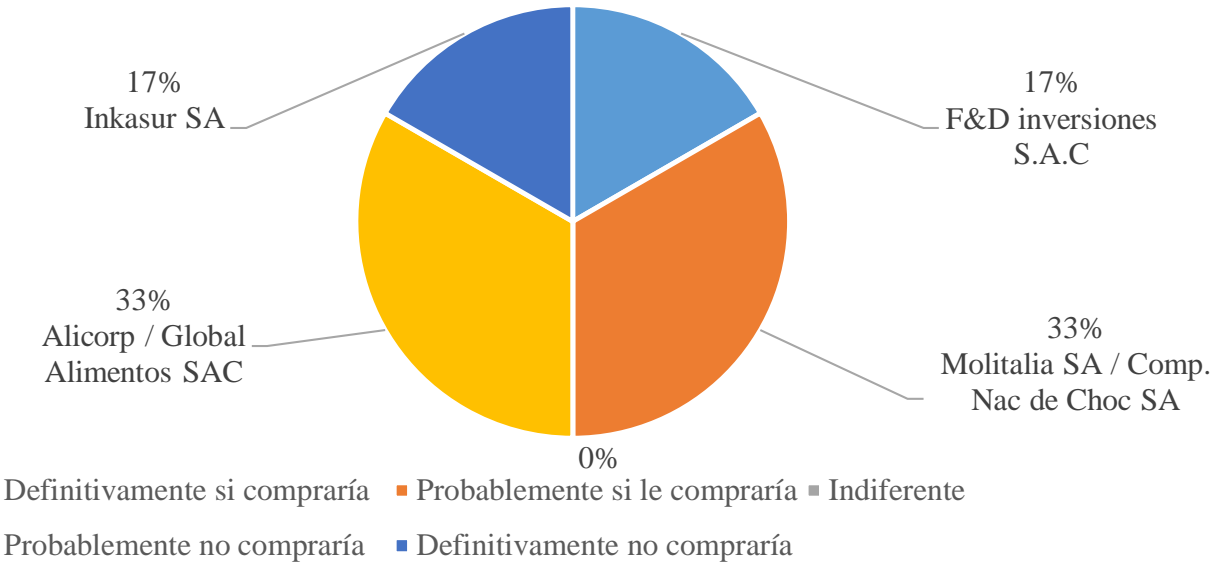

Gráfico 32. Disposición de compra de las frutas deshidratadas de arándanos, piña y manzana por parte de las empresas productoras de alimentos.

Elaboración propia.

De total de seis empresas, únicamente una empresa, 17\% indicó que definitivamente compraría nuestros productos y otro $33 \%$ que probablemente lo comprarían. Un 33\% de empresas probablemente no lo comprarían. Finalmente un 17\% de empresas definitivamente no lo compraría.

Número Porcentaje

\begin{tabular}{|c|c|c|}
\hline Bolsas de polietileno & 5 & $83 \%$ \\
\hline Baldes de polietileno & 0 & $0.00 \%$ \\
\hline Cartón corrugado & 1 & $17 \%$ \\
\hline Otro : & 0 & $0.00 \%$ \\
\hline Total & $\mathbf{6}$ & $\mathbf{1 0 0 \%}$ \\
\hline
\end{tabular}

Cuadro 44. Tipo de empaque de frutos deshidratados de arándanos, piña y manzana deseado por las empresas productoras de alimentos. (Conformado en porcentaje). Fuente: Elaboración propia. 


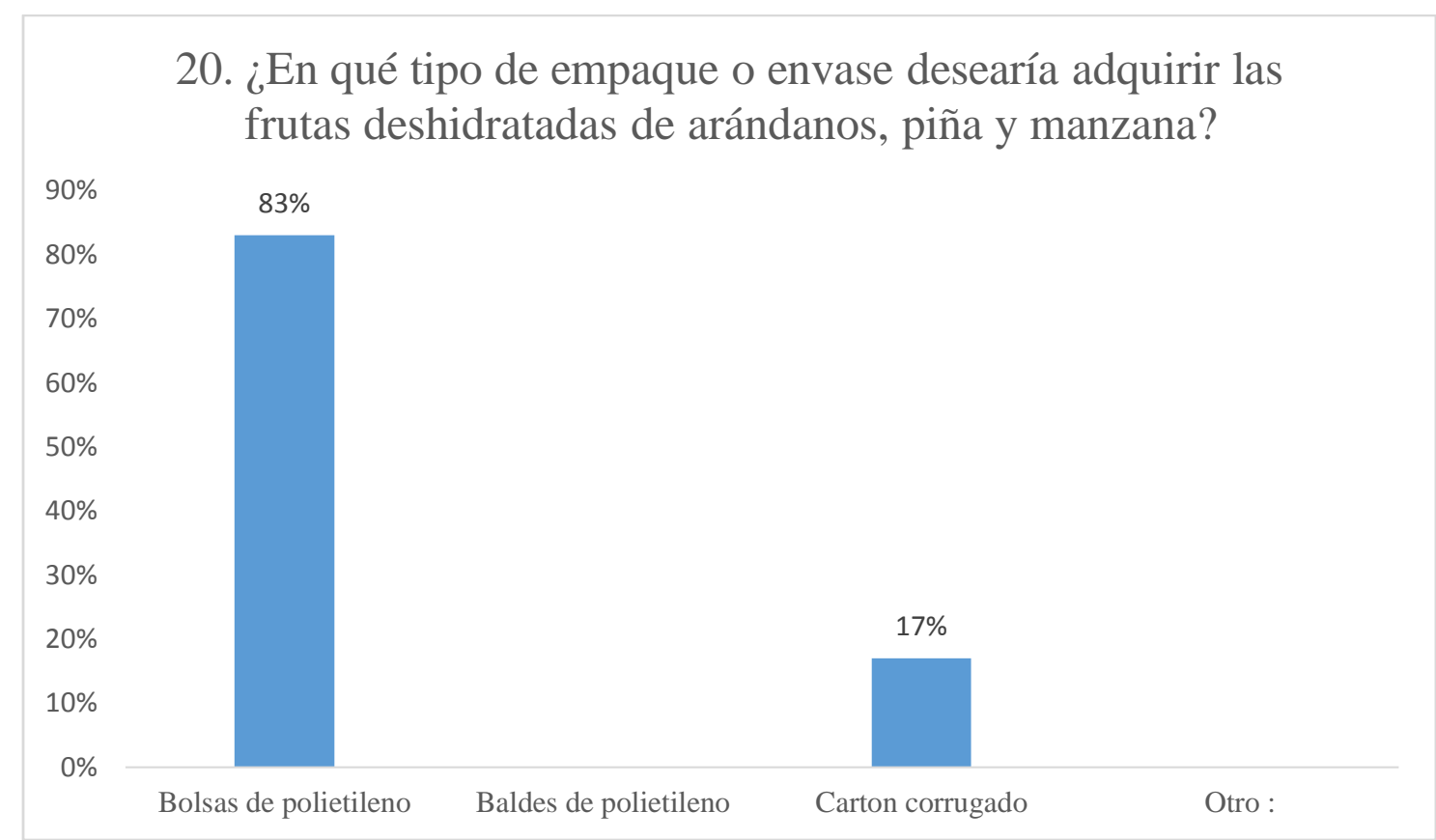

Gráfico 33. Tipo de empaque de frutos deshidratados de arándanos, piña y manzana deseado por las empresas productoras de alimentos.

Fuente: Elaboración propia.

De las empresas consultadas un $83 \%$ desea el producto dentro de una bolsa de polietileno y un $17 \%$ en cartón corrugado.

\begin{tabular}{|c|c|c|}
\cline { 2 - 3 } \multicolumn{1}{c|}{} & $\begin{array}{c}\text { Número de } \\
\text { empresas }\end{array}$ & Porcentaje \\
\hline 10 Kilogramos & 6 & $100 \%$ \\
\hline 15 Kilogramos & 0 & $0 \%$ \\
\hline 20 Kilogramos & 0 & $0 \%$ \\
\hline Total & $\mathbf{6}$ & $\mathbf{1 0 0 \%}$ \\
\hline
\end{tabular}

Cuadro 45. kilos que contendrá el empaque de frutos deshidratados de arándanos, piña y manzana deseados por las empresas elaboradoras de alimentos. (Conformado en porcentajes).

Fuente: Elaboración propia. 


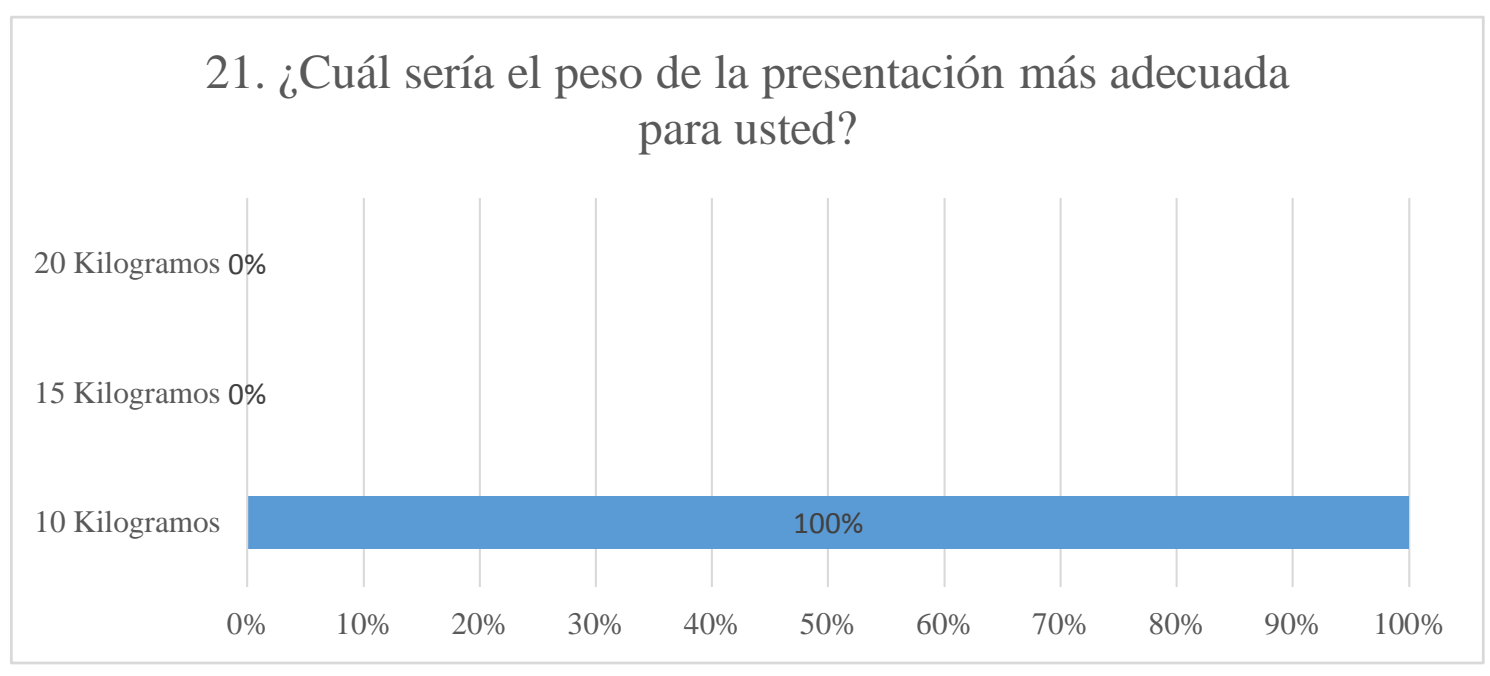

Gráfico 34. Kilos que contendrá el empaque de frutos deshidratados de arándanos, piña y manzana deseados por las empresas elaboradoras de alimentos.

Fuente: Elaboración propia.

De acuerdo al cuadro mostrado el $100 \%$ de empresas elaboradoras de alimentos prefiere envases de 10 kilogramos de peso para los arándanos, piña y manzana deshidratada.

\section{Número Porcentaje}

\begin{tabular}{|l|c|c|}
\hline Contado & 0 & $0 \%$ \\
\hline Crédito & 6 & $100 \%$ \\
\hline Total & $\mathbf{6}$ & $\mathbf{1 0 0 \%}$ \\
\hline
\end{tabular}

Cuadro 46. Condiciones de pago por la compra de frutos deshidratados de arándanos, piña y manzana por parte de las empresas elaboradoras de alimentos (Conformado en porcentajes).

Fuente: Elaboración propia. 
21. ¿Cuál es la política de cobro de sus proveedores?

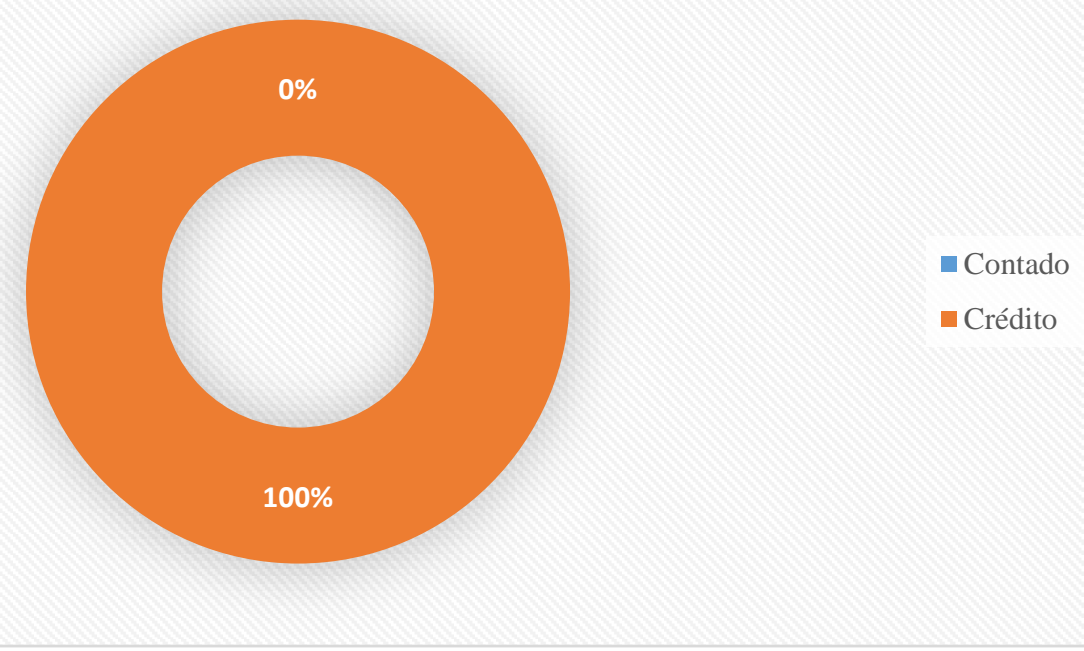

Gráfico 35. Condiciones de pago por la compra de frutos deshidratados de arándanos, piña y manzana por parte de las empresas elaboradoras de alimentos.

Fuente: Elaboración propia.

El $100 \%$ de empresas mencionaron que la política de cobro de los proveedores es al crédito de 30 días.

\subsection{Conclusiones del Estudio Cualitativo}

Se concretaron cuatro entrevistas, las cuales fueron con:

José Carlos Linares Jefe de Cadena de Abastecimiento de la empresa Industrias Alimenticias Cusco SA, Lucas Zécevic Gerente de Logística de Compañía nacional de chocolates, Manuel Terreros Coordinador de Sierra y Selva Exportadora y Luis Llanos de la Puente Gerente de Vitallanos Perú SAC quienes nos brindaron información al respecto A continuación las conclusiones de las entrevistas.

Los principales productos que compran son el arándano, aguaymanto, manzana, piña, durazno y pasas. En menor medida el mango, plátano, fresas.

Los productos sustitutos son en su mayoría los frutos secos y las verduras deshidratadas. Sin embargo el sabor de la fruta es un factor diferenciador frente es estos productos. 
Las principales especificaciones técnicas de las frutas deshidratadas están relacionadas con el tema de la calidad, especificándose en: La humedad, los cuerpos extraños, el tamaño específico, el tiempo de compra de la fruta fresca, el sabor, la textura, y el color.

En cuanto a las razones para el crecimiento de la demanda berries y fruta deshidratada por parte de las empresas elaboradoras de alimentos los entrevistados en su mayoría sostuvieron que a salud y el compromiso con el cuidado personal han sido los factores para el crecimiento del consumo de este tipo de productos.

En el caso de los criterios que se utilizan para elegir a sus proveedores los entrevistados coincidieron en que las especificaciones técnicas y el abastecimiento en las fechas establecidas. En el mismo nivel desean condiciones crediticias aceptables. Finalmente en un grado menor de importancia los certificados de calidad y el precio.

En lo que se refiere a la tendencia de la producción de frutos frescos la mayoría absoluta coincidió en que la producción de frutos frescos se ha incrementado en nuestro país. Sin embargo el fenómeno del niño ha afectado la producción de mango.

Al consultar sobre las zonas de mayor crecimiento de frutos frescos arándanos, piña y manzanas los entrevistados mencionaron que las zonas de producción del arándanos es La Libertad, la piña en Loreto y Junín y la manzana en Lima.

Las estaciones o meses de producción de frutos frescos como la manzana, arándanos y piña son todo el año.

El porcentaje de producción de arándanos que se destina al mercado peruano es del $4 \%$ a $5 \%$ aproximadamente. En el caso de la manzana entre un $60 \%$ a $70 \%$ se destina al mercado peruano. Finalmente en el caso de la piña un $10 \%$.

En cuanto el precio del arándano fresco el precio del arándano se encuentra entre S/. 2.5 a S/.3.5, el de la manzana entre S/. 0.5 a S/. 0.7 y de la piña a un S/. 0.7. 
En cuanto a la cadena de abastecimiento de la fruta que no se exporta, estos se destinan a la venta a través de los diferentes mercados de abastos, a empresas que deshidratan para el consumo industrial e individual, Para la manzana se debe indicar que hay un porcentaje moderado que se destina al mercado internacional, por lo mismo el destino de la manzana en su totalidad es para el mercado de consumo e industrial; del mismo modo también sucede con la piña. La deshidratación de la fruta puede ser cerca del área de cosecha o en el lugar que se destine, para esto se deberá hacer uso de transporte refrigerado.

En cuanto a los usos que se le puede dar a la fruta fresca, estos son diversos, como por ejemplo: mermeladas, bebidas, vinagres, harinas y encurtidos.

\subsection{Conclusiones del Estudio Cuantitativo}

Entre las empresas productoras y comercializadoras de alimentos un $35 \%$ de estas indicaron que estarían muy interesados en conocer más sobre las frutas deshidratadas, un $30 \%$ estaría interesado. Mientras que un $10 \%$ no estaría interesado y para nada interesado.

Las empresas productoras y comercializadoras de alimentos mencionaron que los tipos de frutos que conocen son las pasas con un 18\%, mientras que la manzana un $16 \%$; seguida por los arándanos y aguaymanto con un $14 \%$. Finalmente la piña con un $12 \%$.

Los medios de preferencia para tener información sobre las frutas deshidratadas son: con un $33 \%$ las ferias especializadas y con un $15 \%$ por medio del E-Mailing. Mientras que un $10 \%$ preferiría Folletos y visitas comerciales.

Un 35\% de los encuestados compra fruta deshidratada como insumo o ingrediente para la elaboración de sus productos. 
El 43\% de empresas productoras de alimentos estaría muy interesado en comprar arándanos, manzana y piña deshidratada como insumo para la elaboración de sus productos.

Del total de las seis empresas productoras de alimentos un $25 \%$ indica que las frutas deshidratadas que más compran son las pasas y los arándanos; de igual manera un $15 \%$ indica que su consumo se da también en manzanas y piñas.

El $100 \%$ de empresas productoras de alimentos interesadas indicaron que la compra de fruta deshidrata es muy importante para el uso industrial como insumo en sus productos.

El 100\% de empresas productoras de alimentos indicó que su frecuencia de compra de fruta deshidratada de arándanos, piña y manzana compra es mensual.

El 29\% de las empresas productoras de alimentos mencionaros que la fruta deshidratada es usado en la preparación de galletas y barras. Asimismo un $18 \%$ menciono a las granolas y cereales.

Como se puede observar en el siguiente gráfico las expectativas de crecimiento son unánimes con un 100\%. Un 100\% de empresas productoras de alimentos interesadas mencionaron que las expectativas de crecimiento son definitivamente positivas; asimismo el promedio de crecimiento establecido por ellos fue del $10 \%$.

Los proveedores de fruta deshidrata son los siguientes: Terrafertil Perú S.A.C, Frutos y especias S.A.C., Peruvian Nature S\&S S.A.C, Vitallanos S.A.C, Frutas e Industrias S.A.C, Narvid EIRL y Oxiquim.

El criterio más importante a la hora de elegir a un proveedor es el de especificación del producto con una frecuencia de 6, mientras que el tiempo de entrega, criterio importante, obtuvo un frecuencia de 5 y el de menor importancia el certificado calidad e inocuidad conjuntamente con el precio con una frecuencia de 5. 
La mayor debilidad de los proveedores de fruta deshidratada de acuerdo al estudio realizado es en primer lugar la calidad con una frecuencia de respuesta de 6 y en último lugar el precio con una frecuencia también de 6.

Tres empresas productoras de alimentos, frecuencia de 3, mencionaron que el precio promedio de los arándanos es el de 35 a 40 nuevos soles, el de manzanas de 46 a 50 nuevos soles. Finalmente dos empresas, frecuencia de 2, mencionaron que precio promedio de la piña era de 46 a 50 nuevos soles.

El criterio de mayor importancia, calificación 5, para las empresas productoras de alimentos a la hora de comprar fruta deshidratada es la organoléptica, humedad y calibre con un 6, 9 y 4 de frecuencia de respuestas.

Un $17 \%$ de empresas productoras de alimentos definitivamente compraría nuestros productos y otro 33\% que probablemente lo compraría. Un 33\% de empresas probablemente no lo comprarían. Finalmente un $17 \%$ de empresas definitivamente no lo compraría.

El $83 \%$ de empresas productoras de alimentos desea los frutos deshidratados dentro de una bolsa de polietileno y un $17 \%$ en cartón corrugado.

De acuerdo al cuadro mostrado el $100 \%$ de empresas elaboradoras de alimentos prefiere envases de 10 kilogramos de peso para los arándanos, piña y manzana deshidratada.

El $100 \%$ de empresas productoras de alimentos mencionaron que la política de cobro de los proveedores es al crédito de 30 días. 


\section{Proyección del Mercado Objetivo}

\section{1 Ámbito de la Proyección}

El ámbito de FRUTOS DESHIDRATDOS SAC serán las empresas grandes y medianas ubicadas en departamento de Lima y que usen frutas deshidratadas como arándanos, manzana y piña en la producción de snacks y otros productos alimenticios.

\subsection{Selección del Método de Proyección}

Se usará el modelo de proyección basado en series de tiempo, se cuentan con datos del consumo de arándano, manzana y piña deshidratados por parte de empresas procesadoras de alimentos.

\subsubsection{Mercado potencial}

Éste mercado está compuesto por las empresas del segmento de mercado elegido, geográficamente empresas del departamento de Lima, por tamaño empresas grandes y medianas, y por sector empresas productoras de alimentos como molinería, chocolatería, panadería y otros.

Los datos se obtuvieron del Directorio Nacional de Empresas Manufactureras de MIPYME Ministerio de la Producción. En total las empresas grandes y medianas pertenecientes a la actividad económica Molinería, Chocolatería, Panadería y Otros ubicadas en sector de Lima que consumen o desearían consumir fruta deshidratada para uso industrial conforman un total de 96 empresas.

\section{a. Criterios de segmentación}

- Criterio de segmentación geográfico: Empresas situadas en Lima.

- Criterio de segmentación por sector: Empresas del sector Manufactura, perteneciente a la actividad económica Molinería, Chocolatería, Panadería y otros. 
- Criterio de segmentación por uso de insumo: Empresas que consumen o desearían productos deshidratados para uso industrial.

\section{b. Cálculo del mercado potencial}

Para esto se utilizó el Directorio Nacional de Empresas Manufactureras

\begin{tabular}{|c|c|}
\hline CRITERIO DE SEGMENTACIÓN & $\mathrm{N}^{\mathbf{0}}$ \\
\hline Empresas situadas en Lima & 932 \\
\hline $\begin{array}{c}\text { Sector manufactura, pertenecientes a la actividad } \\
\text { Molinería, Chocolatería, Panadería y otros }\end{array}$ & 346 \\
\hline $\begin{array}{c}\text { Por uso de insumo: Arándanos, Piñas y Manzana } \\
\text { deshidratada }\end{array}$ & 96 \\
\hline MERCADO DISPONIBLE & 96 \\
\hline
\end{tabular}

Cuadro 47. Criterios de segmentación y mercado potencial Fuente: Elaboración propia.

\subsubsection{Mercado disponible}

Este mercado está conformado por las empresas que tienen interés y tiene acceso a la oferta del mercado. Este mercado se calcula multiplicando el porcentaje de empresas de la pregunta 5. ¿Su empresa compra alguna fruta deshidratada como insumo o ingrediente para la elaboración de sus productos? por el mercado potencial, en este caso el 18\% (14) de empresas compra frutas deshidratadas para la elaboración de sus productos.

\begin{tabular}{|c|c|c|}
\cline { 2 - 3 } \multicolumn{1}{c|}{} & $\begin{array}{c}\text { Número de } \\
\text { empresas }\end{array}$ & Porcentaje \\
\hline Sí & 14 & $18 \%$ \\
\hline No & 62 & $32 \%$ \\
\hline Total & $\mathbf{7 6}$ & $100 \%$ \\
\hline
\end{tabular}

Cuadro 48. Mercado disponible (Conformado en porcentajes).

Elaboración propia. 
5, ¿Su empresa compra alguna fruta deshidratada como insumo o ingrediente para la elaboración de sus productos?

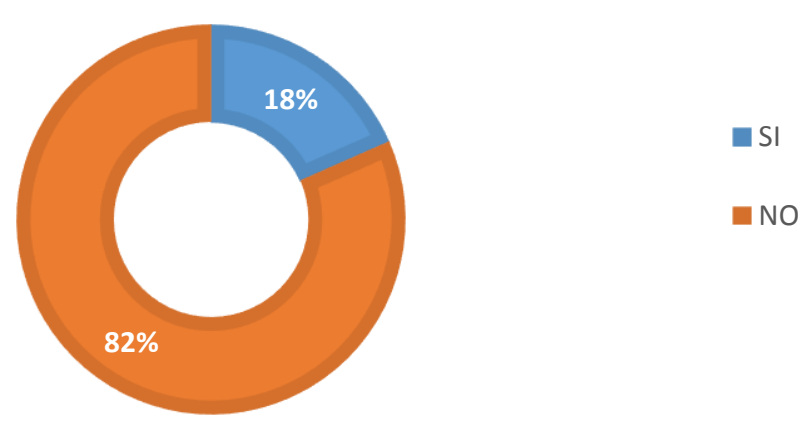

Gráfico 36. Mercado disponible.

Elaboración propia.

\subsubsection{Mercado efectivo}

Este mercado está conformado por las empresas que tienen intención de comprar el producto ofrecido por el plan de negocios. Este mercado se calcula multiplicando el porcentaje de empresas Muy Interesadas en la compra de frutas deshidratadas, obtenido de la pregunta $\mathrm{N}^{\mathrm{o}} 6$ de la encuesta con un porcentaje del $43 \%$ del $18 \%$ perteneciente al mercado disponible. Por lo tanto, el mercado efectivo sería de $8 \%$ lo que representaría a 6 empresas cuyas cuotas representan $80000 \mathrm{~kg}$ arándanos, $50000 \mathrm{~kg}$ de manzanas y $15000 \mathrm{~kg}$ de piña deshidratadas al año.

\begin{tabular}{|l|c|c|c|c|c|c|}
\hline & $\begin{array}{c}\text { Kg. } \\
\text { empresas } \\
\text { empres } \\
\text { demanda } \\
\text { dos de } \\
\text { arándano } \\
\mathbf{S}\end{array}$ & $\begin{array}{c}\text { Kg. } \\
\text { anuales } \\
\text { demandad } \\
\text { os de } \\
\text { manzanas }\end{array}$ & $\begin{array}{c}\text { Kg. } \\
\text { anuales } \\
\text { demandad } \\
\text { os de piña }\end{array}$ & $\begin{array}{c}\% \text { del } \\
\text { medo } \\
\text { potencial }\end{array}$ & $\begin{array}{c}\% \text { del } \\
\text { mcdo } \\
\text { efectivo }\end{array}$ \\
\hline $\begin{array}{l}\text { Muy } \\
\text { interesado }\end{array}$ & 6 & $80000 \mathrm{Kg}$ & $50000 \mathrm{~kg}$ & $15000 \mathrm{Kg}$ & $43 \%$ & $8 \%$ \\
\hline Interesado & 3 & - & - & - & $21 \%$ & $4 \%$ \\
\hline Indiferente & 3 & - & - & - & $21 \%$ & $4 \%$ \\
\hline $\begin{array}{l}\text { No } \\
\text { interesado }\end{array}$ & 2 & - & - & - & $14 \%$ & $3 \%$ \\
\hline
\end{tabular}




\begin{tabular}{|l|c|c|c|c|c|c|}
$\begin{array}{l}\text { Para nada } \\
\text { interesado }\end{array}$ & 0 & - & - & - & $0 \%$ & $0 \%$ \\
\hline Total & $\mathbf{1 4}$ & & & & $\mathbf{1 0 0 \%}$ & $\mathbf{1 8 \%}$ \\
\hline
\end{tabular}

Cuadro 49. Mercado efectivo (Conformado en porcentajes).

Elaboración propia.

6. ¿Estaría usted interesado en comprar fruta deshidratada como arándanos, manzana y piña para utilizarlo como insumo o ingrediente en sus productos o comercializarlos como snacks?

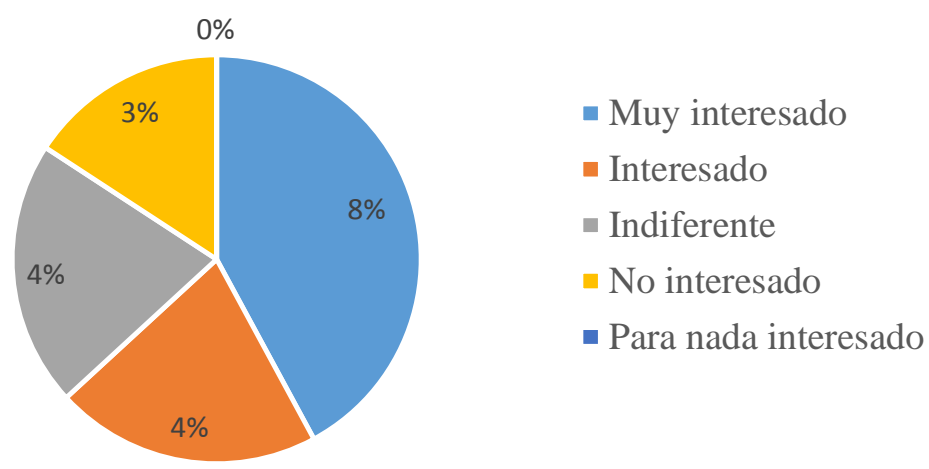

Gráfico 37. Mercado efectivo.

Elaboración propia.

\subsubsection{Mercado objetivo}

Este mercado está conformado por las empresas que estarían dispuestas a comprar el producto ofrecido en el plan de negocios. Este mercado se calcula multiplicando el porcentaje de empresas que Definitivamente si compraría y Probablemente si compraría arándanos, manzana y piña deshidratadas, obtenido de la pregunta $\mathrm{N}^{\mathrm{o}} 19$ de la encuesta con un porcentaje del $1 \%$ y $3 \%$ del $8 \%$ perteneciente al mercado efectivo. Por lo tanto, el mercado objetivo sería de $4 \%$ lo que representaría a 3 empresas

\begin{tabular}{|c|c|c|c|c|c|c|c|}
\hline & $\mathbf{N}^{\mathbf{0}}$ & Empresa & $\begin{array}{c}\text { Kg. } \\
\text { anuales } \\
\text { demand } \\
\text { ados de } \\
\text { arándan } \\
\text { os }\end{array}$ & $\begin{array}{c}\text { Kg. } \\
\text { anuales } \\
\text { demanda } \\
\text { dos de } \\
\text { manzana } \\
\text { S }\end{array}$ & $\begin{array}{c}\text { Kg. } \\
\text { anuales } \\
\text { demand } \\
\text { ados de } \\
\text { piña }\end{array}$ & $\begin{array}{c}\% \text { del } \\
\text { med } \\
\text { efectiv } \\
\mathbf{0}\end{array}$ & $\begin{array}{c}\% \text { del } \\
\text { med } \\
\text { objetivo }\end{array}$ \\
\hline $\begin{array}{c}\text { Definitivamente } \\
\text { si compraría }\end{array}$ & 1 & Incasur SA & $12000 \mathrm{~kg}$ & $4000 \mathrm{~kg}$ & $1200 \mathrm{~kg}$ & $17 \%$ & $1 \%$ \\
\hline
\end{tabular}




\begin{tabular}{|c|c|c|c|c|c|c|c|}
\hline $\begin{array}{l}\text { Probablemente } \\
\text { si le compraría }\end{array}$ & 2 & $\begin{array}{c}\text { Molitalia } \\
\text { SA / } \\
\text { Comp. Nac } \\
\text { de cho SA }\end{array}$ & $44000 \mathrm{~kg}$ & $20000 \mathrm{~kg}$ & $5600 \mathrm{~kg}$ & $33 \%$ & $3 \%$ \\
\hline Indiferente & 0 & - & - & - & - & $0 \%$ & $0 \%$ \\
\hline $\begin{array}{c}\text { Probablemente } \\
\text { no compraría }\end{array}$ & 2 & $\begin{array}{l}\text { Alicorp / } \\
\text { Global } \\
\text { Alimentos } \\
\text { SAC }\end{array}$ & - & - & - & $33 \%$ & $3 \%$ \\
\hline $\begin{array}{c}\text { Definitivamente } \\
\text { no compraría }\end{array}$ & 1 & $\begin{array}{c}\text { F\&D } \\
\text { inversiones } \\
\text { S.A.C }\end{array}$ & - & - & - & $17 \%$ & $1 \%$ \\
\hline Total & 6 & & & & & $100 \%$ & \\
\hline
\end{tabular}

Cuadro 50. Porción de captación de mercado objetivo (Conformado en porcentajes). Elaboración propia.

19. Se está empezando a implementar una planta que elabore y venda fruta deshidratada: arándanos, manzana y piña para consumo industrial ¿Estaría usted dispuesto a comprar dichos productos?

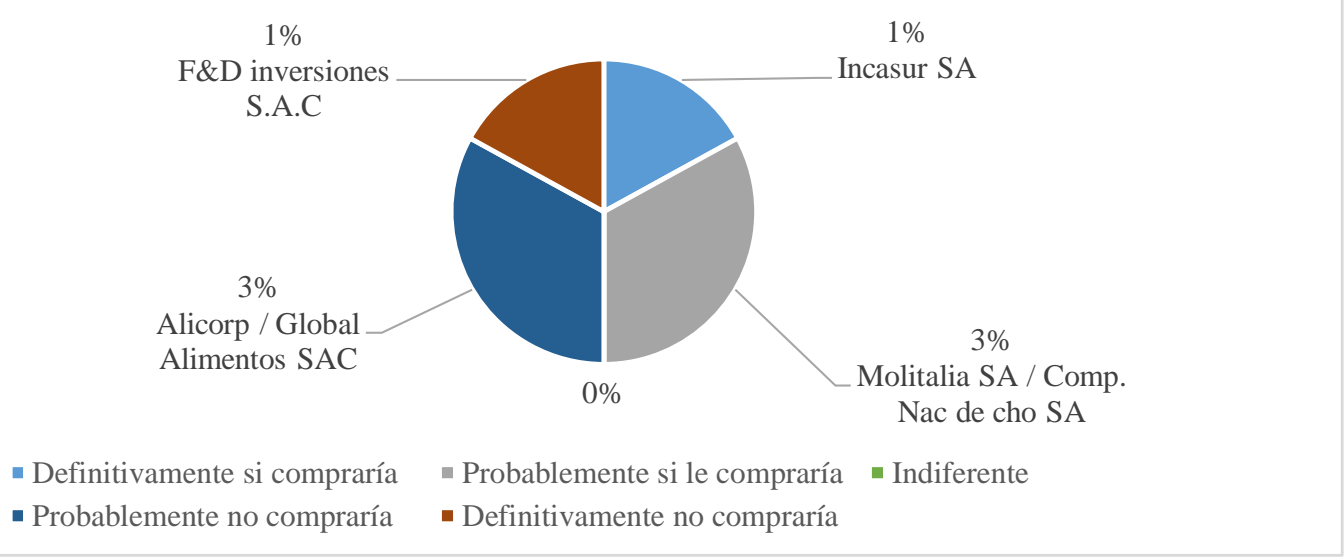

Gráfico 38. Porción de captación de mercado objetivo.

Elaboración propia.

Se desea capturar a empresas del mercado efectivo cuyas cuotas representan 56000 kilogramos de arándanos, 24000 kilogramos de manzanas y 6800 kilogramos de piña deshidratadas al año. 


\begin{tabular}{|c|c|c|c|c|c|c|c|c|}
\hline \multicolumn{2}{|c|}{$\begin{array}{l}\text { 19. Se está enperzando a mplementarar una planta que elabore y venda } \\
\text { fruta deshidratatada: arándanos, manzzana y piñáp para consumo industrial } \\
\text { ¿Estará́ usted dispuesto a comprar dichos productos? }\end{array}$} & \multirow{2}{*}{$\begin{array}{c}\text { Cantidad Kg - } \\
\text { antual } \\
\text { consumida de } \\
\text { arándanos }\end{array}$} & \multirow{2}{*}{\begin{tabular}{|c|}
$\begin{array}{c}\text { Cantidad } \mathrm{Kg} \text {. } \\
\text { antual } \\
\text { consumida de } \\
\text { manranna }\end{array}$ \\
4000 \\
\end{tabular}} & \multirow{2}{*}{\begin{tabular}{|c}
$\begin{array}{c}\text { Cantidad Kg } \\
\text { antual } \\
\text { consumida de } \\
\text { pinina }\end{array}$ \\
1200 \\
\end{tabular}} & \multirow{2}{*}{$\begin{array}{l}\text { Mc } \\
\text { daniels } \\
70 \% \\
\end{array}$} & \multirow{2}{*}{\begin{tabular}{|c|}
$\begin{array}{c}\mathrm{Kg} . \\
\text { Ojjetivo } \\
\text { ab́ándanos }\end{array}$ \\
8400 \\
\end{tabular}} & \multirow{2}{*}{$\begin{array}{c}\mathrm{Kg} \cdot \\
\text { Objetivo } \\
\text { manranana } \\
2800 \\
\end{array}$} & \multirow{2}{*}{\begin{tabular}{|c|}
$\begin{array}{c}\mathrm{Kg} . \\
\text { Objetivo } \\
\text { piña }\end{array}$ \\
840 \\
\end{tabular}} \\
\hline Definitivamente si compraría & Inrasur SA & & & & & & & \\
\hline Probablemente sile compraría & Molitalia SA / Com Nac de Cho SA & 44000 & 20000 & 5600 & $35 \%$ & 15400 & 7000 & 1960 \\
\hline Probablemente no compraría & Alicorp / Global Alimentos SAC & 24000 & 20000 & 6400 & $10 \%$ & 2400 & 2000 & 640 \\
\hline Definitivamente no compraría & F\&D inversiones S.A.C & & 6000 & 1800 & $0 \%$ & 0 & 0 & 0 \\
\hline Total & & 80000 & 50000 & 15000 & & 26200 & 11800 & 3440 \\
\hline \multicolumn{6}{|c|}{ Porción del mercado efectivo } & $32.75 \%$ & $23.60 \%$ & $22.93 \%$ \\
\hline
\end{tabular}

Cuadro 50. Definición de mercado objetivo -McDaniels (Conformado en kilogramos). Elaboración propia.

De acuerdo a la metodología de McDaniels el mercado objetivo se define a 26 200 kilogramos de arándanos lo que representa el 32.75\%, 11800 kilogramos de manzanas lo que representa un $23.06 \%$ y 3440 kilogramos de piña lo que representa un $22.93 \%$

\section{a. Porción captar del mercado objetivo}

\begin{tabular}{|l|c|c|c|c|c|}
\cline { 2 - 6 } \multicolumn{1}{c|}{} & $\%$ & $\begin{array}{c}\mathrm{N}^{\circ} \text { de } \\
\text { empresas }\end{array}$ & $\begin{array}{c}\text { Kg anuales } \\
\text { demandados } \\
\text { de arándano }\end{array}$ & $\begin{array}{c}\text { Kg anuales } \\
\text { demandados } \\
\text { de manzana }\end{array}$ & $\begin{array}{c}\text { Kg anuales } \\
\text { demandados } \\
\text { de piña }\end{array}$ \\
\hline $\begin{array}{l}\text { Mercado } \\
\text { disponible }\end{array}$ & $18 \%$ & 17 & - & - & - \\
\hline $\begin{array}{l}\text { Mercado } \\
\text { efectivo }\end{array}$ & $8 \%$ & 8 & 106670 & 66678 & 20000 \\
\hline $\begin{array}{l}\text { Mercado } \\
\text { objetivo }\end{array}$ & $4 \%$ & 4 & 74600 & 32000 & 9067 \\
\hline
\end{tabular}

Cuadro 52. Porción a captar del mercado objetivo Elaboración propia.

De acuerdo a los porcentajes obtenidos del mercado disponible, efectivo y

objetivo hemos proyectado dichos datos a nuestro segmento objetivo obteniendo como resultado un mercado objetivo a captar de: 74600 kilogramos de arándano, 32000 kilogramos de manzana y 9067 kilogramos de piña respectivamente. 


\section{b.Porción a captar del mercado objetivo: Mc Daniels}

\begin{tabular}{|c|c|c|c|}
\cline { 2 - 4 } \multicolumn{1}{c|}{} & $\begin{array}{c}\text { Kg anuales } \\
\text { demandados } \\
\text { de arándano }\end{array}$ & $\begin{array}{c}\text { Kg anuales } \\
\text { demandados } \\
\text { de manzana }\end{array}$ & $\begin{array}{c}\text { Kg anuales } \\
\text { demandados } \\
\text { de piña }\end{array}$ \\
\hline Mercado efectivo & 106670 & 66678 & 20000 \\
\hline $\begin{array}{c}\text { Porción del mercado } \\
\text { efectivo según } \\
\text { muestreo McDaniels }\end{array}$ & $32.75 \%$ & $23.60 \%$ & $22.93 \%$ \\
\hline $\begin{array}{c}\text { Pronóstico de mercado } \\
\text { objetivo McDaniels }\end{array}$ & 34934 & 15736 & 4586 \\
\hline $\begin{array}{c}\text { Pronóstico de venta } \\
\text { por producto }\end{array}$ & $\mathbf{8 0 0 0}$ & $\mathbf{5 0 0 0}$ & $\mathbf{1 5 0 0}$ \\
\hline
\end{tabular}

Cuadro 53. Porción a captar del mercado objetivo: McDaniels Elaboración propia.

Por otro lado se ha visto por conveniente utilizar McDaniels a fin de poder obtener un mercado objetivo realista. Dicho procedimiento nos ha arrojado que el mercado objetivo sería de: 34934 kilogramos de arándano, 15736 kilogramos de manzana y 4586 kilogramos de piña deshidratada respectivamente.

Siendo conservadores y pesimistas se obtendrá un $10 \%$ del mercado efectivo en el primer año. Del mismo modo se proyectará un crecimiento del 2\%, de acuerdo a la capacidad de planta, hasta llegar al $18 \%$ en el quinto año.

\begin{tabular}{|c|c}
\hline Año & $\begin{array}{c}\text { Porcentaje de captación del } \\
\text { mercado objetivo }\end{array}$ \\
\hline 2019 & $10 \%$ \\
\hline 2020 & $12 \%$ \\
\hline 2021 & $14 \%$ \\
\hline 2022 & $16 \%$ \\
\hline 2023 & $18 \%$ \\
\hline
\end{tabular}

Cuadro 54. Porción de captación de mercado objetivo a través de los años Conformado en porcentajes).

Elaboración propia. 
De igual forma el número de kilos de captación del mercado objetivo a través de los años se desarrollará de la siguiente manera:

\begin{tabular}{|l|l|l|l|l|l}
\hline Tipo & $\mathbf{2 0 1 9}$ & $\mathbf{2 0 2 0}$ & $\mathbf{2 0 2 1}$ & $\mathbf{2 0 2 2}$ & $\mathbf{2 0 2 3}$ \\
\hline Arándano & 8,000 & 10,560 & 13,552 & 17,037 & 21,083 \\
\hline Manzana & 5,000 & 6,360 & 7,865 & 9,528 & 11,362 \\
\hline Piña & 1,500 & 1,908 & 2,360 & 2,858 & 3,409 \\
\hline
\end{tabular}

Cuadro 55. Porción de captación de mercado objetivo a través de los años (Conformado en kilos).

Elaboración propia. 


\section{Plan de Marketing}

\subsection{Estrategia de Marketing}

Como estrategia básica de marketing el proyecto establecerá la diferenciación, la cual estará basada en los resultados de la investigación cuantitativa referidos a las preguntas 15: identifique los criterios de selección de sus proveedores de fruta deshidratada y 16: indique la debilidad de los proveedores, por la cual FRUTOS DESHIDRATADOS SAC se diferenciará en entregar productos deshidratados según el requerimiento de los clientes con respecto al corte y calibración, ya que la necesidad es diferente en corte y medida, para las variedades de sus productos finales, implicando que FRUTOS DESHIDRATADOS SAC ofrece algo único en el mercado, y que es valorado y percibido como único por sus compradores.

Del mismo modo se establecerá un plan de postventa que buscará establecer un nivel de satisfacción del 100\% por parte de nuestros clientes. Para poder lograrlo se buscará:

- Manejar tiempos cortos de respuesta a fin de que las solicitudes sean atendidas de manera rápida.

- Se establecerá canales de fijos de atención: vía telefónica directa con la Jefatura de marketing y ventas FRUTOS DESHIDRATADOS SAC.

Finalmente se buscará también generar un relacionamiento con las empresas a fin de conocer lo que necesitan y convertirse en un aliado cercano en innovación y mejora de productos a base de frutos deshidratados; este tema se explica con más detalle en el punto 8.2.Formulación de Estrategias del Negocio. 


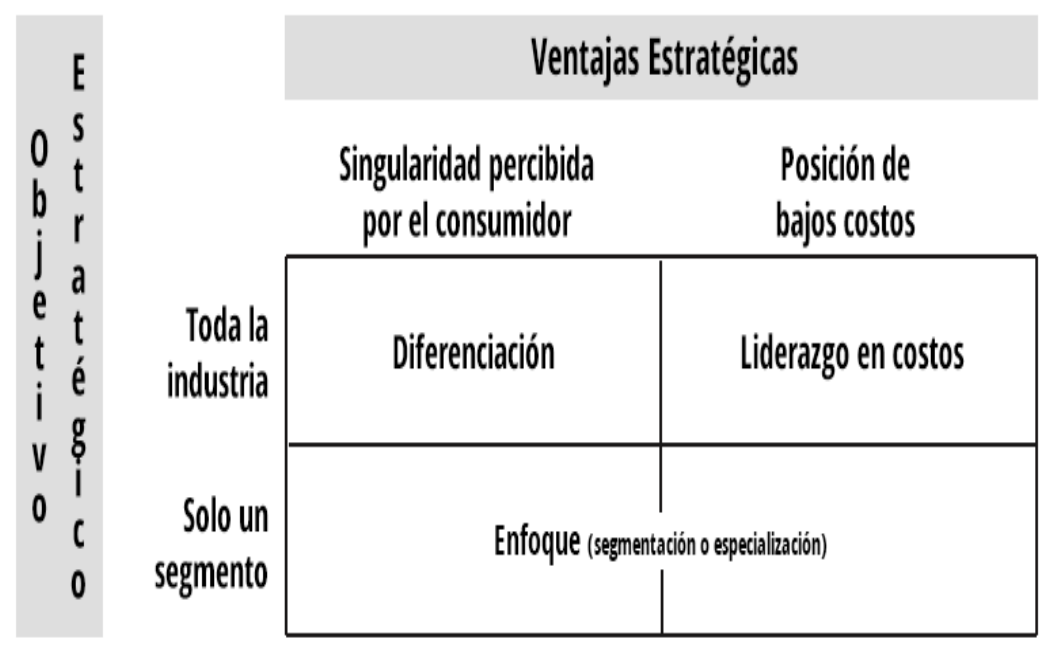

Gráfico 39. Estrategia plaza y distribución.

Fuente: Las tres estrategias genéricas de Porter, p.81.

Por otro lado también será importante definir la estrategia de marketing enfocado a establecer el direccionamiento del crecimiento de la empresa. Para este caso se utilizará la matriz de Ansoff a fin de poder establecer las acciones a realizar para generar crecimiento.

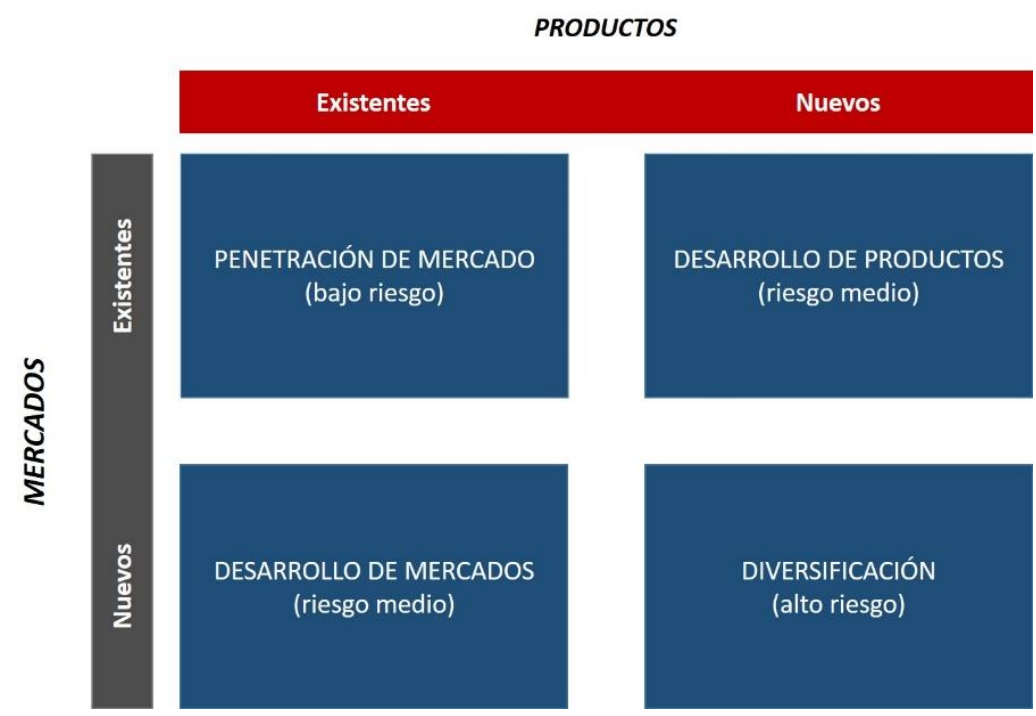

Cuadro 56. Matriz de crecimiento producto mercado.

Tomado de http://www.estrategiamagazine.com/administracion/la-matriz-de-ansoff-deproductomercado-o-vector-de-crecimiento/. 
De acuerdo al análisis realizado utilizando la matriz Ansoff se ha identificado que el proyecto se encuentra en los cuadrantes de: productos existente y mercados existentes; esto indica que la estrategia a seguir será la de penetración de mercados; por lo mismo los atributos que se realzarán en los productos serán: la calidad del producto conjuntamente con el abastecimiento continuo y oportuno.

Finalmente y de acuerdo a Ries y Trout (1986) y Kotler (2008) la estrategia competitiva que asumirá FRUTOS DESHIDRATADOS SAC será la de empresa retadora ya que actualmente no se posee una posición de liderazgo en el sector, por lo tanto buscará obtener una posición en el largo plazo formulando y ejecutando una estrategia de flanqueo, la cual consistirá en atacar aspectos en los que el líder presente debilidades: servicio post venta, cumplimiento de especificaciones de calibración y abastecimiento continuo y oportuno.

\subsubsection{Estrategia de Producto}

- Mejoramiento y mantenimiento de la calidad del producto, a través del uso de Certificados de Calidad HACCP.

- Adición de variedades de modelos, mediante el ofrecimiento tamaños de calibración para el arándano, manzana y piña deshidratada.

- Ingreso a nuevos segmentos del mercado como: pastelería, chocolatería, hoteles de cinco estrellas.

- Ampliación de la cobertura de mercado a través de la comercialización a exportadores de frutos secos.

- Creación de un posicionamiento único a través del uso de publicidad que enfatice las características de calidad, abastecimiento continuo y calibre, así como los beneficios de los productos deshidratados para los consumidores 


\subsubsection{Estrategia de Precio}

El precio y sus modificaciones son elementos de acción en cualquier estrategia de marketing. Se considerará los siguientes criterios para poder determinarlos

\subsubsection{Costos unitarios.}

Los costos unitarios se especifican en el capítulo de costos y gastos. A continuación podemos resumirlos en:

\section{Arándano Manzanas $\quad$ Piña}

\section{Materia Prima S/.}

10.93

Cuadro 56. Costo unitario de un kilo de fruta deshidratada

Elaboración propia.

El costo unitario para un kilo de fruta deshidratada es de S/. 10.93, S/ 3.33 y S/.

\subsection{2}

\subsubsection{Comparación de precios referenciales de competidores.}

Se ha tomado como referencia evaluación del departamento de Compras de Industrias Alimenticias Cusco S.A.

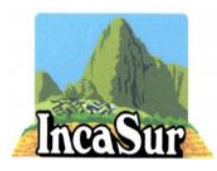

\section{CUADRO COMPARATIVO PARA EVALUACIÓN DE PROVEEDORES}

DEPARTAMENTO DE COMPRAS

\begin{tabular}{|c|c|c|c|c|c|c|c|c|c|}
\hline & \multicolumn{5}{|c|}{ Costo de Fruta Deshicratada por Kilo } & \multicolumn{4}{|c|}{ Cumplimiento de Requisitos } \\
\hline NOMBRE DE LA EMPRESA & Arandano & Manzana & Piña & Aguaymanto & Fresa & Ficha Técnica & Certificado & HACCP & Forma de pago \\
\hline Terrafertil SAC & 38.00 & $x$ & $x$ & $x$ & $x$ & SI & SI & SI & 45 dias \\
\hline Frutos y Especies SAC & S/. $\quad 35.00$ & $x$ & $x$ & $x$ & $x$ & $\mathrm{SI}$ & $\mathrm{SI}$ & NO & 30 dias \\
\hline Narvid EIRL & $x$ & S/. $\quad 40.80$ & S/. $\quad 57.80$ & $x$ & $x$ & SI & NO & NO & 30 dias \\
\hline Oxiquim & $x$ & $x$ & $x$ & $x$ & S/. 11.50 & SI & SI & NO & 30 dias \\
\hline Frutos e Industrias SAC & S/. $\quad 34.50$ & 48.00 & 45.00 & 35.00 & $x$ & SI & SI & NO & 30 dias \\
\hline
\end{tabular}

Cuadro 58. Cuadro comparativo de competidores de fruta deshidratada.

Tomado de departamento de compras Incasur S.A.

\subsubsection{Selección del método de fijación de precios.}

La estrategia de precio será establecida estará basados en la competencia, también definida como "Estrategia de precio de paridad" que ocurre cuando los precios son semejantes a la competencia y existe un elemento diferenciador. 


\subsubsection{Selección del precio final.}

El precio final de los productos será el de arándanos S/. 37, manzanas a S/. 46 y piña a S/. 50 por kilo con pago al crédito por 30 días.

\subsubsection{Estrategia plaza y distribución.}

El canal a utilizar será el canal directo, no se hará uso de intermediarios.

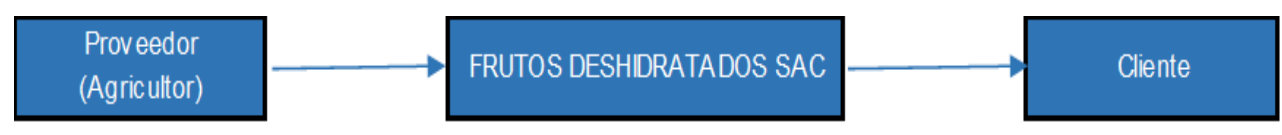

Gráfico 40. Estrategia plaza y distribución. Elaboración propia.

Es importante tener en cuenta que la propiedad de la fruta por parte del agricultor y de FRUTOS DESHIDRATADOS SAC según Dawyer Robert (2007) es una distinción esencial porque trae un compromiso de negocios considerable, ya que implica la compra en efectivo o el financiamiento de la adquisición, requiere un almacenamiento y manejo apropiados y siempre incluye el riesgo del deterioro, robo u obsolescencia.

Asimismo Dawyer Robert (2007) FRUTOS DESHIDRATADOS SAC ha definido lo que se denomina Servicio completo: "Mayoristas de función completaee, los cuales, proporcionan una colección amplia de servicios para sus clientes, en este caso Molitalia, Alicorp e IncaSur abarcando no solo la entrega oportuna de los productos, surtido correcto y facilidades en la forma de pago si no inclusive proporcionar inteligencia de mercado e ideas para productos nuevos a sus proveedores y clientes.

La fábrica de deshidratación estará ubicada en Lima, por otro lado se buscará la venta en las instalaciones del cliente.

Finalmente el Equipo de ventas por tipo de clientes: empresas grandes y medianas. 


\subsubsection{Estrategia de Promoción y Publicidad}

La estrategia estará basada en la generación del relacionamiento con el cliente, es decir un seguimiento que tenga un resultado beneficioso para el comprador, esto se logrará a través de ofrecerles seminarios sobre innovación de productos, visitas a los compradores a fin de asesorar en el uso de los frutos deshidratados dentro de sus plantas de producción. Asimismo se otorgará muestras gratuitas y presencia en ferias alimentarias.

Frutos deshidratados SAC, se lanzará al mercado con la marca Arandamix, conformado por un isologo que muestra una imagen de los frutos del arándano en su presentación de cosecha y el producto final del arándano deshidratado, así como la marca Arandamix con las letras de color rojo, haciendo referencia al tipo de arándano rojo, dentro de un circulo verde pacay representando los colores de la naturaleza, de esta forma se brinda un toque elegante y natural a la marca, adicionalmente se adjunta la razón social FRUTOS DESHIDRATADOS SAC, que busca destacar la protección, ya que permite al consumidor diferenciar un bien de otro, protegiéndolo de los productos defectuosos o de calidad inferior y favoreciendo que nuestros productos se beneficie por la protección que la marca le brinda.

La marca Arandamix otorga un componente de identidad y reconocimiento en el mercado ya que comprende la necesidad de obtener de esta, su máxima rentabilidad y así poder convertirse en un elemento fuerte del patrimonio de la empresa.

Finalmente para poder potenciar la marca Arandamix se buscará utilizar el Brand Equity con el propósito de generar un mayor valor y notoriedad de la marca; de este modo buscaremos lograr lo siguiente: 
- Conocimiento de marca: Se busca que la marca sea de fácil de reconocer por parte del cliente; esto se logrará con el uso de los canales virtuales, participación en ferias especializadas, seminarios de innovación y folletos

- Calidad: Se buscará informar que los productos que se ofrecen están elaborados de acuerdo a la certificación HACCP.

- Posicionamiento: A través del relacionamiento con el cliente, mencionado en el punto 8.2.Formulación de Estrategias del Negocio y el plan de postventa.

\subsubsection{Estrategia de Personas}

- Visitas a las fábricas por parte del personal.

- Capacitar al personal sobre gestión de clientes industriales.

- Elaboración del mapa de la experiencia del cliente personalizado a fin de saber cómo el cliente se relaciona con nosotros y cómo se siente.

\subsubsection{Estrategia de Procesos}

- Elaboración de un registro de incidencias ocurridas a nuestros clientes.

- Realización de entrevistas de satisfacción al cliente.

\subsubsection{Estrategia de Presencia física}

- Páginas web informativas.

- Utilización de Redes Sociales: LinkedIn con el fin de nutrir el perfil de la marca en esta red social y participar en grupos relevantes para el sector para posicionarse como un referente. Opcionalmente invertir en campañas de pago en dicha plataforma y publirreportajes. 


\begin{tabular}{|l|c|c|c|c|c|}
\multicolumn{1}{|c|}{ Actividad } & $\mathbf{2 0 1 9}$ & $\mathbf{2 0 2 0}$ & $\mathbf{2 0 2 1}$ & $\mathbf{2 0 2 2}$ & $\mathbf{2 0 2 3}$ \\
\hline $\begin{array}{l}\text { Stand en Feria Expo } \\
\text { alimentaria }\end{array}$ & 6906.00 & 6906.00 & 6906.00 & 6906.00 & 6906.00 \\
\hline $\begin{array}{l}\text { Seminarios de innovación } \\
\text { en productos en base a } \\
\text { deshidratados }\end{array}$ & 1050.00 & 1050.00 & 1050.00 & 1050.00 & 1050.00 \\
\hline $\begin{array}{l}\text { Mantenimiento de Página } \\
\text { Web }\end{array}$ & 600.00 & 600.00 & 600.00 & 600.00 & 600.00 \\
\hline Folletos & 600.00 & 600.00 & 600.00 & 600.00 & 600.00 \\
\hline $\begin{array}{l}\text { Visitas por parte del } \\
\text { personal de ventas }\end{array}$ & 1440.00 & 1440.00 & 1440.00 & 1440.00 & 1440.00 \\
\hline $\begin{array}{l}\text { Capacitación de personal } \\
\text { sobre clientes industriales }\end{array}$ & 1000.00 & 1000.00 & 1000.00 & 1000.00 & 1000.00 \\
\hline $\begin{array}{l}\text { Entrevistas de satisfacción } \\
\text { al cliente }\end{array}$ & 200.00 & 200.00 & 200.00 & 200.00 & 200.00 \\
\hline \multicolumn{1}{|c|}{ Total } & $\mathbf{1 1 7 9 6 . 0 0}$ & $\mathbf{1 1 7 9 6 . 0 0}$ & $\mathbf{1 1 7 9 6 . 0 0}$ & $\mathbf{1 1 7 9 6 . 0 0}$ & $\mathbf{1 1 7 9 6 . 0 0}$ \\
\hline
\end{tabular}

Cuadro 59. Presupuesto de promoción y publicidad.

Elaboración propia.

La promoción estará más abocado a generar relacionamiento con las empresas que a pujar la venta de la cuenta; esta actividad de relacionamiento está relacionada con las actividades del cuadro 5.4; asimismo dichas cantidades son fijas debido a que el radio de acción del mercado objetivo es pequeño.

\begin{tabular}{|c|c|c|c|c|c|c|c|c|c|c|c|c|}
\hline & \multicolumn{12}{|c|}{ año 2019} \\
\hline & ene & feb & mar & abr & may & jun & jul & ago & sep & oct & nov & dic \\
\hline Stand en Feria Expoalimentaria & & & & & & & & & $\mathrm{X}$ & & & \\
\hline $\begin{array}{l}\text { Seminarios de innovación en } \\
\text { productos en base a } \\
\text { deshidratados }\end{array}$ & & & & & & $\mathrm{X}$ & & & & & & \\
\hline Mantenimiento de Página Web & $\mathrm{X}$ & $\mathrm{X}$ & $\mathrm{X}$ & $\mathrm{X}$ & $\mathrm{X}$ & $\mathrm{X}$ & $\mathrm{X}$ & $\mathrm{X}$ & $\mathrm{X}$ & $\mathrm{X}$ & $\mathrm{X}$ & $\mathrm{X}$ \\
\hline Folletos & $\mathrm{X}$ & $\mathrm{X}$ & $\mathrm{X}$ & $\mathrm{X}$ & $\mathrm{X}$ & $\mathrm{X}$ & $\mathrm{X}$ & $\mathrm{X}$ & $\mathrm{X}$ & $\mathrm{X}$ & $\mathrm{X}$ & $\mathrm{X}$ \\
\hline $\begin{array}{l}\text { Visitas por parte del personal } \\
\text { de ventas }\end{array}$ & $\mathrm{X}$ & $\mathrm{X}$ & $\mathrm{X}$ & $\mathrm{X}$ & $\mathrm{X}$ & $\mathrm{X}$ & $\mathrm{X}$ & $\mathrm{X}$ & $\mathrm{X}$ & $\mathrm{X}$ & $\mathrm{X}$ & $\mathrm{x}$ \\
\hline $\begin{array}{l}\text { Capacitación de personal sobre } \\
\text { clientes industriales }\end{array}$ & & & & & & $\mathrm{X}$ & & & & & & $\mathrm{X}$ \\
\hline $\begin{array}{l}\text { Entrevistas de satisfacción al } \\
\text { cliente }\end{array}$ & & $\mathrm{X}$ & & & $\mathrm{X}$ & & & $\mathrm{x}$ & & & $\mathrm{X}$ & \\
\hline
\end{tabular}

Cuadro 60. Cronograma de actividades de promoción y publicidad.

Elaboración propia. 


\subsection{Estrategia de Venta}

De acuerdo a Dawyer Robert $(2007)^{9}$ la estrategia a utilizar será para satisfacer necesidades; este proceso implica identificar las necesidades del comprador y adaptar el argumento a éstas. Por lo tanto este método cuenta con dos componentes: Identificar las necesidades y hacer la presentación.

La decisión por el uso de esta estrategia se basa en que dentro del mercado existe una variación de requerimientos entre las necesidades de las empresas industriales elaboradoras de productos a base de fruto deshidratado y las opciones que ofrecen los actuales proveedores.

Adicionalmente se desarrollará la venta consultiva que consiste en aplicar la experiencia especializada a un problema complejo para encontrar una solución particular. Para este caso el vendedor será considerado como un asesor pues tiene más conocimiento en como satisfacer las necesidades específicas con el producto que comercializa FRUTOS DESHIDRATADOS SAC.

En este caso se hará uso de las etapas de la construcción de una sociedad ${ }^{10}$ :

- Exploración: En esta etapa se buscará que el comprador y el vendedor puedan conocer lo que ofrecen ambos. Se buscará generar relaciones personales y de generación de confianza. Finalmente se verificará sí el comprador ha recibido la orden de manera oportuna.

- Expansión: El vendedor buscará cerrar más ventas. La confianza se incrementará ya que el vendedor identificará más necesidades adicionales.

\footnotetext{
9 DWYER, Robert TANNER Jhon. Marketing industrial Ed.3. México: McGraw-Hill Interamericana de México S.A de C.V, 2007. p. 371

${ }^{10}$ DWYER, Robert TANNER Jhon. Marketing industrial Ed.3. México: McGraw-Hill Interamericana de México S.A de C.V, 2007. p. 372
} 
- Compromiso: Se generará una promesa implícita de desear continuar con la relación comercial.

\subsubsection{Estrategia de Presencia física}

La proyección de ventas formulada apoyará la viabilidad económica y financiera de FRUTOS DESHIDRATADOS SAC. A continuación la cantidad por cada año y de forma trimestral en kilos

\begin{tabular}{|l|r|r|r|r|r|}
\cline { 2 - 6 } \multicolumn{1}{c|}{} & \multicolumn{5}{|c|}{ Años } \\
\hline Arándano & 2019 & 2020 & 2021 & 2022 & 2023 \\
\hline Manzana & 8,950 & 10,829 & 13,866 & 17,401 & 21,505 \\
\hline Piña & 6,081 & 6,616 & 8,015 & 9,693 & 11,544 \\
\hline Total & 1,672 & 1,949 & 2,404 & 2,908 & 3,463 \\
\hline
\end{tabular}

Cuadro 61. Proyección trimestral de ventas 2023 (Conformado en kilos). Elaboración propia

\subsubsection{Políticas de servicios y garantías}

La proyección de ventas formulada apoyará la viabilidad económica y financiera de FRUTOS DESHIDRATADOS SAC. A continuación la cantidad por cada año y de forma trimestral en kilos

- Adquisiciones mínimas: FRUTOS DESHIDRATADOS SAC no ha estipulado una cantidad mínima de adquisición. Puede solicitar la cantidad de productos que desee, muy independientemente de su precio.

- Valor de producto: Las solicitudes de compra serán efectuadas vía factura por FRUTOS DESHIDRATADOS SAC a precios establecidos a la fecha de envío.

- Modalidades de pago en efectivo: Las órdenes de compras se harán efectivas por FRUTOS DESHIDRATADOS SAC al recibir la totalidad del pago de los productos, se sugiere efectuar los pagos vía el sistema de banca on line. 
- Crédito: Dirigido a clientes con línea de crédito aprobada y en actual vigencia. Las facturas de ventas a crédito emitidas por FRUTOS DESHIDRATADOS SAC generarán gastos financieros si no son abonadas a la fecha de vencimiento.

- Devoluciones: Toda devolución de productos generados a consecuencias atribuibles al comprador, implicará un cargo adicional del 20\% sobre el valor de su envío, asimismo el flete será pagado por el cliente a los almacenes de FRUTOS DESHIDRATADOS SAC. Si los productos son devueltos por causas atribuibles a FRUTOS DESHIDRATADOS SAC, se efectuará la devolución del dinero o se extenderá un crédito a la cuenta del cliente después de recibir y haber sido aceptada la devolución. Finalmente no se aceptarán devoluciones por encima de las 24 horas una vez recibido el pedido. 


\section{Pronóstico de Ventas}

\subsection{Fundamentos y Supuestos}

Se ha realizado un pronóstico de ventas en basados en los volúmenes de producto consumido, calculados a partir del mercado objetivo de empresas que se obtuvo en el capítulo cuatro proyección del mercado objetivo.

Las tasas de crecimiento se establecieron en $2 \%$ interanual, en los 3 productos se tienen crecimientos mayores al $2 \%$ según las tasas de crecimiento interanuales de cada fruta deshidratada.

\begin{tabular}{|l|r|r|r|r|r|}
\hline PROYECCION POR PRODUCTO $(\mathrm{KG})$ & \multicolumn{1}{|c|}{2019} & \multicolumn{1}{|c|}{2020} & 2021 & \multicolumn{1}{c|}{2022} & 2023 \\
\hline Arándanos & 8,000 & 10,560 & 13,552 & 17,037 & 21,083 \\
\hline Manzana & 5,000 & 6,360 & 7,865 & 9,528 & 11,362 \\
\hline Piña & 1,500 & 1,908 & 2,360 & 2,858 & 3,409 \\
\hline Total proyección de venta & $\mathbf{1 4 , 5 0 0}$ & $\mathbf{1 8 , 8 2 8}$ & $\mathbf{2 3 , 7 7 7}$ & $\mathbf{2 9 , 4 2 3}$ & $\mathbf{3 5 , 8 5 4}$ \\
\hline
\end{tabular}

Cuadro 62. Pronóstico de demanda objetiva (unidades)

Fuente: Elaboración propia.

\subsection{Justificación}

En el mercado de los arándanos deshidratados se desea capturar el 10\% del mercado efectivo, las empresas Incasur y Compañía Nacional de Chocolates afirmaron que comprarían los productos ofrecidos según la encuestas realizadas a dichas empresas, el crecimiento interanual de producción de arándano deshidratado se calcula en un $15 \%$ interanual debido a que según datos de importación de arándano deshidratados de ADEX su crecimiento es de $53 \%$ interanual. Si consideramos el escenario actual hay un incremento de la demanda de este producto sin embargo en algún momento la demanda llegará a estabilizarse. Por tanto capturar el 10\% del mercado efectivo al inicio es razonable 


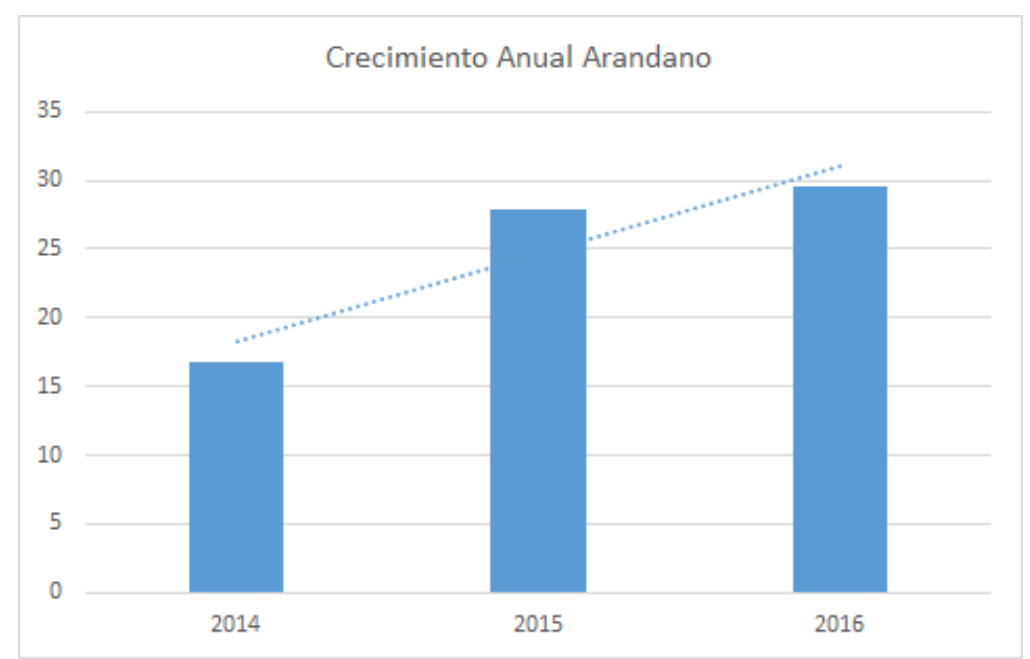

Gráfico 41. Crecimiento anual de arándano (t).

Elaboración propia.

En la piña deshidratada ha observado una producción anual de 15 toneladas y un crecimiento sostenido del volumen de producción anual del 10\% por lo que el primer año se desea capturar el $10 \%$ e incrementar su producción en $2 \%$ del mercado efectivo interanual.

En la manzana deshidratada se ha observado una producción anual de 50 toneladas y un crecimiento sostenido del volumen de producción anual del 10\% por lo que el primer año se desea capturar el 10\% e incrementar su producción en $2 \%$ del mercado efectivo interanual.

\subsection{Análisis de los Riesgos y Aspectos Críticos que Impactan el Pronóstico}

Uno de los riesgos a este pronóstico son los competidores directos e indirectos, los competidores directos son las empresas deshidratadoras que pueden mejorar su proceso productivo obteniendo certificaciones como la $\mathrm{HACCP}^{11}$ que aún no es común en la industria nacional.

11 Bsgroup.(2018, 06 de agosto) [bsgrupo.com] https://bsgrupo.com/bs-campus/blog/Importancia-delSistema-HACCP-Para-la-Industria-de-Alimentos-35 
Ya que la industria de la producción de berries deshidratados está en la fase de crecimiento se espera la aparición de nuevos competidores.

En la industria de las frutas, un factor muy importante son los factores climatológicos que pueden tener impacto altamente imprevisto y moderado en el precio de la materia prima necesaria para la producción de las frutas deshidratadas.

Las políticas de importación y exportación es otro factor importante que puede tener impacto tanto negativo como positivo para el pronóstico. Una política de incremento de aranceles de importación a los arándanos deshidratados favorecería positivamente al plan de negocios. 


\section{Ingeniería del Proyecto}

\subsection{Estudio de Ingeniería}

\subsubsection{Modelamiento y selección de procesos productivos.}

Con el resultado de la investigación de mercado se ha determinado que el producto unitario de producción es una caja de fruta deshidratada con un peso de 10 kilogramos. El empaque primario es una bolsa de polietileno y el secundario es de cartón corrugado.

Descripción del proceso productivo:

\subsubsection{Abastecimiento de frutas frescas.}

Para el proyecto de frutas deshidratadas, se realizará la compra a empresas acopiadoras y agricultores nacionales de manzana, piña y arándanos; se considera la adquisición de saldos de exportación. En el siguiente cuadro se muestra saldos de producción nacional disponibles para el consumo interno, tal es así que en el año 2013 se tuvo 233 toneladas, el año 2014 no registra saldos, el año 2015 se tuvo 431 toneladas de saldo, el año 2016 se tuvo 325 toneladas y el año 2017 se cerró con 25,000 toneladas.

El origen de la materia prima es de las regiones productivas del norte como La Libertad y Lambayeque, de Lima Provincia, del centro como Junín y sur del país como Ica y Arequipa. 


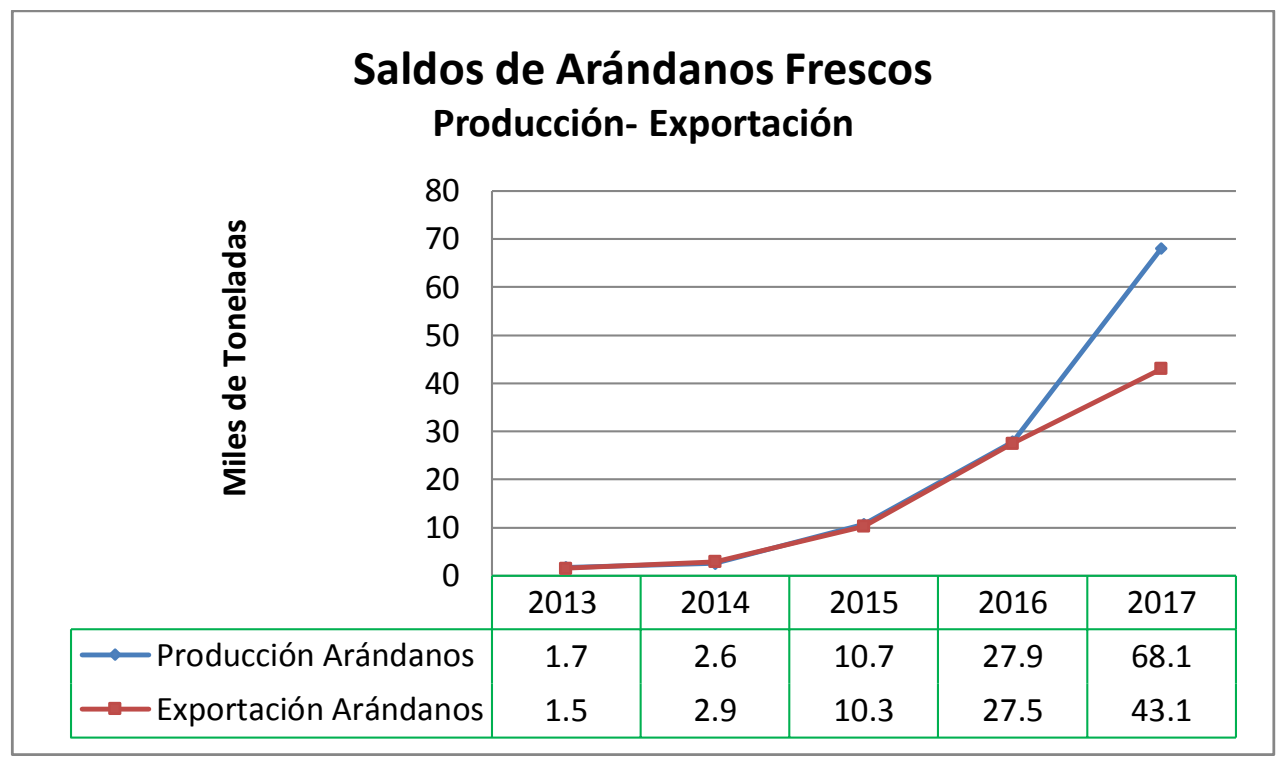

Gráfico 42. Saldos de producción nacional de arándanos.

Fuente: Elaboración propia.

En el siguiente cuadro mostramos la estadística de producción nacional de frutas desde el año 2012 al 2016.

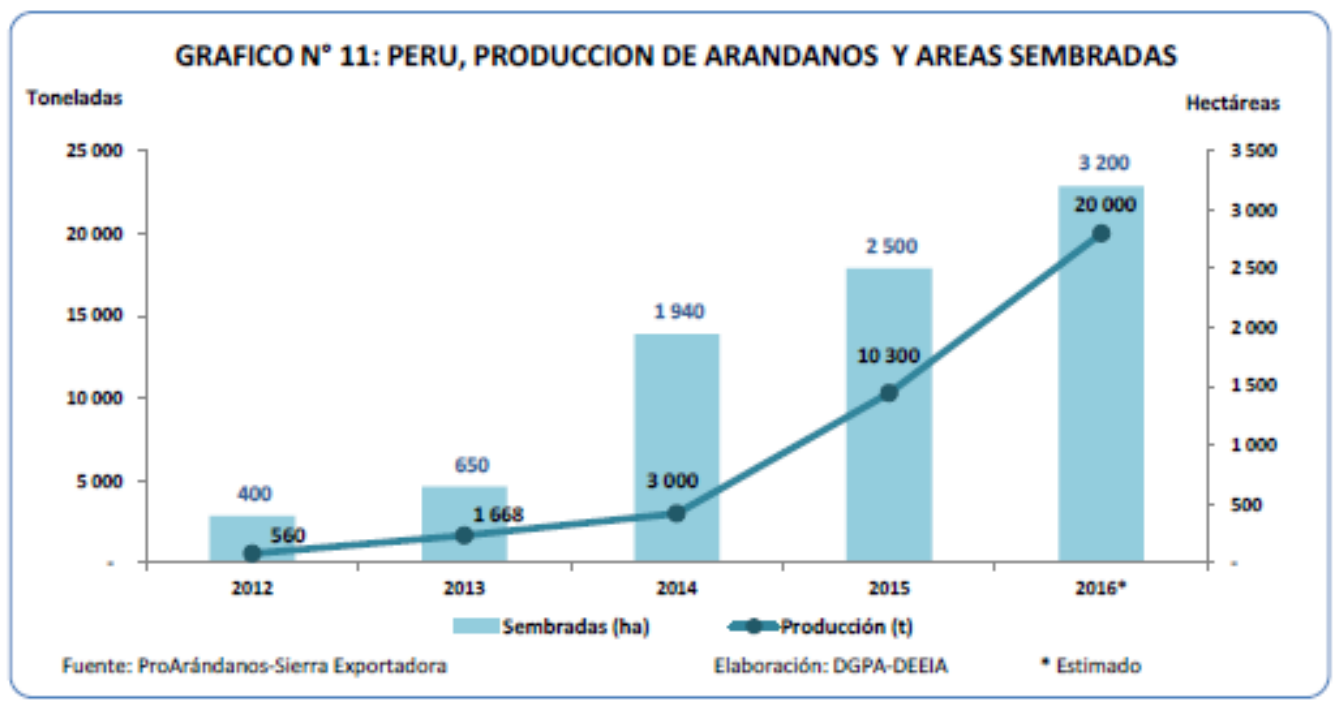

Gráfico 43. Producción nacional de arándanos.

Pro Arándanos-sierra exportadora

El Perú cuenta con una diversidad de climas y micro climas en todas las regiones, se puede producir arándanos durante todos los meses del año, excepcionalmente la mayor producción se presenta en los meses de septiembre a noviembre. 
El arándano es una baya o frutas del bosque originario de América del Norte,

donde crece en forma natural y silvestre. El arándano pertenece a la familia de los berries, tiene proyecciones de crecimiento en diversos mercados del exterior debido a sus características nutricionales, contiene gran cantidad de antioxidantes con beneficios para la salud de las personas. ${ }^{12}$

Con respecto a las zonas de producción, en la siguiente imagen mostramos las regiones de Perú con mayor potencial de producción de arándanos y listado de productores.

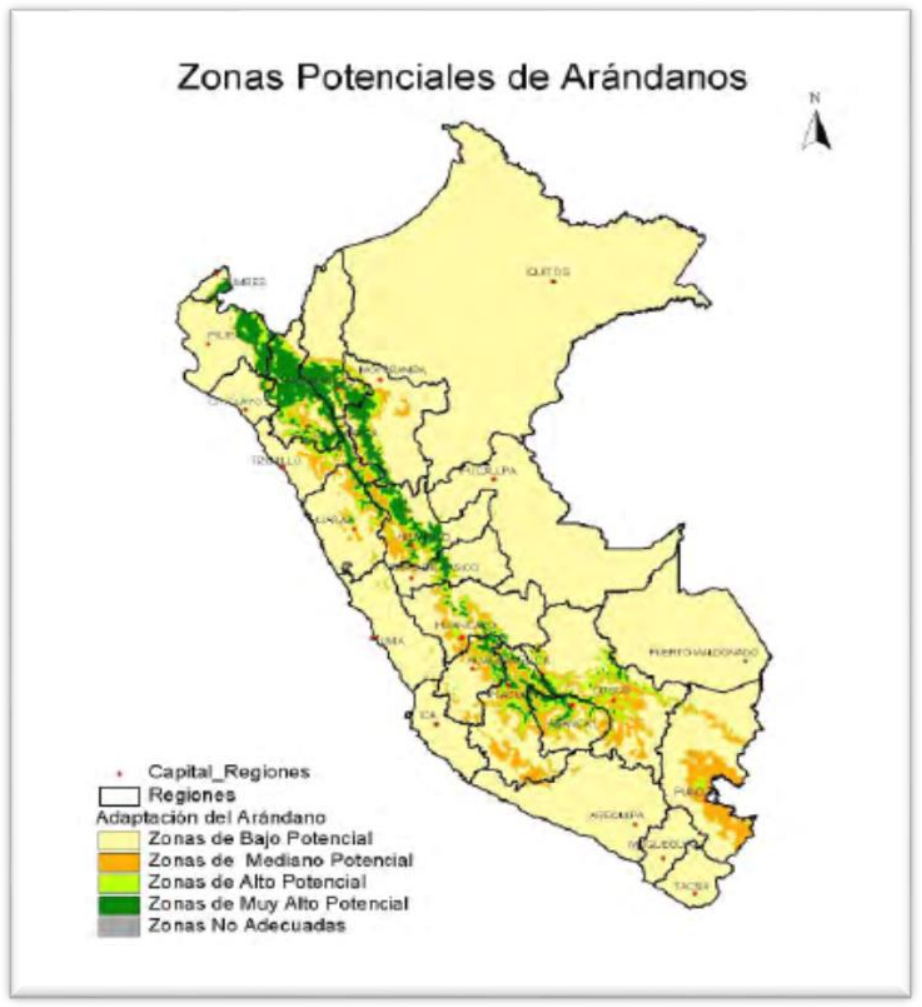

Gráfico 44. Zonas potenciales de producción de arándanos.

Tomado de Minagri arandano 2016.

\footnotetext{
12 Minagri (2018, $05 \quad$ de $\quad$ Julio) http://agroaldia.minagri.gob.pe/biblioteca/download/pdf/tematicas/f-taxonomia_plantas/f01cultivo/el_arandano.pdf
} 
También se ha identificado a algunos de los agricultores y empresas en las regiones del país que formaran parte de la base de datos de los proveedores con quienes debemos negociar la compra de la materia prima principal como es el arándano fresco.

\begin{tabular}{|l|l|l|}
\hline$N^{\circ}$ & \multicolumn{1}{|c|}{ EMPRESA } & DEPARTAMENTO \\
\hline 1 & Agroinversiones Valle y Pampa Perú S.A & Lima \\
\hline 2 & Bcg Publicidad \& Agronegocios SAC & Lima \\
\hline 3 & Berries del Sur SAC & Arequipa \\
\hline 4 & Camposol S.A. & La Libertad \\
\hline 5 & Green Box & Junín \\
\hline 6 & Inka Fresh & Lima \\
\hline 7 & Procesos Agroindustriales & Ica \\
\hline 8 & Pronatur & Lambayeque \\
\hline 9 & Agrícola don Ricardo SAC & Ica \\
\hline 10 & Arequipa Berries & Arequipa \\
\hline 11 & Agrícola Isabel SAC & Lima \\
\hline 12 & Agroindustria Santa Marina SAC & Ancash \\
\hline 13 & Apu Ecolodge & Ancash \\
\hline 14 & $\begin{array}{l}\text { Asociación Productora Agropecuaria Forestal, Acuícola } \\
\text { Vertiente la Leche }\end{array}$ & Lambayeque \\
\hline 15 & $\begin{array}{l}\text { Asociación de Productores Ecológicos Altoandinos } \\
\text { Pozuzo - Totoras }\end{array}$ & Lambayeque \\
\hline 16 & Asociación Virgen de la Medalla Milagrosa & Trujillo \\
\hline 17 & Best Berries Peru SAC. & Arequipa \\
\hline 18 & Consorcio Iberia & \\
\hline 19 & Empresa Productos del Valle & Lima \\
\hline 20 & Frutícola la Joyita & Arajo \\
\hline
\end{tabular}

Cuadro 62. Proveedores de arándanos.

Tomado de Revista Directorio Berries Perú. 
Los proveedores de manzana y piña que están ubicados en Lima con mayor disponibilidad en todo el año es el Mercado Mayorista de Fruta $\mathrm{N}^{\circ}$ 2, en donde están asociados los mayoristas y sectorizados según tipo de fruta. Para el proyecto tenemos identificado a un mayorista Inv. Vitto SAC del señor Víctor Gonzales Salsavilca que actualmente abastece de fruta para uso industrial a la empresa Procesadora Catalina SAC que tiene como principal marca Naturale.

Así mismo se menciona algunas empresas comercializadoras de fruta como: Agroselva SAC, Valle y Pampa, Agrícola Cerro Prieto.

Para el acopio y compra directa a los agricultores se tendrán en cuentas las estrategias definidas que garanticen el flujo del proceso del negocio. A continuación se detalla el diagrama de proceso.

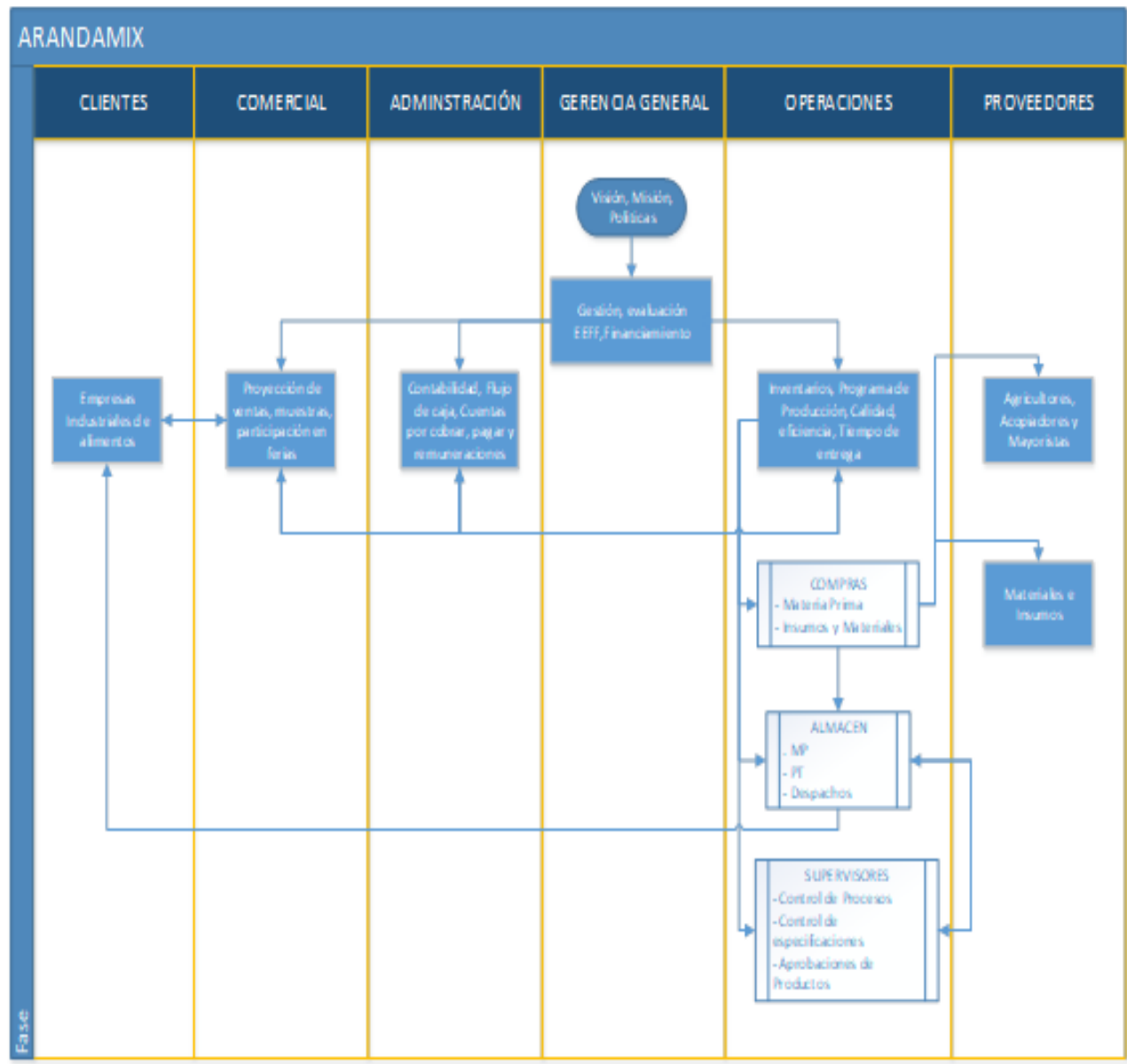

Gráfico 45. Diagrama de proceso.

Elaboración propia. 


\subsubsection{Recepción.}

Todas las frutas se reciben de las unidades de carga y se procede a ingresar en almacén de materias primas, se debe realizar controles cualitativos y cuantitativos de las frutas, nos deben permitir garantizar la inocuidad de la materia prima y registrar las mermas. Las actividades que se realizan en esta operación son de pesado, inspección y acondicionamiento para entrega posterior a planta de proceso. También se debe rechazar todo producto que no cumpla con las especificaciones requeridas. En el laboratorio se deben realizar análisis para evaluar los atributos organolépticos de cada fruta.

\subsubsection{Almacenamiento.}

La fruta cosechada pierde su resistencia natural a la acción de los microorganismos, es decir se deteriora en el tiempo. Son perecibles.

Se deben cumplir medidas para prevenir la pudrición de la fruta, en donde incluye lo siguiente:

- Evitar cortes y magulladuras durante la cosecha, transporte y almacenamiento.

- Controlar y registrar la intensidad de respiración y de maduración durante el almacenamiento.

Los almacenes deben estar herméticos, ventilados y secos, no debe tener circulación forzada del aire que pudiera influenciar a pérdidas de peso mediante evaporación del aire. La humedad relativa de los almacenes debe estar entre 70 a $80 \%$.

\subsubsection{Lavado y enjuague.}

La operación de lavado tiene un objetivo específico, solo retirar las impurezas del campo, como tierra y polvo, además de las materias extrañas que puedan estar adheridas a la fruta. El lavado también retira los microorganismos. El agua para lavar contiene detergentes y otras sustancias desinfectantes que sirven para remover completamente estos residuos. Se tiene una dosificación de acuerdo a la ficha técnica. 
Finalmente después de lavar se enjuagan para eliminar residuos de desinfectante.

\subsubsection{Selección.}

En esta operación las frutas que cumplen la especificación son aquellas con buen sabor, apariencia buena, limpios, de tamaño estándar y color uniforme. Todas aquellas que no cumplen serán separadas para tener otro tratamiento y disposición.

\subsubsection{Corte.}

Según la fruta a procesar como la manzana y la piña se procede con el corte por la mitad, se debe pelar o rebanar según el tipo de fruta. Los cortes deben realizarse en un tamaño estándar, la finalidad es asegurar el cumplimiento de la calidad y tiempo estándar al momento del deshidratado.

Para el caso de los arándanos no procede el corte.

\subsubsection{Control químico.}

Esta operación tiene como objetivo preservar el color y el sabor de la fruta, además de mantener sus nutrientes, reducir la descomposición de acción enzimática, asegurar un deshidratado estándar y extender la vida útil del producto.

La fruta debe ser tratada químicamente antes del proceso de deshidratación. Para detener la acción enzimática.

\subsubsection{Colocación en Bandejas.}

Una vez que la fruta ha sido pelada, cortada por la mitad, en rodajas y sometido al control químico; estás se colocan en bandejas en una cantidad aproximada de 4-6 kg/m². Es importante tener en consideración al momento de cortar, los trozos deben tener el mismo grosor, deben colocarse una a una sin traslaparse ni toparse para evitar que se peguen. Finalmente la fruta se coloca sobre bandejas que han sido previamente rociadas con una fina capa de glicerina. 


\subsubsection{Deshidratado.}

Es la operación más importante del flujo, para garantizar un proceso de deshidratado de calidad superior se debe cumplir lo siguiente:

- El sistema debe tener suficiente calor para extraer eficientemente toda la humedad que se genera, no debe generar cocción que pudiera afectar el sabor, textura y color de la fruta.

- El aire que ingresa al sistema debe ser seco para extraer la humedad del producto.

- La circulación de aire debe ser continuo y suficiente para absorber la humedad fuera del túnel de secado.

La temperatura para deshidratar frutas es de $50^{\circ}$ a $60^{\circ} \mathrm{C}$. El tiempo para el proceso de deshidratado de la fruta va a depender de las características como su grosor, humedad relativa, calor y temperatura ambiente en la máquina y sala de proceso.

Los tiempos de secado para las frutas a deshidratar son: arándanos de 8 a 12 horas, manzana de 2 a 3 horas y piña de 3 a 4 horas.

\subsubsection{Enfriamiento.}

Etapa de reposo en condiciones controladas de temperatura entre $20^{\circ} \mathrm{C} \mathrm{a} 24^{\circ} \mathrm{C}$ y humedad entre $50 \%$ a $70 \%$ para mantener las características organolépticas del producto deshidratado.

\subsubsection{Empacado.}

Las frutas deshidratadas en óptimas condiciones de conservación se llenan a granel en bolsas de polietileno de 10 kilogramos como empaque primario y en cajas de cartón corrugado como empaque secundario para luego ser rotulado con los datos respectivos de cada producto. 


\subsubsection{Almacenado.}

Una vez que el producto deshidratado esta empacado y paletizado, se entrega al almacén para ser ubicado en la posición respectiva; el almacén debe cumplir con condiciones de temperatura ambiente de 18 a $22^{\circ} \mathrm{C}$ y humedad relativa entre 60 a $75 \%$.

\section{Flujo de Deshidratado}

A continuación se detalla el diagrama de operaciones del proceso teniendo como resumen lo siguiente:

\section{RESUMEN}

\begin{tabular}{|l|c|c|}
\hline \multicolumn{1}{|c|}{ ACTIVIDAD } & SIMBOLO & CANTIDAD \\
\hline Operación & & 7 \\
\hline Operación/Inspección & & 3 \\
\hline Inspección & & 2 \\
\hline Almacenamiento & $\nabla$ & 2 \\
\hline Transporte & $\checkmark$ & 2 \\
\hline
\end{tabular}

Cuadro 64. Resumen flujo deshidratado Elaboración propia. 
Gráfico 46. Diagrama de flujo.

Fuente: Elaboración propia.

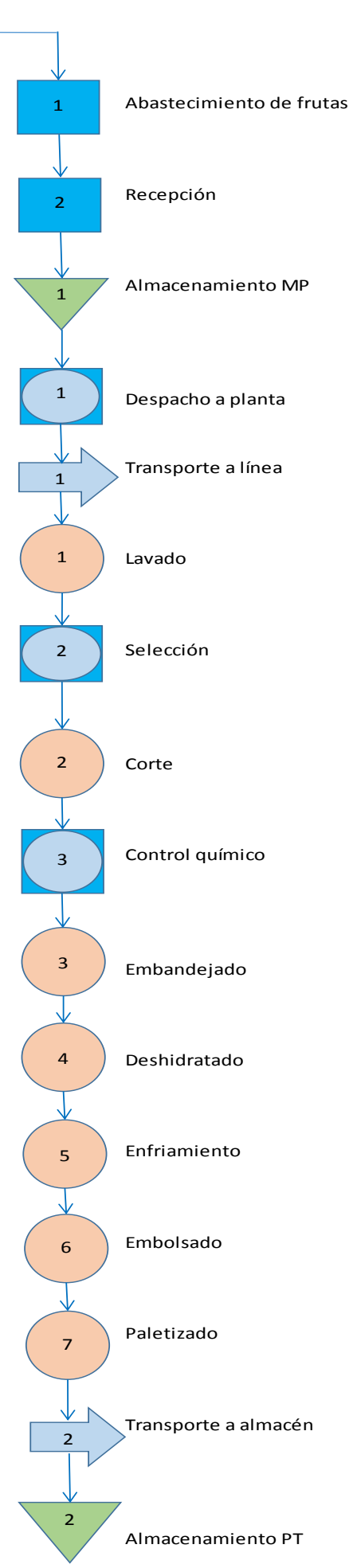




\subsubsection{Selección de Equipamiento}

A continuación detallamos los activos fijos a adquirir para el área productiva y

administrativa.

\begin{tabular}{|c|c|c|}
\hline ACTIVO TANGIBLE & & \\
\hline ACTIVO FIJO DEPRECIABLE & & \\
\hline PRODUCCION & Cantidad & $\begin{array}{c}\text { Valor Total con IGV en } \\
\text { S/. }\end{array}$ \\
\hline Edificio y amoblado & 1 & 190,000 \\
\hline Tanque de lavado & 1 & 10,000 \\
\hline Mesa escurridora & 1 & 1,500 \\
\hline Camara de frío & 1 & 40,000 \\
\hline Tamizador eléctrico & 1 & 8,000 \\
\hline Cortador y rajador & 1 & 4,000 \\
\hline Horno deshidratador & 1 & 100,000 \\
\hline Mesa de selección & 1 & 1,500 \\
\hline Embolsadora & 1 & 80,000 \\
\hline Detector de metal & 1 & 48,000 \\
\hline Encintadora & 1 & 3,500 \\
\hline Laptop HP Ci5 Pavilion 14-bs026la 7G/8/1/14/W10 & 2 & 3,620 \\
\hline $\begin{array}{l}\text { TOTAL } \\
\end{array}$ & & 490,120 \\
\hline ADMINISTRACION & Cantidad & $\begin{array}{c}\text { Valor Total con IGV en } \\
\text { S/. }\end{array}$ \\
\hline Laptop HP Ci5 Pavilion 14-bs026la 7G/8/1/14/W10 & 3 & 5,430 \\
\hline Proyector Viewsonic PJD5255 3300XGA HDMI & 1 & 1,642 \\
\hline TOTAL & & 7,072 \\
\hline VENTAS & Cantidad & $\begin{array}{c}\text { Valor Total con IGV en } \\
\text { S/. }\end{array}$ \\
\hline Laptop HP Ci5 Pavilion 14-bs026la 7G/8/1/14/W10 & 1 & 1,810 \\
\hline $\begin{array}{l}\text { TOTAL } \\
\end{array}$ & & 1,810 \\
\hline TOTAL ACTIVO DEPRECIABLE & & 499,002 \\
\hline
\end{tabular}

Cuadro 65. Activo fijo depreciable

Elaboración propia.

\subsubsection{Lay Out}

La planta para producir frutas deshidratadas requiere un área de $900 \mathrm{~m} 2$ con una

capacidad de $180 \mathrm{~kg} /$ día. La infraestructura y edificación que se caracteriza para procesar frutas debe cumplir las siguientes normas:

Decreto supremo 007-98-SA y Reglamento nacional de edificaciones (RNE). 
El lay out nos permite disponer en forma general la planta considerando actividades de procesos productivos, operaciones, servicios y gestión integral.

Las áreas que se requieren están determinadas para el almacenamiento, procesos productivos, laboratorio, servicios generales, vestuarios, estacionamientos y oficinas administrativas.

Para optimizar los recursos se realiza un diagrama relacional entre las diferentes áreas que se proyecta implementar.

\begin{tabular}{|c|c|}
\hline Código & Valor de proximidad \\
\hline A & Absolutamente necesario \\
\hline E & Especialmente necesario \\
\hline I & Importante \\
\hline 0 & Normal \\
\hline $\mathrm{U}$ & Sin importancia \\
\hline $\mathrm{X}$ & No recomendable \\
\hline
\end{tabular}

Cuadro 66. Cuadro de optimización de recursos.

Tomado de Disposición de planta. Diaz, Jarufe y Nriega.2001

Haciendo uso de la tabla de proximidad se procede a la elaboración de la tabla relacional; este último es un cuadro organizado en forma diagonal, en el que se registran las relaciones de cercanía o proximidad entre cada actividad. 
LAY OUT DE PLANTA DESHIDRATADORA DE FRUTAS

ARANDAMIX

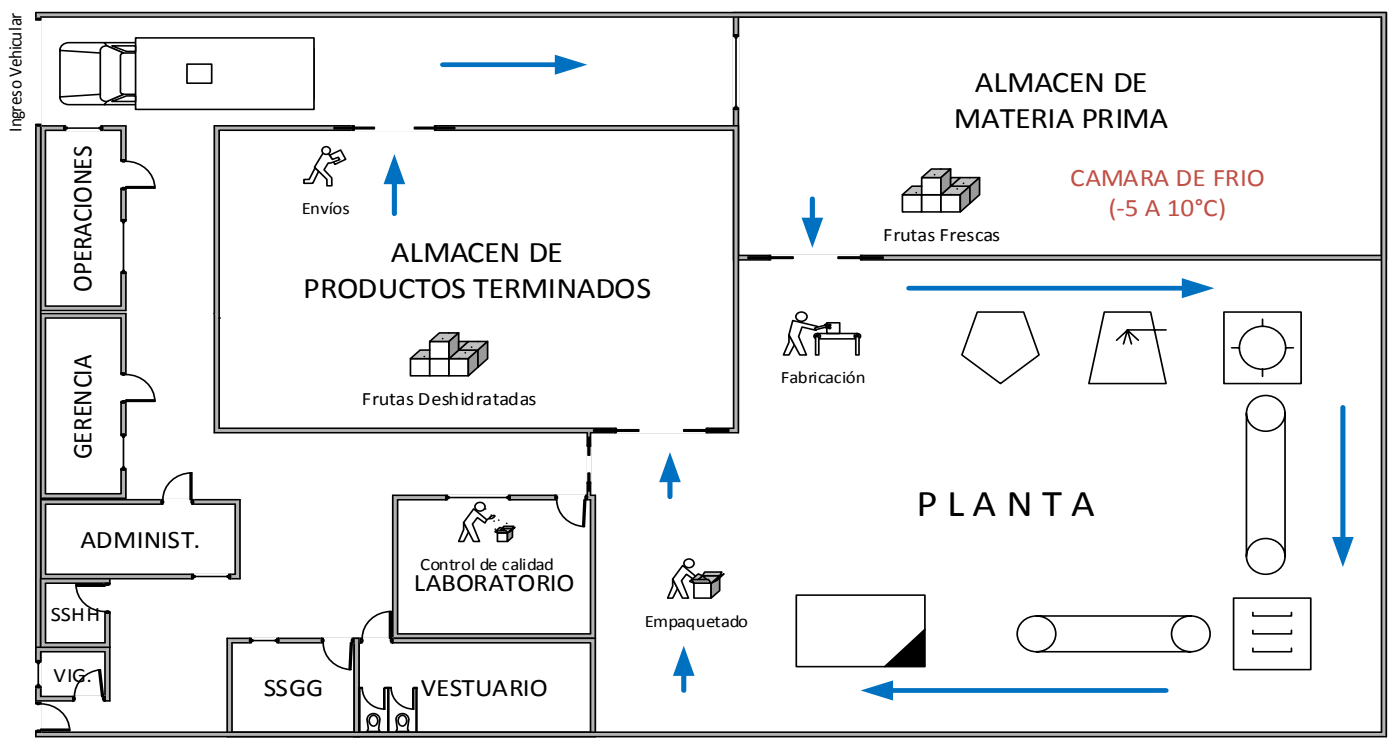

Gráfico 47. Layout de planta deshidratadora.

Elaboración propia.

\subsection{Determinación del Tamaño}

El tamaño del proyecto está en función de la capacidad instalada de producción, al tiempo de duración y la demanda proyectada. El proyecto tiene un horizonte de cinco años en donde se realizará la inversión de maquinaria y equipos.

La ubicación del proyecto está definido ejecutar en el departamento de Lima de acuerdo a los factores asignados en la evaluación de macro localización y micro localización.

\subsubsection{Proyección de crecimiento.}

Capacidad Máxima (sistema).

La capacidad máxima se obtiene de manera integrada utilizando los 365 días del año y todos los recursos que esto implica. En este caso la capacidad máxima anual será:

$180 \mathrm{~kg} /$ día x 365 días/año = $65700 \mathrm{~kg} / \mathrm{año}$. 


\subsubsection{Capacidad de Diseño.}

La capacidad de diseño está dada en condiciones normales de funcionamiento y está definida por el sistema de deshidratado continuo, siendo $180 \mathrm{~kg} /$ día.

Utilizando todos los recursos en el horario establecido se tiene la siguiente capacidad anual: $180 \mathrm{~kg} /$ día x 6 días/semana x 52 semanas = 56160 kg/año.

\subsubsection{Capacidad Real.}

Capacidad promedio anual, de acuerdo con variables internas como capacidad de respuesta y externas como la demanda potencial. Para el proyecto tenemos la capacidad del año 2019 en 14500 kg/año, teniendo una ocupación del 26\% de la capacidad de diseño.

A continuación se muestra cuadro de uso de capacidades.

\begin{tabular}{|l|r|r|r|r|r|}
\cline { 2 - 6 } \multicolumn{1}{c|}{} & \multicolumn{5}{c|}{ AÑOS } \\
\hline TAMAÑO & \multicolumn{1}{c|}{2019} & \multicolumn{1}{c|}{2020} & \multicolumn{1}{c|}{2021} & \multicolumn{1}{c|}{2022} & \multicolumn{1}{c|}{2023} \\
\hline Máxima (Kg) & 65,700 & 65,700 & 65,700 & 65,700 & 65,700 \\
\hline Diseño (Kg) & 56,160 & 56,160 & 56,160 & 56,160 & 56,160 \\
\hline Pronostico (Kg) & 14,500 & 18,828 & 23,777 & 29,423 & 35,854 \\
\hline Utilización (\%) & $26 \%$ & $34 \%$ & $42 \%$ & $52 \%$ & $64 \%$ \\
\hline
\end{tabular}

Cuadro 66. Capacidad y uso de la planta.

Elaboración propia.

\subsubsection{Recursos.}

A continuación detallamos el personal que se requiere para cubrir las áreas de producción y almacenamiento de acuerdo a puesto y función dentro de la empresa; para el proceso productivo se tiene 4 operarios y 1 operador senior quienes realizaran la primera etapa del proceso hasta el deshidratado; la segunda etapa corresponde al envasado con el mismo personal. 


\begin{tabular}{|c|c|c|}
\hline CANTIDAD & PUESTO & FUNCIÓN \\
\hline \multirow{3}{*}{1} & \multirow{3}{*}{$\begin{array}{l}\text { Operario de } \\
\text { Recepción / } \\
\text { Almacenamiento }\end{array}$} & $\begin{array}{l}\text { Se encarga de recibir las frutas frescas de los proveedores } \\
\text { cumpliendo con los controles de calidad. }\end{array}$ \\
\hline & & $\begin{array}{l}\text { Se encarga ubicar las frutas en el almacén cumpliendo los } \\
\text { estandares FIFO. }\end{array}$ \\
\hline & & $\begin{array}{l}\text { Se encarga de entregar la fruta fresca a la linea para el } \\
\text { proceso productivo cumpliendo con los estándares de calidad, } \\
\text { inocuidad y seguridad. }\end{array}$ \\
\hline 1 & Operario de Lavado & $\begin{array}{l}\text { Se encarga de lavar la fruta y seleccionar aquellas que no } \\
\text { cumplen con los atributos de calidad. }\end{array}$ \\
\hline 2 & $\begin{array}{l}\text { Operario de } \\
\text { Selección / } \\
\text { Embolsado }\end{array}$ & $\begin{array}{l}\text { Se encarga de seleccionar la fruta de acuerdo a la } \\
\text { especificación de calidad para ser deshidratado. Separa } \\
\text { aquellas frutas que no cumplen la especificación. }\end{array}$ \\
\hline \multirow{3}{*}{1} & Operario de Corte & $\begin{array}{l}\text { Se encargan de realizar el corte a las frutas como manzana y } \\
\text { piña según la especificación técnica del producto a } \\
\text { deshidratar. }\end{array}$ \\
\hline & \multirow{2}{*}{$\begin{array}{l}\text { Operario de } \\
\text { Enbandejado } \\
\text { /Paletizado }\end{array}$} & $\begin{array}{l}\text { Se encarga de colocar las frutas previamente lavadas, } \\
\text { seleccionadas y cortadas en bandejas. Deben tener cuidado } \\
\text { con colocar la cantidad uniformemente y según cantidad } \\
\text { especificada. }\end{array}$ \\
\hline & & $\begin{array}{l}\text { Se encarga de apilar las cajas de producto deshidratado en } \\
\text { una parihuela, debe ordenarlos y rotularlos según la } \\
\text { especificación del producto. }\end{array}$ \\
\hline \multirow{2}{*}{1} & \multirow{2}{*}{$\begin{array}{l}\text { Operador de } \\
\text { Deshidratado / } \\
\text { Envasado }\end{array}$} & $\begin{array}{l}\text { Se encarga de colocar las bandejas en el horno o cámara } \\
\text { deshidratadora para iniciar el proceso durante una cantidad } \\
\text { de horas de acuerdo al tipo de fruta. }\end{array}$ \\
\hline & & $\begin{array}{l}\text { Se encarga de llenar y embolsar el producto deshidratado en } \\
\text { los envases primario y secundario. Debe realizar el rotulado } \\
\text { de acuerdo a la especificación del producto. }\end{array}$ \\
\hline
\end{tabular}

Cuadro 68. Cuadro de personal

Elaboración propia.

\subsubsection{Tecnología}

Para el proyecto se detallan las necesidades de Máquinas y Equipos.

\subsubsection{Tanques de Lavado.}

Estructura de acero inoxidable de $1 \frac{1}{2} 2$, se utiliza para lavar las frutas luego de haber sido recepcionados de los centros de acopio.

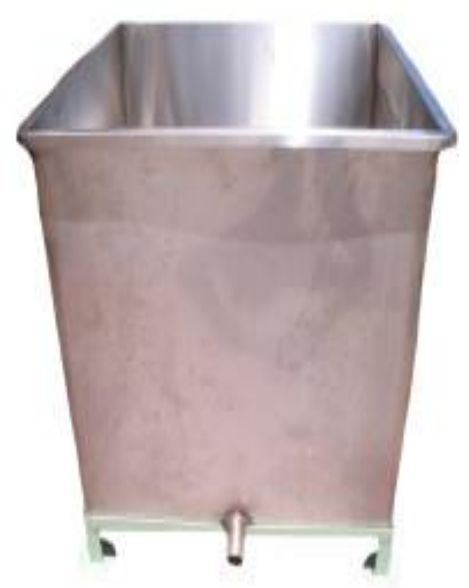

Figura 1. Tanque de lavado.

Tomado de Sttradinco Industrial S.A.C. 


\subsubsection{Mesa Escurridora}

Mesas de acero inoxidable con perforaciones circulares de 3 a $5 \mathrm{~mm}$, que permite reducir los restos de agua al momento de retirar del tanque de lavado.

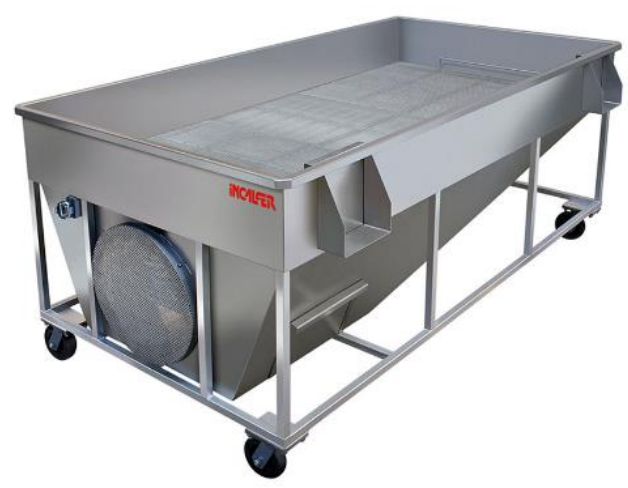

Figura 2. Mesa escurridora.

Tomado de Sttradinco Industrial S.A.C.

\subsubsection{Cámara de frio}

Espacio cerrado herméticamente con un sistema de refrigeración que mantiene la temperatura entre -5 a $10{ }^{\circ} \mathrm{C}$ que permite almacenar las frutas frescas y lavados en espera de la siguiente operación. Minimiza el deterioro por madurez de la fruta.

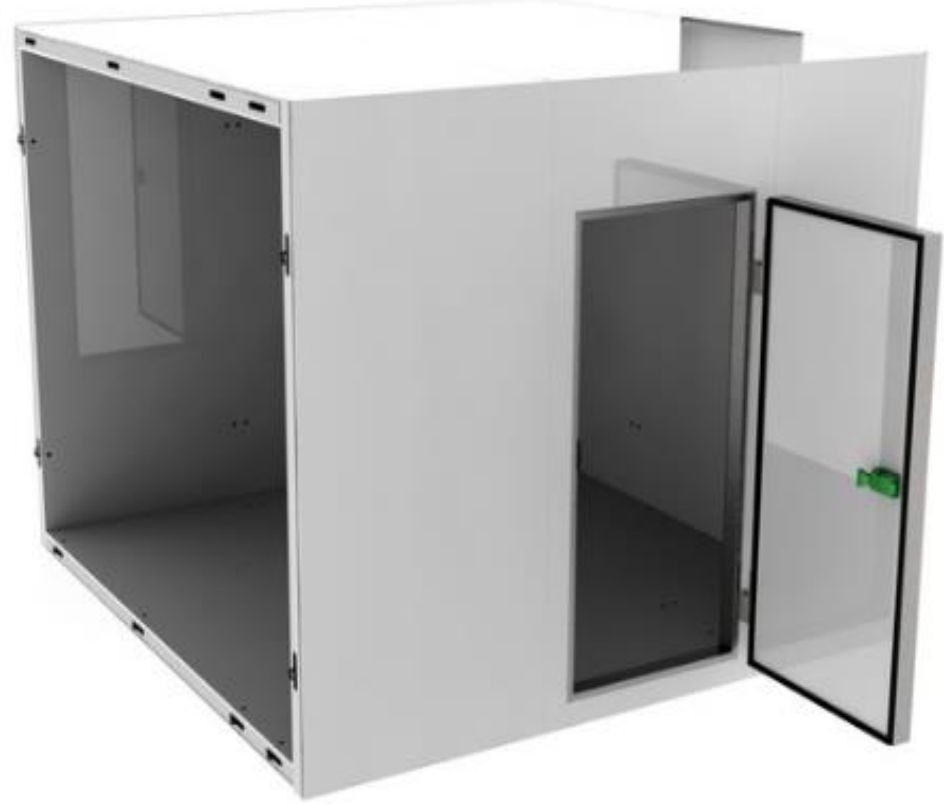

Figura 3. Cámara de frío

Tomado de Sttradinco Industrial S.A.C. 


\subsubsection{Tamizador eléctrico}

Equipo que clasifica la fruta de acuerdo a la especificación del producto.

Figura 4. Tamizador eléctrico.

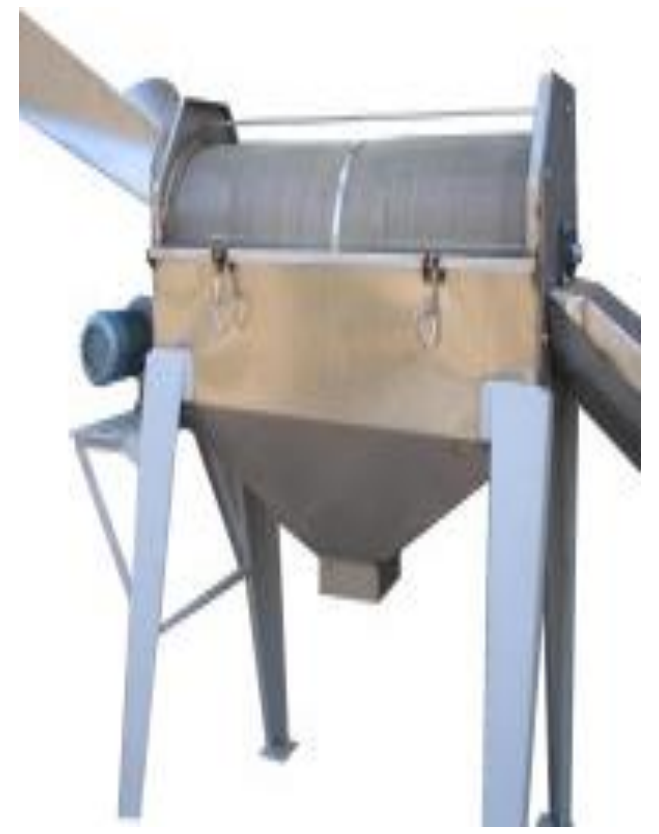

Tomado de Sttradinco Industrial S.A.C.

\subsubsection{Cortador y rajador}

Equipo que troza la fruta según el tamaño especificado. Utiliza mallas que determinan el calibre a procesar.

Figura 5. Cortador y rajador.

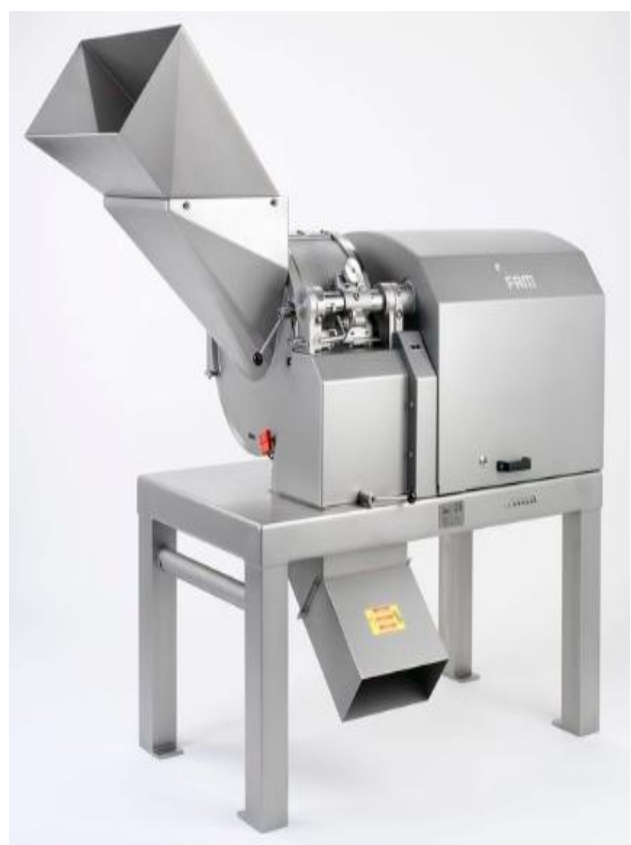

Tomado de Sttradinco Industrial S.A.C. 


\subsubsection{Horno Deshidratador}

Equipo eléctrico con un sistema de inyección y extracción de aire caliente que trabaja de acuerdo al tipo de fruta a deshidratar estando entre 50 a $70{ }^{\circ} \mathrm{C}$. Utiliza bandejas en donde se coloca las frutas trozadas o picadas en rodajas.

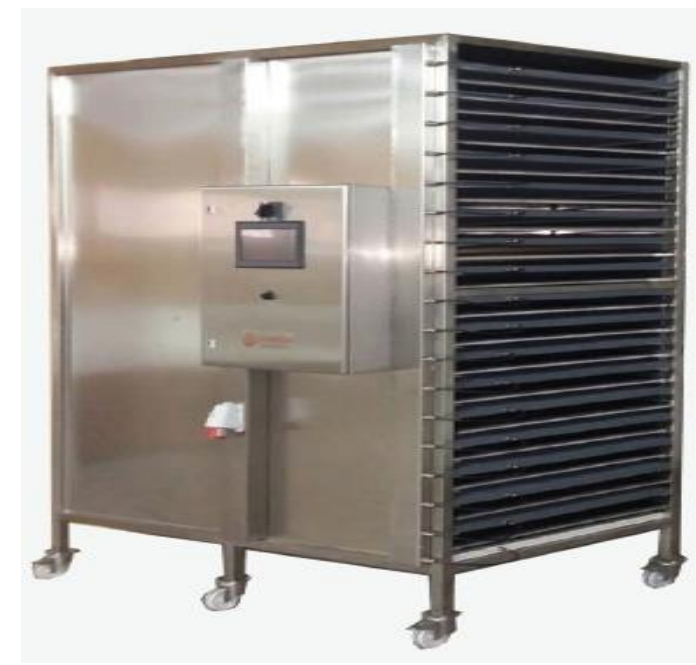

Figura 6. Horno deshidratador.

Fuente: Sttradinco Industrial S.A.C.

\subsubsection{Mesas de Selección}

Mesas de acero inoxidable que se utiliza para seleccionar, clasificar o separar frutas deshidratadas que no cumplen la especificación del producto terminado.

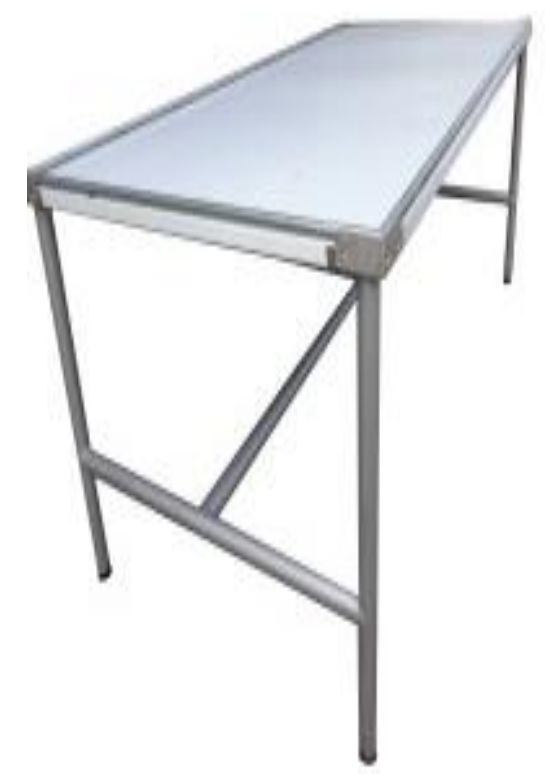

Figura 7. Mesa de selección.

Tomado de Sttradinco Industrial S.A.C. 


\subsubsection{Embolsadora}

Para realizar esta operación, se utilizará una máquina con el diseño apropiado para el llenado a granel en bolsas de boca abierta hasta $50 \mathrm{~kg}$. Las características principales son: Sistema sujeta bolsas neumático, conducto de despresurización, pesaje directo en la bolsa, sistema de doble velocidad de carga.

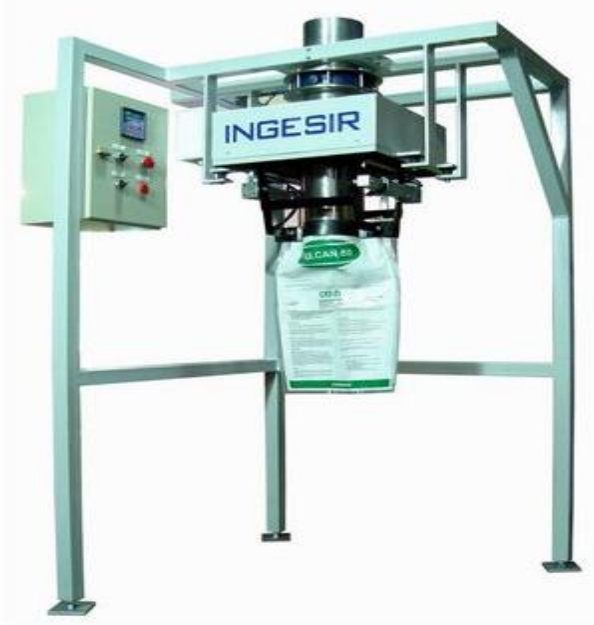

Figura 8. Embolsadora.

Tomado de Sttradinco Industrial S.A.C.

\subsubsection{Detector de metal}

Equipo de control y monitoreo para asegurar la inocuidad del producto, identificando elementos físicos metálicos y no metálicos que contaminen el producto.

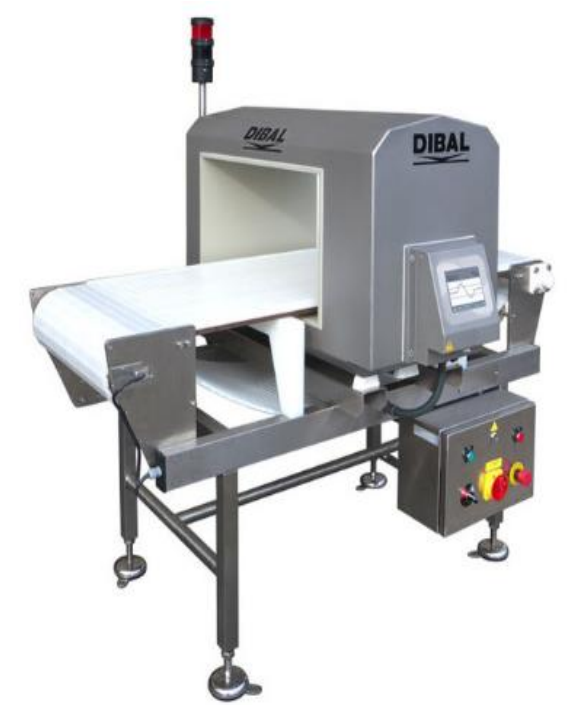

Figura 9. Detector de metal.

Tomado de Sttradinco Industrial S.A.C. 


\subsubsection{Encintadora.}

Es una máquina semiautomática que utiliza bandas laterales y una base de rodillos giratorios para el desplazamiento de la caja, evitando así atascamientos. Utiliza cinta adhesiva superior e inferior.

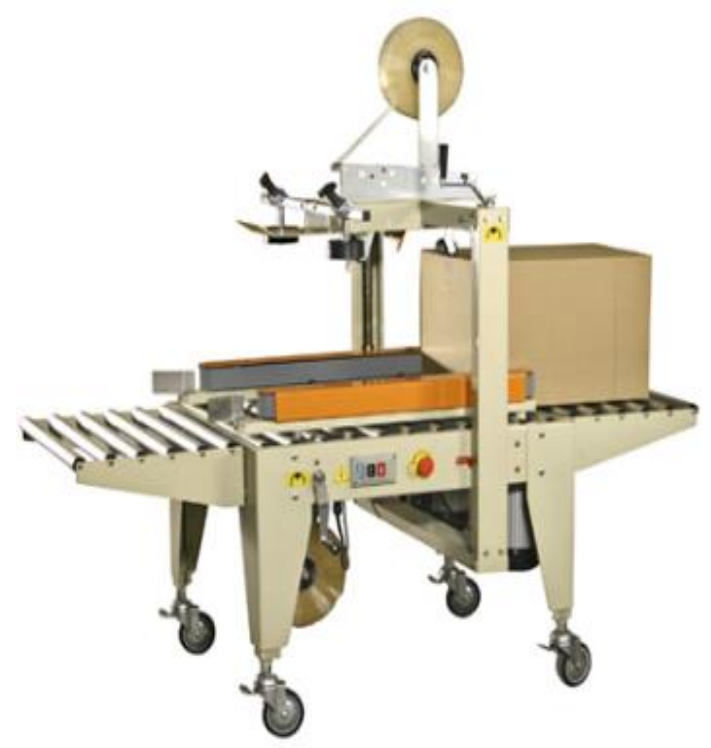

Figura 10. Encintadora.

Tomado de Sttradinco Industrial S.A.C.

\subsubsection{Flexibilidad.}

La tecnología a utilizar es de uso general, la línea de deshidratado tiene máquinas y quipos que pueden adaptarse fácilmente a cualquier otra fruta o verdura fresca para deshidratar.

La máquina de mayor importancia es el horno deshidratador, esta máquina tiene el mismo principio de operación, tiene variación de los tiempos de procesos que están asociados a los rendimientos de cada fruta.

\subsubsection{Selección del tamaño ideal.}

Para determinar el tamaño ideal utilizamos el método Guerchett, se basa en el cálculo del área mínima de cada sección mediante el cálculo de: 
i. Superficie Estática (SS), es el área mínima que necesita para que trabaje la máquina. Se calcula el largo por ancho de la máquina o equipo.

ii. Superficie Gravitacional (SG), es el área necesaria que se necesita cuando la máquina está en funcionamiento. Se calcula multiplicando el número de lados útiles por la superficie estática.

iii. Superficie Evolutiva (SE), es una parte del área total requerida, que se destina para la circulación y ejecución de elementos adicionales. Se calcula multiplicando la constante K por la suma de las superficies estática y gravitacional.

Para calcular $\mathrm{K}$ se tiene la siguiente formula: $\mathrm{K}=\mathrm{hEm} / 2 \mathrm{hEE}$

Dónde:

h, es la altura promedio de los elementos que se desplazan dentro de la línea productiva.

2h, es la altura promedio de los elementos que no se desplazan dentro de la línea productiva

Para el proyecto, se han realizado los cálculos y se ha determinado que la necesidad total de espacio es de $1000 \mathrm{~m} 2$. El resumen se muestra en el siguiente cuadro.

\begin{tabular}{|l|c|c|}
\hline \multicolumn{1}{|c|}{ ITEM } & UNIDAD & TAMAÑO \\
\hline Almacén de materia prima & $\mathrm{m} 2$ & 160 \\
\hline Area de lavado y procesamiento humedo & $\mathrm{m} 2$ & 80 \\
\hline Area de procesamiento seco & $\mathrm{m} 2$ & 120 \\
\hline Area de envasado & $\mathrm{m} 2$ & 100 \\
\hline Laboratorio de Control de Calidad & $\mathrm{m} 2$ & 28 \\
\hline Almacén de producto terminado & $\mathrm{m} 2$ & 200 \\
\hline Servicios generales & $\mathrm{m} 2$ & 20 \\
\hline Vestuarios y servicios higienicos & $\mathrm{m} 2$ & 26 \\
\hline Oficinas administrativas & $\mathrm{m} 2$ & 42 \\
\hline Patio de maniobra & $\mathrm{m} 2$ & 74 \\
\hline Accesos y estacionamiento TOTAL & $\mathrm{m} 2$ & 50 \\
\hline
\end{tabular}

Cuadro 69. Áreas de la planta deshidratadora.

Elaboración propia 


\section{3. $\quad$ Estudio de Localización}

\subsubsection{Definición de factores locacionales}

Para determinar la localización optima, se tiene en consideración criterios que minimicen los costos de inversión y los gastos dentro del proceso productivo del deshidratado de frutas.

\subsubsection{Macro Localización.}

Ha sido seleccionado el departamento de Lima, los factores de mayor relevancia fueron la ubicación del mercado por estar cerca a los clientes; la disponibilidad de mano de obra calificada y la cercanía a los puntos de acopio y agricultores. A continuación se muestra la evaluación.

\begin{tabular}{|c|c|c|c|c|c|c|c|}
\hline \multirow[b]{2}{*}{ FACTORES } & \multicolumn{3}{|c|}{ TRUJILO } & \multicolumn{2}{|c|}{ AREQUPA } & \multicolumn{2}{|c|}{ LIMA } \\
\hline & & $\begin{array}{c}\text { Calificación } \\
(0-10)\end{array}$ & Ponderación & $\begin{array}{c}\text { Calificación } \\
(0-10)\end{array}$ & Ponderación & $\begin{array}{c}\text { Calificación } \\
(0-10)\end{array}$ & Ponderación \\
\hline Mercado, cercania a los clientes & 0.25 & 5 & 1.25 & 5 & 1.25 & 8 & 2 \\
\hline Niveles de producción de frutas & 0.05 & 7 & 1.75 & 6 & 1.5 & 6 & 1.5 \\
\hline Productores, acopiadores & 0.20 & 9 & 2.25 & 7 & 1.75 & 6 & 1.5 \\
\hline Disponibilildad de mano de obra calificada & 0.10 & 6 & 1.5 & 6 & 1.5 & 7 & 1.75 \\
\hline Transporte yaccesibilididad de los usuarios. & 0.10 & 7 & 1.75 & 7 & 1.75 & 8 & 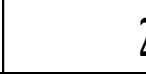 \\
\hline Seguridad y aspectos legales para instalación. & 0.05 & 4 & 1 & 6 & 1.5 & 5 & 1.25 \\
\hline Aspectos ambientales. & 0.05 & 5 & 1.25 & 6 & 1.5 & 6 & 1.5 \\
\hline Costoy disponibililidad de terrenos. & 0.20 & 8 & 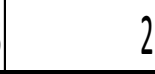 & 7 & 1.75 & 7 & 1.75 \\
\hline & 1.00 & & 12.75 & & 12.50 & & 13.25 \\
\hline
\end{tabular}

Cuadro 69. Macro localización.

Fuente: Elaboración propia

\subsubsection{Micro Localización.}

En el departamento de lima fueron evaluados los distritos de mayor disponibilidad de cumplimiento para los factores seleccionados. Los distritos elegidos fueron Los 
Olivos, Santa Anita y Ate. Los factores de mayor relevancia fueron la ubicación del terreno y los accesos para el transporte de carga y descarga, ampliación futura y costo de alquiler del terreno.

A continuación se detalla la evaluación.

\begin{tabular}{|c|c|c|c|c|c|c|c|}
\hline \multirow{2}{*}{ FACTORES } & \multirow{2}{*}{ PESO } & \multicolumn{2}{|c|}{ LOSOLIVOS } & \multicolumn{2}{|c|}{ SANTAANITA } & \multicolumn{2}{|c|}{ ATE } \\
\hline & & $\begin{array}{c}\text { Calificación } \\
(0-10)\end{array}$ & Ponderación & $\begin{array}{c}\text { Calificación } \\
(0-10)\end{array}$ & Ponderación & $\begin{array}{c}\text { Calificación } \\
(0-10)\end{array}$ & Ponderación \\
\hline Costo del terreno o alquiler. & 0.35 & 8 & 2.8 & 6 & 2.1 & 7 & 2.45 \\
\hline Ubicación del terreno & 0.15 & 6 & 2.1 & 8 & 2.8 & 6 & 2.1 \\
\hline Tamaño del terreno. & 0.15 & 5 & 1.75 & 6 & 2.1 & 5 & 1.75 \\
\hline Pago de servicios. & 0.05 & 6 & 2.1 & 5 & 1.75 & 6 & 2.1 \\
\hline Accesos para cargay descarga. & 0.20 & 7 & 2.45 & 8 & 2.8 & 7 & 2.45 \\
\hline Ampliación futura. & 0.10 & 5 & 1.75 & 6 & 2.1. & 5 & 1.75 \\
\hline & 1.00 & & 12.95 & & 13.65 & & 12.60 \\
\hline
\end{tabular}

Cuadro 70. Micro localización

Fuente: Elaboración propia

\subsubsection{Consideraciones legales.}

Normas legales de mercado, para el inicio de operaciones se requiere que la empresa se encuentre registrada en el Registro Único de Contribuyentes, según la ley $\mathrm{N}^{\circ}$ 26935, ley sobre simplificación de procedimientos para obtener Registros Administrativos. Adicionalmente contaremos con la Licencia Municipal de Funcionamiento de la Municipalidad de Santa Anita.

Licencia de Funcionamiento, la licencia de funcionamiento es requisito para el funcionamiento de la planta, es necesario que se presente la siguiente documentación:

- Solicitud de Licencia de Funcionamiento, la cual debe incluir el número de RUC y DNI del representante legal.

- Vigencia de poder del representante legal. 
- Declaración Jurada de Observancia de Condiciones de Seguridad o Inspección Técnica de Seguridad en Defensa Civil de Detalle o Multidisciplinaria, según corresponda.

- Informar sobre el número de estacionamientos de acuerdo a normativa vigente.

Registro Sanitario, requisito indispensable para estar autorizados a comercializar alimentos procesados en nuestro establecimiento. A continuación detallamos el proceso para obtenerlo:

Llenar formulario y anexo, el cual será presentado luego de obtener el análisis físico - químico y microbiológico suscrito por el representante legal. Este formulario debe contener la siguiente información:

- Nombre o Razón Social, domicilio y número de RUC.

- Nombre comercial y marca del producto o grupo de productos.

- Relación de ingredientes y composición cuantitativa de los aditivos.

- Condiciones de conservación y almacenamiento.

- Datos sobre el envase utilizado.

- Período de vida útil del producto en condiciones normales de conservación y almacenamiento, en función al estudio de vida del producto en anaquel.

- Llevar el producto a analizar en un laboratorio acreditado por INDECOPI para realizar análisis físicos, químicos y microbiológicos.

- Adjuntar los resultados de los análisis (tiene vigencia de 1 año).

- Luego de la revisión se debe efectuar el depósito por concepto de pago en el Banco de la Nación, el pago por trámite es de S/.241.50, tiene una duración de siete días útiles y una vigencia de cinco años. 


\subsubsection{Identificación del marco legal.}

La empresa se constituirá bajo la forma jurídica de Sociedad Anónima Cerrada (S.A.C.), cumpliendo con las disposiciones estipuladas en la ley General de Sociedades, ley 26887. Siendo principales características el no realizar cotizaciones en bolsa, suprimir al directorio, acreditar representación en la junta de accionistas mediante terceros, y responsabilidad limitada sólo por el patrimonio aportado de la empresa.

El accionariado está conformado por: Omar Aguilar 25\% de participación, Johnny Berrospi con 25\% de participación, Carlos Carbajal con 25\% de participación y Jorge Nieves con $25 \%$ de participación. La junta general de accionistas, conformada por los 4 participantes, designará como Administrador a Carlos Carbajal, el cual se encargará de la representación y administración de la empresa.

\subsubsection{Ordenamiento jurídico de la empresa.}

En cuanto a la legislación tributaria, las operaciones de la empresa se desarrollan dentro del régimen general del impuesto a la renta y renta empresarial (3ra categoría) donde se aplican el pago del $28 \%$ por concepto de Impuesto a la Renta (IR) y el $18 \%$ por concepto de pago de Impuesto General a las Ventas (IGV).

En cuanto a la legislación laboral, la empresa se acoge al régimen de Pequeña y Mediana Empresa (Pymes), DS No 009-2003-TR, con base en la ley No 28015 de promoción y formalización de la micro y pequeña empresa.

Encontramos como característica principal a la reducción de la carga laboral al $50 \%$, la obligatoriedad del seguro de EsSalud cuyo costo es subvencionado por el estado al $50 \%$ y la no obligatoriedad del pago de utilidades.

\subsection{Determinación de la localización óptima}

La localización óptima se encuentra en el departamento de Lima, distrito de Santa Anita. 


\section{Aspectos Organizacionales}

\subsection{Caracterización de la Cultura Organizacional Deseada}

En la actualidad, el análisis de la cultura organizacional se ha convertido en elemento primordial en las organizaciones de todo rubro. Nuestra cultura organizacional comprende la responsabilidad, el trabajo en equipo generando un ambiente adecuado y saludable para todos nuestros colaboradores, el respeto al medio ambiente, a la moral y buenas costumbres.

Nuestro equipo de colaboradores estará conformado por personal calificado y proactivo, con el compromiso de mejorar con el día a día y la vocación de excelencia frente a la organización.

Nuestra estructura organizacional será horizontal es decir una cadena sin mandos intermedios donde se les permite a los colaboradores tomar sus propias decisiones operativas del día a día, obteniendo sinergia y promoviendo el sano debate a mejoras continuas dentro de la organización.

\subsubsection{Visión.}

En el libro de Administración Estratégica de Fred David nos presenta desarrollar la visión de una empresa, planteando las preguntas siguientes:

¿Qué queremos llegar a ser?

Ser líder en venta y producción de frutos deshidratados a nivel nacional.

¿Qué resultados queremos alcanzar en el futuro?

Obtención de fidelización y fortalecimiento de la marca y tener posicionamiento en la mente de los clientes.

De acuerdo a las respuestas anteriores podemos plantear la siguiente visión: "Ser líder en venta y producción de frutos deshidratados a nivel nacional, obteniendo la 
fidelización de nuestros clientes a través de nuestros productos de calidad, consolidando nuestra posición con una imagen corporativa propia y diferenciada de sus competidores.

\subsubsection{Misión.}

En el libro de Administración Estratégica de Fred David nos presenta desarrollar la misión de una empresa, planteando las preguntas siguientes:

¿Cuál es nuestro negocio?

La producción y venta de frutos deshidratados a nivel nacional.

¿Qué necesidad satisfacemos?

La necesidad de proveer insumos de frutos deshidratados para uso industrial.

De acuerdo a las respuestas anteriores podemos plantear la siguiente misión:

"Producir y vender frutos deshidratados a nivel nacional, satisfaciendo las necesidades de nuestros clientes como a sus consumidores, actuando en forma sólida, responsable y amigable con el medio ambiente.

\subsubsection{Principios.}

Los principios organizacionales son los siguientes:

- Nuestros productos son $100 \%$ natural, conservando las vitaminas, fibras antioxidantes, reteniendo un alto porcentaje de nutrientes de los alimentos.

- Nos adaptamos a las necesidades de nuestros clientes, mediante una atención personalizada, respetuosa y la entrega de nuestros productos justo a tiempo. Destacar en el mercado por la calidad de nuestros diversos productos, manteniendo lo más altos estándares de calidad y normas internacionales de higiene, garantizando la fidelización de nuestros clientes.

\subsection{Formulación de Estrategias del Negocio}

Como base tenemos el análisis estructural del sector industrial desarrollado en el capítulo II y con los objetivos de crear una posición defendible para confrontar el micro 
entorno definimos la estrategia genérica de Michael Porter como la diferenciación, basada en:

- Productos naturales al $100 \%$, fomentando el consumo de productos saludables.

- La característica de Mejoramiento y mantenimiento de la calidad del producto, a través del uso de Certificados de Calidad HACCP.

- Adición de variedades de modelos, mediante el ofrecimiento en tamaños de calibración para frutos deshidratados, según requerimiento de los clientes.

- Establecimiento de un relacionamiento con el cliente.

\subsection{Determinación de las Ventajas Competitivas Críticas}

En adelante describimos las ventajas que nos permitirán desarrollar una posición competitiva en el mercado basados en el libro "Ventajas Competitivas" de Michael Porter y de nuestra matriz del perfil competitivo desarrollado en el capítulo II.

\subsubsection{Producto innovador.}

Nuestro producto es innovador, ya que serán entregados con las especificaciones técnicas de acuerdo a corte y calibración requeridas por los clientes.

\subsubsection{Gestión de la calidad.}

Una gestión de la calidad de procesos y productos; en resumen nuestra selección de procesos productivos desarrollados en el capítulo $\mathrm{V}$ representa una ventaja competitiva para la empresa, que conlleva efectos positivos sobre las ventas y la posible reducción de costos a largo plazo. Con respecto a la calidad del producto, ésta se refleja en los siguientes aspectos:

\subsubsection{Calidad de los insumos.}

Insumos de proveedores previamente seleccionados.

Insumos serán manipulados según las prácticas de manipulación de alimentos (BPM) 


\subsubsection{Consistencia y sabor.}

El diseño, combinación y elaboración de las fórmulas de los frutos deshidratados brinda como resultado una consistencia y características organolépticas.

\subsubsection{Procesos productivos.}

Un factor diferenciador valorado la matriz del perfil competitivo del capítulo II es la limpieza y orden el cual esta descrito en la configuración de procesos productivos del capítulo V.

\subsubsection{Capacidad de respuesta a los clientes}

De acuerdo a Dawyer Robert (2007)13 el efecto de la calidad y el servicio en el establecimiento de una relación viene de dar servicio y calidad todo el tiempo. La ejecución continua es lo que vale para que el cliente distinga su oferta de lo que promete la competencia. A continuación se detalla los siguientes aspectos de este punto.

\subsubsection{Lazos sociales}

Las relaciones comerciales se levantan sobre amistades que se erigen en diversas interacciones sociales. De hecho a menudo estos intercambios sociales sirven para motivar revelaciones de buena fé, comentarios francos y propuestas arriesgadas para resolver problemas, además de inevitables solicitudes de flexibilidad y ajustes que entrañan las actividades comerciales.

\subsubsection{Inversiones}

En este aspecto se ha determinado dentro de FRUTOS DESHIDRATADOS SAC inversiones en seminarios para nuestros clientes sobre innovación en productos en base a

\footnotetext{
${ }^{13}$ DWYER, Robert TANNER Jhon. Marketing industrial Ed.3. México: McGraw-Hill Interamericana de México S.A de C.V, 2007. p. 480
} 
deshidratados, visitas a clientes, así mismo en la capacitación del personal de ventas sobre clientes industriales, del mismo modo en entrevistas de satisfacción al cliente.

\subsubsection{Comunicación}

La Jefatura de marketing y ventas FRUTOS DESHIDRATADOS SAC establecerá contacto con los decisores de compra de cada una de las empresas que se han establecido como cliente, así como con otros contactos: ingenieros, encargados de planeación financiera y de producción, entre operadores y personal de entrega y servicio. Dichos contactos tendrán en cuenta los canales de comunicación y el grado de formalidad respectivo. Finalmente se utilizará medios electrónicos para difundir información sobre pedidos, inventarios y entregas.

\subsubsection{Entrevistas de satisfacción al cliente}

Con esta herramienta de comunicación se busca la influir en la retención. Luego de aplicadas se debe tomar acción inmediata pues muchos clientes no tienen tiempo para plantear sus quejas al proveedor, simplemente cambian de proveedor.

\subsection{Diseño de la Estructura Organizacional Deseada}

Nuestro organigrama está compuesto por la plana gerencial, las jefaturas encargadas de sus respectivas áreas, el personal de producción y operativo. 


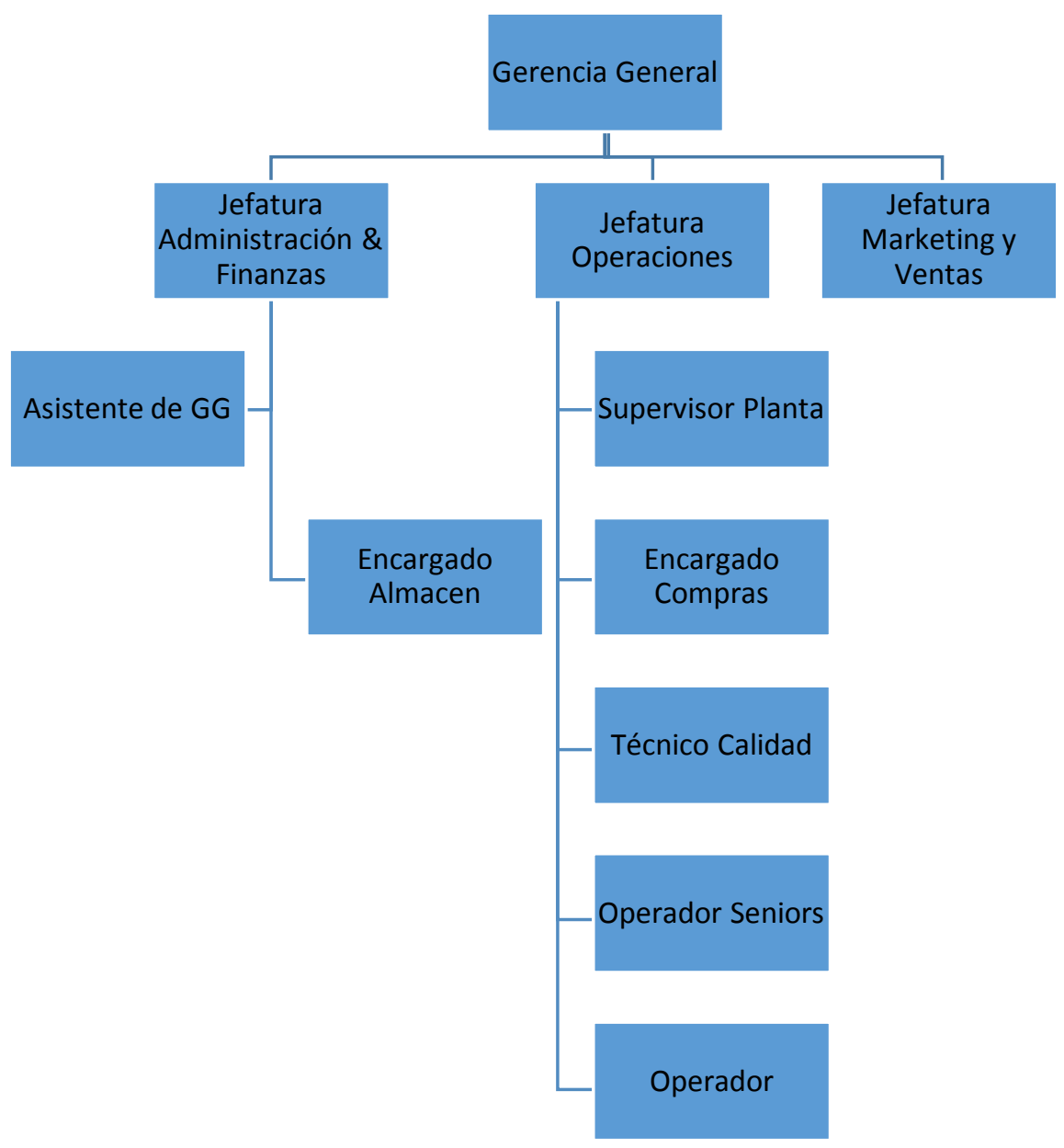

Gráfico 48. Organigrama de Frutos deshidratados SAC.

Fuente: Elaboración propia

\subsection{Diseño de los Perfiles de Puestos Clave}

En seguida desarrollamos una breve descripción de los requisitos mínimos exigidos y de las funciones de los puestos de trabajo que forman la estructura organizacional de la empresa.

\subsubsection{Gerente General.}

\subsubsection{Requisito para el cargo:}

- Profesional Titulado de la carrera de Ingeniería Industrial, Administración o carrera afines.

- Experiencia mínima de 2 años ocupando posiciones de Gerencia.

- Experiencia, formulación de planes de ventas y presupuestos en general. 


\subsubsection{Funciones.}

- Dirigir, planificar y controlar las actividades de la empresa a fin de garantizar el cumplimiento de las metas y objetivos establecidos.

- Guiar la elaboración del plan estratégico de la empresa, el presupuesto de venta y presentarlo a la Junta General de Accionista para su aprobación.

- Supervisión de desarrollo y producción de producto.

- Aprobar y presentar los informes de resultados.

- Recomendar lineamientos estratégicos en función a los cambios del mercado.

- Representar judicial y legalmente a la empresa.

- Gestionar las operaciones de la sociedad, los libros de contabilidad, mantenerlos al día y suscribir la correspondencia de la sociedad, cuando sea necesario.

- Girar, aceptar y endosar letras, abrir cuentas corrientes, girar cheques y endosar los mismos, retirar depósitos, contratar sobregiros y avances en cuenta corriente.

- Promover, nombrar, amonestar, suspender y despedir de acuerdo a las disposiciones vigentes de los empleados.

\subsubsection{Jefe de Administración y Finanzas.}

\subsubsection{Requisito para el cargo:}

- Profesional Titulado en Administración de Empresa, Contabilidad y Finanzas.

- Experiencia mínima de 2 años ocupando posiciones de Gerencia.

- Sólidos conocimientos en Marketing y Gestión de ventas.

\subsubsection{Funciones.}

- Formula y propone a la Gerencia General, normas, políticas y procedimientos para el mejor funcionamiento de las actividades relacionadas con la administración de la organización. 
- Supervisar la formulación, ejecución y evaluación del presupuesto anual, de conformidad con las disposiciones legales aplicables.

- Elaborar informe de estados financieros para su presentación a la Gerencia General.

- Control de Cuentas por Cobrar y Cuentas por Pagar.

- Apoyar en todas las gestiones legales y reglamentarias de la organización.

- Análisis de los Estados Financieros para facilitar la toma de decisiones a la Gerencia.

- Controlar los contratos en ejecución en cuanto al inicio, finalización y cobros de los trabajos realizados.

\subsubsection{Asistente Gerencia.}

\subsubsection{Requisito para el cargo.}

- Título de secretaria otorgado por una institución educativa Técnica Profesional.

- Experiencia profesional mínima de 2 años.

- Conocimientos básicos de tecnologías informáticas

- Conocimientos básicos de Contabilidad

\subsubsection{Funciones.}

- Brindar el apoyo constante en todas las actividades propias del puesto, tales como clasificar, registrar y distribuir la documentación. También deberá apoyar a nivel administrativo a las tareas del jefe de administración y de la Gerencia General.

- Atención telefónica y virtual. En el caso de la atención telefónica se incluye la orientación de los clientes y socios, al igual que la organización y administración de agendas. 
- Monitoreo y el registro de los gastos que se producen dentro de la empresa. Estos deberes pueden ser simples, como el registro de ciertos gastos en una hoja de cálculo.

- Presentación informes contables a la Jefatura de administración.

\subsubsection{Encargado de Almacén.}

\subsubsection{Requisito para el cargo.}

- Egresado técnico o universitario en Administración, Logística o carreras afines.

- Experiencia profesional mínima de 2 años en posiciones similares.

\subsubsection{Funciones.}

- Supervisar las actividades diarias de los almacenes.

- Gestionar el lanzamiento de las actividades programadas.

- Gestionar los procedimientos de distribución de las operaciones comerciales.

- Supervisar las acciones de mejora necesarias del Almacén.

- Planificar la recepción de contenedores y/o compras nacionales a almacén.

- Organizar la clasificación, ordenamiento y distribución de los diferentes materiales e insumos de la empresa

- Optimizar el transporte: reducir el coste, plazos e itinerarios de entrega.

- Velar por el cumplimiento de la actualización permanente del stock físico de los artículos del almacén con sus respectivas consistencias en el sistema.

\subsubsection{Encargado de Compras.}

\subsubsection{Requisito para el cargo.}

- Profesional técnico o universitario en Administración de empresa, Logística o carreras afines.

- Experiencia profesional mínima de 2 años en posiciones similares. 


\subsubsection{Funciones:}

- Realizar la búsqueda y la negociación más óptima con los proveedores de servicios e insumos que la empresa requiere para poder llevar acabo sus actividades con éxito. Recibir facturas de los proveedores y revisar que cumplan con los requisitos que la empresa exige. Tener un control y actualización del inventario de los insumos con los que cuenta la empresa.

\subsubsection{Jefatura de Operaciones.}

\subsubsection{Requisito para el cargo.}

- Profesional Titulado en Ingeniería industrial.

- Experiencia mínima de 2 años ocupando cargos similares.

- Sólidos conocimientos en Seguridad Industrial.

\subsubsection{Funciones.}

- Garantizar el buen funcionamiento de la línea de producción.

- Controlar los stocks de materia prima y su almacenamiento.

- Garantizar el buen almacenamiento del producto final.

- Establecer y mejorar el proceso de producción.

- Gestionar el lanzamiento de las actividades programadas.

- Optimizar la política de aprovisionamiento y distribución de la empresa.

- Optimizar procesos de trabajo. - Gestionar y supervisar al personal a su cargo.

\subsubsection{Supervisor de Planta.}

\subsubsection{Requisito para el cargo.}

- Profesional Titulado o Bachiller en Ingeniería Industrias Alimentarias, Ing. Agroindustrias. Experiencia mínima 02 años en manejo comprobado de planta de alimentos en el sector agroindustrial y o similares.

- Sólidos conocimientos en Seguridad Industrial. 


\subsubsection{Funciones.}

- Planificar, coordinar, controlar y verificar toda la producción en la planta

- Salvaguardar la integridad de la propiedad de la empresa activos, insumos, etc. así como su control y mantenimiento.

- Realizar las capacitaciones programadas de acuerdo al plan anual establecido.

- Desarrollar yo mejorar las líneas de producción y montaje para los nuevos productos.

- Controlar y supervisar que se cumpla con todos los documentos normativos internos que cuenta la empresa políticas, procedimientos, instrucciones, etc.

- Realizar gestión económica de la planta de procesos.

- Gestionar todo el sistema de aseguramiento de la inocuidad de los productos.

- Realizar las verificaciones internas, etc.

- Informar y aportar sugerencias respecto a los peligros existentes en los lugares de trabajo.

- Informar a las gerencias y áreas respectivas cada vez que exista algún incidente.

\subsubsection{Técnico Calidad}

\subsubsection{Requisito para el cargo.}

- Profesional Titulado o Bachiller en Biología, Microbiología y/o Afines, Técnico en carreras afines.

- Experiencia mínima comprobado de 02 años en manejo de planta de alimentos en el sector agroindustrial y o similares.

\subsubsection{Funciones.}

- Verificar los cumplimientos de los parámetros de calidad de los productos, aplicando acciones correctivas inmediatas que lleven al control del proceso ante cualquier desviación. 
- Responsable del monitoreo y llenado del registro del Plan HACCP, Higiene, Saneamiento y BPM.

\subsubsection{Operador Seniors.}

\subsubsection{Requisito para el cargo.}

- Formación Académica Técnico en Mantenimiento

- Experiencia laboral en industrias de alimentos o procesos industriales mínimo 1 año.

\subsubsection{Funciones.}

- Realizar las actividades de operación de acuerdo a los procedimientos establecidos.

- Ejecutar los programas de limpieza e inspección, de los equipos en el área de asignada, manteniendo el orden y limpieza, cumpliendo estándares microbiológicos de calidad.

- Realizar trabajos de mantenimiento autónomo a los equipos asignados a su cargo acorde con las buenas prácticas de manufactura, a fin de garantizar la operatividad de los equipos.

- Comunicar al Ingeniero de Producción cualquier desviación fuera del estándar de calidad, seguridad o algún desperfecto o avería de algún equipo, maquina o edificio, y hacer el seguimiento respectivo hasta la corrección del mismo para mantener un adecuado ambiente de trabajo.

- Cumplir estándares y las normas de seguridad en el uso de dispositivos de seguridad de las máquinas guardas y equipos de protección personal, paradas de emergencia, avisos seguridad con el fin de evitar accidentes de trabajo.

\subsubsection{Operarios.}

\subsubsection{Requisito para el cargo.}

- Primaria Completa 
- Experiencia mínima 01 año en planta

\subsubsection{Funciones.}

- Manejo de máquinas envasadoras.

- Manejo de máquinas embolsadoras.

- Manejo de marmitas, pailas, etc.

- Indispensable vivir por la carretera central

\subsubsection{Jefe Marketing y Ventas.}

\subsubsection{Requisito para el cargo.}

- Egresado de Administración, Marketing y/o Publicidad.

- Experiencia de 03 años realizando planificación y ejecución de campañas publicitarias (marketing estratégico) y como Jefe de Ventas o Supervisor de ventas.

- Experiencia manejando equipos de ventas.

- Manejo a todo nivel de marketing digital e impreso

- Competencias del perfil: proactivo, creativo, con orientación a resultados. Adaptación y flexibilidad ante cambios, Capacidad de negociación, análisis, Orientación al cliente, Trabajo en equipo, Comunicación y Automotivación

\subsubsection{Funciones.}

- Analizar las actividades de publicidad y rendimiento de ventas de los competidores.

- Realizarla inteligencia competitiva de la empresa realizaron investigaciones de mercado que garanticen el desarrollo del producto de la empresa.

- Gestionar las relaciones públicas de la organización.

- Desarrollo de la marca de la empresa alineada con la misión de la empresa.

- Realiza las tareas destinadas a desarrollar e implementar las mejores estrategias de marketing a corto y largo plazo de la organización. 
- Elaborar, ejecutar y controlar el plan de Marketing de la empresa

- Gestionar el concepto creativo del branding

- Identificar los principales medios de llegada de clientes, evaluando el impacto de los diferentes medios publicitarios contratados.

- Coordinar y supervisar el diseño de material gráfico.

- Lograr o superar los objetivos de ventas mensuales, trimestrales y anuales de la empresa, así como los de cada cartera de clientes en particular.

- Supervisar y desarrollar a sus vendedores, de manera a incrementar permanentemente su productividad y nivel de profesionalización.

- Conocer, interactuar y comunicarse permanentemente con los clientes, desarrollando relaciones de confianza y de largo plazo con ellos.

\subsection{Remuneraciones, Compensaciones e Incentivos}

El nivel de remuneraciones está determinada en funciones de la formación académica, desempeño y funciones encomendadas.

Las remuneraciones definidas se han propuesto en base al promedio del mercado laboral para la función asignada.

\begin{tabular}{|c|c|c|c|c|c|c|c|}
\hline Nombre del Puesto & $\begin{array}{l}\text { Sueldo } \\
\text { Básico }\end{array}$ & $\begin{array}{c}\text { Remuner } \\
\text { ación } \\
\text { Anual }\end{array}$ & $\begin{array}{c}\text { Gratifica } \\
\text { ciones } \\
\text { (Jul/Dic) }\end{array}$ & Sub Total & $\begin{array}{c}\text { ESSAL } \\
\text { UD } \\
(9 \%)\end{array}$ & CTS & $\begin{array}{c}\text { Remuner } \\
\text { ación } \\
\text { Anual }\end{array}$ \\
\hline Jefe Operaciones & 3,500 & 42,000 & 7,000 & 49,000 & 3,780 & 4,083 & 56,863 \\
\hline Supervisor de Planta & 1,800 & 21,600 & 3,600 & 25,200 & 1,944 & 2,100 & 29,244 \\
\hline Supervisor Compras & 1,800 & 21,600 & 3,600 & 25,200 & 1,944 & 2,100 & 29,244 \\
\hline Técnico Calidad & 1,500 & 18,000 & 3,000 & 21,000 & 1,620 & 1,750 & 24,370 \\
\hline Operador Seniors & 1,000 & 12,000 & 2,000 & 14,000 & 1,080 & 1,167 & 16,247 \\
\hline Operador & 850 & 40,800 & 1,700 & 42,500 & 3,672 & 992 & 47,164 \\
\hline TOTAL & & 156,000 & 20,900 & 176,900 & 14,040 & 12,191 & 203,131 \\
\hline
\end{tabular}

Cuadro 72. Planilla de Operaciones en Soles.

Fuente: Elaboración propia 


\subsubsection{Compensación e incentivos.}

- Pago de horas extras laboradas

- Bonificaciones salariales cuando incrementen las ventas

- Remuneraciones de acuerdo al mercado

\subsection{Políticas de Recursos Humanos}

FRUTOS DESHIDRATADOS S.A.C. está orientada a la formación de un equipo humano altamente motivado y calificado, identificado con los valores corporativos de la empresa.

Así también con la finalidad de conservar la comprensión laboral en favor de una óptima productividad, los trabajadores de la empresa tendrán acceso a una copia del Reglamento Interno de Trabajo, con el único fin de que conozcan sus deberes y obligaciones, quedando obligado a cumplir todas sus normas, firmando una constancia en señal de recepción.

Por otro lado, se generará las condiciones de trabajo dignas para los trabajadores, que aseguren un estado de vida saludable, mental, física y social.

Por ello, se implantará como mecanismo para garantizar una constante colaboración en materia de seguridad y salud en el entorno laboral.

\subsubsection{Forma de contratación.}

FRUTOS DESHIDRATADOS SAC, se rige dentro de la legislación laboral peruana para pequeña empresa, bajo contratos de trabajo sujeto a plazo fijo o determinado, dependiendo básicamente de las necesidades específicas de la Empresa. (Ley $\left.\mathrm{N}^{\circ} 28015,2003\right)$.

\subsubsection{Régimen laboral.}

FRUTOS DESHIDRATADOS SAC pertenecerá al régimen laboral de la pequeña Empresa. (Ley N² 28015, 2003). 
- Remuneración: no menor a la Remuneración Mínima Vital (S/ 850,00).

- Jornada Laboral: 8 horas diarias o 48 horas semanales.

- Descanso Vacacional: 15 días calendario por cada año de servicios.

- Aporte a Essalud de 9\% de la remuneración mensual del trabajador.

- Descanso semanal y descanso por días feriados.

- Derecho a 2 gratificaciones en el año.

- Aporte al Sistema de Pensiones, ya sea el nacional o el privado.

\subsubsection{Beneficios sociales.}

Según lo correspondiente a Ley y en adicional generaremos una oferta de valor que permita brindarles bienestar a nuestros trabajadores.

- Essalud.

- Inducción y capacitación.

- Actividades de confraternidad. 


\section{Planificación Financiera}

\subsection{La Inversión}

\subsubsection{Inversión pre operativa.}

\subsubsection{Inversión en activo fijo.}

El plan de negocio consta de una inversión de activo fijo de S/. 499,002 soles distribuidos en S/. 490,120 en la parte operativa, S/. 7,072 la parte administrativa y S/. 1,810 la parte de ventas.

\begin{tabular}{|l|r|}
\hline \multicolumn{2}{|c|}{ ACTIVO FIJO } \\
\hline Operaciones & 490,120 \\
\hline Administración & 7,072 \\
\hline Ventas & 1,810 \\
\hline Total & 499,002 \\
\hline
\end{tabular}

Cuadro 73. Resumen de activo fijo (en nuevos soles).

Elaboración propia.

\subsubsection{Inversión en activo intangible.}

El proyecto de negocio consta de una inversión de activos intangibles de S/. 360 soles y de gastos pre operativos de S/. 86,149.

\begin{tabular}{|l|r|}
\hline \multicolumn{2}{|c|}{ ACTIVO INTANGIBLE } \\
\hline Activo intangible & 360 \\
\hline Gastos Preoperativos & 86,149 \\
\hline Total & $\mathbf{8 6 , 5 0 9}$ \\
\hline
\end{tabular}

Cuadro 74. Resumen de activo intangible y gastos pre operativos (en nuevos soles). Elaboración propia.

\subsubsection{Inversión en capital de trabajo.}

Para el cálculo del capital de trabajo del proyecto se ha utilizado el método déficit acumulado máximo en la proyección de caja del primer año de operaciones, se obtiene un capital de trabajo de S/. 81,262. 


\begin{tabular}{|c|c|c|c|c|c|c|c|c|c|c|c|c|}
\hline INGRESOS EFECTIVO (Contado) & Ene-19 & Feb-19 & Mar-19 & Abr-19 & May-19 & Jun-19 & Jul-19 & Ago-19 & Set-19 & Oct-19 & Nov-19 & Dic-19 \\
\hline Ventas mensuales & 54,090 & 48,080 & 42,070 & 42,070 & 42,070 & 42,070 & 42,070 & 54,090 & 60,100 & 60,100 & 60,100 & 54,090 \\
\hline IGV Ventas & 9,736 & 8,654 & 7,573 & 7,573 & 7,573 & 7,573 & 7,573 & 9,736 & 10,818 & 10,818 & 10,818 & 9,736 \\
\hline Venta total mensual & 63,826 & 56,734 & 49,643 & 49,643 & 49,643 & 49,643 & 49,643 & 63,826 & 70,918 & 70,918 & 70,918 & 63,826 \\
\hline Cobranza (30 dias) & 0 & 63,826 & 56,734 & 49,643 & 49,643 & 49,643 & 49,643 & 49,643 & 63,826 & 70,918 & 70,918 & 70,918 \\
\hline \multicolumn{13}{|l|}{ Capital Trabajo Adicional } \\
\hline TOTAL INGRESOS EFECTIVO & 0 & 63,826 & 56,734 & 49,643 & 49,643 & 49,643 & 49,643 & 49,643 & 63,826 & 70,918 & 70,918 & 70,918 \\
\hline EGRESOS EFECTIVO & Ene-19 & Feb-19 & Mar-19 & Abr-19 & May-19 & Jun-19 & Jul-19 & Ago-19 & Set-19 & Oct-19 & Nov-19 & Dic-19 \\
\hline Materia Prima Directa & 18,727 & 5,462 & 5,462 & 5,462 & 5,462 & 7,023 & 7,803 & 7,803 & 7,803 & 7,023 & 9,219 & 8,195 \\
\hline IGV MPD & 3,371 & 983 & 983 & 983 & 983 & 1,264 & 1,405 & 1,405 & 1,405 & 1,264 & 1,659 & 1,475 \\
\hline Pago a 30 días MPD & & 22,098 & 6,445 & 6,445 & 6,445 & 6,445 & 8,287 & 9,207 & 9,207 & 9,207 & 8,287 & 10,879 \\
\hline Materia Prima Indirecta & 553 & 161 & 161 & 161 & 161 & 207 & 230 & 230 & 230 & 207 & 269 & 239 \\
\hline IGV MPI & 99 & 29 & 29 & 29 & 29 & 37 & 41 & 41 & 41 & 37 & 48 & 43 \\
\hline Pago a 30 días MPI & & 652 & 190 & 190 & 190 & 190 & 245 & 272 & 272 & 272 & 245 & 318 \\
\hline Mano de obra directa & 4,905 & 4,905 & 4,905 & 4,905 & 7,155 & 4,905 & 9,405 & 4,905 & 4,905 & 4,905 & 7,155 & 9,405 \\
\hline CIF Prod & 4,936 & 2,032 & 2,032 & 2,032 & 2,032 & 2,032 & 2,613 & 2,903 & 2,903 & 2,903 & 2,613 & 3,409 \\
\hline IGV CIF Prod & 888 & 366 & 366 & 366 & 366 & 366 & 470 & 523 & 523 & 523 & 470 & 614 \\
\hline Pago CIF MPI 30 dias & & 5,824 & 2,398 & 2,398 & 2,398 & 2,398 & 2,398 & 3,083 & 3,426 & 3,426 & 3,426 & 3,083 \\
\hline CIF Ope & 14,878 & 14,878 & 14,878 & 14,878 & 14,878 & 14,878 & 14,878 & 14,878 & 14,878 & 14,878 & 14,878 & 14,878 \\
\hline IGV CIF Ope & 268 & 268 & 268 & 268 & 268 & 268 & 268 & 268 & 268 & 268 & 268 & 268 \\
\hline Gastos administrativos & 18,076 & 18,076 & 18,076 & 18,076 & 18,076 & 18,076 & 18,076 & 18,076 & 18,076 & 18,076 & 18,076 & 18,076 \\
\hline IGV Gastos administrativos & 410 & 410 & 410 & 410 & 410 & 410 & 410 & 410 & 410 & 410 & 410 & 410 \\
\hline Gastos ventas & 5,533 & 5,533 & 5,533 & 5,533 & 5,533 & 5,533 & 5,533 & 5,533 & 5,533 & 5,533 & 5,533 & 5,533 \\
\hline IGV Gastos ventas & 316 & 316 & 316 & 316 & 316 & 316 & 316 & 316 & 316 & 316 & 316 & 316 \\
\hline IGV del módulo de IGV & 4,384 & 6,282 & 5,201 & 5,201 & 5,201 & 4,911 & 4,662 & 6,774 & 7,856 & 8,000 & 7,646 & 6,610 \\
\hline Pago IGV Total & & 0 & 0 & 0 & 0 & 0 & 0 & 0 & 0 & 0 & 0 & 0 \\
\hline \multicolumn{13}{|l|}{ Pago IR } \\
\hline TOTAL EGRESOS EFECTIVO & 44,386 & 72,960 & 53,419 & 53,419 & 55,669 & 53,419 & 59,815 & 56,948 & 57,291 & 57,291 & 58,593 & 63,166 \\
\hline SALDO CAJA (ingresos - egresos) & $-44,386$ & $-9,133$ & 3,315 & $-3,777$ & $-6,027$ & $-3,777$ & $-10,172$ & $-7,306$ & 6,535 & 13,627 & 12,325 & 7,752 \\
\hline Saldo acumulado & $-44,386$ & $-53,519$ & $-50,204$ & $-53,981$ & $-60,007$ & $-63,784$ & $-73,956$ & $-81,262$ & $-74,726$ & $-61,099$ & $-48,774$ & $-41,021$ \\
\hline
\end{tabular}

Cuadro 74. Resumen de capital de trabajo (en nuevos soles).

Elaboración propia.

\subsubsection{Costo del proyecto.}

El costo del proyecto es la suma de la inversión en activo fijo, activo intangible y

capital de trabajo, se obtuvo un monto de S/. 676,773 que incluye el IGV.

\begin{tabular}{|l|r|}
\hline \multicolumn{2}{|c|}{ COSTO DEL PROYECTO } \\
\hline Activos intangibles & 86,509 \\
\hline Capital de trabajo & 81,262 \\
\hline Activos fijos & 499,002 \\
\hline Total & $\mathbf{6 6 6 , 7 7 3}$ \\
\hline
\end{tabular}

Cuadro 76. Costo del proyecto (en nuevos soles).

Fuente: Elaboración Propia.

\subsubsection{Inversiones futuras.}

El dimensionamiento de la planta fue hecho de tal manera que no se haría

inversión en más activos fijos para el período de evaluación de 5 años. 


\subsection{Financiamiento}

Para el presente proyecto se hizo consulta con diferentes operadores bancarios, éstos informaron que para proyectos de inversión nuevos no se ofrecía financiamiento.

Se hizo las consultas con COFIDE, sin embargo por tratarse de un proyecto con fines de lucro, el proyecto pudo aplicar a los requisitos solicitados.

Por tanto en el presente proyecto no se tendrá financiamiento por entidades bancarias, el costo del proyecto tendrá que ser asumido completamente por inversionistas.

\subsubsection{Capital y costo de oportunidad.}

Se realizó el cálculo del COK para la industria alimenticia en Perú.

- Beta desapalancada, se obtuvo del historial del Aswath Damodaran al 5 de enero del 2018, para la industria alimenticia el beta es de 0.55 .

- Tasa libre de riesgo (Rf), se obtuvo del promedio de los diez últimos años de los bonos de tesoro estadounidense con un valor de $4.29 \%$.

- Tasa de rendimiento del mercado, se obtuvo del promedio de los últimos diez años con un valor de $10.27 \%$ de la página de historial de Aswath Damodaran.

- Inflación de Estados Unidos, fue calculada por el promedio de los diez últimos años con un valor de $1.43 \%$.

- Inflación de Perú, calculada con el promedio de los cinco últimos años con un promedio de $3.18 \%$

- Riesgo país de Perú, calculada desde la página de historial de Aswath Damodaran con fecha primero de enero del 2018 y un valor de $1.38 \%$ El cok en Perú se calcula hallando el cok en Estados Unidos, apalancando con la estructura financiera del proyecto que, en este caso serán iguales pues no hay financiamiento, se suma el riesgo país de Perú, se multiplicando por la razón entre la 
inflación de Estados Unidos y Perú, y finalmente se suma una tasa de riesgo de proyecto nuevo de un $4 \%$.

El COK para el proyecto resulta en $23.87 \%$.

\begin{tabular}{|lr|}
\hline \multicolumn{2}{|c|}{ CALCULO COK PROYECTO } \\
\hline Beta Desapalancado & $0.55 \%$ \\
\hline Beta Apalancado & $0.55 \%$ \\
\hline Tasa Libre de Riesgo & $4.29 \%$ \\
\hline Rendimiento del Mercado & $10.27 \%$ \\
\hline COK Nominal USA & $7.58 \%$ \\
\hline Inflación USA & $1.43 \%$ \\
\hline Riesgo Pais - Perú & $1.38 \%$ \\
\hline Inflación Perú & $3.18 \%$ \\
\hline COK Perú & $19.87 \%$ \\
\hline Riesgo del Proyecto nuevo & $4.00 \%$ \\
\hline COK del Proyecto & $23.87 \%$ \\
\hline
\end{tabular}

Cuadro 77. Calculo del COK del proyecto.

Fuente: Elaboración propia.

\subsection{Presupuesto Base}

\subsubsection{Presupuesto de ventas.}

La proyección de la demanda objetivo se hizo en el capítulo IV Pronóstico de ventas para el período de evaluación de 5 años del proyecto.

Para este plan de negocios se tienen 3 tipos de productos deshidratados:

arándanos, manzana y piña. Se hizo el presupuesto para cada producto.

\begin{tabular}{|l|r|r|r|r|r|}
\hline PROYECCION POR PRODUCTO $(\mathrm{KG})$ & \multicolumn{1}{|c|}{2019} & \multicolumn{1}{c|}{2020} & \multicolumn{1}{c|}{2021} & \multicolumn{1}{c|}{2022} & \multicolumn{1}{c|}{2023} \\
\hline Arándanos & 8,000 & 10,560 & 13,552 & 17,037 & 21,083 \\
\hline Manzana & 5,000 & 6,360 & 7,865 & 9,528 & 11,362 \\
\hline Piña & 1,500 & 1,908 & 2,360 & 2,858 & 3,409 \\
\hline Total proyección de venta & $\mathbf{1 4 , 5 0 0}$ & $\mathbf{1 8 , 8 2 8}$ & $\mathbf{2 3 , 7 7 7}$ & $\mathbf{2 9 , 4 2 3}$ & $\mathbf{3 5 , 8 5 4}$ \\
\hline
\end{tabular}

Cuadro 78. Proyección de venta por producto $(\mathrm{Kg})$.

Fuente: Elaboración propia. 


\begin{tabular}{|l|r|r|r|r|r|}
\hline VALOR VENTA PRODUCTOS & \multicolumn{1}{|c|}{2019} & \multicolumn{1}{|c|}{2020} & \multicolumn{1}{c|}{2021} & \multicolumn{1}{c|}{2022} & \multicolumn{1}{c|}{2023} \\
\hline Valor venta arándano Kg & 37.0 & 37.0 & 37.0 & 37.0 & 37.0 \\
\hline Valor venta manzana Kg & 46.0 & 46.0 & 46.0 & 46.0 & 46.0 \\
\hline Valor venta piña Kg & 50.0 & 50.0 & 50.0 & 50.0 & 50.0 \\
\hline
\end{tabular}

Cuadro 79. Valor de venta por producto (S/.).

Elaboración propia.

\begin{tabular}{|l|r|r|r|r|r|}
\hline PRESUPUESTO VENTA ANUAL & \multicolumn{1}{|c|}{2019} & \multicolumn{1}{|c|}{2020} & \multicolumn{1}{c|}{2021} & \multicolumn{1}{c|}{2022} & \multicolumn{1}{c|}{2023} \\
\hline Valor venta anual arándano & 296,000 & 390,720 & 501,424 & 630,362 & 780,072 \\
\hline Valor venta anual manzana & 230,000 & 292,560 & 361,799 & 438,294 & 522,665 \\
\hline Valor venta anual piña & 75,000 & 95,400 & 117,978 & 142,922 & 170,434 \\
\hline TOTAL & 601,000 & 778,680 & 981,201 & $1,211,577$ & $1,473,172$ \\
\hline
\end{tabular}

Cuadro 80. Presupuesto de venta anual por producto y total (S/.).

Elaboración propia.

\subsubsection{Presupuesto de costos de producción.}

Para el presupuesto de producción se tienen los siguientes costos unitarios.

\begin{tabular}{|l|r|r|r|}
\hline \multicolumn{1}{|c|}{ ARÁNDO } & \multicolumn{1}{c|}{$\mathrm{Q}$} & \multicolumn{1}{c|}{$\mathrm{P}$} & \multicolumn{1}{c|}{ S/. } \\
\hline Arandano fresco & 3.3 & 2.54 & 8.30 \\
\hline Energía eléctrica & 3.7 & 0.36 & 1.32 \\
\hline Transporte & 3.3 & 0.35 & 1.16 \\
\hline Hipoclorito de sodio & 0.0005 & 28.81 & 0.01 \\
\hline Bisulfito de sodio & 0.0003 & 23.73 & 0.01 \\
\hline Glicerina & 0.0001 & 16.95 & 0.00 \\
\hline Carton corrugado & 1 & 0.12 & 0.12 \\
\hline Bolsa & 1 & 0.02 & 0.02 \\
\hline Cinta adhesiva & 1 & 0.00 & 0.00 \\
\hline COSTO DE PRODUCCIÓN 1KG ARÁNDO DESHIDRATADO & 10.93 \\
\hline & $\mathrm{Q}$ & $\mathrm{P}$ & $\mathrm{S} /$. \\
\hline Manzana fresca & 3.4 & 0.51 & 1.75 \\
\hline Energía eléctrica & 3.7 & 0.36 & 1.32 \\
\hline Transporte & 3.4 & 0.03 & 0.10 \\
\hline Hipoclorito de sodio & 0.0005 & 28.81 & 0.01 \\
\hline Bisulfito de sodio & 0.0003 & 23.73 & 0.01 \\
\hline Glicerina & 0.0001 & 16.95 & 0.00 \\
\hline Carton corrugado & 1 & 0.12 & 0.12 \\
\hline Bolsa & 1 & 0.02 & 0.02 \\
\hline Cinta adhesiva & 1 & 0.00 & 0.00 \\
\hline OSTO DE PRODUCCIÓN 1KG MANZANA DESHIDRATADA & 3.33 \\
\hline
\end{tabular}




\begin{tabular}{|l|r|r|r|}
\multicolumn{1}{|c|}{ PIÑA } & \multicolumn{1}{c|}{ Q } & \multicolumn{1}{c|}{ P } & \multicolumn{1}{c|}{ S/. } \\
\hline Piña fresca & 2.9 & 0.68 & 1.95 \\
\hline Transporte & 2.9 & 0.03 & 0.09 \\
\hline Energía eléctrica & 3.7 & 0.36 & 1.32 \\
\hline Hipoclorito de sodio & 0.0005 & 28.81 & 0.01 \\
\hline Bisulfito de sodio & 0.0003 & 23.73 & 0.01 \\
\hline Glicerina & 0.0001 & 16.95 & 0.00 \\
\hline Carton corrugado & 1 & 0.12 & 0.12 \\
\hline Bolsa & 1 & 0.02 & 0.02 \\
\hline Cinta adhesiva & 1 & 0.00 & 0.00 \\
\hline \multicolumn{2}{|r|}{ COSTO DE PRODUCCIÓN 1KG PIÑA DESHIDRATADA } & 3.52 \\
\hline
\end{tabular}

Cuadro 81. Costos unitarios de producción por producto (S/.).

Fuente: Elaboración propia.

\begin{tabular}{|c|c|c|c|c|c|}
\hline \multicolumn{6}{|c|}{ PRESUPUESTO COSTO DE PRODUCCIÓN POR PRODUCTO } \\
\hline & 2019 & 2020 & 2021 & 2022 & 2023 \\
\hline Cantidad arándano & 8,253 & 10,856 & 13,897 & 17,437 & 21,083 \\
\hline Cantidad piña & 5,135 & 6,509 & 8,030 & 9,710 & 11,562 \\
\hline Cantidad manzana & 1,540 & 1,953 & 2,409 & 2,913 & 3,469 \\
\hline Total producido & 14,928 & 19,318 & 24,336 & 30,060 & 36,114 \\
\hline Presupuesto arándano & 90,217 & 118,668 & 151,906 & 190,606 & 230,456 \\
\hline Presupuesto piña & 17,089 & 21,663 & 26,725 & 32,316 & 38,482 \\
\hline Presupuesto manzana & 5,419 & 6,869 & 8,475 & 10,247 & 12,203 \\
\hline Presupuc & 112,726 & 147,201 & 187,106 & 233,169 & 281,140 \\
\hline & 20,291 & 26,496 & 33,679 & 41,970 & 50,605 \\
\hline & 3,01 & 173,697 & 220,785 & 275,140 & \\
\hline
\end{tabular}

Cuadro 82. Presupuesto de producción por producto y total (S/.).

Fuente: Elaboración propia.

\subsubsection{Presupuesto de compras.}

Para la materia prima e insumos de producción se tienen los siguientes costos unitarios. 


\begin{tabular}{|c|c|c|c|}
\hline ARÁNDO & Q & $\mathrm{P}$ & $\mathrm{S} /$. \\
\hline Arandano fresco & 3.3 & 2.5 & 8.30 \\
\hline Hipoclorito de sodio & 0.0005 & 28.8 & 0.01 \\
\hline Bisulfito de sodio & 0.0003 & 23.7 & 0.01 \\
\hline Glicerina & 0.0001 & 16.9 & 0.00 \\
\hline Carton corrugado & 1 & 0.117 & 0.12 \\
\hline Bolsa & 1 & 0.016 & 0.02 \\
\hline Cinta adhesiva & 1 & 0.003 & 0.00 \\
\hline & \multicolumn{2}{|r|}{ TOTAL } & 8.45 \\
\hline MANZANA & Q & $\mathrm{P}$ & $\mathrm{S} /$. \\
\hline Manzana fresca & 3.4 & 0.5 & 1.75 \\
\hline Hipoclorito de sodio & 0.0005 & 28.8 & 0.01441 \\
\hline Bisulfito de sodio & 0.0003 & 23.7 & 0.00712 \\
\hline Glicerina & 0.0001 & 16.9 & 0.00169 \\
\hline Carton corrugado & 1 & 0.117 & 0.12 \\
\hline Bolsa & 1 & 0.016 & 0.02 \\
\hline \multirow[t]{2}{*}{ Cinta adhesiva } & 1 & 0.003 & 0.00 \\
\hline & \multicolumn{2}{|r|}{ TOTAL } & 1.91 \\
\hline PIÑA & Q & $\mathrm{P}$ & $\mathrm{S} /$. \\
\hline Piña fresca & 2.9 & 0.7 & 1.95 \\
\hline Hipoclorito de sodio & 0.0005 & 28.8 & 0.01441 \\
\hline Bisulfito de sodio & 0.0003 & 23.7 & 0.00712 \\
\hline Glicerina & 0.0001 & 16.9 & 0.00169 \\
\hline Carton corrugado & 1 & 0.117 & 0.12 \\
\hline Bolsa & 1 & 0.016 & 0.02 \\
\hline Cinta adhesiva & 1 & 0.003 & 0.00 \\
\hline & & TOTAL & 2.11 \\
\hline
\end{tabular}

Cuadro 83. Presupuesto de materia prima por producto y total (S/.).

Fuente: Elaboración propia.

\begin{tabular}{|l|r|r|r|r|r|}
\hline ARÁNDANOS & \multicolumn{1}{|c|}{2019} & \multicolumn{1}{c|}{2020} & \multicolumn{1}{c|}{2021} & \multicolumn{1}{c|}{2022} & \multicolumn{1}{c|}{2023} \\
\hline Inventario inicial & 0 & 7,143 & 9,167 & 11,524 & 14,261 \\
\hline Compras MP arándano & 82,818 & 93,585 & 119,591 & 149,862 & 186,734 \\
\hline Inventario final & 7,143 & 9,167 & 11,524 & 14,261 & 19,172 \\
\hline MP a Fabricación (unidades) & 75,675 & 91,561 & 117,234 & 147,125 & 181,822 \\
\hline MANZANA & 2019 & 2020 & \multicolumn{1}{|c|}{2021} & \multicolumn{1}{|c|}{2022} & 2023 \\
\hline Inventario inicial & 0 & 969 & 1,199 & 1,452 & 1,732 \\
\hline Compras MP manzana & 11,587 & 12,605 & 15,524 & 18,748 & 22,048 \\
\hline Inventario final & 969 & 1,199 & 1,452 & 1,732 & 1,785 \\
\hline MP a Fabricación (unidades) & 10,617 & 12,376 & 15,271 & 18,469 & 21,995 \\
\hline
\end{tabular}




\begin{tabular}{|c|c|c|c|c|c|}
\hline PIÑA & 2019 & 2020 & 2021 & 2022 & 2023 \\
\hline Inventario inicial & & 32 & 398 & 483 & 575 \\
\hline Compras MP piña & 3,84 & 4,18 & 5,158 & 6,229 & 7,325 \\
\hline Inventario final & 32 & 39 & 483 & 575 & 593 \\
\hline MP a Fabricación (unidades) & 3,52 & 4,11 & 5,073 & 6,136 & 7,308 \\
\hline \multicolumn{6}{|c|}{ PRESUPUESTO DE COMPRAS } \\
\hline & 2019 & 2020 & 2021 & 2022 & 2023 \\
\hline Inventario inicial & 0 & 8,434 & 10,764 & 13,458 & 16,568 \\
\hline Compras MP Total & 98,254 & 110,378 & 140,273 & 174,839 & 216,107 \\
\hline Inventario final & 8,434 & 10,764 & 13,458 & 16,568 & 21,550 \\
\hline MP a Fabricación & 89,820 & 108,049 & 137,578 & 171,729 & 211,124 \\
\hline
\end{tabular}

Cuadro 84. Presupuesto de compras por producto y total (S/.).

Elaboración propia.

\subsubsection{Presupuesto de costo de ventas.}

\begin{tabular}{|l|r|r|r|r|r|}
\hline COSTO DE VENTAS & 335,973 & 394,200 & 556,266 & 645,313 & 762,949 \\
\hline Costo materia prima & 78,029 & 102,438 & 130,770 & 163,558 & 201,404 \\
\hline Mano de obra directa & 62,955 & 72,360 & 174,487 & 189,744 & 252,699 \\
\hline CIF & 194,989 & 219,402 & 251,009 & 292,010 & 308,846 \\
\hline
\end{tabular}

Cuadro 85. Presupuesto de costo de ventas por producto y total (S/.).

Elaboración propia.

\subsubsection{Presupuesto de gastos administrativos.}

\begin{tabular}{|l|r|r|r|r|r|}
\hline GASTOS ADMINISTRATIVOS & 2019 & 2020 & 2021 & 2022 & 2023 \\
\hline PERSONAL & 153,564 & 153,564 & 153,564 & 153,564 & 153,564 \\
\hline SEGUROS & 12,394 & 12,394 & 12,394 & 12,394 & 12,394 \\
\hline OTROS GASTOS ADMINISTRATIVOS & 50,952 & 50,952 & 50,952 & 50,952 & 50,952 \\
\hline DEPRECIACION ACTIVOS FIJOS & 6,029 & 6,029 & 6,029 & 6,029 & 6,029 \\
\hline AMORTIZACION ACTIVOS INTANGIBLES & 5,007 & 5,007 & 5,007 & 5,007 & 5,007 \\
\hline TOTAL GASTOS ADMINISTRATIVOS & 227,946 & 227,946 & 227,946 & 227,946 & 227,946 \\
\hline
\end{tabular}

Cuadro 86. Presupuesto de gastos administrativos (S/.).

Elaboración propia.

\subsubsection{Presupuesto de gastos marketing y de ventas.}

\begin{tabular}{|l|r|r|r|r|r|}
\hline GASTOS VENTAS & 2019 & 2020 & 2021 & 2022 & 2023 \\
\hline PERSONAL & $32,160.00$ & $32,160.00$ & $32,160.00$ & $32,160.00$ & $32,160.00$ \\
\hline PROMOCION & $11,756.00$ & $12,131.88$ & $12,477.84$ & $12,834.17$ & $13,201.20$ \\
\hline COMISIÓN VENTAS & $6,000.00$ & $7,200.00$ & $8,640.00$ & $10,368.00$ & $12,441.60$ \\
\hline OTROS GASTOS VENTAS & $16,485.15$ & $16,485.15$ & $16,485.15$ & $16,485.15$ & $16,485.15$ \\
\hline DEPRECIACION ACTIVOS FIJC & $3,527.12$ & $3,527.12$ & $3,527.12$ & $3,527.12$ & $3,527.12$ \\
\hline AMORTIZACION ACTIVOS IN' & $1,430.17$ & $1,430.17$ & $1,430.17$ & $1,430.17$ & $1,430.17$ \\
\hline TOTAL GASTOS VENTAS & $71,358.44$ & $72,934.32$ & $74,720.28$ & $76,804.61$ & $79,245.24$ \\
\hline
\end{tabular}

Cuadro 87. Presupuesto de gastos de marketing y ventas (S/.).

Elaboración propia. 
Con respecto al Cuadro 72 Presupuesto de gastos de marketing y ventas, es importante señalar que el gasto de personal es fijo debido a que las empresas a las que se va a cubrir, de acuerdo al mercado objetivo página 97, son únicamente 3; estas empresas consumen en Arándano, Manzana y Piña más de lo que FRUTOS DESHIDRATADOS SAC venderá a estas. Como se puede observar al comparar el Cuadro 38 Porción de captación de mercado objetivo con el Cuadro 23. Cantidad comprada de frutos deshidratados, se puede anotar que la cantidad que compran las tres empresas es mucho mayor que la cantidad que vamos a producir y venderles; como consecuencia el personal de venta tendrá un campo de acción pequeño y no será necesario contratar más personal durante la vida útil del Proyecto.

En cuanto a la comisión de ventas es bueno precisar que el trabajo del vendedor en este tipo de negocio B2B, estará más abocado a generar relacionamiento con las empresas que a pujar la venta de la cuenta; es decir que el personal de venta buscará poder "blindar" al cliente y evitar de que otro competidor pueda ingresar y quitar la cuenta. Esta actividad de blindar está relacionada con lo siguiente:

- Conocimiento del todo el personal de la empresa (Desde el de seguridad, mantenimiento, hasta la persona encargada de la compra)

- Asesoramiento técnico y comercial

- Exposición en Ferias Alimentarias

- Capacitaciones

Estos 4 puntos están sustentados a nivel de gastos en la página 105 Cuadro 44 Presupuesto de promoción y publicidad y 5.5 Cronograma de actividades de promoción y publicidad. 


\subsubsection{Estado de ganancias y pérdidas proyectado.}

En el estado de resultados, se tiene utilidades netas positivas a partir del segundo año, el resto de años se incrementa conforme aumenta la cantidad de ventas anuales, debido a la pérdida del primer año se tiene un alto escudo fiscal, recién en el cuarto año se empieza a pagar el impuesto a la renta.

\begin{tabular}{|l|r|r|r|r|r|r|}
\hline ESTADO DE GANANCIAS Y PERDIDAS INCLUYE GASTOS FINANCIEROS \\
\hline VENTAS & 2019 & 2020 & 2021 & 2022 & 2023 \\
\hline COSTO DE VENTAS & 601,000 & 778,680 & 981,201 & $1,211,577$ & $1,473,172$ \\
\hline Materia prima & 335,973 & 394,200 & 556,266 & 645,313 & 762,949 \\
\hline Mano de obra directa & 78,029 & 102,438 & 130,770 & 163,558 & 201,404 \\
\hline CIF & 62,955 & 72,360 & 174,487 & 189,744 & 252,699 \\
\hline UTILIDAD BRUTA & 194,989 & 219,402 & 251,009 & 292,010 & 308,846 \\
\hline GASTOS OPERATIVOS & 265,027 & 384,480 & 424,935 & 566,265 & 710,223 \\
\hline Gastos administración & 367,847 & 369,423 & 371,209 & 373,293 & 375,734 \\
\hline Gasto ventas & 216,910 & 216,910 & 216,910 & 216,910 & 216,910 \\
\hline Depreciación & 66,401 & 67,977 & 69,763 & 71,847 & 74,288 \\
\hline Amortización & 68,475 & 68,475 & 68,475 & 68,475 & 68,475 \\
\hline UTILIDAD OPERATIVA (EBIT) & 16,062 & 16,062 & 16,062 & 16,062 & 16,062 \\
\hline Gastos financieros & $-102,820$ & 15,057 & 53,726 & 192,971 & 334,489 \\
\hline UTILIDAD ANTES DE IMPUES & $-102,820$ & 15,057 & 53,726 & 192,971 & 334,489 \\
\hline Impuesto renta & 0 & 0 & 0 & 42,912 & 90,312 \\
\hline UTILIDAD NETA & $-102,820$ & 15,057 & 53,726 & 150,059 & 244,177 \\
\hline
\end{tabular}

Cuadro 88. Estado de ganancias y pérdidas proyectado (S/.).

Fuente: Elaboración propia. 


\subsubsection{Balance proyectado.}

\begin{tabular}{|c|c|c|c|c|c|c|}
\hline \multicolumn{7}{|c|}{ BALANCE GENERAL PROYECTADO } \\
\hline & 2018 & 2019 & 2020 & 2021 & 2022 & 2023 \\
\hline \multicolumn{7}{|l|}{ ACTIVO } \\
\hline ACTIVO CORRIENTE & 163,582 & 165,885 & 271,597 & 416,883 & 702,433 & $1,089,140$ \\
\hline Caja bancos & 81,262 & 40,240 & 137,420 & 237,286 & 488,144 & 827,277 \\
\hline Cuentas por cobrar & & 63,826 & 82,696 & 104,204 & 128,670 & 156,451 \\
\hline Credito fiscal & 82,321 & 16,203 & 0 & 0 & 0 & 0 \\
\hline Inventarios & & 45,615 & 51,481 & 75,394 & 85,619 & 105,413 \\
\hline ACTIVO NO CORRIENTE & 503,191 & 418,654 & 334,118 & 249,581 & 165,045 & 80,508 \\
\hline Activo tangible & 422,883 & 422,883 & 422,883 & 422,883 & 422,883 & 422,883 \\
\hline (-) Depreciacion & & $(68,475)$ & $(136,950)$ & $(205,425)$ & $(273,900)$ & $(342,375)$ \\
\hline Activo intangible & 80,308 & 80,308 & 80,308 & 80,308 & 80,308 & 80,308 \\
\hline (-) Amortizacion & & $(16,062)$ & $(32,123)$ & $(48,185)$ & $(64,246)$ & $(80,308)$ \\
\hline TOTAL ACTIVO & 666,773 & 584,539 & 605,715 & 666,464 & 867,478 & $1,169,649$ \\
\hline \multicolumn{7}{|l|}{ PASIVO Y PATRIMONIO } \\
\hline \multicolumn{7}{|l|}{ PASIVO } \\
\hline Cuentas por pagar & & 13,975 & 17,806 & 22,228 & 27,320 & 34,827 \\
\hline $\mathrm{CxP}$ materia prima & & 9,670 & 12,345 & 15,440 & 19,013 & 24,776 \\
\hline CxP costo fabricación & & 4,023 & 5,105 & 6,347 & 7,770 & 9,398 \\
\hline CxP insumos & & 282 & 356 & 441 & 538 & 653 \\
\hline Otras cuentas por pagar & & 6,610 & 8,899 & 11,500 & 57,362 & 107,849 \\
\hline IGV & & 6,610 & 8,899 & 11,500 & 14,450 & 17,537 \\
\hline IR & & 0 & 0 & 0 & 42,912 & 90,312 \\
\hline TOTAL PASIVO & 0 & 20,586 & 26,705 & 33,728 & 84,683 & 142,677 \\
\hline \multicolumn{7}{|l|}{ PATRIMONIO } \\
\hline Capital & 666,773 & 666,773 & 666,773 & 666,773 & 666,773 & 666,773 \\
\hline Utilidades acumuladas & 0 & 0 & $(102,820)$ & $(87,763)$ & $(34,037)$ & 116,022 \\
\hline Utilidades retenidas & 0 & $(102,820)$ & 15,057 & 53,726 & 150,059 & 244,177 \\
\hline TOTAL PATRIMONIO & 666,773 & 563,953 & 579,010 & 632,736 & 782,795 & $1,026,972$ \\
\hline TOTAL PASIVO Y PATRIMONIO & 666,773 & 584,539 & 605,715 & 666,464 & 867,478 & $1,169,649$ \\
\hline
\end{tabular}

Cuadro 89. Balance proyectado (S/.).

Fuente: Elaboración propia. 


\subsubsection{Flujo de caja proyectado.}

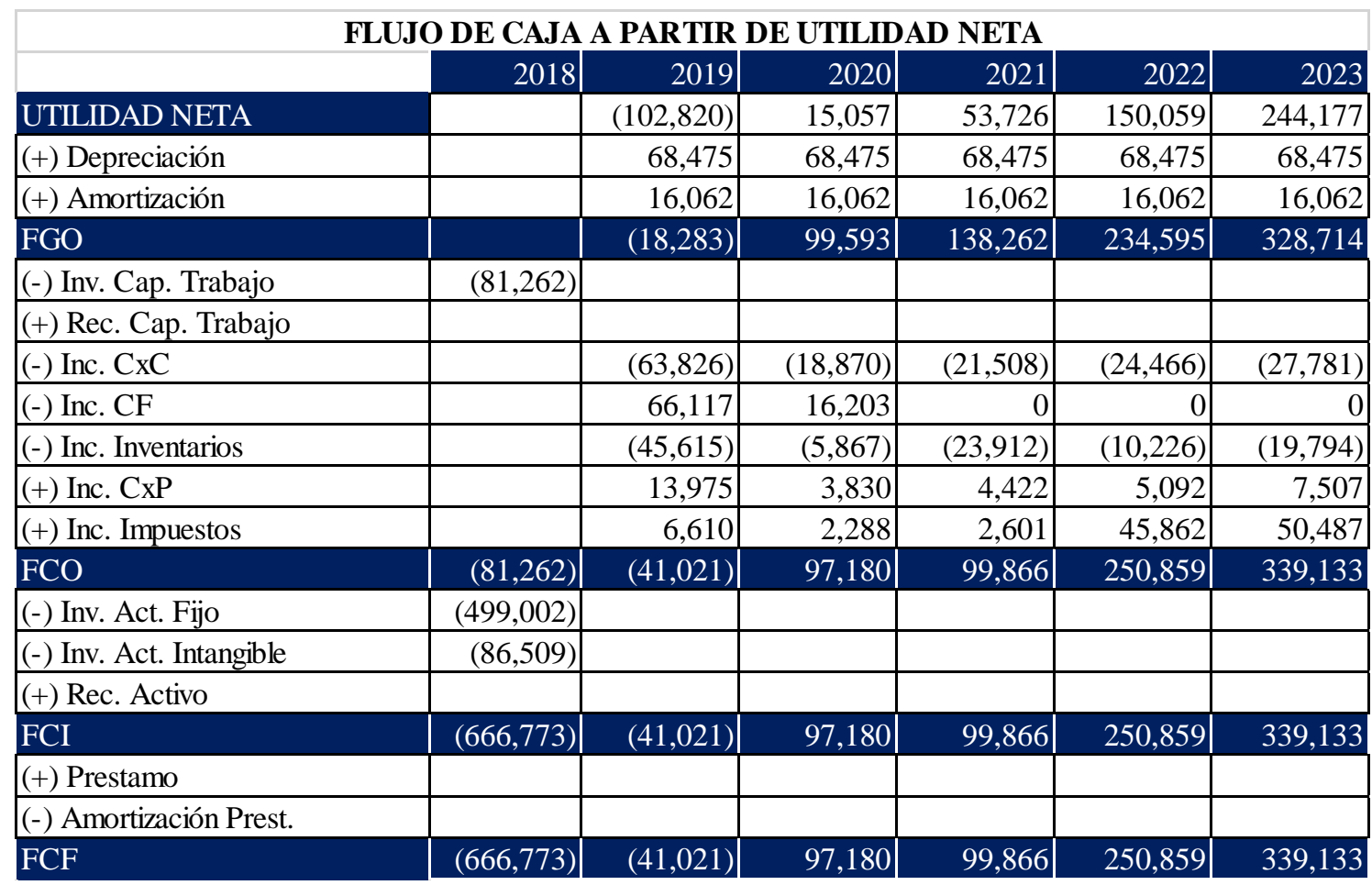

Cuadro 90. Flujo de caja proyectado (S/.)

Elaboración propia. 


\section{Evaluación Económico Financiera}

\subsection{Evaluación Financiera}

\subsubsection{TIR.}

Se obtuvo un TIR de $26.72 \%$ superior al COK de $23.87 \%$, lo que hace el proyecto rentable, se considera una perpetuidad puesto que este tipo de proyectos con activos fijos con instalaciones no se puede terminar en el tiempo de evaluación. La fórmula utilizada para cálculo TIR=i fue:

$$
0=-666,773+\frac{-41,021}{(1+i)^{1}}+\frac{97,180}{(1+i)^{2}}+\frac{99,866}{(1+i)^{3}}+\frac{250,859}{(1+i)^{4}}+\frac{339,133+\frac{339,133}{i}}{(1+i)^{5}}
$$

\begin{tabular}{|l|c|c|c|c|c|c|}
\hline TIR FINANCIERO & $\mathbf{2 0 1 8}$ & $\mathbf{2 0 1 9}$ & $\mathbf{2 0 2 0}$ & $\mathbf{2 0 2 1}$ & $\mathbf{2 0 2 2}$ & $\mathbf{2 0 2 3}$ \\
\hline Flujo de Caja Financiero & $-666,773$ & $-41,021$ & 97,180 & 99,866 & 250,859 & 339,133 \\
\hline & & & & & & $1,269,272$ \\
\hline & $-666,773$ & $-41,021$ & 97,180 & 99,866 & 250,859 & $1,608,405$ \\
\hline TIRF & $\mathbf{2 6 . 7 2 \%}$ & & &
\end{tabular}

Cuadro 91. TIR financiera del proyecto.

Elaboración propia.

\subsubsection{VAN.}

En la evaluación se obtuvo un VAN positivo de 109,809 soles, haciendo el proyecto rentable.

\begin{tabular}{|c|c|c|c|c|c|c|}
\hline VAN FINANCIERO & 2018 & 2019 & 2020 & 2021 & 2022 & 2023 \\
\hline Flujo de Caja Financiero & $-666,773$ & $-41,021$ & 97,180 & 99,866 & 250,859 & 339,133 \\
\hline Perpetuidad & & & & & & $1,420,914$ \\
\hline Flujo de Caja Financiero (Inc. Perpetuidad) & $-666,773$ & $-41,021$ & 97,180 & 99,866 & 250,859 & $1,760,047$ \\
\hline $\mathrm{COK}$ & $23.87 \%$ & & & & & \\
\hline VANF & 126,146 & & & & & \\
\hline
\end{tabular}

Cuadro 92. VAN financiera del proyecto.

Elaboración propia. 


\subsubsection{ROA.}

Se muestra la evaluación del ROA durante los años de evaluación del proyecto.

\begin{tabular}{|l|r|r|r|r|r|}
\hline & 2019 & 2020 & 2021 & 2022 & 2023 \\
\hline Utilidad neta & $(102,820)$ & 15,057 & 53,726 & 150,059 & 244,177 \\
\cline { 2 - 6 } Patrimonitio & 584,539 & 605,715 & 666,464 & 867,478 & $1,169,649$ \\
\hline ROA & $-17.6 \%$ & $2.5 \%$ & $8.1 \%$ & $17.3 \%$ & $20.9 \%$ \\
\hline
\end{tabular}

Cuadro 93. Evolución del ROA del proyecto.

Elaboración propia.

\subsubsection{ROI.}

Se muestra la evaluación del ROI durante los años de evaluación del proyecto.

\begin{tabular}{|l|r|r|r|r|r|}
\hline & 2019 & 2020 & 2021 & 2022 & 2023 \\
\hline EBIT & $(102,820)$ & 15,057 & 53,726 & 192,971 & 334,489 \\
\cline { 2 - 6 } Patrimonio & 563,953 & 579,010 & 632,736 & 782,795 & $1,026,972$ \\
\hline ROI & $-18.2 \%$ & $2.6 \%$ & $8.5 \%$ & $24.7 \%$ & $32.6 \%$ \\
\hline
\end{tabular}

Cuadro 94. Evolución del ROI del proyecto.

Elaboración propia.

\subsubsection{ROE.}

En la evaluación del ROE se muestra como evoluciona año tras año, el último año se obtiene un $21.6 \%$.

\begin{tabular}{|l|r|r|r|r|r|}
\hline & 2019 & 2020 & 2021 & 2022 & 2023 \\
\hline Utilidad neta & $(102,820)$ & 15,057 & 53,726 & 150,059 & 244,177 \\
\cline { 2 - 6 } Patrimonio & 563,953 & 579,010 & 632,736 & 782,795 & $1,026,972$ \\
\hline ROE & $-18.2 \%$ & $2.6 \%$ & $8.5 \%$ & $19.2 \%$ & $23.8 \%$ \\
\hline
\end{tabular}

Cuadro 95. Evolución del ROE del proyecto.

Elaboración propia.

\subsection{Análisis de Riesgo}

\subsubsection{Análisis de punto de equilibrio.}

Como se tiene 3 productos se debe hacer análisis con promedios ponderados en función de los porcentajes de las ventas de cada producto respecto de las ventas totales. 


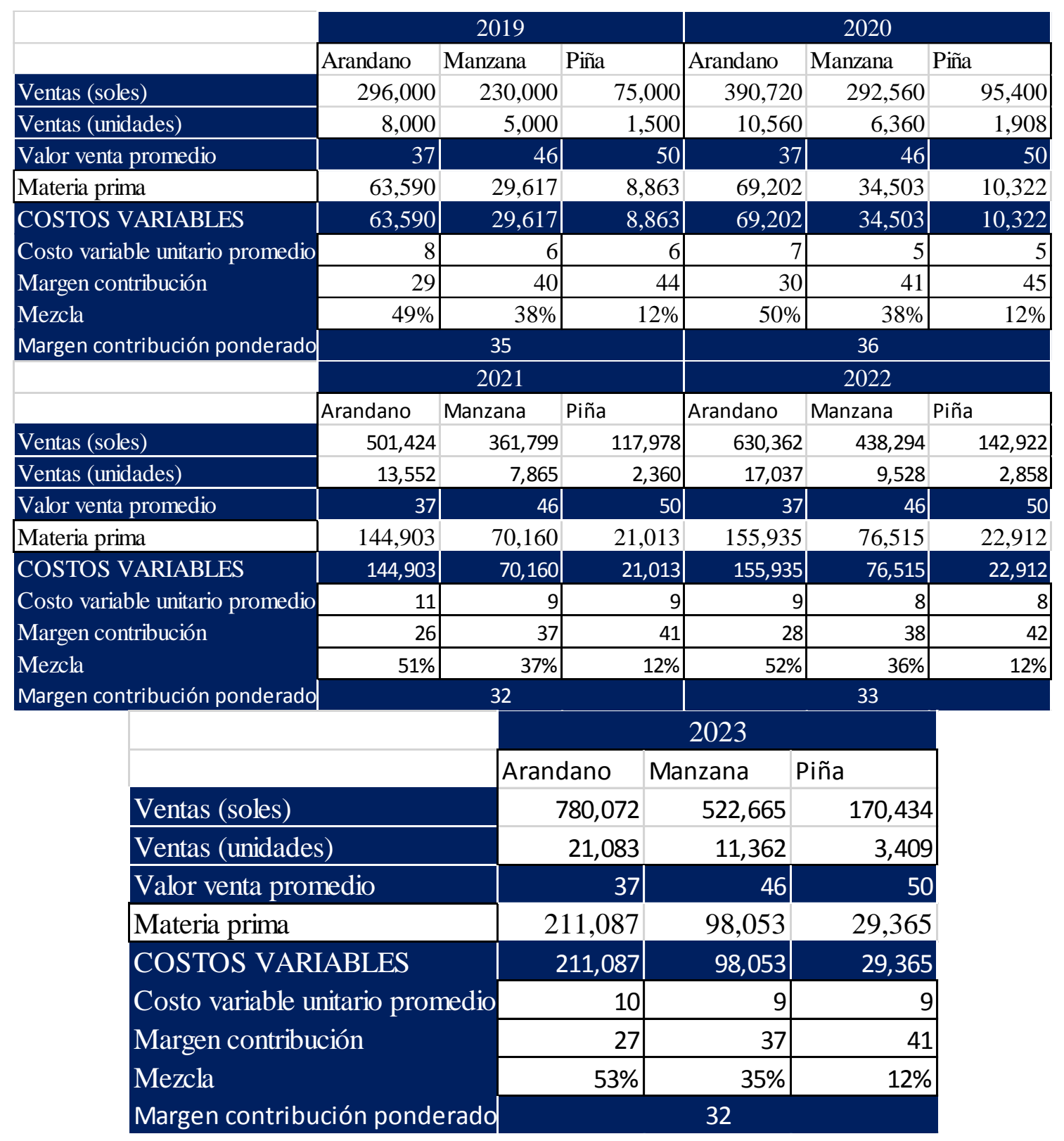

Cuadro 96. Evaluación margen contribución ponderado por año.

Elaboración propia.

Luego se hace el análisis de punto de equilibrio con los márgenes de contribución ponderados. 


\begin{tabular}{|l|r|r|r|r|r|}
\hline Margen contribución ponderado & 35 & 36 & 32 & 33 & 32 \\
\hline Mano de obra directa & 72,360 & 72,360 & 189,744 & 189,744 & 262,104 \\
\hline CIF & 247,073 & 247,073 & 269,585 & 298,529 & 298,529 \\
\hline Gastos administración & 227,946 & 227,946 & 227,946 & 227,946 & 227,946 \\
\hline Gasto ventas & 71,358 & 72,934 & 74,720 & 76,805 & 79,245 \\
\hline COSTOS FIJOS & $\mathbf{6 1 8 , 7 3 7}$ & $\mathbf{6 2 0 , 3 1 3}$ & $\mathbf{7 6 1 , 9 9 5}$ & $\mathbf{7 9 3 , 0 2 4}$ & $\mathbf{8 6 7 , 8 2 4}$ \\
\hline $\begin{array}{l}\text { Punto equilibrio (unidades) } \\
\text { Punto equilibrio (soles) }\end{array}$ & 17,604 & 17,238 & 23,770 & 23,903 & 26,837 \\
\cline { 2 - 6 } & 740,541 & 723,557 & 995,509 & 998,892 & $1,119,017$ \\
\hline Producto (unidades) & & & & & 2023 \\
\hline Arándano & 2019 & 2020 & 2021 & 2022 & 2023 \\
\hline Piña & 8,670 & 8,650 & 12,147 & 12,436 & 14,211 \\
\hline Manzana & 6,737 & 6,477 & 8,765 & 8,647 & 9,521 \\
\hline
\end{tabular}

Cuadro 97. Análisis de punto de equilibro por año.

Elaboración propia.

Se puede mostrar la variación del valor de punto de equilibrio respecto de las ventas anuales para revisar la tendencia, en el primer año no se cubren los costos fijos, en el segundo año los costos fijos son cubiertos ligeramente, en el tercer año los costos fijos no se puede cubrirá por el incremento de mano de obra directa para aumentar la producción, a partir del cuarto año de evaluación los costos fijos son completamente cubiertos.

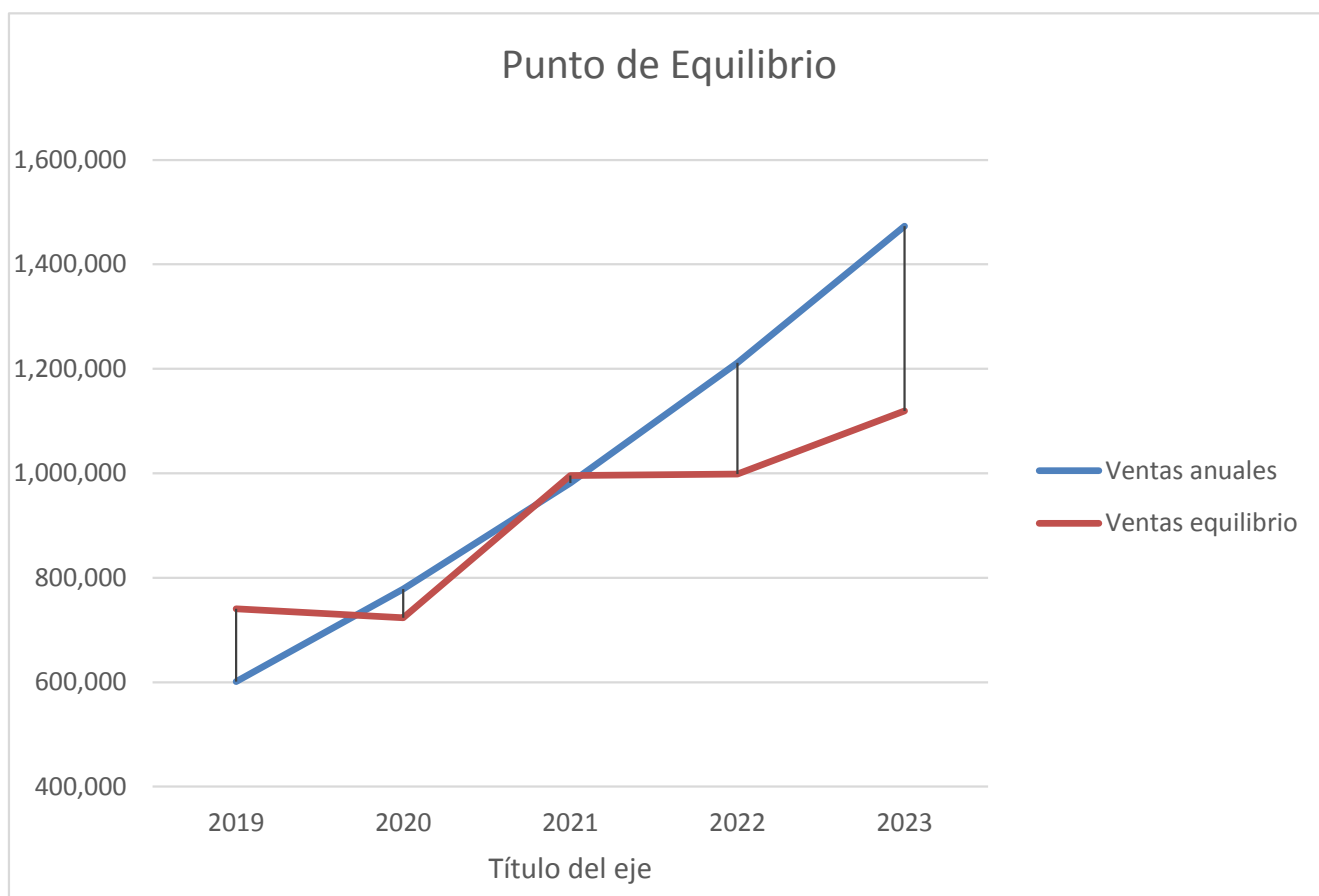

Gráfico 49. Tendencias del punto de equilibrio y ventas anuales. Elaboración propia 


\subsubsection{Análisis de sensibilidad.}

Para el plan de negocios se identificaron tres factores que podrían causar la variación de la rentabilidad del proyecto: el valor de compra de las frutas frescas materia prima, el valor de venta del producto y la demanda objetivo del mercado.

\subsubsection{Abastecimiento de materia prima.}

Los principales proveedores de la materia prima de la fruta fresca son los pequeños y medianos agricultores de la sierra de Limay del norte del Perú. La materia prima que será utilizada para el proyecto de negocios serán los saldos de exportación principalmente en el arándano.

Los saldos deben ser vendidos por los agricultores rápidamente pues se trata de productos perecibles. Por otro lado en el caso de los arándanos, las áreas de cultivo se están incrementado sostenidamente debido al incremento de la demanda del exterior, lo que consecuentemente incrementan los saldos. Esta situación deja bajo margen de negociación a los proveedores respecto de los saldos.

En este escenario se esperaría una disminución del precio de la materia prima como ha venido sucediendo desde el año 2013.

A pesar de las condiciones favorables para la disminución del precio de la materia prima se considera un escenario desfavorable con $50 \%$ de probabilidades de que el precio se incrementará $10 \%$ para el arándano, manzana y piña respectivamente, y un escenario promedio con un $50 \%$ de probabilidades de que el precio se mantenga según lo determinado en el plan de negocios, se obtuvieron los siguientes resultados: 


\begin{tabular}{|c|c|c|c|c|}
\hline \multicolumn{5}{|c|}{ ANALISIS UNIDIMENSIONAL VALOR FRUTOS FRESCOS } \\
\hline \multicolumn{3}{|c|}{ Probabilidad } & \multicolumn{2}{|c|}{ TIRF } \\
\hline \multicolumn{2}{|c|}{$\mathrm{P}($ Precio promedio $)=50 \%$} & $50 \%$ & $26.72 \%$ & $13 \%$ \\
\hline \multicolumn{2}{|c|}{$\mathrm{P}($ Prec.$+10 \%)=50 \%$} & $50 \%$ & $25.57 \%$ & $13 \%$ \\
\hline \multirow{5}{*}{$\mathrm{COK}$} & \multirow[t]{5}{*}{$23.87 \%$} & & TIRF Pond. & $26.1 \%$ \\
\hline & & & Varianza & 0.000033 \\
\hline & & & Desv & 0.005750 \\
\hline & & & Coef Var & $2 \%$ \\
\hline & & & Prob Norm & $99.98 \%$ \\
\hline
\end{tabular}

Cuadro 98. Análisis de sensibilidad del efecto del precio de la materia prima en la rentabilidad del plan de negocios.

Elaboración propia.

Bajo las condiciones de variación del precio de la materia prima, la probabilidad sale mayor al 50\% con una variación muy baja del 3\%, esta variable tiene bajo impacto en la rentabilidad del plan.

\subsubsection{Reacción de la competencia actual y potencial.}

La empresa Terrafertil Perú es el principal competidor del sector, es una empresa comercializadora de alimentos procesados a base de arándanos, uno de sus productos es el arándano deshidratado. Terrafertil importa sus productos finales desde Norte América, los productos son comprados principalmente a la empresa Ocean Spray. Para el caso de los arándanos deshidratados sería un poco complicado que su proveedor cambie su proceso para cumplir los requerimientos de tamaño sólo para el mercado peruano.

Similarmente los siguientes dos proveedores más relevantes como Frutos y Especias SAC y Frutos e Industrias SAC también son empresas comercializadoras, compran el producto final a empresas terceras que no tienen certificación HACCP, para poder vender producto con las especificaciones técnicas y de calidad necesarias tendrían que solicitarlo a sus proveedores.

En este escenario se espera una reacción leve de parte de las empresas competidoras en cuanto a las características y certificaciones. 
Para el análisis se considerará un escenario con 50\% de que el valor de venta se mantenga y un 50\% de probabilidad de que el valor de venta disminuya un $10 \%$ debido a la reacción de la competencia. Similarmente se considerará otro escenario con $50 \%$ de probabilidad de que la demanda se mantenga según el pronóstico del plan de negocios y un $50 \%$ de probabilidad de que el la demanda disminuya un $10 \%$.

En este escenario consideraremos escenarios cautelosos con valor de venta y con la demanda del mercado objetivo, esto nos da los siguientes resultados:

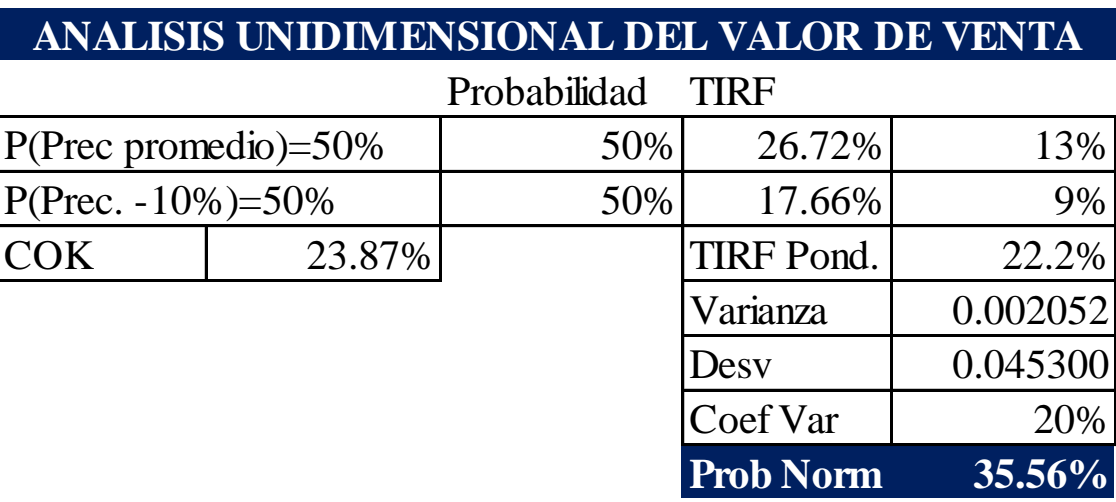

ANALISIS UNIDIMENSIONAL DEMANDA OBJETIVA

\begin{tabular}{|c|c|c|c|c|}
\hline \multicolumn{3}{|c|}{ Probabilidad } & \multicolumn{2}{|l|}{ TIRF } \\
\hline \multicolumn{2}{|c|}{$\mathrm{P}($ Demanda promedio $)=50$} & $50 \%$ & $26.72 \%$ & $13 \%$ \\
\hline \multicolumn{2}{|c|}{$\mathrm{P}($ Demanda $-10 \%)=50 \%$} & $50 \%$ & $19.80 \%$ & $10 \%$ \\
\hline $\mathrm{COK}$ & \multirow[t]{5}{*}{$23.87 \%$} & & TIRF Pond. & $23.3 \%$ \\
\hline & & & Varianza & 0.001197 \\
\hline & & & Desv & 0.034600 \\
\hline & & & Coef Var & $15 \%$ \\
\hline & & & Prob Norm & $43.03 \%$ \\
\hline
\end{tabular}

Cuadro 99. Análisis de sensibilidad del valor de venta y la demanda objetica en la rentabilidad del plan de negocios.

Elaboración propia.

Considerando el valor de venta, la probabilidad de que la TIRF sea mayor que el COK es de $35.56 \%$, esta variable tiene impacto alto en la rentabilidad del plan de negocios, en el mismo sentido pero con un menor impacto en la demanda se obtiene una probabilidad de $43.03 \%$ de que el TIRF sea mayor que el COK, esto también tendría un impacto alto en la rentabilidad del plan de negocios. 


\subsubsection{Disminución de la productividad.}

El plan de negocios fue concebido con un sobredimensionamiento de la capacidad de producción de la planta según un experto de la industria de procesamiento de alimentos, esto para asegurar el nivel de producción según el plan de producción anual, sin embargo en este apartado se hará un análisis de impacto de una bajada de productividad de un $10 \%$ por merma, es decir que para obtener una misma cantidad de producto final debe utilizarse un $10 \%$ más de materia prima y eficiencia en la operación de los equipos.

\begin{tabular}{|c|c|c|c|c|}
\hline \multirow{2}{*}{\multicolumn{5}{|c|}{ ANALISIS UNIDIMENSIONAL PRODUCTIVIDAD }} \\
\hline & & & & \\
\hline \multicolumn{2}{|c|}{$\mathrm{P}($ Productividad promedio $)=500$} & $50 \%$ & $26.72 \%$ & $13.36 \%$ \\
\hline \multicolumn{2}{|c|}{$\mathrm{P}($ Productividad $-10 \%)=50 \%$} & $50 \%$ & $25.32 \%$ & $12.66 \%$ \\
\hline \multirow[t]{5}{*}{$\mathrm{COK}$} & \multirow[t]{5}{*}{$23.87 \%$} & & TIRF Pond. & $26.0 \%$ \\
\hline & & & Varianza & 0.000049 \\
\hline & & & Desv & 0.007000 \\
\hline & & & Coef Var & $3 \%$ \\
\hline & & & Prob Norm & $9 \%$ \\
\hline
\end{tabular}

Cuadro 100. Análisis de sensibilidad por disminución en la productividad del proceso productivo del plan de negocios

Fuente: Elaboración propia.

\subsubsection{Análisis de escenarios.}

Se identificaron tres factores que podrían variar significativamente la rentabilidad del proyecto: el valor de compra de las frutas frescas materia prima, el valor de venta del producto y la demanda objetivo del mercado.

En los escenarios pesimistas si los factores aumentan o bajan de los valores promedios, el proyecto ya no sería rentable pues la tasa de retorno sería menor al COK.

\begin{tabular}{|l|r|r|r|}
\hline & \multicolumn{3}{|c|}{ PESIMISTA PROMEDIO OPTIMISTA } \\
\hline Variación valor frutos frescos & $25 \%$ & $0 \%$ & $-5 \%$ \\
\hline Variación valor de venta & $-5 \%$ & $0 \%$ & $5 \%$ \\
\hline Variación demanda objetiva & $-3 \%$ & $0 \%$ & $5 \%$ \\
\hline TIR & $\mathbf{2 3 . 8 7} \%$ & $\mathbf{2 6 . 7 2 \%}$ & $\mathbf{2 9 . 5 9 \%}$ \\
\hline
\end{tabular}

Cuadro 101. Escenarios por factores relevantes.

Fuente: Elaboración propia. 


\section{CONCLUSIONES Y RECOMENDACIONES}

\section{Conclusiones}

- En el subsector de alimentos y específicamente la actividad de las empresas y el consumo de frutas deshidratadas está atravesando un período de crecimiento sostenido debido a la toma de conciencia de los consumidores sobre el consumo de alimentos saludables, la fruta deshidratada conserva un alto porcentaje de las propiedades organolépticas de la fruta fresca.

- En el análisis del micro entorno del sector basado en el modelo de las 5 fuerzas de Porter, nos refiere un entorno "Neutral" en atractividad.

- En el análisis de la Matriz de Perfil Competitivo se observa que los factores claves de mayor relevancia son la especificación técnica, características organolépticas que definen la calidad del producto y el precio; siendo la empresa Terrafertil SAC quien tiene el mayor puntaje ponderado de 3.7.

- Como estrategia básica de marketing el proyecto establecerá la diferenciación, la cual estará basada en la calidad del producto y servicio ofrecido, características identificadas en la investigación de mercado.

- De acuerdo al análisis con la matriz Ansoff se ha identificado que el proyecto se encuentra en los cuadrantes de: "productos existente y mercados existentes"; esto indica que la estrategia a seguir será la de penetración de mercados basado también en la calidad del producto y abastecimiento continuo y oportuno.

- En la ingeniería del proyecto se determinó la capacidad de diseño, está dada en condiciones normales de funcionamiento y está definida por el sistema de deshidratado continuo, siendo $180 \mathrm{~kg} /$ día. Tiene la capacidad para cubrir la demanda del plan de negocio. 
- La localización óptima se encuentra en el departamento de Lima, distrito de Santa Anita, determinado con detalle de los factores en la macro y micro localización.

- El proyecto de negocio consta de una inversión de activo fijo de S/. 499,002 soles.

- El costo del proyecto es la suma de la inversión en activo fijo, activo intangible y capital de trabajo, se obtuvo un monto de S/. 666,773.

- $\quad$ El COK para el proyecto resulta en $23.87 \%$.

- Se obtuvo un TIR de $26.72 \%$, superior al COK lo que hace el proyecto rentable.

- En la evaluación se obtuvo un VAN positivo de S/. 126,146 haciendo el proyecto rentable.

- En el último año del horizonte del plan de negocio se obtiene un ROE de 23.8\%, ROA de $20.9 \%$ y ROI de $32.6 \%$

- Se realizó análisis por el precio de venta y la demanda, y lo máximo que puede bajar es de $5 \%$ y $3 \%$ respectivamente para que el plan de negocios sea rentable.

- Ante un escenario de disminución del valor de venta de los frutos deshidratados se tiene un margen máximo del 5\%, debajo de ese margen existe el riesgo de que el plan de negocios no sea rentable. Por otro lado si por algún factor disminuye la demanda más del 3\%, también existe un riesgo de que el plan de negocios no sea rentable.

- Los bajos porcentajes de variación para la disminución del valor del producto final y de la demanda hacen que el plan de negocios sea de alto riesgo.

- El plan de negocios se podría implementar si las recomendaciones indicadas son factibles. 


\section{Recomendaciones}

- Contribuir con el desarrollo de nuevos productos para el consumidor final, a base de frutas deshidratadas y de acuerdo a las tendencias del mercado; con el objetivo de incrementar la demanda por parte de empresas industriales de alimentos; nos permitirá aumentar el uso de capacidad instalada.

- Ampliar el portafolio de productos deshidratados realizando estudio detallado de disponibilidad de materia prima en el territorio nacional, tenemos el caso de aguaymanto, frambuesa y otras frutas.

- Ampliar la cartera de clientes en el mediano y largo plazo, considerar el mercado de exportación para ofertar arándanos, piña y manzana deshidratada. Se impulsa el crecimiento del negocio mediante la identificación de nuevas plazas y oportunidades presentes en el mercado exterior.

- Implementar programas de mejora de procesos productivos basados en tecnología de punta con el fin de poder obtener eficiencia, rendimiento y calidad superior. Un caso específico es el deshidratador IRCDi -20 con emisores FIR es modular y ocupa poco espacio. Estos equipos conservan la totalidad de las propiedades organolépticas tras el proceso de deshidratado. 
ANEXOS

Anexo 1. Investigación cualitativa

1.1 Ficha técnica de estudio cualitativo

\begin{tabular}{|l|l|}
\hline Técnica & Exploración cualitativa por entrevistas en profundidad. \\
\hline Sesiones & 4 sesiones \\
\hline Estructura de las & Conformados por: \\
Jefe de cadena de abastecimiento. \\
Gerente de Logística \\
Comercializador de Frutas deshidratadas. \\
Coordinador de Sierra y Selva Exportadora. \\
\hline Método de selección & Organismos estatales que promuevan la agroindustria \\
& Participantes en la cadena de abastecimiento \\
\hline Método de muestreo & No probabilístico \\
\hline Duración & Entre 1:00 a 1:15 hrs \\
\hline
\end{tabular}

1.2 Integrantes - con conocimiento del sector

- Jefe de cadena de abastecimiento

- Gerente de Logística

- Comercializador de Frutas deshidratadas.

- Coordinador de Sierra y Selva Exportadora. 


\subsection{Estructura de cuestionario}

1. ¿Cuáles son los productos deshidratados de mayor demanda?

2. ¿Cuáles son los productos sustitutos de la fruta deshidratada?

3. ¿Cuáles son las principales especificaciones técnicas de las frutas deshidratadas?

4. ¿Cuál o cuáles cree usted que son las razones para el crecimiento de la demanda berries y fruta deshidratada por parte de las empresas elaboradoras de alimentos?

5. ¿Cuáles son los criterios que utiliza para elegir a sus proveedores?

6. ¿Cómo considera la tendencia de la producción de frutos frescos?

7. ¿Cuáles son las zonas de mayor crecimiento de frutos frescos arándanos, piña y manzana?

8. ¿Cuáles son las estaciones o meses de producción de frutos frescos como la manzana, arándanos y piña?

9. Aproximadamente, ¿cuánto cree que es el porcentaje de frutos frescos que no se exportan?

10. En promedio ¿Cuánto es el precio de la fruta fresca que no se exporta?

11. ¿Cómo es el proceso de abastecimiento de fruta fresca que no se exporta?

12. ¿Qué usos se le puede dar a la fruta fresca que no se exporta? 
José Carlos Linares Jefe de Cadena de Abastecimiento de la empresa Industrias

Alimenticias Cusco SA

1. ¿Cuáles son los productos deshidratados de mayor demanda?

Industrias Alimenticias Cusco SA compra pasas, arándanos, piña y manzanas

2. ¿Cuáles son los productos sustitutos de la fruta deshidratada?

Las verduras deshidratadas aunque con un nivel bajo de afectación porque las solicitudes de los clientes son específicas.

3. ¿Cuáles son las principales especificaciones técnicas de las frutas deshidratadas?

La característica de calidad, la cual se detalla en: porcentaje de humedad, libre de pedúnculos o cualquier otro tipo de partículas extrañas; así como de calibre, es decir, el tamaño específico que necesita tener la pasa, el arándano y la manzana.

4. ¿Cuál o cuáles cree usted que son las razones para el crecimiento de la demanda berries y fruta deshidratada por parte de las empresas elaboradoras de alimentos?

Desde mediados del 2016 en que decidimos sacar galletas con quinua, en el caso de frutos rojos ha sido creciente debido a que los productos están satisfaciendo la necesidad de las personas por alimentos saludables y de alto poder vitamínico. Dentro de la empresa nos encontramos muy confiados en que este año las ventas se volverán a incrementar.

5. ¿Cuáles son los criterios que utiliza para elegir a sus proveedores?

Los criterios están definidos fundamentalmente en: cumplimiento de especificaciones de calidad, certificados de calidad, fecha de entrega, abastecimiento continuo, precio y plazos de pago. 
6. ¿Cómo considera la tendencia de la producción de frutos frescos?

Las pasas y los arándanos son de procedencia extranjera, en el caso de la manzana esta procede del mercado nacional. No conozco al detalle la tendencia de producción; lo que si les puedo decir es que las pasas y los arándanos de procedencia nacional presentan diferencias no beneficiosas para Industrias Alimenticias Cusco SA, esto debido a que el proceso de deshidratación no es el adecuado.

7. ¿Cuáles son las zonas de mayor crecimiento de frutos frescos arándanos, piña y manzana?

En la zona sur centro y norte del Perú. Junín.

8. ¿Cuáles son las estaciones o meses de producción de frutos frescos como la manzana, arándanos y piña?

En nuestro caso como empresa solicitamos frutos deshidratados y su abastecimiento es continuo en el año.

9. Aproximadamente, ¿cuánto cree que es el porcentaje de frutos frescos que no se exportan?

En realidad es muy poco lo que se exporta aún. En el caso de los arándanos un $4 \%$ aproximadamente. En el caso de la manzana un $60 \%$.

10. En promedio ¿Cuánto es el precio de la fruta fresca que no se exporta? No tengo esos precios por los que preguntas pero hay que diferenciar que el precio en chacra es diferente al precio en Lima. El tema logístico es crucial.

11. ¿Cómo es el proceso de abastecimiento de fruta fresca que no se exporta? Exactamente no lo conozco al detalle es vendidos a diferentes personas o empresas. Los cuales los venden o los procesan, pero como lo mencioné los procesos de deshidratados no son los esperados. 
12. ¿Qué usos se le puede dar a la fruta fresca que no se exporta?

Muchos en verdad, desde venderla como fruta fresca, fruta procesada como la deshidratación, hasta néctares, mermeladas o para fermentación. 
1. ¿Cuáles son los productos deshidratados de mayor demanda? Arándanos, manzana, pasas y fresas. Son las frutas con las que trabajamos.

2. ¿Cuáles son los productos sustitutos de la fruta deshidratada? Los frutos secos como el maní, almendras, avellanas. En nuestra empresa trabajamos también con estos productos.

3. ¿Cuáles son las principales especificaciones técnicas de las frutas deshidratadas?

La humedad, los cuerpos extraños, el tamaño específico de acuerdo a nuestros productos.

4. ¿Cuál o cuáles cree usted que son las razones para el crecimiento de la demanda berries y fruta deshidratada por parte de las empresas elaboradoras de alimentos?

Existe una corriente en crecimiento ya que los consumidores en el mundo son cada vez más conscientes de que su ingesta proporciona vitaminas, antioxidantes y fibras.

5. ¿Cuáles son los criterios que utiliza para elegir a sus proveedores? Las fechas de entrega es fundamental para nuestro negocio puesto que existe pedidos que debemos cumplir en fechas establecidas. En paralelo las especificaciones técnicas solicitadas, el precio y el crédito.

6. ¿Cómo considera la tendencia de la producción de frutos frescos? Como insumo de frutos deshidratados ¡Por supuesto que sí!, los berries han tenido un crecimiento importante de cultivo en el Perú, sin embargo se puede crecer más 
si se utiliza mayor investigación tecnología en su producción. Argentina y Chile son los mayores productores en Sudamérica.

7. ¿Cuáles son las zonas de mayor crecimiento de frutos frescos arándanos, piña y manzana?

La libertad, Ica por supuesto en el caso del arándano, Lima en el caso de la manzana y la Selva-Loreto en el caso de la Piña, alguna vez tuvimos pedidos de manzana y piña para un cliente en el extranjero.

8. ¿Cuáles son las estaciones o meses de producción de frutos frescos como la manzana, arándanos y piña?

La producción es continua todo el año.

9. Aproximadamente, ¿cuánto cree que es el porcentaje de frutos frescos que no se exportan?

Aproximadamente entre un $80 \%$ a $90 \%$ Aun es reducido la cantidad que se exporta pues se necesita abrir más mercado para nuestros productos en el mundo.

10. En promedio ¿Cuánto es el precio de la fruta fresca que no se exporta? El arándano fresco se encuentra a S/. 3.5 por ejemplo.

11. ¿Cómo es el proceso de abastecimiento de fruta fresca que no se exporta? El proceso es simple: Los agricultores venden su producción a las empresas, comerciantes que lo destinan a la comercialización en su mismo estado o en su defecto a la transformación industrial.

12. ¿Qué usos se le puede dar a la fruta fresca que no se exporta?

A parte de la deshidratación existe la transformación en néctares y bebidas naturales; hay una demanda creciente en el Perú 
1. ¿Cuáles son los productos deshidratados de mayor demanda? Aguaymanto, plátano muquicho, piña, mango, manzana y betarraga, porque el mercado internacional (EEUU, Australia y Japón y La Unión Europea) lo solicita.

2. ¿Cuáles son los productos sustitutos de la fruta deshidratada?

En el mundo los frutos secos y las verduras, en el Perú lo son las frutas frescas ya que son muchos más accesibles en precio y plaza.

3. ¿Cuáles son las principales especificaciones técnicas de las frutas deshidratadas?

El sabor, la textura, el color y el aroma.

4. ¿Cuál o cuáles cree usted que son las razones para el crecimiento de la demanda berries y fruta deshidratada por parte de las empresas elaboradoras de alimentos?

Existe en el mundo la tendencia de consumir alimentos naturales y que sean sanos al ser humano, aspectos como la obesidad y un mayor compromiso por cuidar la salud son elementos clave.

5. ¿Cuáles son los criterios que utiliza para elegir a sus proveedores?

Nosotros trabajamos mucho en el asesoramiento a los productores y pequeños empresarios sobre lo que se debe hacer en la deshidratación de frutas. Por ejemplo es importante que el empresario pueda presentar un producto hecho a una temperatura y humedad adecuadas; cuidando la textura y el tamaño del fruto: 
finalmente se debe tener en cuenta la fase de maduración de la fruta. Todos estos aspectos son exigidos por las empresas que requieren este tipo de productos.

6. ¿Cómo considera la tendencia de la producción de frutos frescos?

Los frutos frescos para exportación tienen un crecimiento importante; Sierra y selva exportadora cumplen un papel importante en promover el acceso a los mercados, de los pequeños y medianos productores por medio de productos competitivos y sostenibles.

7. ¿Cuáles son las zonas de mayor crecimiento de frutos frescos arándanos, piña y manzana?

La libertad, Lima y Junín.

8. ¿Cuáles son las estaciones o meses de producción de frutos frescos como la manzana, arándanos y piña?

Es diverso, miren tenemos Lima, Ica, La libertad, Loreto, Puno, Ancash, Tacna, Lambayeque.

9. Aproximadamente, ¿Cuánto cree que es el porcentaje de frutos frescos que no se exportan?

En el caso de la manzana un $70 \%$, el de la piña un $10 \%$ en el caso del arándano un $95 \%$ es exportado el resto se queda en el Perú. Hasta el año pasado exportamos un $24 \%$ del total de fruta al extranjero, esto compuesto por arándonos, mangos, uvas, palta, manzana, piña y granadas.

10. En promedio ¿Cuánto es el precio de la fruta fresca que no se exporta? El arándano está a S/. 2.5, la manzana a un S/. 0.5. y la piña a S/. 0.7 
¿Cómo es el proceso de abastecimiento de fruta fresca que no se exporta?

La fruta fresca de descarte se vende o es utilizada por los mismos productores para su utilización como ingrediente en mermeladas o deshidratación. Otro es la venta a comerciantes o intermediarios para el consumo en mercados o elaboración de otros productos.

11. ¿Qué usos se le puede dar a la fruta fresca que no se exporta?

A parte de la deshidratación existe la transformación en néctares, bebidas naturales, mermeladas, encurtidos y vinagres. 
1. ¿Cuáles son los productos deshidratados de mayor demanda? Arándanos, plátano, piña, mango y manzana.

\section{2. ¿Cuáles son los productos sustitutos de la fruta deshidratada?}

Considero que las frutas frescas, en el Perú las personas prefieren mil veces la fruta fresca que la deshidratada, la fruta deshidratada es buena para los países en donde hace mucho frío y no hay fruta fresca; además la fruta fresca es mucho más barata que la deshidratada. En el mundo las verduras deshidratadas son sustitutos pero el sabor de la fruta es el elemento diferenciador a resaltar.

3. ¿Cuáles son las principales especificaciones técnicas de las frutas deshidratadas?

La humedad, la variedad de fruta que compras, por ejemplo la variedad roja en los arándanos es lo mejor, la Golden en piñas; otro punto es el tiempo en la que compras la materia prima que será luego deshidratada. En mi caso el sistema de deshidratación es por secado por aire caliente, es eficiente; sin embargo me han dicho que este tipo de tecnología generada por gas es mucho más eficiente sin embargo necesito ver que eso sea verdad para analizar el cambio.

\section{4. ¿Cuál o cuáles cree usted que son las razones para el crecimiento de la} demanda berries y fruta deshidratada por parte de las empresas elaboradoras de alimentos?

El punto clave es la salud. En el Perú el consumo es mínimo, lo que quiero decir es que las personas lo consumen pero no en todas las zonas de Lima, en la zonas de Niveles socioeconómicos altos la frecuencia en compra es buena pero en otro aún no o están en un crecimiento pequeño; or lo mismo la exportación es una vía en 
donde los beneficios son mayores en comparación con la venta en el mercado peruano. Sin embargo es interesante que empresas estén colocando frutos deshidratados en sus productos como galletas, barras energéticas, etc.

5. ¿Cuáles son los criterios que utiliza para elegir a sus proveedores? En mi caso los proveedores deberán darme un precio adecuado ya que lo que compro son productos de saldos de exportación. Los productores siempre están desesperados por tratar de poder vender sus productos lo más rápido posible ya que se pueden malograrse rápidamente.

6. ¿Cómo considera la tendencia de la producción de frutos frescos?

Esto del fenómeno del niño nos ha afectado, por ejemplo la producción de mangos. Yo particularmente trabajo con el mango, sin embargo deshidrato de todo y eso me ha permitido poder no verme tan afectado.

7. ¿Cuáles son las zonas de mayor crecimiento de frutos frescos arándanos, piña y manzana?

Las manzanas están botadas en Lima hay una infinidad de variedades con las que se pueden trabajar, arándanos Junín y la Piña en la selva; en el caso de la piña se debe evaluar el transporte ya que únicamente se utiliza el $40 \%$ de la fruta pues el resto se desecha.

8. ¿Cuáles son las estaciones o meses de producción de frutos frescos como la manzana, arándanos y piña?

Es diverso, pero tenemos abastecimiento todo el año. Los problemas se dan cuando hay huaycos.

9. Aproximadamente, ¿Cuánto cree que es el porcentaje de frutos frescos que no se exportan?

Uhmm un $30 \%$ aproximadamente. 
10. En promedio ¿Cuánto es el precio de la fruta fresca que no se exporta?

Es variable por ejemplo un kilo de manzana está 3 soles en Lima, la del tipo Israel. La del tipo delicia a4 soles al menudeo.

11. ¿Cómo es el proceso de abastecimiento de fruta fresca que no se exporta? En mi caso yo las compro y las deshidrato para luego exportarlas. Hay otros que los compran y me piden que las deshidraten. Por último otros los traen de forma fresca y venderlos en los mercados tradicionales.

12. ¿Qué usos se le puede dar a la fruta fresca que no se exporta?

Los podemos hacer harina, que es lo que también hago en mi planta de Ate Vitarte. 
2.1 Ficha técnica de estudio cuantitativo

\begin{tabular}{|l|l|}
\hline Técnica & Cuantitativa - encuesta \\
\hline Universo & $\begin{array}{l}\text { Empresas grandes y medianas elaboradoras } \\
\text { de productos alimenticios, dentro del } \\
\text { departamento de Lima. }\end{array}$ \\
\hline Público objetivo & $\begin{array}{l}\text { Empresas grandes y medianas elaboradoras } \\
\text { de productos alimenticios, dentro del } \\
\text { departamento de Lima, que están en los rubros } \\
\text { de Molinería, Chocolatería, Panadería y Otros, } \\
\text { las cuales se encarguen de elaborar Barras } \\
\text { Energéticas, Granolas, Galletas y Snacks }\end{array}$ \\
\hline Muestra & 40 \\
\hline Método de muestreo & No probabilístico \\
\hline Duración & 20 minutos \\
\hline Fecha & 20 de febrero \\
\hline
\end{tabular}

\subsection{Encuesta estudio cuantitativo}

PARTE I

1. ¿Su empresa produce alimentos y/o los comercializa?
a) Sí ( )
b) No ( )

2. De acuerdo a APEGA MERCADOS: "los frutos deshidratados van ganando cada día más consumidores en el mercado peruano como snack"; por otro lado, su utilización como insumo en la producción de diversos alimentos de panadería pastelería, hotelería, catering. Por lo anteriormente expuesto usted o su empresa:

a) Estaría muy interesado en conocer más sobre fruta deshidratada ( )

b) Estaría interesado en conocer más sobre fruta deshidratada ( ) 

c) Indiferente ( )
d) No estaría interesado en conocer más sobre fruta deshidratada ()
e) Para nada estaría interesado en conocer más sobre fruta deshidratada ( )

3. Mencione qué frutos deshidratados conoce usted. (marque del 1 al 10; en donde 10 es el que más conoce y 1 el que menos conoce)
a) Arándanos ( )
b) Aguaymanto ( )
c) Manzana ( )
d) Piña ( )
e) Pasas ( )
f) Guindones ( )
g) Mango ( )
h) Durazno ( )
i) Plátano ( )
j) Fresas ( )

4. ¿A través de qué medios desearía conocer más sobre las frutas deshidratadas?
a) Ferias sectoriales ( )
b) Publicidad en revistas especializadas ( )
c) Facebook ( )
d) Visita comercial ( )
e) E-mailing ( ) 
5. ¿Su empresa compra alguna fruta deshidratada ingrediente para la elaboración de sus productos?
a) Sì ( )
b) No ( ) Fin de la encuesta.

6. ¿Estaría usted interesado en comprar fruta deshidratada como arándanos, aguaymanto, manzana y piña para utilizarlo como insumo o ingrediente en la elaboración de sus productos?
a)Muy interesado ( )
b)Interesado ( )
c)Indiferente ( )
d)No interesado ( )
e)Para nada interesado ( )

PARTE 2

\section{RESPONDA SI SOLO COMPRA ALGUNA FRUTA DESHIDRATADA}

7. ¿Qué tipo o variedad de fruta deshidratada es la que compra?
a) Arándanos ( )
b) Aguaymanto ( )
c) Manzana ( )
d) Piña ( )
e) Pasas ( )
f) Guindones ( )
g) Mango ( ) 

h) Durazno ( )
i) Plátano ( )
j) Fresas ( )

8. ¿Qué tan importante considera usted la compra de frutos deshidratados de arándanos, piña y manzanas para la elaboración de sus productos?
a) Muy importante ( )
b) Importante ( )
c) Ni importante ni poco importante ( )
d) Poco importante ( )
e) Nada importante ( )

9. Indique la cantidad (en kilos) que compra de deshidratados de arándanos, piña y manzana:

\begin{tabular}{l|l|l|}
\cline { 2 - 3 } \multicolumn{1}{|c|}{ Fruta deshidratada } & \multicolumn{1}{c|}{ Kilos } \\
\cline { 2 - 3 } a) & & \\
\cline { 3 - 3 } b) & & \\
\cline { 2 - 3 } c) & & \\
\cline { 2 - 3 } d) & & \\
\cline { 2 - 3 } & &
\end{tabular}


10.¿Cuál es la frecuencia de compra de frutas deshidratadas de arándanos, piña y manzana?

a) Quincenal

b) Mensual

c) Bimestral

d) Trimestral

e) Semestral

11. ¿En qué tipos de productos utiliza como ingrediente las frutas deshidratadas de arándanos, piña y manzana?

a)

b)

\begin{tabular}{|l|l|}
\hline PRODUCTOS & \\
\hline & \\
\hline & \\
\hline & \\
\hline & \\
\hline
\end{tabular}

12.En un horizonte de cinco años ¿considera que sus compras de frutas deshidratadas de arándanos, piña y manzana?
a) Definitivamente se incrementarán ( )
b) Probablemente se incrementarán ( )
c) Se mantendrán estables ( )
d) Probablemente se reducirán ( )
e) Definitivamente se reducirán ( ) 
13. ¿Cuánto es aproximadamente el porcentaje de crecimiento que usted estima en sus compras de fruta deshidratada de arándanos, piña y manzana.

\begin{tabular}{l|l|l|}
\cline { 2 - 3 } & \multicolumn{2}{|l|}{ FRUTAS DESHIDRATADAS } \\
a) & arandano & \\
b) & aguaymanto & \\
c) & piña & \\
d) & manzana & \\
\cline { 2 - 3 }
\end{tabular}

14. Mencione el (los) proveedor(es) de las frutas deshidratadas de arándanos, piña y manzana:

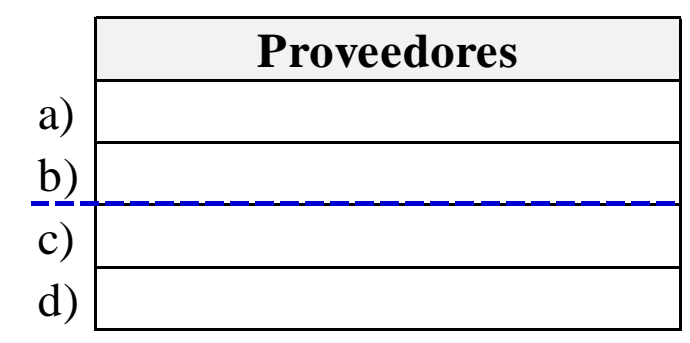

15.Identificar los criterios de selección de sus proveedores de fruta deshidratada de arándanos, piña y manzana. Ordene. donde (5) es el criterio de mayor importancia y (1) es el criterio es de menor importancia.

\begin{tabular}{l|l|l|}
\cline { 2 - 3 } \multicolumn{1}{|c|}{ CRITERIO } & IMPORTANCIA (MAYOR A MENOR) \\
\cline { 2 - 3 } a) & Condiciones de crédito & \\
b) & Certificado de calidad e inocuidad & \\
c) & Tiempo de entrega & \\
d) & Especificación del producto & \\
e) & Precio & \\
\cline { 2 - 3 }
\end{tabular}


16.Indique la(s) debilidad(es) asignando un puntaje a sus proveedor(es) de las frutas deshidratadas de arándanos, piña y manzana:

El puntaje es de (1) al (3), en donde (3) es la mayor debilidad y (1) es la menor debilidad

a) Calidad

\begin{tabular}{|l|l|}
\hline \multicolumn{1}{|c|}{ CRITERIO } & VALOR \\
\hline Calidad & \\
\hline Abastecimiento continuo & \\
\hline Precio & \\
\hline
\end{tabular}

17. ‘Cuál es el precio promedio que usted paga por un kilo de la fruta deshidratada de arándanos, piña y manzana?

\begin{tabular}{|c|l|l|l|}
\hline Rango de precios & Arándanos & Manzana & Piña \\
\hline S/.35 - S/.40 & & & \\
\hline S/.41 - S/.45 & & & \\
\hline S/.46-S/.50 & & & \\
\hline S/.51-S/.55 & & & \\
\hline S/.56-S/.60 & & & \\
\hline
\end{tabular}

18. Ordene según criterio más importante para las frutas deshidratadas de arándanos, piña y manzana. En donde (5) es el criterio de mayor importancia y (1) es el criterio es de menor importancia.

\begin{tabular}{|c|c|c|}
\hline a) & Organoléptico & \\
\hline b) & Calibre & \\
\hline c) & Humedad & \\
\hline d) & Libre de materia extraña visible & \\
\hline e) & Otro: & \\
\hline
\end{tabular}


19. Se está pensando a implementar una planta que elabore y venda fruta deshidratada de arándanos, piña y manzana. ¿Estaría usted dispuesto a comprar dichos productos?
a) Definitivamente si compraría.
b) Probablemente si le compraría.
c) Indiferente.
d) Probablemente no compraría.
e) Definitivamente no compraría.

20. ¿En qué tipo de empaque o envase desearía adquirir las frutas deshidratadas de arándanos, piña y manzanag?
a) Bolsas de polietileno ( )
b) Baldes de polietileno ( )
c) Cartón corrugado ( )
d) Otro:

21.¿Cuál sería el peso de la presentación más adecuada para usted?

FRUTA DESHIDRATADA

a)

\begin{tabular}{|c|c|}
\hline & FRUTA DESHIDRATADA \\
\hline PESO & \\
\hline $10 \mathrm{Kg}$ & \\
\hline $15 \mathrm{Kg}$ & \\
\hline $20 \mathrm{Kg}$ & \\
\hline
\end{tabular}

22.Indique: ¿Cuál es la política de cobro de sus proveedores?
a) Contado ( )
b) Crédito ( ) Si es crédito mencionar los días ( ) 
Nombre de la empresa:

Cargo que ocupa:

Nombres y Apellidos:

\section{Anexo 3. Adex Data Trade en referencia a empresas importadoras y}

\section{comercializadoras}

ADEX

Data Trade

Empresas - Importaciones

2010, 2011, 2012, 2013, 2014, 2015, 2016, 2017

Enero, Febrero, Marzo, Abril, Mayo, Junio, Julio, Agosto, Septiembre, Octubre, Noviembre, Diciembre

Sectores

AGROPECUARIO Y AGROINDUSTRIAS

Productos

$081340000 \quad$ LAS DEMAS FRUTAS U OTROS FRUTOS SECOS

\begin{tabular}{|c|c|c|c|c|c|c|c|c|c|c|c|c|c|c|c|c|c|c|c|c|c|c|c|c|}
\hline & & & & & & & & alor C & CIF(Mile & iles US & & & & & & & & & Pesol & oNeto (I) & & & & \\
\hline № & RUC & Razón Social & $2010 \mid$ & & $20122^{2}-x-3$ & 20132 & $\left.2014\right|_{2}$ & $2015 \mid 2$ & $2016 \mid 20$ & 2017 & \begin{tabular}{|c|} 
Var.\% \\
$2017 / 201$ \\
6 \\
\end{tabular} & \begin{tabular}{|c|} 
Part.\% \\
2017 \\
\end{tabular} & \begin{tabular}{|c|} 
Crec.\% \\
$2017 / 201$ \\
0
\end{tabular} & & & & & & & & 0172 & \begin{tabular}{c|} 
Var.\% \\
$2017 / 201$ \\
6
\end{tabular} & $\begin{array}{l}\text { Part.\% } \\
2017\end{array}$ & \begin{tabular}{|c|} 
Crec.\% \\
$2017 / 201$ \\
0
\end{tabular} \\
\hline & & TOTAL & 257 & 480 & 462 & 473 & 516 & 510 & 492 & 580 & $17.91 \%$ & $100.0 \%$ & $12.32 \%$ & 65 & 96 & 81 & 88 & 70 & 105 & 1271 & 165 & $29.15 \%$ & $100.0 \%$ & $14.26 \%$ \\
\hline & 12020784504 & 4 FRUTOS Y ESPECIASS.A.C. & 222 & 335 & 335 & 390 & 389 & 372 & 319 & 407 & $27.42 \%$ & $70.06 \%$ & $9.05 \%$ & 46 & 70 & 60 & 68 & 51 & 69 & 691 & 102 & $48.8 \%$ & $62.15 \%$ & $12.03 \%$ \\
\hline & 20056612238 & 4 PLATER'S FOOD S.A.C. & 0 & 0 & 0 & 0 & 0 & 0 & 0 & 36 & $0.0 \%$ & $6.26 \%$ & $0.0 \%$ & 0 & 0 & 0 & 0 & 0 & 0 & 0 & 11 & $0.0 \%$ & $6.89 \%$ & $0.0 \%$ \\
\hline & 3'2047789044 & 1 FRUTA & 30 & 28 & 48 & 0 & 5 & 22 & 31 & 27 & $-13.49 \%$ & $4.61 \%$ & $-1.67 \%$ & 13 & 7 & 6 & 0 & 1 & 2 & 9 & 9 & $0.0 \%$ & $5.51 \%$ & $-5.01 \%$ \\
\hline & $4^{\prime 2} 2020708000$ & 5 DELTAG & 0 & 0 & 0 & 0 & 0 & 0 & 0 & 25 & $0.0 \%$ & $4.25 \%$ & $0.0 \%$ & 0 & 0 & 0 & 0 & 0 & 0 & 0 & 2 & $0.0 \%$ & $0.93 \%$ & $0.0 \%$ \\
\hline & $5^{\prime 2} 2053289070$ & 6 CORPORACION AGRO FRUT E.I.R.L. & 0 & 0 & 6 & 11 & 14 & 43 & 55 & 24 & $-57.19 \%$ & $4.08 \%$ & $0.0 \%$ & 0 & 0 & 9 & 15 & 11 & 23 & 35 & 15 & $-57.45 \%$ & $9.07 \%$ & $0.0 \%$ \\
\hline & $6^{\prime 2} 2060125385$ & 3 MERCADO DE SURQUILLO E.I.R.L.L. & 0 & 0 & 0 & 0 & 0 & 0 & 16 & 17 & $9.6 \%$ & $3.0 \%$ & $0.0 \%$ & 0 & 0 & 0 & 0 & 0 & 0 & 8 & 9 & $12.13 \%$ & $5.64 \%$ & $0.0 \%$ \\
\hline & $7 " 1000474300$ & 3 USEDO DE COAQUER & 0 & 0 & 0 & 0 & 0 & 0 & 0 & 14 & $0.0 \%$ & $2.49 \%$ & $0.0 \%$ & 0 & 0 & 0 & 0 & 0 & 0 & 0 & 10 & $0.0 \%$ & $6.08 \%$ & $0.0 \%$ \\
\hline & 8'2050098532 & 2 MACHU PICCHU FOODS S.A.C. & 0 & 109 & 65 & 21 & 8 & 0 & 0 & 8 & $0.0 \%$ & $1.35 \%$ & $0.0 \%$ & 0 & 15 & 2 & 1 & 0 & 0 & 0 & 1 & $0.0 \%$ & $0.7 \%$ & $0.0 \%$ \\
\hline & $9^{\prime 2} 2049250762$ & 9 RED TIGER SOCIEDAD ANONIMA CEE & 0 & 0 & 0 & 0 & 4 & 8 & 4 & 7 & $52.32 \%$ & $1.14 \%$ & $0.0 \%$ & 0 & 0 & 0 & 0 & 0 & 0 & 0 & 0 & $31.6 \%$ & $0.1 \%$ & $0.0 \%$ \\
\hline & o'2010907217 & 7 CENCOSUD RETAIL PERUS.A. & 0 & 0 & 0 & 0 & 0 & 0 & 0 & 5 & $0.0 \%$ & $0.84 \%$ & $0.0 \%$ & 0 & 0 & 0 & 0 & 0 & 0 & 0 & 0 & $0.0 \%$ & $0.09 \%$ & \\
\hline
\end{tabular}

Elaboración: ADEX DATA TRADE

Fuente: Aduanas - Perú 


\section{BIBLIOGRAFÍA}

Boletín Estadístico Trimestral de Producción Agrícola y Ganadera 2017. Recuperado de http://siea.minagri.gob.pe/siea/?q=produccion-agricola-y-ganadera-2017

Clasificación Industrial Internacional Uniforme (CIIU) Revisión 4. Recuperado de https://www1.inei.gob.pe/media/MenuRecursivo/publicaciones_digitales/Est/Lib0883/Li bro.pdf

El peruano, 2013. Ley 30021 Ley de promoción de la alimentación saludable para niños, niñas y adolescentes. Recuperado de http://busquedas.elperuano.pe/normaslegales/leyde-promocion-de-la-alimentacion-saludable-para-ninos-ni-ley-n-30021-938532-1/

El Peruano, 2008. Ley de inocuidad alimentaria de los alimentos. Recuperado de http://www.leyes.congreso.gob.pe/Documentos/DecretosLegislativos/01062.pdf

Gestión, 2014. Ministerio de Salud publicará reglamento de Ley de Alimentación Saludable este mes. Recuperado de https://gestion.pe/economia/ministerio-saludpublicara-reglamento-ley-alimentacion-saludable-mes-76481

Issuu, 2017. Administración estratégica Recuperado de https://issuu.com/giaagu/docs/conceptos-de-administracion-estrate 
Investigación de Mercado, 5ta edición - Naresh K. Malhotra. Recuperado de https://dochub.com/marvins-underground/QKXOvl/investigacion-de-mercados5ta-edicion-naresh-k-malhotra

La Republica, 2010. En diez años, exoneraciones tributarias cuestan al Estado S/ 93 mil millones. Recuperado de https://larepublica.pe/politica/989810-en-diez-anosexoneraciones-tributarias-cuestan-al-estado-s-93-mil-millones

Las tres estrategias genéricas de Porter. Recuperado de https://aprendiendoadministracion.com/las-3-estrategias-genericas-porter/

Matriz de ansoff. Recuperado de http://www.estrategiamagazine.com/administracion/la-matriz-de-ansoff-deproductomercado-o-vector-de-crecimiento/.

Ministerio de trabajo, 2003. Ley de la promoción y formalización de la Micro y Pequeña empresa, Ley N. 28015. Recuperado de http://www.mintra.gob.pe/contenidos/archivos/prodlab/legislacion/LEY_28015.pdf (MINTRA)

Ministerio de la Producción. Listado de grandes empresas manufactureras. Recuperado de: http://ogeiee.produce.gob.pe/index.php/shortcode/oee-directorio/directorio-grandesEmpresas 
Ministerio de la Producción. Listado de Empresas MIPYME. Recuperado de:

http://ogeiee.produce.gob.pe/index.php/shortcode/oee-directorio/directorio-mipyme

Proinversión, 1991. Decreto legislativo $n^{o} 757$ - aprueban ley marco. Recuperado de https://www.proinversion.gob.pe/RepositorioAPS/0/0/arc/ML_GRAL_INVERSION_DL 757/11-D_L_757.pdf

Seminario de Berries y Cerezas de Sierra Exportadora. Recuperado de https://www.sierraexportadora.gob.pe/v-seminario-internacional-de-berries-y-cerezas2015/

Tecnología industrial de deshidratado de frutas. Recuperado de https://www.ubicome.pe/empresa/sttradinco-industrial-s-a-c--lima-19539 